\title{
LA TRANSFORMACIÓN DE LA IDENTIDAD LOCAL EN LA ARQUITECTURA DE LA COMARCA DE LA SAGRA BAJA TOLEDANA
}

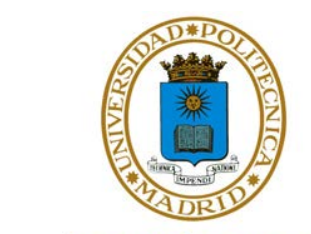

POLITÉCNICA

TESIS DOCTORAL

Autor: Alejandro García Hermida Arquitecto

Director: Fernando Vela Cossío

Dr. Arqueólogo 



\section{AGRADECIMIENTOS}

La realización de esta tesis ha sido posible gracias a un gran número de personas e instituciones. Primeramente a su director, Fernando Vela Cossío, mi maestro, quien desde el comienzo apoyó y enriqueció con su consejo y aportaciones la investigación que determiné acometer, así como al equipo de excelentes profesores, compañeros e investigadores de los programas de Máster y Doctorado en Restauración y Conservación del Patrimonio Arquitectónico de la Escuela Técnica Superior de Arquitectura de la Universidad Politécnica de Madrid (ETSA-UPM), de quienes tanto he tenido la fortuna de poder aprender durante estos años. Fundamentales han sido las aportaciones, el apoyo y las muchas enseñanzas de numerosos compañeros y amigos: Jaime de Hoz Onrubia, profesor de Historia de la Arquitectura y compañero de la Universidad Alfonso X el Sabio, David Rivera Gámez, profesor de Historia de la Arquitectura de la ETSA-UPM, Javier Cenicacelaya, catedrático de Composición Arquitectónica de la Universidad del País Vasco, Leon Krier, Donald Gray, Rafael Manzano Martos, Leopoldo Gil Cornet, José Baganha, Lucien Steil, Frank Martínez y Stefanos Polyzoides, todos ellos grandes referentes para mí, Samir Younés, Richard Economakis, Douglas Duany y Ettore Mazzola, profesores de la Escuela de Arquitectura de la Universidad de Notre Dame, así como su director, Michael Lykoudis, José Carlos Palacios, José Luis García Grinda y José Miguel Merino de Cáceres, que fueron mis profesores en la ETSA-UPM, y el resto de compañeros y amigos del Centro de Investigación de Arquitectura Tradicional (CIAT), de INTBAU y de INTBAU España, del Premio Rafael Manzano de Nueva Arquitectura Tradicional, de la Red Nacional de Maestros de la Construcción Tradicional y de Terrachidia, en especial Marta Colmenares Fernández, Oriol Domínguez Martínez, Rebeca Gómez-Gordo Villa, Carmen Moreno Adán, Raquel Peña López y Emilio Roldán Zamarrón, con quienes he tenido ocasión de poner en práctica muchas de las ideas que han dado forma a esta tesis en el frágil contexto de los valles presaharianos del sur de Marruecos.

Agradezco mucho su apoyo a Eduardo Corral Caballero, a Sergio López Ibáñez y a Lorenzo García Hermida, quienes me acompañaron y ayudaron en la toma de datos realizada durante el desarrollo de esta investigación, así como al resto de mi familia, 
amigos y, muy especialmente, a María Expósito Provencio, al haber contribuido todos ellos de forma inestimable con su ayuda y sus constantes aliento y comprensión.

Un especial agradecimiento debe ir dirigido a Richard H. Driehaus, cuya visión y generosidad tanto están contribuyendo a aliviar parte de la problemática aquí analizada, y a cuya confianza y apoyo tanto debo profesionalmente.

También han sido importantes durante estos años, por muy diversas cuestiones, Carol Wyant, Harriet Wennberg, Michael Gallo, Irene Pérez-Porro Stillman, Paolo Marconi, Javier de Cárdenas y Chávarri, Luis Maldonado Ramos, Santos García, Jorge Sainz, Miguel Sobrino, Enrique Nuere, Javier de Mingo, Ramón Mayo, Pier Carlo Bontempi, Maurice Culot, Abdel-Wahed El-Wakil, José Cornelio da Silva, David Watkin, Hans Stimmann, Charles Jencks, Paul Goldberger, Vittorio Magnago Lampugnani, Íñigo Saloña, Philippe Rotthier, Norman Crowe, Ricardo López, Óscar Machado, Taisto Mäkelä, Marcel Vellinga, Andrés Duany, Elizabeth Plater-Zyberk, Christopher Miller, Ruth Equipaje, Rino Fernández, Juan de Dios de la Hoz, Luis Fernando Abril Urmente, Miguel Ángel García Valero, Manolo Guardia Magán, Scott Merrill, Robert Adam, JeanFrançois Lejeune, Giuseppe Amoruso, José María Ballester, Enrique Rabasa, Pablo Álvarez Funes, Rui Florentino, Mariana Correia, Francisco Adão da Fonseca, Alexandre Resende, Rita Pinto Coelho, Anselmo Menéndez, Javier Martín Ramiro, Antonio Amorós, Daniel Muñoz de Julián, Salima Naji, Mohamad Hamouie, Tomasz Jelenski, Mieke Bosse, Yasmeen Lari, Timothy Smith, Jonathan Taylor, Ken De Cooman, Salma Samar Damluji, Natalia Escalada, Aina Batlle, María Brañas, María Pía Timón Tiemblo, Ángel Hermida Hita, Carlos Hermida García, Ramón Lozano Reviriego, Ruth López Calzada, Alba Ramírez Arteaga, Lander Unzilla Cortaberria, Raquel Soler Porras, Fernando Vegas, Camilla Mileto, Manuel Navarrete, Fátima Quesada, Valeriano Jaurrieta, Luis Prieto, Juan Emilio Cristóbal, Pepe Garrido y los muchos maestros que hoy forman parte de la Red Nacional de Maestros de la Construcción Tradicional.

Quiero finalmente agradecer la documentación y la opinión experta proporcionadas por los ayuntamientos, técnicos municipales y arquitectos que trabajan en algunos de los municipios de La Sagra, así como su amable acogida a cuantos vecinos de La Sagra me han abierto las puertas de sus casas durante estos años, casas que custodian como el valioso legado que son para el futuro de la región. 
La transformación de la identidad local en la arquitectura de la comarca de la Sagra Baja toledana 
La transformación de la identidad local en la arquitectura de la comarca de la Sagra Baja toledana 


\section{ÍNDICE}

Resumen

1. Objeto y metodología de este estudio constructivas, arquitectónicas y urbanísticas para el desarrollo de esta investigación implícitos en su conservación 
2.2.3. Naturaleza de los procesos que amenazan la pervivencia de las tradiciones arquitectónicas y constructivas

2.2.4. Herramientas para la preservación de la identidad local tradicional

2.3. Globalización e identidad local. Consecuencias en el ámbito de la arquitectura y el urbanismo relación con otras reivindicaciones de la recuperación de la tradición arquitectónica

3.1. El nacimiento del interés por la preservación de las tradiciones constructivas y arquitectónicas locales

3.2. El primer planteamiento integral del problema por el movimiento de las Artes y los Oficios inglés. Reivindicaciones sociales implícitas en él. Repercusión internacional

3.3. Nuevas experiencias desarrolladas desde el regionalismo arquitectónico

3.4. El papel de las exposiciones internacionales y de los museos al aire libre en el desarrollo de la cuestión 
3.5. Lo vernáculo como reivindicación formal de la arquitectura moderna internacional

3.6. La nueva valoración de las tradiciones locales tras la crisis de la modernidad

4. Arquitectura tradicional e identidad local en la comarca de la Sagra toledana

4.1. El territorio objeto de estudio y el paisaje urbano tradicional de la Sagra

4.2. Técnicas constructivas tradicionales que dan forma a ese paisaje

4.3. El área de estudio y los casos seleccionados

4.3.1. Bargas

4.4. Normativa dirigida preservación de la identidad local vigente en la Sagra Baja

4.4.1. Regulaciones, directrices y recomendaciones supramunicipales

4.4.2. Normativa municipal 
5.1. Bargas

5.2. Olías del Rey

5.3. Magán

5.4. Mocejón

6. Conclusiones

6.1. Principales resultados de esta investigación

6.2. Propuestas de investigación pata el futuro

7. Bibliografía

ANEXO: Fichas de toma de datos de los casos de estudio seleccionados 


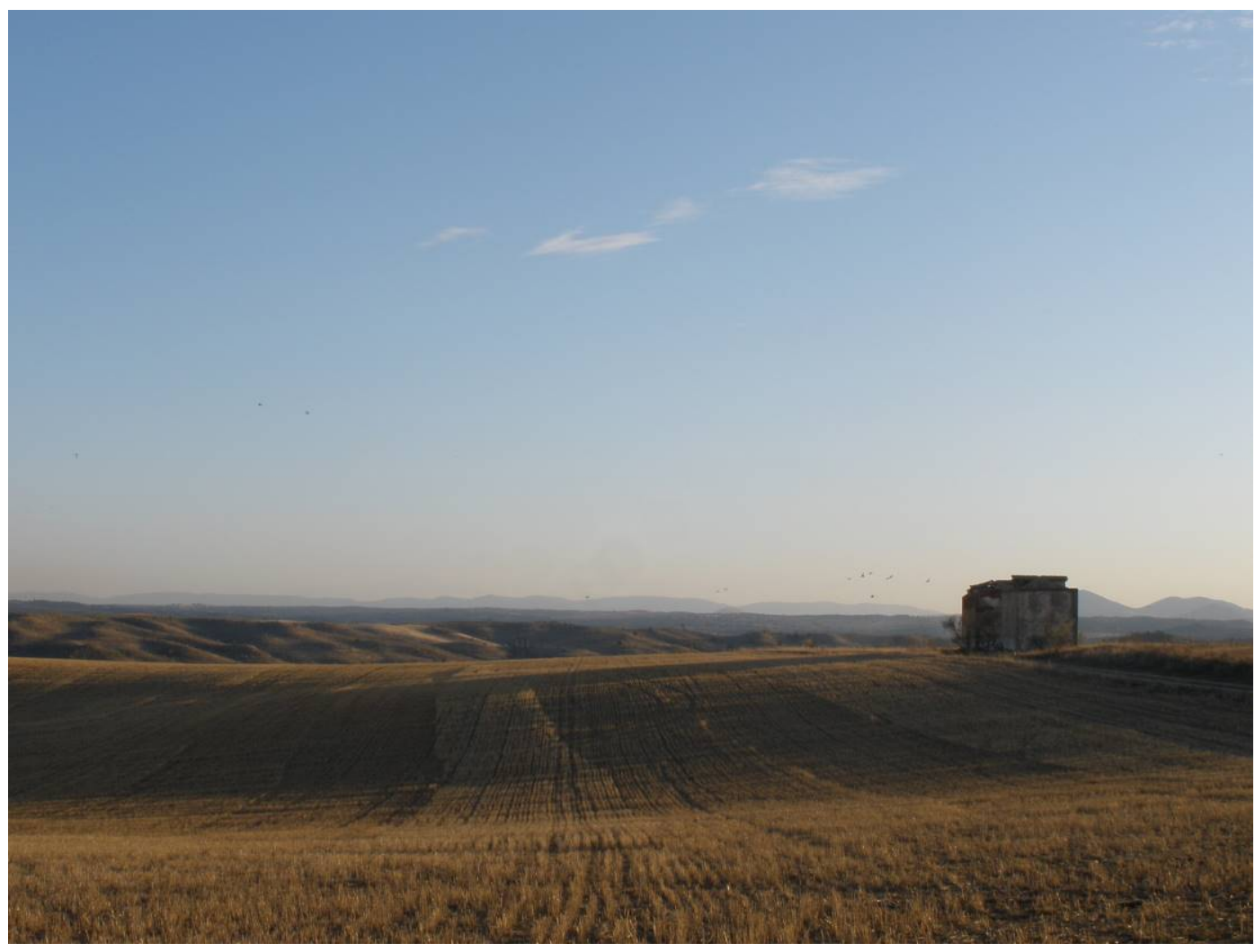

Campos de Bargas (fotografía del autor, octubre de 2009) 
La transformación de la identidad local en la arquitectura de la comarca de la Sagra Baja toledana 
In archeology, the interest shifted a while ago from temples, palaces, and tombs to the whole city as an expression of a culture and a way of life (...). Similar shifts have taken place in general history, in the history of art, and in that of music, to an extent. In architecture, however, such an interest is only now starting, and it has not yet gone very far nor beyond the purely visual. It is therefore a topic which has been rather neglected.

Amos Rapoport, House Form and Culture $(1969,1)$

Scientists usually seek to attribute historical developments to cold economic and demographic factors. It sits better with their rational and mathematical methods. In the case of modern history, scholars cannot avoid taking into account non-material factors such as ideology and culture. The written evidence forces their hand.

Yuval Noah Harari, Sapiens. A Brief History of Humankind $(2015,100)$ 
La transformación de la identidad local en la arquitectura de la comarca de la Sagra Baja toledana 


\section{RESUMEN}

Observamos cómo la identidad propia de la tradición arquitectónica de nuestros pueblos, ciudades y regiones está sufriendo una transformación sin precedentes históricos, que llega en algunos casos a su práctica desaparición. Mientras esto sucede, se reconoce, disfruta e intenta preservar este patrimonio cultural de forma creciente e igualmente no parangonable con ningún momento pretérito. Esta desviación entre los objetivos perseguidos y los resultados obtenidos queda reflejada en numerosos debates, proyectos, publicaciones, documentos y regulaciones contemporáneos.

Apenas existen, sin embargo, estudios que aborden esta cuestión, y, para poder enfrentar este problema con suficiente rigor, es necesario comprender primero cómo se están transformando las identidades locales que se pretenden conservar, qué factores están incidiendo sobre estas alteraciones y en qué medida lo vienen haciendo, y qué incidencia tienen sobre ellas las normativas hoy comúnmente vigentes para combatir este género de procesos. Dar respuesta a estas cuestiones ha sido el objetivo de esta investigación.

Tras abordar el problema de forma global, desde la apropiada definición de sus más básicos conceptos hasta las repercusiones de su evolución histórica en el campo de la arquitectura, se ha procedido a estudiar de forma pormenorizada este tipo de transformaciones en el caso particular de la comarca toledana de La Sagra, y se ha desarrollado para ello un método que permitiera identificar las variables que están incidiendo sobre los procesos estudiados.

Por esta vía, se ha podido probar fehacientemente que entre los aspectos que más están incidiendo en la transformación de la arquitectura de esta región, por encima de cuestiones técnicas, económicas y funcionales, destacan las aspiraciones, intereses y formación de cuantos se encuentran implicados en estos mecanismos. Es decir, se trata de un fenómeno de índole cultural que ha de enfrentarse por tanto con herramientas que habrán de dirigirse hacia objetivos igualmente culturales. 


\begin{abstract}
We notice how the particular identities of the architectural tradition of our villages, towns and regions are suffering a historically unprecedented transformation, leading in some cases to its almost entire disappearance. While this is happening, this cultural heritage is intended to be preserved, recognised and enjoyed in a growing manner, equally unrivalled in any other past times. This deviation from the pursued aims to the obtained outcome is reflected in numerous contemporary debates, projects, publications and regulations.
\end{abstract}

Nevertheless, there are hardly any studies dealing with this subject, and, in order to face this problem in a sufficiently rigorous way, it is necessary to understand, first of all, how those identities we seek for preserving are being transformed, which factors are influencing these processes and to what extent they have an impact on them, and how are they affected by the regulations nowadays in force to fight this kind of phenomena. To provide an answer to these questions has been the aim of this research.

After addressing this problem globally, from the appropriate definition of its most basic concepts till the impact in the architectural field of its historical evolution, this kind of transformations have been meticulously analysed in the specific case of La Sagra region in Toledo. In order to allow identifying the variables which are affecting the studied processes a methodology has had to be developed.

Using this tool, it has been possible to reliably prove those aspects having the most impact on the transformation of the architecture of this region, beyond technical, economic or functional reasons, are those related to the aspirations, interests and training of all those who are involved in these mechanisms. This is, this a problem of cultural character and, as such, it must be mainly faced also using tools addressing cultural aims. 


\section{OBJETO Y METODOLOGÍA DE ESTE ESTUDIO}

\subsection{INTRODUCCIÓN}

Uno de los temas de mayor actualidad en el mundo de la arquitectura y el urbanismo en general y en el de la preservación del patrimonio en particular es el de la progresiva y hasta hoy inexorable pérdida de las diversas identidades locales tradicionales ante el avance de la homogeneización de nuestro entorno construido.

La cuestión resulta más acuciante que nunca. En el Plan Nacional de Arquitectura Tradicional, recientemente desarrollado por el Instituto de Patrimonio Cultural de España, se afirma, subrayando los aspectos identitarios y paisajísticos de la tradición arquitectónica $(2014,8)$ : "Frente a la creciente homogeneización de los paisajes urbanos a nivel mundial, la arquitectura tradicional debe de ser igualmente valorada por la diversidad de matices y calidad de los paisajes culturales, urbanos y rurales que ha contribuido a conformar".

Como explica con gran claridad el polémico arquitecto Rem Koolhaas (2004, 1-2), nuestra voluntad de preservar "no es el enemigo de la modernidad, sino realmente una de sus consecuencias", ya que "la propia idea de modernizar contiene latente o abiertamente el asunto de qué conservar". Es decir, la expansión de una implica el incremento de la otra. La intensa transformación sufrida por nuestro entorno en las últimas décadas ha estado acompañada por un crecimiento de una dimensión sin precedentes de nuestra voluntad de preservar aquello que estamos viendo desaparecer por su causa. Lo que percibimos como patrimonio ha ido creciendo cuantitativa y tipológicamente hasta abarcar paisajes e incluso regiones enteras. La exploración de nuevas alternativas hábiles para poder responder de un modo viable a los exigentes requerimientos de tal incremento se hace prioritaria, pero ésta requiere estudiar los resultados de las políticas aplicadas hasta la fecha, siendo hoy ya posible evaluarlos de modo científico.

De hecho, si aceptamos las consecuencias de las citadas palabras de Koolhaas, hemos de concluir que los efectos de la presente transformación de nuestro entorno son percibidos como un problema de una magnitud sin posible parangón histórico, pues ninguna de las 
grandes catástrofes o intervenciones que en el pasado cambiaron la faz de las ciudades produjo tal inflación de nuestra voluntad de conservación. Ninguna llegó a ser considerada un riesgo semejante para la preservación de su identidad. O bien, planteándolo en otros términos, nunca el "Espíritu del Lugar" se había visto tan amenazado por el "Espíritu del Tiempo". Nunca, por tanto, había sido tan necesario estudiar los efectos de los más esenciales mecanismos hasta hoy ensayados para dar respuesta a este proceso, integrados en buena parte de la normativa urbanística vigente en nuestra geografía.

En enero del año 2018, de forma extraordinaria y con motivo de la celebración del Año Europeo de Patrimonio Cultural, los ministros de Cultura y Jefes de las Delegaciones de los países firmantes del Convenio Cultural Europeo y de los estados observadores del Consejo de Europa, representantes de la UNESCO, del ICCROM, del Consejo de Europa, de la Comisión Europea, del Consejo de Arquitectos de Europa, del Consejo de Europa de Urbanistas, de ICOMOS International y de Europa NOSTRA se reunieron en Davos, Suiza, en el marco de la reunión anual del Foro Económico Mundial. Fruto de este encuentro, la Declaración de Davos señala cómo (2018, 1-2):

Siendo conscientes de la tendencia a la pérdida de calidad tanto en el entorno construido, como en los paisajes abiertos en toda Europa, reflejada en la banalización de la construcción, en la falta de valores de diseño, incluyendo la falta de preocupación por la sostenibilidad, el aumento de la dispersión urbana y del uso irresponsable de la tierra, el deterioro del tejido histórico y la pérdida de las tradiciones e identidades regionales (...), cabe subrayar el valor y el carácter irreemplazables de los paisajes y del patrimonio cultural (...). Existe una necesidad urgente de tener enfoques integrales y centrados en la cultura para el entorno construido y para la visión humanista de la forma en la que configuramos conjuntamente los lugares en los que vivimos y la herencia que dejamos a nuestro paso.

Este llamamiento, compartido y firmado por un creciente número de países e instituciones europeas viene a sumarse a los múltiples documentos internacionales que abundan sobre la cuestión planteada, que encontró también un lugar, a pesar de la amplitud temática de los propósitos en ella recogidos, en la Nueva Agenda Urbana, aprobada en la Conferencia 
de las Naciones Unidas sobre la Vivienda y el Desarrollo Urbano Sostenible (Hábitat III), celebrada en Quito el 20 de octubre de 2016, al declararse en ella (2016, 38): "incorporaremos a los pueblos indígenas y las comunidades locales en la promoción y difusión de los conocimientos del patrimonio cultural tangible e intangible y en la protección de las expresiones y los lenguajes tradicionales, incluso mediante el uso de nuevas tecnologías y técnicas".

En la presente investigación se abordará este problema circunscribiéndolo únicamente a aquellas identidades locales que residen en las tradiciones constructivas, arquitectónicas y urbanísticas que son propias de lugares concretos. Es decir, quedarán fuera de los límites de este estudio aquellas identidades basadas en aspectos cuya vernacularidad se haya gestado por factores ajenos a estas tradiciones locales, aquellas que se hayan desarrollado con cierta autonomía de las particularidades de la geografía, la climatología o los materiales de un lugar o de la cultura que le es propia.

Pese a tratarse de un tema tan manido en apariencia, y tan presente en el debate actual, no existen apenas estudios científicos sobre él desde el ámbito de la arquitectura y del urbanismo, especialmente en nuestro país, limitándose con ello su utilidad práctica en el ejercicio profesional de restauradores, arquitectos y urbanistas. Como se ha dicho, es, sin embargo, uno de los principales retos para los que la sociedad demanda soluciones y sobre el que numerosos e importantes profesionales de estas disciplinas llevan décadas debatiendo y trabajando. Los resultados de este esfuerzo, desgraciadamente, apenas son conocidos. Sus importantes consecuencias en el campo de la preservación del patrimonio en particular y de la práctica profesional en general se encuentran veladas por el desinterés por este tema imperante en las décadas precedentes, dificultándose la explotación o puesta en práctica de pasados o incluso presentes aciertos en esta materia.

Además, las ideas de globalización, de identidad, de tradición, de lo vernáculo o de lo popular, que constituyen un recurso habitual en el lenguaje arquitectónico, se utilizan por lo general de modo impreciso e incluso erróneo y la forma en que se abordan estos aspectos en la práctica totalidad de las normativas municipales contemporáneas adolece de la misma falta de rigor y de semejante desconocimiento del amplio corpus teórico y práctico que ha ido conformándose en torno a este tema. Se confunden también a menudo los objetivos perseguidos, siendo muy diferente y requiriendo actuaciones y herramientas 
completamente diversas el preservar una tradición arquitectónica local del mantener los restos materiales que de particulares momentos de ella se conservan (Lawrence 2006; Marchand 2006; Oliver 2006a, 42).

Tal vez como consecuencia de las carencias mencionadas, esta creciente voluntad de preservación, que encuentra su reflejo en las múltiples teorías, propuestas, normativas y planes elaborados con el fin de regular los habituales modelos de transformación urbana, resulta continuamente sobrepasada por aquello que pretende controlar: la grave pérdida de riqueza cultural que supone la homogeneización progresiva de arquitecturas y conjuntos urbanos. A día de hoy, la puesta en práctica de planteamientos dirigidos a hacer frente a este proceso adolece de una amplia problemática que incluye la carencia de unos objetivos generales bien definidos, importantes errores metodológicos o incluso falta de confianza en la factibilidad o conveniencia de este tipo de propuestas. Mientras tanto, por doquier podemos observar cómo van desapareciendo los últimos vestigios de las tradiciones constructivas, arquitectónicas y urbanísticas locales, a menudo reemplazadas consciente o inconscientemente por vulgares sucedáneos.

Resulta fundamental, en resumen, buscar comprender cómo estamos transformando este patrimonio, qué puede o debe ser alterado o reemplazado en él para que su conservación sea efectiva y sostenible y qué hemos de mantener para lograr preservarlo de forma satisfactoria.

Este trabajo pretende ser un primer paso en esta dirección, y contribuir con ello a abrir el camino a futuros estudios que lo complementen y afinen, bien también regionales, bien de carácter más general.

Por otra parte, estas preocupaciones no son nuevas, sino que, surgidas casi al mismo tiempo que la propia industrialización de la construcción, han ido desarrollándose desde entonces con intensidad variable tanto en el tiempo como en el espacio, convirtiéndose durante el siglo XX en una de las principales polémicas de la historia de la arquitectura, y provocando arduas disputas. Comprender sus orígenes y evolución resulta también fundamental como paso previo para abordar este estudio. Por ello, antes de analizar los resultados del caso concreto elegido, se acometerá primero una exposición general de las aportaciones pretéritas más representativas a nivel tanto teórico como práctico. 
Sin embargo, evaluar los éxitos y fracasos de la totalidad de las teorías y prácticas al respecto desarrolladas durante décadas trasciende los límites de esta investigación. El principal objetivo de ésta es únicamente un importante y necesario primer paso: analizar el efecto de los procesos de transformación sufridos por un área concreta, caracterizada por una determinada tradición arquitectónica, y estudiar su posible relación con las políticas de preservación de la identidad local que han sido aplicadas en ella.

Este campo, pese a estar sujeto a normativas municipales diversas, se ha tomado como un caso de estudio representativo de las más convencionales políticas al respecto, buscando así identificar los procesos más comunes. Se ha evitado, por ello, elegir conjuntos urbanos especialmente protegidos, tales como aquellos declarados Bien de Interés Cultural, o bajo un régimen de conservación atípico por sus singulares valores o cualidades, pese a estar éstos necesitados igualmente de este tipo de estudios.

La necesidad y la urgencia de acometer investigaciones de esta naturaleza quedan también claramente explicadas en el ya citado Plan Nacional de Arquitectura Tradicional (2014, 7):

En cuanto a las intervenciones realizadas sobre este tipo de arquitectura en España, existen criterios y políticas de actuación inadecuados debido a la falta de formación, de valorización y de sensibilización sobre esta materia. Esto se traduce en diversos aspectos, tales como la elección inapropiada de materiales y sistemas constructivos ajenos a este tipo de arquitectura, frente a la aplicación de técnicas tradicionales. Por otro lado existe una marcada tendencia al fachadismo, así como una excesiva descontextualización de estas construcciones con el entorno, motivado también, por la abusiva especulación inmobiliaria de nuestro país, que deja multitud de edificaciones tradicionales desarticuladas. Por último, muchas de las intervenciones carecen de la participación directa de los usuarios, sin tener en cuenta sus opiniones y necesidades.

En definitiva, haría falta en este sentido auspiciar tanto la promulgación, a ser posible coordinada en sus significados, contenidos y aplicaciones, de medidas legislativas (acompañadas de los correspondientes planes 
económicos que las hagan factibles) que protejan esta arquitectura tradicional. Para ello también es igualmente necesario promover y desarrollar proyectos de investigación y documentación (incluidos inventarios) que nos permitan conocer en su globalidad la situación en que se encuentra esta arquitectura tradicional. Así mismo, la protección de esta arquitectura en España debe pasar por la recuperación de los sistemas tradicionales para que se apliquen en las intervenciones, así como por el desarrollo de acciones de sensibilización, difusión, transmisión y cooperación.

En este contexto, la realización de esta investigación ha requerido el desarrollo previo de un método de análisis científico y objetivo que permitiera cuantificar con precisión y exactitud el fenómeno estudiado. Este método se fundamentó en el análisis por observación directa de los conjuntos urbanos estudiados, limitándolo a los aspectos relativos al paisaje urbano, al ser éstos los únicos comúnmente regulados por las normativas urbanísticas. La zona estudiada se ha analizado edificio por edificio y elemento constructivo por elemento constructivo, contrastándose finalmente los resultados obtenidos con las regulaciones existentes.

De este modo, esta tesis podría sentar bases metodológicas para futuros trabajos de este tipo, orientar la evaluación de otros ejemplos y contribuir al futuro desarrollo de políticas más adecuadas para la consecución de los objetivos fijados.

Es importante señalar, en cualquier caso, que el estudio realizado ha demostrado que las características tipológicas y constructivas de la tradición arquitectónica de una determinada población constituyen importantes variables en el proceso analizado. Del estudio de un conjunto urbano donde la composición de los tipos de vivienda tradicionales y, con ella, su adaptabilidad a los usos actuales sean diversos o donde, por ejemplo, los materiales con los que se hayan ejecutado los muros de fachada sean distintos, se obtendrán necesariamente resultados diferentes. Se ha buscado, por tanto, que variables de este tipo no alteren en modo alguno las conclusiones de este estudio, eligiéndose para ello un marco de trabajo pormenorizado suficientemente homogéneo dentro del área estudiada. 


\subsection{HIPÓTESIS Y PREMISAS BÁSICAS}

El abandono de las tradiciones constructivas, arquitectónicas y urbanísticas ha motivado que nuestras intervenciones contemporáneas sean percibidas con frecuencia como una amenaza para la preservación de las diversas identidades locales que éstas definían, sin que se hayan reconocido aún de forma general referencias prácticas o herramientas válidas para atenuar o anular los efectos negativos que las nuevas actuaciones pueden conllevar para la preservación de este patrimonio. Así, por el momento, los profesionales implicados en la conservación y transformación de este patrimonio no hemos sido capaces de detener este proceso, ni de avanzar en tal dirección. El modo en que ha de acometerse esta cuestión continúa pues indefinido y es reflejo de una dispersión metodológica tan amplia como irregulares son sus resultados. Este proceso de deterioro puede, sin embargo, cuantificarse y analizarse pormenorizadamente, buscando así comprender los factores que inciden sobre el mismo, y cuáles lo hacen en mayor o menor medida. Su estudio y mejor comprensión podría, de esta forma, servir de base a las futuras fórmulas que se desarrollen para combatirlo.

Pese a existir numerosas referencias teóricas y herramientas desarrolladas para avanzar sobre esta cuestión y que han sido puestas en práctica durante las últimas décadas, sus resultados no han sido suficientemente analizados ni evaluados. Tampoco se ha consensuado aún metodología científica alguna para estudiar este tipo de procesos. Acometer esta investigación implica, por ello, definir una metodología básica de análisis de posible utilidad general que, más allá de las particularidades de cada caso concreto, podría contribuir a la búsqueda de vías más apropiadas para enfrentarse a la problemática estudiada.

En el ejercicio del urbanismo, la arquitectura y la conservación del patrimonio arquitectónico y urbano existe una preocupación creciente por la preservación de los caracteres esenciales del paisaje cultural en el que se interviene, particularmente cuando éstos tienen su origen en tradiciones locales. Esta situación queda reflejada en gran número de polémicas, declaraciones, publicaciones, proyectos de intervención, inventarios o herramientas de protección que han venido desarrollándose en torno a esta cuestión, y puede estudiarse también en base a las más extendidas prácticas 
arquitectónicas. Por ello, la aceptación social de nuestras intervenciones arquitectónicas podría estar en el futuro más que nunca estrechamente relacionada con la medida en que sean capaces de responder a esta voluntad, pudiendo convertirse por ello en uno de sus principales condicionantes. 


\subsection{OBJETIVOS}

Primeramente, conviene aclarar que esta investigación tiene como fin partir de las hipótesis planteadas para avanzar en la resolución de una serie de dudas deontológicas que se presentan y que probablemente, tal como ya se ha explicado, se presentarán en el futuro con creciente vigor en el ejercicio de las más comunes labores arquitectónicas.

Con este fin, sin desatender las distintas aportaciones teóricas y prácticas ya existentes, se desarrolla un nuevo método de análisis que se aplica y pone a prueba en el estudio de un caso concreto: el de la comarca de la Sagra Baja toledana.

La elección de esta comarca, dada su cercanía a Madrid y su extensión entre los grandes núcleos de población madrileños y la ciudad de Toledo, permite estudiar conjuntos urbanos cuya transformación reciente ha sido singularmente intensa y en los que, sin embargo, aún no se ha producido el tipo de explosión demográfica y urbanística que ha prácticamente suprimido la identidad tradicional de los municipios más próximos a Madrid con los que limita. Con el fin de protegerla han estado vigentes en ellos diversas normativas que con mayor o menor detalle han condicionado las alteraciones sufridas por su paisaje urbano. Tenemos, en resumen, una identidad tradicional aún identificable, unas herramientas conocidas que se han utilizado o intentado utilizar para su conservación y un gran número de intervenciones arquitectónicas que las han puesto especialmente a prueba durante los últimos años.

Pormenorizadamente, los objetivos primordiales de esta investigación son:

1. Estudiar la evolución contemporánea de los rasgos arquitectónicos y constructivos que definen la identidad local tradicional del ámbito estudiado, tanto en las transformaciones sufridas por los edificios históricos como el uso que de ellos se ha hecho en nuevas obras.

2. Desarrollar para ello un método de análisis científico universalmente válido o fácilmente adaptable a otros contextos. 
3. Identificar posibles parámetros que puedan explicar el grado de conservación o deterioro de estos rasgos, tales como elementos o tipologías arquitectónicas o constructivas más o menos susceptibles de sufrir alteraciones.

4. Contrastar la incidencia de los procesos identificados con la normativa municipal relativa a la preservación de la identidad local vigente en el ámbito estudiado.

5. Buscar posibles principios o criterios generales que, en caso de hallarse, pudieran llevar a la obtención de unos mejores resultados en este campo o ser de utilidad para la práctica profesional en el futuro.

La satisfacción de los objetivos enumerados como fundamentales, implica atender previamente a un problema sin cuya solución difícilmente podrá estudiarse el problema en toda su complejidad: el de la indefinición o la confusión existente en torno a la terminología vinculada con el proceso estudiado. Por ello, resulta fundamental definir correctamente de inicio el problema del deterioro de las identidades locales, así como los principales conceptos implicados en él, clarificando el modo en que la globalización o la homogeneización de nuestro entorno construido están afectando a este patrimonio.

La correcta definición y clasificación de las principales aportaciones prácticas y teóricas precedentes contribuirá también a este objetivo. 


\subsection{METODOLOGÍA Y FUENTES}

Los planteamientos pretéritos relacionados directa o indirectamente con el problema estudiado aparecieron prácticamente al mismo tiempo que el proceso industrializador con el que comenzó su evolución y, desde entonces, han ido desarrollándose con intensidad temporal y geográfica variable. De este modo, han llegado a erigirse en un problema capital para las teorías arquitectónicas de los siglos XX y XXI. Sin embargo, se halla muy distorsionado y existen multitud de imprecisiones en la forma en que es comprendido. Por ello, tal como se ha dicho, una etapa primaria de este trabajo es su correcta definición, recurriendo a las principales fuentes teóricas existentes al respecto tanto en el ámbito de la arquitectura, el urbanismo o la preservación del patrimonio, como en otros campos, tratando de clarificar distintos conceptos y procesos implicados, como pueden ser el de globalización, el de identidad local o el de autenticidad.

La dispersión metodológica imperante y la ausencia de estudios integrales en este campo convierten su análisis previo en una enriquecedora aportación en sí misma. Sin embargo, existen numerosos arquitectos e intelectuales que desde diversos ámbitos se han ocupado de esta cuestión durante décadas, constituyendo sus intervenciones profesionales, sus declaraciones y escritos, así como las reacciones provocadas por ellos, las principales fuentes de este apartado preliminar de la investigación. De este modo, se exponen inicialmente las más significativas aportaciones teóricas y metodológicas hasta la fecha y se hace especial hincapié en los resultados de su aplicación y en las relaciones entre las diversas teorías y prácticas identificadas. Siempre que ha sido posible, se ha recurrido directamente a entrevistas y reconocimientos in situ, pero la bibliografia tradicional constituye la herramienta fundamental de este primer paso: monografías, ensayos, artículos, publicaciones electrónicas, etc.

Se han estudiado también desde este prisma los principales documentos publicados por distintas instituciones y administraciones con el fin de guiar a la disciplina en esta materia, con frecuencia aquejados de un cierto anacronismo con respecto a las teorías y prácticas pioneras en este ámbito, pero claves para comprender la evolución general de la cuestión. 
Llegados a este punto y en base a ello, se ha desarrollo un método de análisis que permitiera cuantificar de forma objetiva y rigurosa el grado de transformación de cada uno de los diversos rasgos arquitectónicos y constructivos que determinan la identidad local tradicional de cada conjunto urbano estudiado.

Definido este método por medio de proceso previo de prueba y error hasta ajustarlo por completo a las necesidades del estudio planteado, se pasa a analizar con él de forma pormenorizada la serie de casos particulares seleccionados, representativos tanto de los más habituales procesos de alteración de la identidad local como de las políticas convencionales actualmente vigentes en nuestro país para su preservación.

Una vez identificados los parámetros arquitectónicos y constructivos característicos del paisaje urbano tradicional local, se estudian por medio de este método tres cuestiones fundamentales:

1. Qué rasgos arquitectónicos y constructivos tradicionales perviven en las construcciones históricas, cuáles han sido alterados o sustituidos y, en su caso, qué les ha reemplazado.

2. Qué rasgos arquitectónicos y constructivos tradicionales han seguido utilizándose en los edificios realizados en las últimas décadas, cuáles han sido alterados o sustituidos y, en su caso, qué les ha reemplazado.

3. Qué parámetros arquitectónicos, constructivos o sociológicos parecen haber influido en los resultados obtenidos.

Con todo ello, finalmente, se pasa a estudiar el grado de relación existente entre la normativa urbanística vigente y las conclusiones obtenidas en los apartados anteriores.

Como se mencionaba en el apartado anterior, se ha seleccionado para ello una región particularmente expuesta a procesos de transformación de su arquitectura tradicional por su situación entre dos capitales, Madrid y Toledo, cercana a las áreas de mayor expansión demográfica del entorno madrileño, y bien comunicada con ellas a través de las importantes vías de comunicación que hoy la atraviesan, La Sagra, situada a caballo entre 
dos comunidades autónomas, la de Madrid y la de Castilla-La Mancha, cada una de ellas con sus propias regulación y problemática al respecto. Esta diferencia distorsionaría la comparación final de los resultados obtenidos con la normativa vigente, por lo que se ha evitado en la selección final de casos para su estudio pormenorizado.

Además, se ha podido comprobar en la práctica que una distorsión igual o mayor en los resultados obtenidos puede producirse por el hecho de que, como se verá más adelante, las tradiciones arquitectónicas y constructivas sagreñas no son homogéneas. Esta heterogeneidad nunca había sido estudiada con anterioridad, siendo su definición un resultado indirecto del desarrollo de este trabajo. En consecuencia, por ejemplo, no se obtienen las mismas conclusiones al poner en relación las regulaciones urbanísticas con, por ejemplo, el análisis de un municipio donde los muros de sus edificios tradicionales son mayoritariamente de tapial y el análisis de otro donde estén realizados principalmente en mampostería. Los mecanismos y tendencias de transformación que afectan a estos distintos casos han demostrado ser muy diversos. Este tipo de variables, por tanto, alterarían en gran medida la validez de contrastar los resultados obtenidos en cada caso con la normativa vigente. Habría siempre que tener en cuenta estos parámetros. Por ello, la selección final de los casos de estudio ha buscado también eludirlas.

Así, se ha seleccionado un grupo de municipios donde, por un lado, las tradiciones arquitectónicas y constructivas pueden considerarse prácticamente idénticas y, por otro, la normativa supramunicipal de aplicación es la misma, cuidando, en cualquier caso, de que la muestra elegida presente un abanico suficientemente amplio de casos.

Con estas premisas, pudo identificarse un área integrada por cuatro municipios circunscrita enteramente a la provincia de Toledo y cuyas tradiciones constructivas son prácticamente análogas y diversas del resto de municipios de la comarca: la zona meridional de la Sagra Baja, conformada por los términos municipales de Bargas, Olías del Rey, Magán y Mocejón.

Para realizar esta elección, sin embargo, ha sido necesario estudiar primeramente de modo general las tradiciones arquitectónicas y constructivas de la Sagra en su totalidad, recorriendo cada uno de sus centros urbanos hasta determinar qué muestra se ajustaba 
mejor a los requerimientos de la última etapa de investigación e identificar correctamente los límites en los que ésta podría desarrollarse.

Tras este análisis general, en cada uno de los municipios finalmente seleccionados para su estudio pormenorizado se ha realizado una exhaustiva labor de campo, estudiando edificio por edificio la arquitectura hoy existente en cada uno de sus centros históricos, fotografiando cada uno de ellos y elaborando fichas individualizadas en las que se describen y analizan numerosos parámetros de los mismos, de modo que se ha recogido en ellas una serie de características cuantificables para su posterior análisis comparativo. Estas fichas se adjuntan a modo de anexos.

De esta forma, los resultados de este estudio han podido, por último, contrastarse de manera objetiva con las herramientas existentes en cada caso para su protección.

Se pretende con ello, como se ha explicado, analizar su incidencia y resultados, buscando identificar probables carencias, así como la posible existencia de unos principios esenciales que pudieran enriquecer o afinar este tipo de normas en un futuro. En cualquier caso, ha de puntualizarse que esta pretensión no impide que se reconozca la necesidad de aceptar la especificidad de cada caso y del desarrollo de una ulterior actitud crítica ante cada problema en particular. 


\section{DEFINICIONES PRELIMINARES}

Antes de pasar a tratar los principales aspectos de esta investigación es importante aclarar algunas cuestiones que serán fundamentales a lo largo de su desarrollo. En los conceptos a manejar en este estudio existen, como se mencionaba anteriormente, imprecisiones y errores muy extendidos que lo ensombrecen, dificultando la comprensión de los procesos estudiados. Entre éstas, destaca la indefinición y el frecuente uso incorrecto en el ámbito de la arquitectura de ideas tan básicas como qué es lo vernáculo, qué es lo popular o qué es lo tradicional. Sobre ellas arrojan luz diversos autores, que, a lo largo de la historia de la disciplina, han ido enriqueciendo con sus aportaciones el modo en que hoy las entendemos. Conviene referir en primera instancia las principales de ellas, tratando de aclarar cómo se utilizarán estos términos en el resto del texto.

No menos importante es proceder del mismo modo en lo referente a conceptos como el de globalización u homogeneización del paisaje construido, o en lo relativo a qué aspectos se hallan implicados en esa identidad local a cuya preservación dirigen su mirada los fenómenos aquí analizados. Se trata de una terminología desdibujada por su utilización recurrente, a menudo de forma simplificada en exceso e incluso banalizada. Por tanto, es necesario abordar primero su apropiada y matizada definición. 


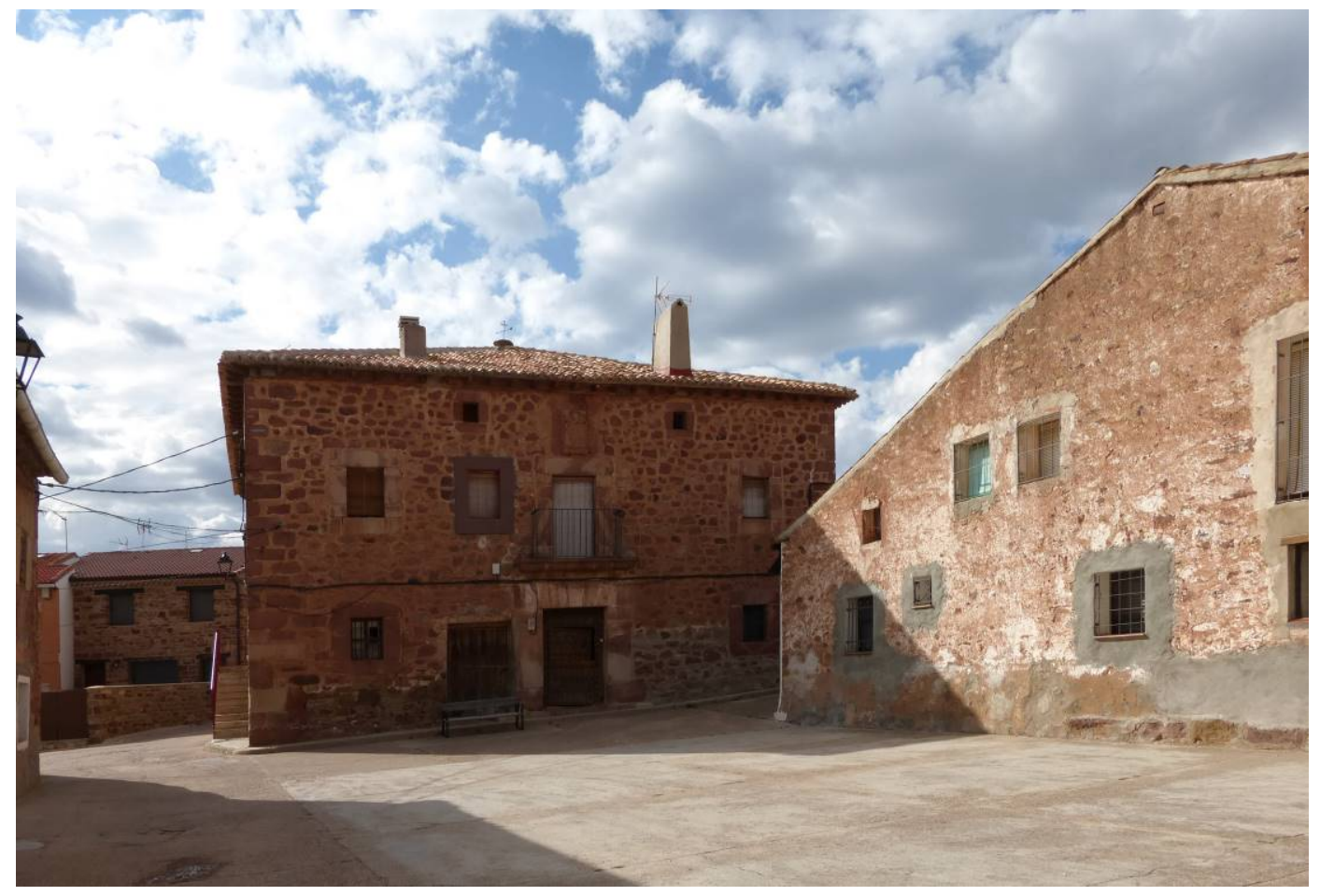

Diversidad cronológica y tipológica en la tradición arquitectónica de Hombrados, Guadalajara, y de Brujas (fotografías del autor, julio de 2014 y agosto de 2010)

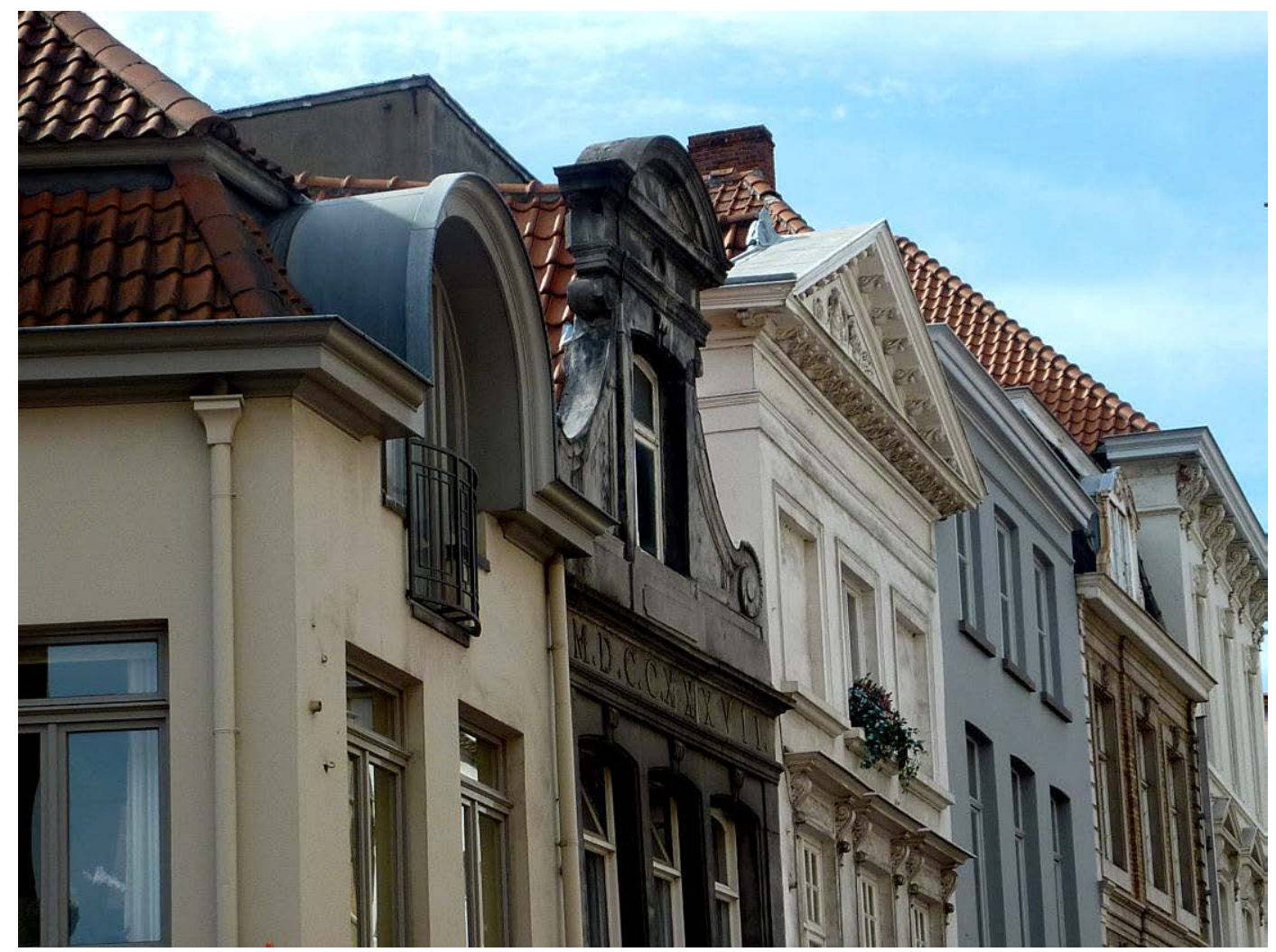




\subsection{LO TRADICIONAL, LO VERNÁCULO Y LO POPULAR EN LA ARQUITECTURA}

\subsubsection{Arquitectura tradicional}

La defensa de las tradiciones arquitectónicas se asocia generalmente a estatismo, a rechazo del progreso o el cambio, e incluso, en ocasiones, a ideas reaccionarias. Sin embargo, el concepto de tradición no implica sólo continuidad, sino también evolución (Gadamer 2004). Los investigadores analizaban hasta hace unas décadas cada cultura como algo estático, completo y armonioso, cuya esencia la definía para siempre, mientras que hoy en día se ha concluido lo contrario, que "cada cultura tiene sus creencias, normas y valores típicos, pero éstos están en constante fluctuación”, y no sólo por el efecto de los cambios acaecidos en su medio físico o por la interacción con otras culturas, sino también “por sus propias dinámicas internas” (Harari 2015).

La tradición nunca es algo cerrado y estable, sino que está siempre cambiando, adaptándose a nuevos requerimientos, a variantes condicionantes $\mathrm{e}$ incluso a transformaciones de la propia cultura transmisora. En consecuencia, normalizarla o estabilizarla sería pues un paso más hacia su desaparición. Cesare Poppi $(2008,9)$, doctor en antropología social por la Universidad de Cambridge, explica cómo la tradición ha de entenderse no como un conjunto limitado de caracteres, sino como una serie de procesos determinados por un "estado de constante flujo de cultura que constituye su savia, mientras que su 'definición' implica 'detención' y, por tanto, su muerte”, por ello, “no resulta ninguna sorpresa que si, habiendo definido y acordado un canon para una tradición, creamos un objeto según esa definición, no podemos lograr más que una réplica"1.

Conforme a esta definición, para una misma región, una casa tradicional erigida en el siglo XV, por ejemplo, generalmente presentará diferencias notables con una construida en el siglo XVIII. Sin embargo, el modelo de la segunda, si continúa dentro de la misma tradición, se habrá desarrollado desde el de la primera, sin que exista ruptura entre uno y otro, sino una progresiva evolución que no ha de ser necesariamente completamente

\footnotetext{
${ }^{1}$ Esta idea ha de ponerse en relación con el tipo de instrumentos normativos dirigidos a la preservación de la identidad local que se han recogido en el apartado 4.4.2. de esta investigación.
} 
lineal. Hay, por tanto, estabilidad en la tradición, pero no es ésta "estática, sino evolutiva, aunque de tan mansa evolución como el lento cambio de la Naturaleza", tal como líricamente la describiera en 1913 Manuel B. Cossío en el catálogo de una pionera exposición dedicada al arte popular en España $(1922,1)$.

Esta continuidad "natural" de la tradición arquitectónica reside en su vitalidad, garante de su adaptabilidad. Perdida ésta, su recuperación supone una ardua tarea que ha de enfrentar múltiples dificultades para realizarse con éxito, implicando complejos procesos de análisis y experimentación previos.

Como reza la Declaración de Boceguillas $(2012,16-17)$, que se consensuara y redactara desde el Centro de Investigación de Arquitectura Tradicional (CIAT), la Arquitectura Tradicional "se aprende, se desarrolla y se transmite mediante vía oral y heredada, esto es: la tradición, lo que la ha alejado hasta hace relativamente poco tiempo de la observación intelectual y científica, ahora imprescindible, sin embargo, para su conocimiento, su conservación y, en su caso, su revalorización".

La base del proceso generador de una tradición arquitectónica está en que alguien halla una solución a un problema que resulta válida para un determinado lugar y una determinada cultura y transmite este hallazgo a un segundo, quien puede replicar su éxito, combinarlo con otras aportaciones o avanzar sobre el mismo. Una tradición no es, por tanto, contraria al progreso, sino un marco apropiado para cimentar un progreso empírico, basado en la acumulación de experiencia, y estrechamente ligado al medio concreto en el que se desarrolla. La tradición puede, de hecho, entenderse como un proceso creativo de naturaleza procesual (Oliver 1989; Asquith y Vellinga 2006, 7; Bronner 2006; Marchand 2006). Es continuamente reconsiderada, permitiendo adaptaciones e innovaciones que, una vez son socialmente aceptadas, pueden convertirse en parte de la misma tradición. En cualquier caso, dado tales adaptaciones e innovaciones requieren de esa aceptación para su generalización, por lo que los procesos evolutivos se dan en la tradición de forma lenta y sopesada. Estabilidad y cambio son igualmente esenciales en ella (Lowenthal 1985, 69; Oliver 2006a, 115). 
Sí puede oponerse el concepto de tradición, sin embargo, al cambio por el cambio, a la novedad por la mera búsqueda de la novedad, a la idealización de lo nuevo (Caro Baroja 1970, 37-40). En palabras del arquitecto Hassan Fathy (1976, 24-25):

Tradición no es necesariamente algo anticuado, ni es sinónimo de estancamiento. Es más, una tradición no necesita ser muy antigua para serlo, pudiendo haber comenzado bastante recientemente (...). Hay, por otra parte, tradiciones que, aunque hayan aparecido sólo recientemente y deberían estar en una fase reciente de su ciclo, nacieron de hecho muertas. Modernidad no necesariamente significa vitalidad, y el cambio no siempre es para mejor. Sin embargo, hay situaciones que llaman a la innovación. Mi postura es que la innovación debe ser una respuesta concienzuda a un cambio en las circunstancias, sin consentirse la innovación por la propia innovación.

Miguel de Unamuno explicaba esta visión de la tradición como algo mutable diferenciando entre la tradición propia de un momento determinado de su evolución, sea pasado, presente o futuro, y lo que denominó Tradición Eterna, el cambiante flujo de la misma a lo largo del tiempo (2005, 143-145; Raguette 2012, 9): “Tradición, de tradere, equivale a entrega, es lo que pasa de uno a otro, trans, un concepto hermano de los de transmisión, traslado, traspaso. Pero lo que pasa queda, porque hay algo que sirve de sustento al perpetuo flujo de las cosas". La transmisión ha de entenderse pues como la esencia de una tradición (Shils 1981, 12). Esta distinción unamuniana entre la tradición de un momento y un lugar concretos y la que denomina "Tradición Eterna" resulta fundamental, como se tratará más adelante, para la comprensión de los planteamientos de buena parte de los arquitectos que en España se han ocupado hasta hoy de la compleja cuestión de la identidad local tradicional.

Volviendo a lo que podríamos denominar "progreso dentro de una tradición", es decir, el lento y sopesado evolucionar que caracteriza a la tradición, conviene señalar que depende, por tanto, entre otros factores, de la continuidad en la transmisión de las experiencias. Y esta transmisión de experiencias permite ir conformando un corpus de saberes sobre cómo habitar un entorno de forma satisfactoria, provechosa y sostenible a largo plazo. Se trata, por ello, de un progreso no lineal, condicionado, en el que puede haber etapas de recesión 
o retroceso, momentos en los que un volumen importante de conocimiento, es decir, de experiencias acumuladas, caiga en el olvido, o donde una alteración en el medio produzca un temporal o definitivo desequilibrio.

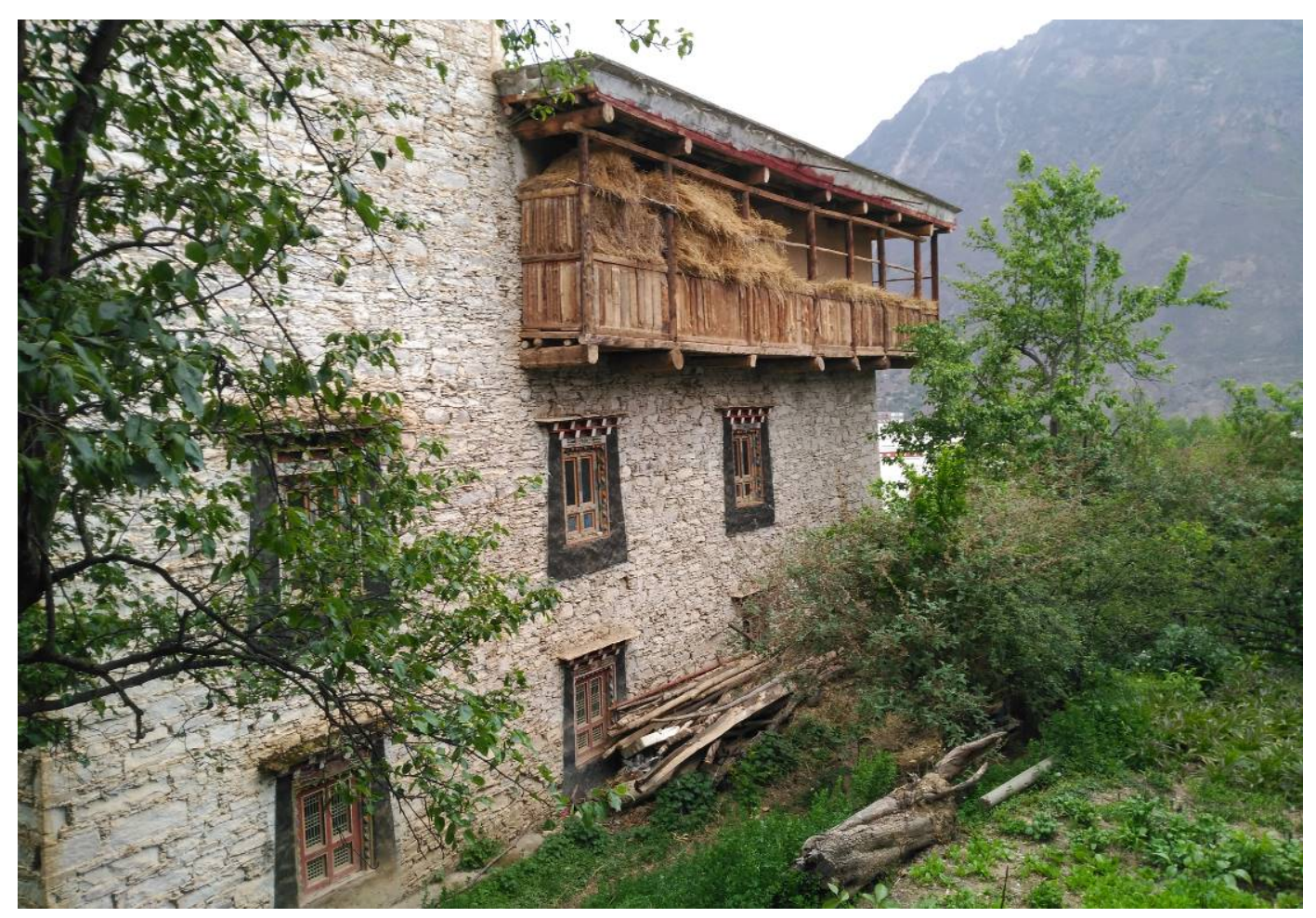

Arquitectura tradicional de Chonglu, Sichuan, China: edificio histórico y nuevo edificio en construcción (fotografías del autor, mayo de 2018)

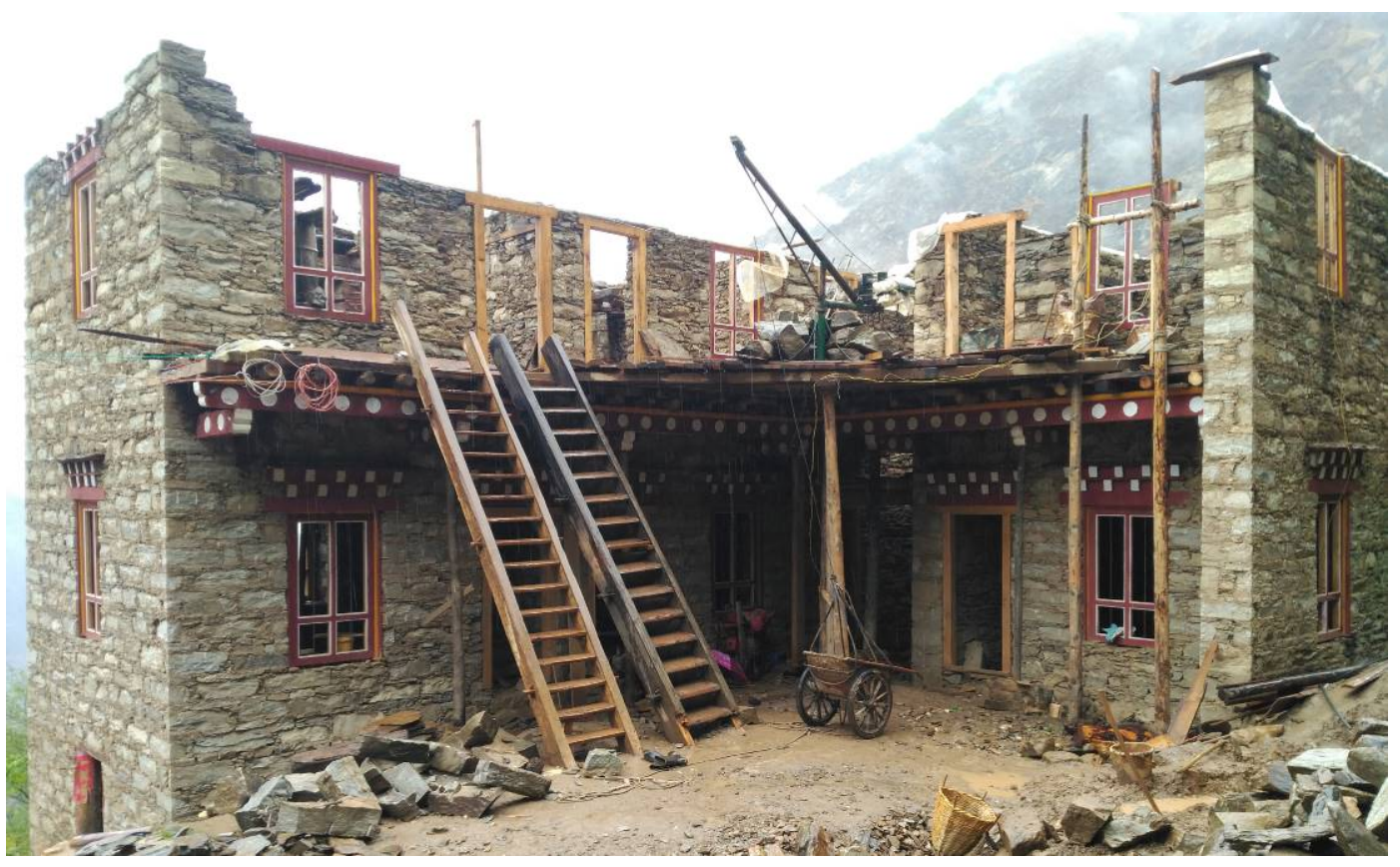


Pero esos saberes pueden también, por supuesto y de igual modo, revitalizarse y volver a desarrollarse de forma progresiva. Su recuperación necesariamente requerirá, en cualquier caso, de un volumen de estudios o de experiencias equivalente al previamente perdido para alcanzar un nivel de "evolución" o de conocimiento y aprovechamiento racional del medio semejantes.

Sin embargo, esta forma de entender la tradición no ha sido, ni es hoy, la única, y las muy diversas maneras de interpretarla han dado lugar también a muy diversas formas de acometer su preservación, tal como podrá comprobarse en el recorrido histórico incluido en el posterior repaso del estado de la cuestión.

Contrariamente a la definición aquí expuesta de tradición como proceso, un gran número de autores han defendido una versión fija y estática de este concepto, muy extendida entre buena parte de la modernidad arquitectónica, que se ha servido de ella y de las ideas que a ella naturalmente se asocian para rechazar sin ambages cualquier voluntad de mantener vivas las tradiciones locales (Vellinga 2006; Harris 2007, 57-58).

En esta línea, Eric Hobsbawm, en su influyente The Invention of Tradition, editado junto a Terence Ranger, afirma que lo característico de la tradición es precisamente su invariabilidad (1983, 2-3). Se trata, sin embargo, de un argumento fácil de rebatir en el propio campo de la arquitectura tradicional, donde las tradiciones se han mostrado cambiantes y adaptables durante siglos, salvo quizá en el caso de las más primitivas y sencillas arquitecturas populares conservadas. Para este autor, "el pasado real o inventado al que hacen referencia impone prácticas fijas (normalmente formalizadas), tales como la repetición". Distingue, sin embargo, las tradiciones de las "costumbres", a las que asigna un carácter análogo al otorgado en el presente estudio a la tradición, pues las considera sujetas a procesos de innovación y cambio, aunque hayan de ser éstos compatibles con los patrones establecidos por los modelos pretéritos. Por ello, para Hobsbawm, a diferencia de la tradición, "la costumbre no puede permitirse ser invariable, porque incluso en las sociedades tradicionales la vida no lo es". Pero "da a cualquier cambio (o resistencia a la innovación) deseado la sanción de lo precedente, de la continuidad social y de la ley natural tal como se expresa en la historia". 
Sin embargo, es precisamente este entendimiento de la "costumbre" análogo al que se utiliza en este trabajo al hablar de tradición, que proporciona, como veremos en los siguientes apartados, un marco apropiado para lograr afianzar justamente esa continuidad social mencionada por Hobsbawm, al contribuir a la definición de las diversas identidades locales ${ }^{2}$.

En cualquier caso, según la acepción de arquitectura tradicional utilizada en esta investigación, el origen de la tradición se halla en el mismo origen de la arquitectura y resulta inextricable de su progreso o evolución.

Atendiendo a esta última cuestión, Bernard Rudofsky, en su influyente obra en defensa de los valores de la arquitectura popular The Prodigious Builders (1977, 49-83), arrojaba luz sobre la naturaleza no instintiva, sino imitativa, de las construcciones humanas. Destacaba en ella el grado de sofisticación y calidad alcanzado por las construcciones de diversos animales, elogiando cómo éstos son capaces de llevar a cabo de forma eficaz sus edificaciones de manera meramente instintiva, sin ensayo previo alguno, sobrepasando así en ello al ser humano, por lo general incapaz de hacerlo con éxito sin basarse en experiencias anteriores, sin partir de una tradición previa. La sorprendente durabilidad y adaptabilidad a situaciones diversas de las obras de algunos de ellos, como pueden ser los castores, las termitas o las avispas, le llevaban a considerarlas logros superiores a los alcanzados por la mayoría de los humanos, para quienes resulta fundamental el conocimiento del precedente para alcanzar soluciones de semejante complejidad.

Esta aceptación de la naturaleza imitativa de las construcciones humanas abre la puerta a la posibilidad de que el ser humano hubiera sido capaz de mejorar e incluso de concebir sus más primitivos cobijos gracias a la observación e imitación de las obras de los animales o de la constitución del propio medio natural, es decir, estableciendo una tradición. Partiendo de ello, los primeros refugios humanos, los primeros ensayos arquitectónicos, clásicamente tipificados como la cueva, la tienda y la cabaña, se desarrollarían durante siglos hasta dar lugar a arquitecturas de mayor complejidad, adaptándose en el proceso a diversas condiciones físicas y dando así lugar a tradiciones divergentes.

\footnotetext{
${ }^{2}$ De hecho, atendiendo al uso que se hará en esta investigación de los conceptos tradición e identidad, el título de la obra citada podría haber sido The Invention of Identities.
} 
Estos tipos de vivienda primitivos, más extensa y apropiadamente clasificados, se ponen hoy día en relación no sólo con el medio físico para el que fueron creadas, sino también con las formas de vida de los tipos humanos que las construyeron, en función de su estructura socio-económica y su mayor o menor sedentarismo (Vela Cossío 2002a, 8384). Es decir, podríamos hablar en definitiva de la tradición como un mecanismo de adaptación progresiva de un grupo humano a un determinado medio físico, dando lugar a diversas culturas materiales.

Ya el propio Vitruvio, en el más antiguo texto de teoría arquitectónica que ha llegado hasta nosotros, nos habla del carácter imitativo de las construcciones humanas (Ortiz y Sanz 2001, 28):

Teniendo por naturaleza, á diferencia de los otros animales, el no caminar inclinados á la tierra, sino rectos y elevados para ver la magnificencia del cielo y astros; como también hallándose aptos con sus manos y articulaciones para tratar fácilmente quanto querían, empezaron unos á disponer sus cubiertos de ramas: otros á cavar cuevas á la raíz de los montes: algunos imitando los nidos de golondrinas y su estructura, con virgultos y lodo hicieron donde guarecerse: otros finalmente, que observaban estos abrigos, adelantando un poco mas sus invenciones, iban de dia en dia erigiendo menos mal arregladas chozas: asi, que siendo aquellos hombres de imitadora y dócil naturaleza, gloriándose cada dia de sus invenciones, se enseñaban unos a otros las nuevas formas de las casas que levantaban; y exercitandose los ingenios en estas emulaciones, las iban de grado en grado mejorando de gusto.

Otros le habían precedido en esta argumentación, que se remonta hasta Demócrito, apareciendo después en los trabajos de diversos pensadores clásicos, y muy especialmente entre los epicúreos. El filósofo abderitano se refería expresamente también, de hecho, al ejemplo vitruviano de la imitación de los nidos de las golondrinas, que puede tener por tanto su origen en esta tradición filosófica griega.

La consecuencia lógica de este razonamiento es que no existe progreso sin imitación. Así, las construcciones humanas fueron enriqueciéndose y adaptándose a las limitaciones 
impuestas por cada nuevo condicionante afrontado, precisamente gracias a esa subrayada capacidad de imitación, a esa habilidad para reproducir las soluciones válidas y desechar las fallidas. Los modelos irían así desarrollándose de forma puramente empírica, definiendo lo que conocemos como tradiciones constructivas, arquitectónicas y urbanísticas. Lo que Vitruvio explica en este pasaje no sólo es el origen de la Arquitectura, sino también la esencia de la tradición, cuyos mecanismos evolutivos y carácter dinámico expone ya con gran claridad. De hecho, otra consecuencia indirecta de esta reflexión es ya la negación de la posibilidad de un progreso efectivo sin una tradición dentro de la que progresar, sin un proceso imitativo que lo dirija.

Para completar el correcto planteamiento de la cuestión de la imitación dentro de la tradición, en todo caso, es importante señalar, siguiendo lo razonado por Julio Caro Baroja en la introducción a su Tecnología popular española $(1996,32)$, que se trata siempre de una imitación condicionada. Como afirmara éste, el creador con frecuencia no imita libremente, sino que lo hace sometido a las imposiciones de su medio social y cultural. El propio autor apunta a Émile Durkheim como inspirador de su defensa de la naturaleza coercitiva del medio cultural en los procesos de imitación. Según esto, las modas, es decir, determinadas convenciones culturales, coaccionan al autor al enfrentarse a su obra. Este argumento adquirirá una importancia fundamental en esta tesis, en especial en el posterior análisis de la problemática actual para la preservación de las tradiciones arquitectónicas locales.

Regresando a Vitruvio, fue también su texto el más antiguo conservado que dirigió su atención hacia las más sencillas arquitecturas populares, que el autor había conocido en sus viajes por el Imperio, para intentar dilucidar cómo hubieron de ser las primitivas viviendas humanas. Es decir, entendiendo los mecanismos evolutivos de la tradición como un mecanismo no lineal ni homogéneo temporal o geográficamente. Tras el pasaje antes citado se refiere con este fin a los más sencillos edificios que seguían siendo utilizados por habitantes de remotas regiones, como las altas cabañas de madera de los colcos, que habitaban en la costa oriental del Mar Negro, o las chozas semiexcavadas de los frigios, que lo hacían en lo que hoy es el noroeste de Turquía. Pero viviendas populares de semejantes características habían de seguir siendo una tradición viva incluso en las más civilizadas y urbanizadas provincias romanas. El mismo Vitruvio nos habla de cómo incluso en la mismísima Roma se conservaba entonces como una valiosa reliquia la 
legendaria cabaña de Rómulo, de la que se sabe que sufrió varios incendios, siendo necesario restaurarla en diversas ocasiones. Así como de que, en el Areópago ateniense, sede del Consejo de la ciudad, se conservaba un antiguo edificio de similares características. Comprendía, al hacerlo, la naturaleza evolutiva y geográficamente y culturalmente determinada de las tradiciones arquitectónicas, e implícitamente establecía una diferenciación entre tipos arquitectónicos más populares, más condicionados por el medio; y tipos más clásicos o de estilo, reflejo en mayor medida de las cambiantes circunstancias socio-culturales y menos limitados por condicionantes físicos.

Esta mayor o menor dependencia del medio físico señala así una posible, aunque a menudo difícil, división entre dos géneros distintos de tradición arquitectónica. Ambos se presentan comúnmente entremezclados y son múltiples las influencias y dependencias mutuas.

Así pues, una arquitectura concebida según las reglas de un estilo histórico culto no tiene por qué excluirse de la categoría de arquitectura tradicional, estando esta práctica, sin embargo, muy extendida. Amos Rapoport, en la obra que se convertiría en una referencia fundamental para muchos de los estudios sobre arquitectura tradicional realizados tras su publicación en 1969, House Form and Culture (2-4), ya establecía esta dualidad dentro de la arquitectura tradicional, diferenciando entre lo que denominaba "grand design tradition" y "folk tradition". La arquitectura de estilo, englobada por numerosos autores, en algunos casos refiriéndose a un concepto universal, intercultural, bajo la denominación de "clásica", está más sometida a las condiciones socio-culturales del momento que la arquitectura popular tradicional y es en menor medida dependiente del medio físico en que se desarrolle que ésta ${ }^{3}$. Presenta por lo general, por ello, menos rasgos vernáculos, pero eso no implica que sea independiente de las tradiciones de un determinado lugar. Tampoco es más evolucionada que la arquitectura popular tradicional, ni ha de considerarse ésta una arquitectura "menor", término utilizado con frecuencia para denostarla frente a las arquitecturas más académicas. Por el contrario, se trata de respuestas diversas a una problemática y unos requerimientos distintos, para algunos de los cuales la arquitectura popular tradicional puede proporcionar la solución más

\footnotetext{
${ }^{3}$ Esto resulta coherente con los resultados de esta investigación, puesto que las transformaciones de la arquitectura analizada en ella de forma pormenorizada son en gran medida obras de autor, siendo sólo populares en ocasiones. Así, inciden sobre ellas de forma notable los factores socioculturales.
} 
perfeccionada e inteligente (Boas 1955, 1-4; Lévi-Strauss 1962, 11-59; Oliver 2006a, 124). Diversos autores, sin embargo, han defendido y aún hoy defienden la supremacía de la arquitectura de autor, sea ésta la de la tradición clásica o la de las tendencias arquitectónicas del momento, sobre la arquitectura popular. Por ello, se refieren a menudo a la arquitectura popular como algo de una inferior categoría, irracional o simplemente, tal como se ha mencionado, como "arquitectura menor".

En cualquier caso, es importante no confundir estilos históricos con tradiciones. Una arquitectura puede ser de estilo gótico, por ejemplo, sin ser tradicional, pero podemos hablar también de un gótico de tradición levantina o de un gótico de tradición veneciana, es decir, de un gótico adaptado a la tradición de estos lugares, como podemos afirmar que el lenguaje barroco fue adoptado y adaptado de modo diverso por las tradiciones arquitectónicas del noroeste español o por las del sur peninsular, tiñéndose en el proceso con numerosos rasgos vernáculos. De este modo, podríamos hablar de una arquitectura tradicional madrileña que incorporase, sin embargo, rasgos estilísticos clásicos en mayor o menor medida, o de una arquitectura monumental de tradición local en el nordeste de la provincia de Segovia, pese a haberse ésta ido transformando a lo largo del tiempo con la llegada de diversas corrientes estilísticas.

En consecuencia, entre las arquitecturas plenamente dependientes de la tradición local y las que incorporan más elementos culturales supralocales no tradicionales existe también toda una gradación de arquitecturas más o menos vernáculas en función de su mayor o menor dependencia de los condicionantes puramente físico-geográficos. Por ello, Vicente Lampérez y Romea, en su pionera obra Arquitectura civil española de los siglos I al XVIII, según estos diversos grados de dependencia del medio físico, diferenciaba entre lo que denominaba casas señoriales o urbanas, más cambiantes ante aspectos culturales y, por tanto, más variables en el tiempo, y las casas humildes o de labriegos, menos afectadas por las variaciones del gusto del momento y más por los condicionantes de su entorno, tales como el clima o la mayor o menor disponibilidad de unos u otros materiales de construcción (1922, 35-36, 105-106). En palabras de Leopoldo Torres Balbás (1988, 165): "muchos problemas de la gran historia han de encontrar su explicación en la arquitectura popular. Y se verá, si se analiza ésta, la influencia ejercida sobre la erudita, cómo el pueblo coge espontáneamente los elementos más vitales y afines a su propia naturaleza de aquélla, en algunas ocasiones, y los adapta a su sentir". 
En este aspecto concreto, la delimitación planteada de lo que es arquitectura tradicional se aleja de la presentada en la ya mencionada Declaración de Boceguillas (2012, 16-18), donde se circunscribe al conjunto de edificaciones que "se han mantenido siempre al margen de las corrientes cultas y de la Historia de la Arquitectura y, por lo tanto, de la evolución estilística o constructiva que las caracteriza", refiriéndose así tan solo a lo que en este trabajo se denominará arquitectura popular tradicional, y afirmando también, por la misma causa, que "no incorpora soluciones extrañas a su propio medio, carece generalmente de autor concreto o individualizado y no está sometida, ni material ni formalmente, a los cambios y la evolución temporal que vinculan a los edificios con una época determinada". Atendiendo a estas afirmaciones, quedarían fuera de la definición arquitecturas tan representativas de una tradición regional concreta como pueden ser los cortijos andaluces o las masías catalanas, donde se incorporan elementos y detalles de arquitecturas "cultas", entremezclados con otros puramente populares; cuentan en ocasiones con autor conocido; y existe en ellos evolución estilística y técnica, ausente esta última, en realidad, únicamente en las más primitivas construcciones populares que han llegado hasta nosotros, como son algunos chozos y tenadas pastoriles. Más inclusiva resulta, sin embargo, la acepción de arquitectura tradicional utilizada en el Plan Nacional de Arquitectura Tradicional desarrollado por el Instituto de Patrimonio Cultural de España $(2014,7)$ : "Se considera Arquitectura Tradicional al conjunto de construcciones que surgen de la implantación de una comunidad en su territorio y que manifiestan en su diversidad y evolución su adaptación ecológica, tanto a los condicionantes y recursos naturales, como a los procesos históricos y modelos socioeconómicos que se han desarrollado en cada lugar. Constituyen un destacado referente entre las señas de identidad culturales de la comunidad que la ha generado, y es el resultado de experiencias y conocimientos compartidos, transmitidos y enriquecidos de una generación a otra".

Resulta también fundamental comprender que una tradición arquitectónica puede dar lugar a muy diversos tipos de edificaciones, sin que éstos hayan de corresponderse necesariamente con formas de vida rurales. Sin embargo, con frecuencia se asocia la arquitectura tradicional exclusivamente con lo rural o con lo campesino. En el seno de una misma tradición local pueden haber ido surgiendo arquitecturas de mayor o menor complejidad, ligadas a muy variadas funciones $\mathrm{y}$, en el caso de las viviendas, a muy distintas formas de habitar, siendo muy diversas las casas concebidas para gentes dedicadas al trabajo en el campo de, por ejemplo, aquéllas no menos tradicionales 
pensadas para personas con oficios liberales $\mathrm{u}$ otros medios de vida, y pudiendo conformar éstas desde pequeñas aldeas hasta populosas y jerarquizadas urbes.

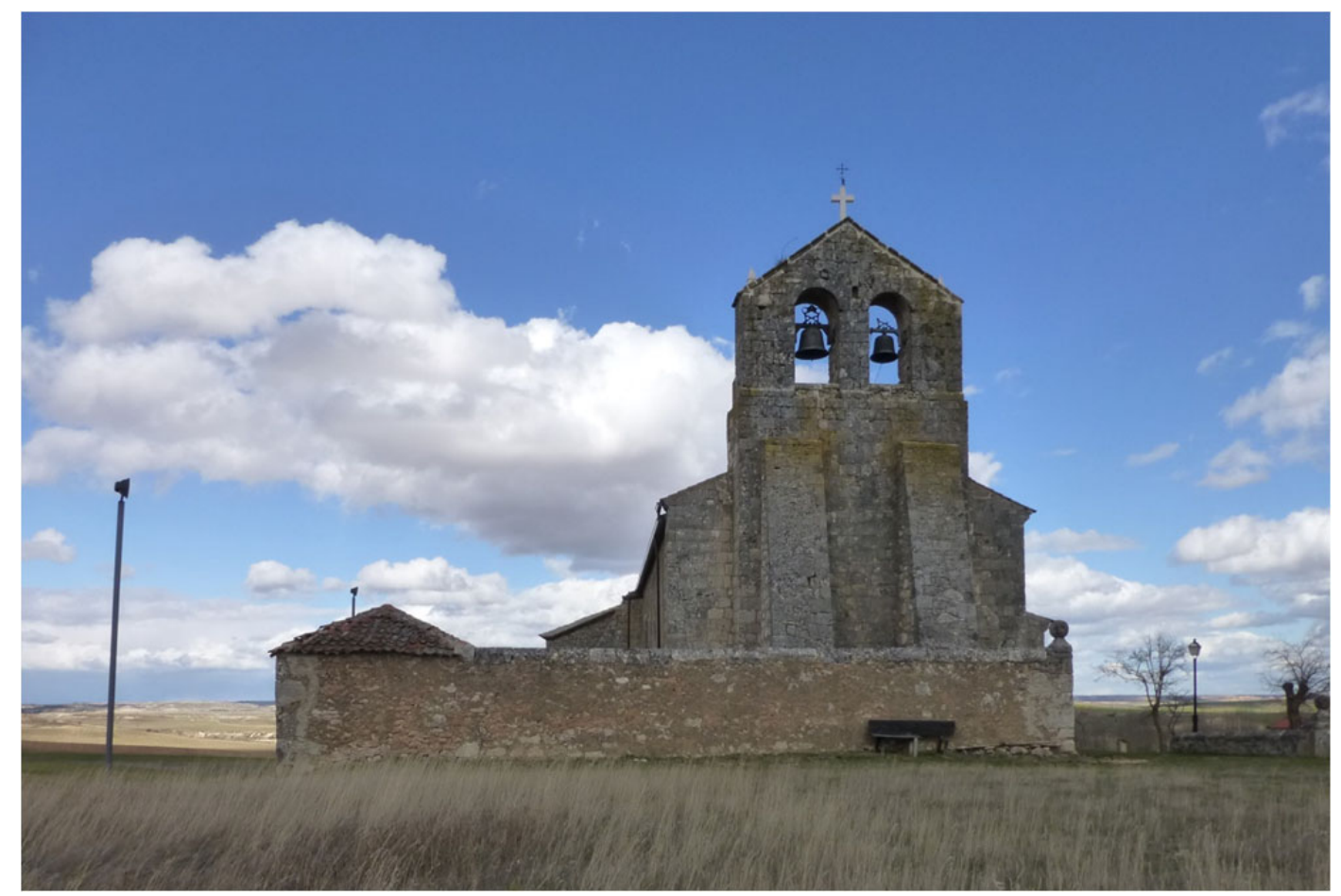

Rasgos vernáculos de tradición local en la arquitectura "culta": Iglesia de San Cristóbal en Valdevarnés, Segovia, y Ermita de Nuestra Señora de las Angustias en Villaseca de la Sagra, Toledo (fotografías del autor, marzo de 2014 y abril de 2015)

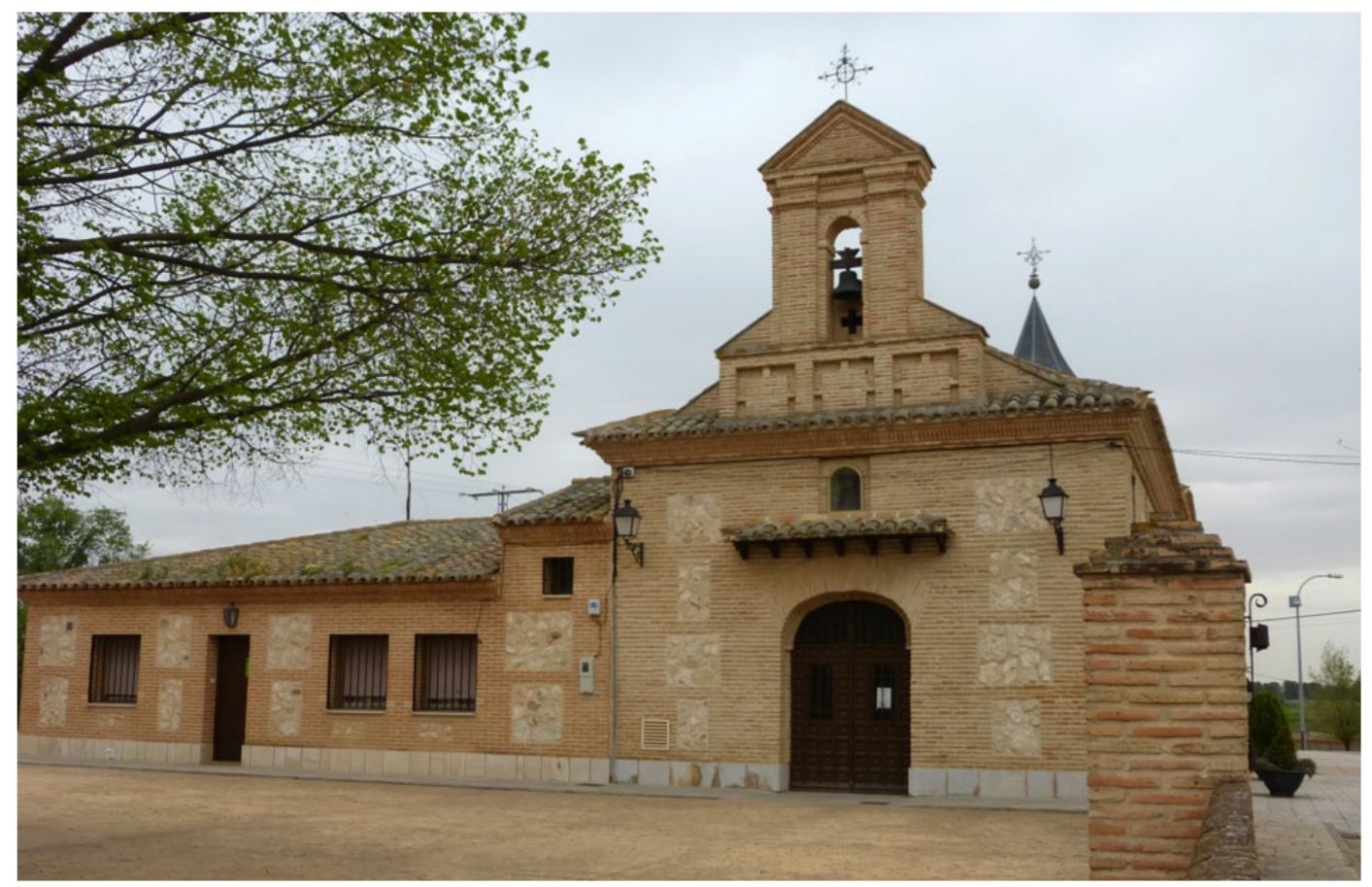


Según lo planteado, la arquitectura tradicional puede o no ser popular, pero, a su vez, también la arquitectura popular puede o no ser tradicional y puede o no ser vernácula. Así, una infravivienda suburbana será hoy en día, por lo general, popular, pero rara vez tradicional y sólo en ocasiones vernácula.

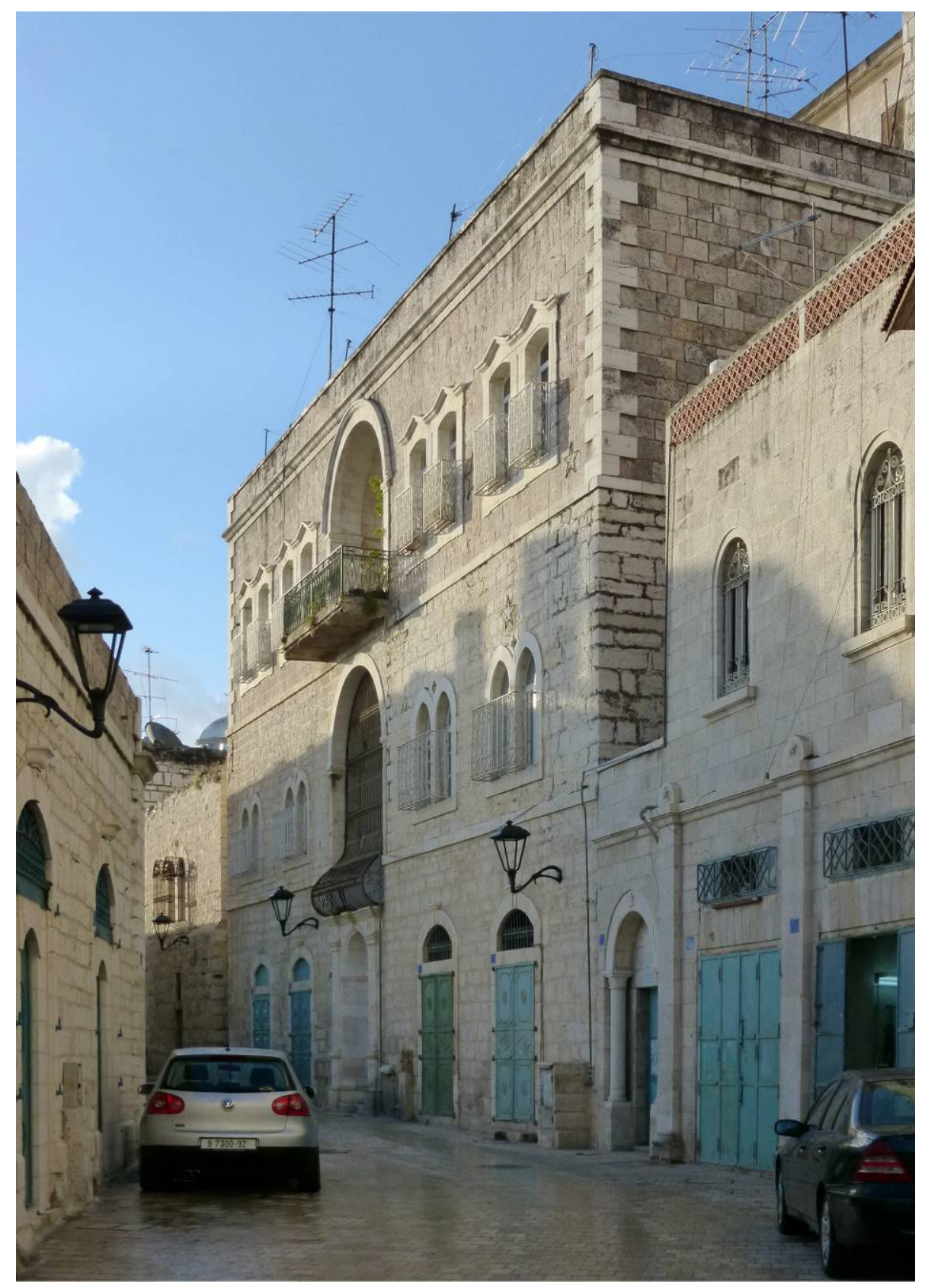

Arquitectura tradicional, vernácula y no popular en Belén, Palestina

(fotografía del autor, noviembre de 2014) 


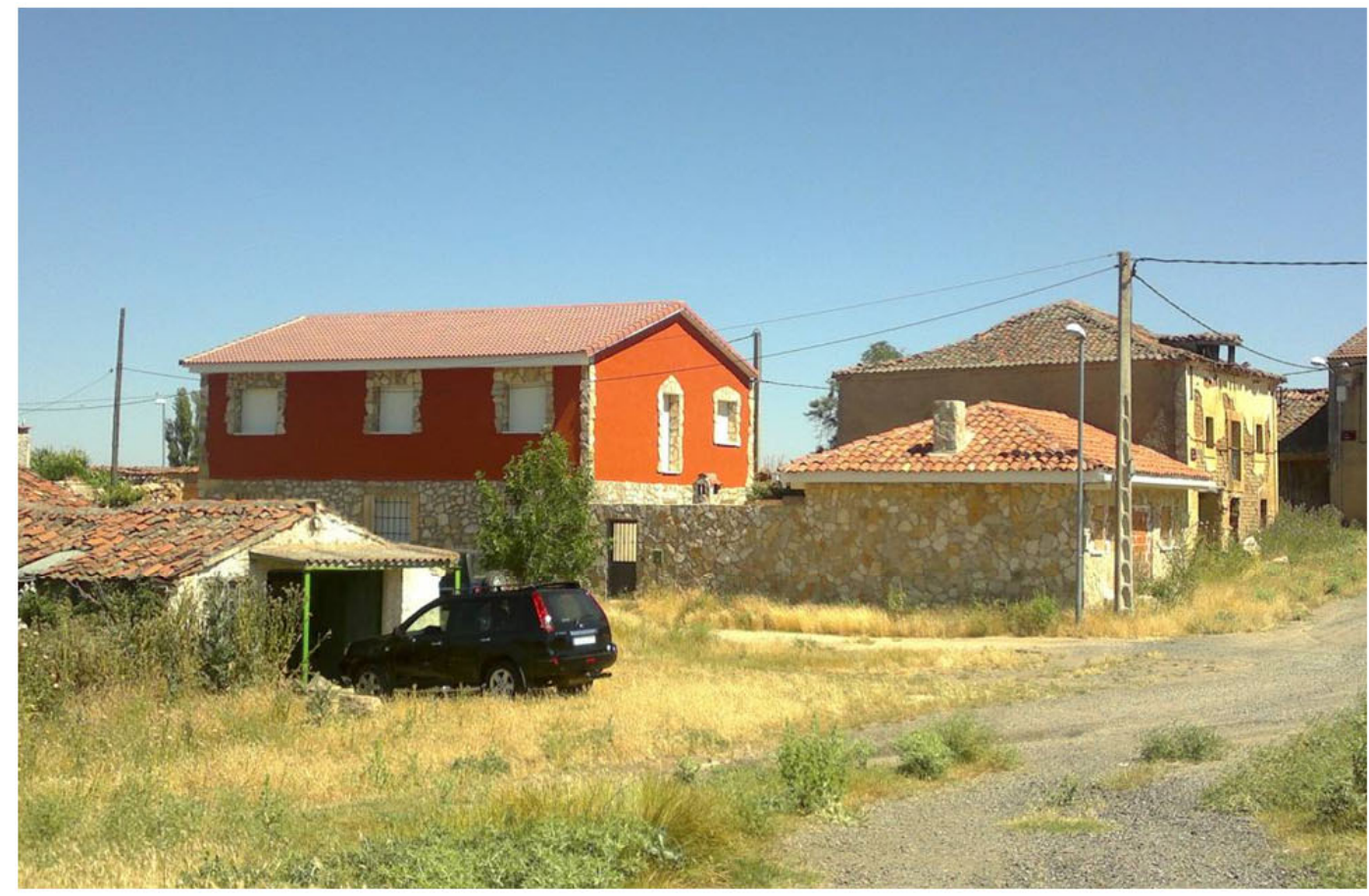

Arquitecturas populares no tradicionales, que incorporan, sin embargo, determinados rasgos vernáculos propios de la tradición local en Aldeanueva de Campanario, Segovia, y Agdz, Zagora, Marruecos (fotografias del autor, julio de 2013 y enero de 2014)

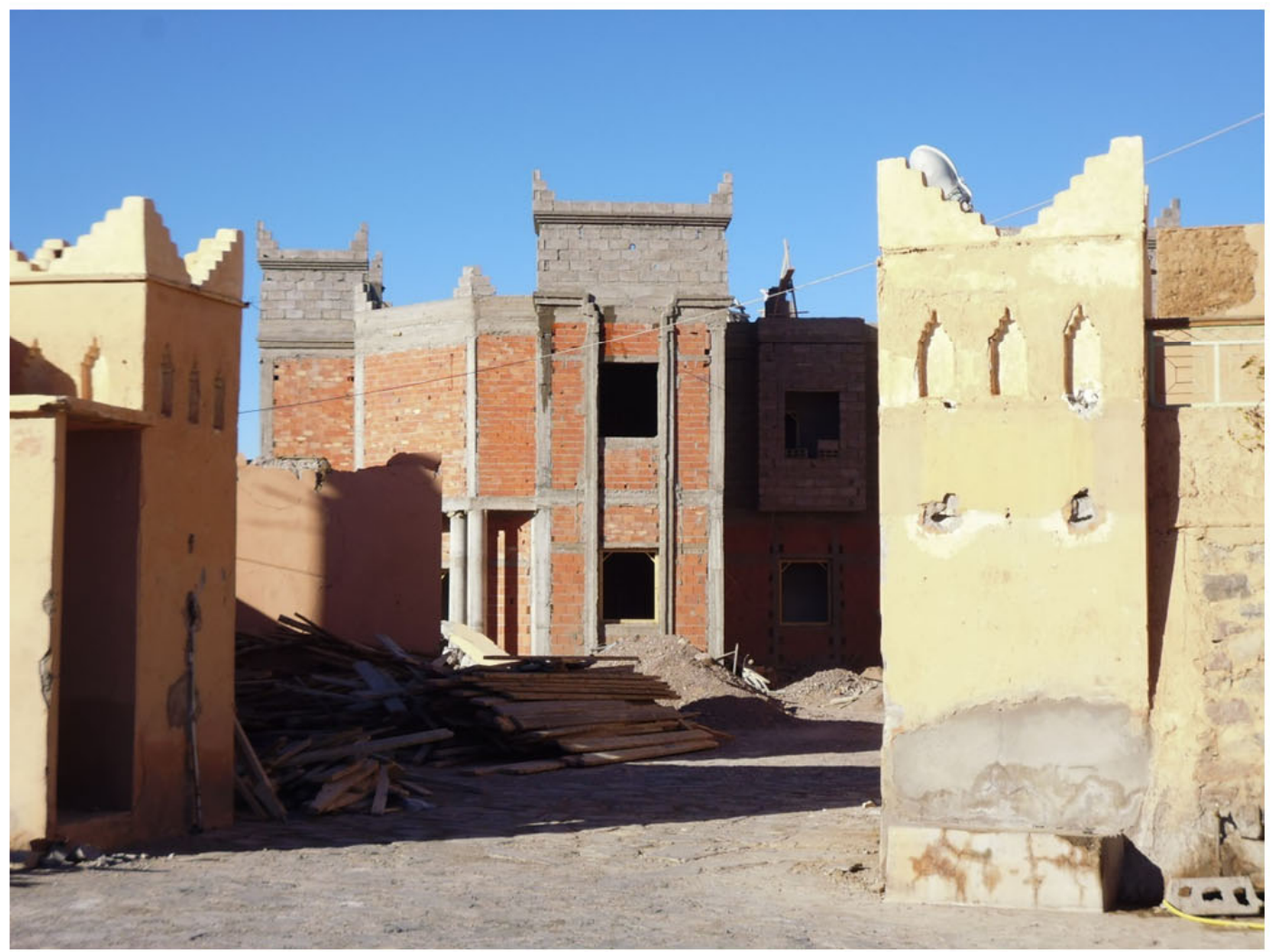




\subsubsection{Arquitectura popular}

Expuesto todo ello, conviene ahora arrojar luz también sobre la definición de lo popular, que se utilizará en el desarrollo de esta investigación como todo aquello que es obra del "pueblo" o, en otras palabras, aquello que carece de autor con formación académica. Sobre esta acepción, en cualquier caso, existe y ha existido también una gran disparidad. Esta indefinición ha venido con frecuencia motivada por la incorrecta identificación de este término con los de tradicional o vernáculo, confundiéndose así lo que a unos u otros caracteriza.

El propio Carlos Flores (1973 - 1977, vol. 1, 9-61), en el capítulo inicial de su monumental obra Arquitectura popular española, sin duda una de las principales referencias nacionales al respecto, tratando de explicar el concepto de popular sin establecer la necesaria diferenciación entre lo tradicional y lo popular, y buscando excluir por ello de la definición de arquitectura popular las manifestaciones no tradicionales de la misma, se ve obligado a establecer una forzada diferenciación entre el pueblo más humilde de las sociedades tradicionales y la "clase proletaria" propia de sociedades industriales, argumentando que es sólo el primero de ellos el que es capaz de producir una arquitectura verdaderamente popular. Por ello, coherentemente, más adelante, al enumerar las características de la arquitectura popular, considera que ésta es en todo caso tradicional y que técnica y materialmente se encuentra siempre ligada a lo pre-industrial.

Sin embargo, Torres Balbás estableció con claridad la integración de arquitecturas "cultas" y populares dentro del marco común de la tradición, de lo heredado durante generaciones. También hizo referencia a su interdependencia, existiendo en realidad multitud de tipos de casos intermedios. Así, entendía que no podían considerarse arquitecturas puramente populares muchas de las casas montañesas, ni buena parte de las masías catalanas, ni otras arquitecturas tradicionales en las que se hibridaba ya lo culto y lo popular, aunque estas últimas fueran igualmente dependientes tanto de factores físicogeográficos como humanos o culturales $(1988,154)$.

Entre las características de lo popular (Torres Balbás 1988, 152-155; García Mercadal 1930, 7-9; Flores 1973 - 1977, vol. 1, 14-26; Feduchi 1974 - 1984, vol. 1, 9-10) ha habido un cierto consenso, por el contrario, en aspectos como su sencillez, es decir, en el 
ingenio y la audacia que manifiestan en la resolución de la problemática más esencial, que algunos han querido entender como un vínculo con un cierto funcionalismo y que otros han matizado, especialmente fuera de nuestro país, subrayando incluso la mayor preponderancia en lo popular de condicionantes puramente culturales (Rapoport 1969; Oliver 2003, 192-209). También existe un amplio acuerdo en su carácter puramente imitativo, huyendo de cualquier innecesaria experimentación; en su general búsqueda de la durabilidad, del constituirse en legado familiar; y en su utilización de materiales eminentemente "naturales", o menos industrializados, y generalmente procedentes del entorno inmediato, aunque esto no siempre es así, habiendo materiales como la madera que tradicionalmente en algunas regiones se transportaban a largas distancias. También es comúnmente aceptada su estrecha vinculación con el medio en el que se ha desarrollado, aunque, frente a un muy extendido determinismo que trata de relacionar de forma directa las condiciones de un particular entorno y la arquitectura de las gentes que lo habitan, otros autores han tratado de demostrar en sus estudios las carencias de este planteamiento, constatando cómo las costumbres de un pueblo condicionan la tradición arquitectónica en mayor grado que el propio medio (Oliver 1969, Asquith y Vellinga 2006). De esta última posición son buena muestra, por ejemplo, los trabajos sobre la arquitectura tradicional ibicenca del conocido dadaísta Raoul Haussmann (1944, 238-244), o las investigaciones del ya mencionado Amos Rapoport, tales como su citado House Form and Culture. En esta obra, Rapoport considera que aspectos como el clima o los materiales y técnicas constructivas disponibles pueden producir alteraciones en la arquitectura tradicional, pero no determinar su forma. Las formas arquitectónicas tradicionales no suelen variar, por ejemplo, entre un pueblo y otro vecino simplemente porque en uno de ellos sus muros hayan de construirse en piedra y en el otro tengan que ser edificados en tierra. Estos factores, por tanto, condicionan la forma, limitando las opciones disponibles, pero la forma es en última instancia una elección cultural entre esas posibles opciones. Los denomina por ello "factores secundarios o modificadores", mientras que considera los factores socio-culturales "fuerzas primarias" (1969, 46-47). Sobre esta teoría Rapoport fundamentó un nuevo campo de investigación que él mismo bautizó como "environmentbehaviour studies", desarrollado en trabajos posteriores como Human Aspects of Urban Form. Towards a Man-Environment Approach to Urban Form and Design (1977). Un planteamiento semejante al de Rapoport fue defendido en España por Julio Caro Baroja, quien rechazaba que la producción material del hombre fuera consecuencia directa de 
"ciclos funcionales", subrayando la importancia de la "estructura social" y la cultura como condicionantes principales de la misma (1971, 15-16).

También se han utilizado para referirse a la arquitectura popular otros términos. "Arquitectura anónima" estuvo muy extendido, por ejemplo, entre la vanguardia arquitectónica española en los años 20 y 30 del siglo pasado e incluso en trabajos posteriores como Native genius in anonymous architecture, de Sybil Moholy-Nagy, publicado en 1957. "Arquitectura espontánea" se ha utilizado también de forma equivalente al anterior. Con semejante sentido, "arquitectura natural" y "arquitectura sin estilo" han sido especialmente populares entre los más beligerantes arquitectos de vanguardia. La preferencia por estas denominaciones no está exenta de contenidos ideológicos, y se han usado generalmente todas estas acepciones precisamente en defensa del determinismo criticado por Rapoport, Oliver, Caro Baroja y otros autores. Pueden ponerse por lo común en relación con lo que el propio Caro Baroja (1983, 91-91) denominó "esquema hesiódico de las edades sucesivas, arrancando de una primera y más feliz, para llegar a una última y peor", que ha estado y sigue estando tan extendido como la igualmente nociva idea de su progresivo perfeccionamiento. Los adjetivos "natural", "sin estilo", “espontánea”, etc. se utilizaban así en contraposición con la arquitectura que se practicaba de forma mayoritaria en su tiempo, denostada por buena parte de estos mismos autores como artificiosa e impostada.

En todo caso, a menudo en esta misma línea, es quizá "Arquitectura sin arquitectos" la denominación que mayor repercusión ha tenido en el campo arquitectónico. Entre los primeros en hacer uso de esta última denominación parecen haber estado José Luis Sert, en un artículo significativamente titulado "Arquitectura sense 'estil' i sense arquitecte", y Raoul Hausmann, en otro de nombre "Eivissa i l'arquitectura sense arquitecte", respectivamente publicados en 1934 y 1936 en la revista catalana D’Ací i d'Allá. Sin embargo, quien definitivamente popularizó este término fue otro de los grandes apologistas y admiradores de la arquitectura vernácula mediterránea ya desde la misma década de los 30, Bernard Rudofsky. El interés de Rudofsky por este tema se manifiesta tempranamente en su tesis doctoral, que defendió en 1931, y que centró su atención en la construcción popular tradicional de las islas Cícladas. Décadas más tarde, tras diversas publicaciones y múltiples viajes, en especial por el Mediterráneo, sería su exposición Architecture without Architects, inaugurada en 1964 en el MOMA de Nueva York, la que 
consagraría el uso de esta denominación. La exposición viajó después por ochenta y cuatro localizaciones diferentes durante doce años y su famoso catálogo, publicado en el mismo año, se tradujo a siete idiomas, incluido el castellano, vendiéndose más de cien mil copias del mismo sólo en los Estados Unidos (Guarnieri 2010, 246). Precisamente este trabajo de Rudofsky es citado por Lindsay Asquith y Marcel Vellinga en su introducción al libro Vernacular Architecture in the Twenty-First Century: Theory, education and practice como ejemplo tardío de la presentación de la arquitectura tradicional sin prestar suficiente atención a su contexto cultural $(2006,4)$, sin que ello vaya en detrimento de la importancia que su contribución tuvo para la popularización del interés por la tradición arquitectónica.

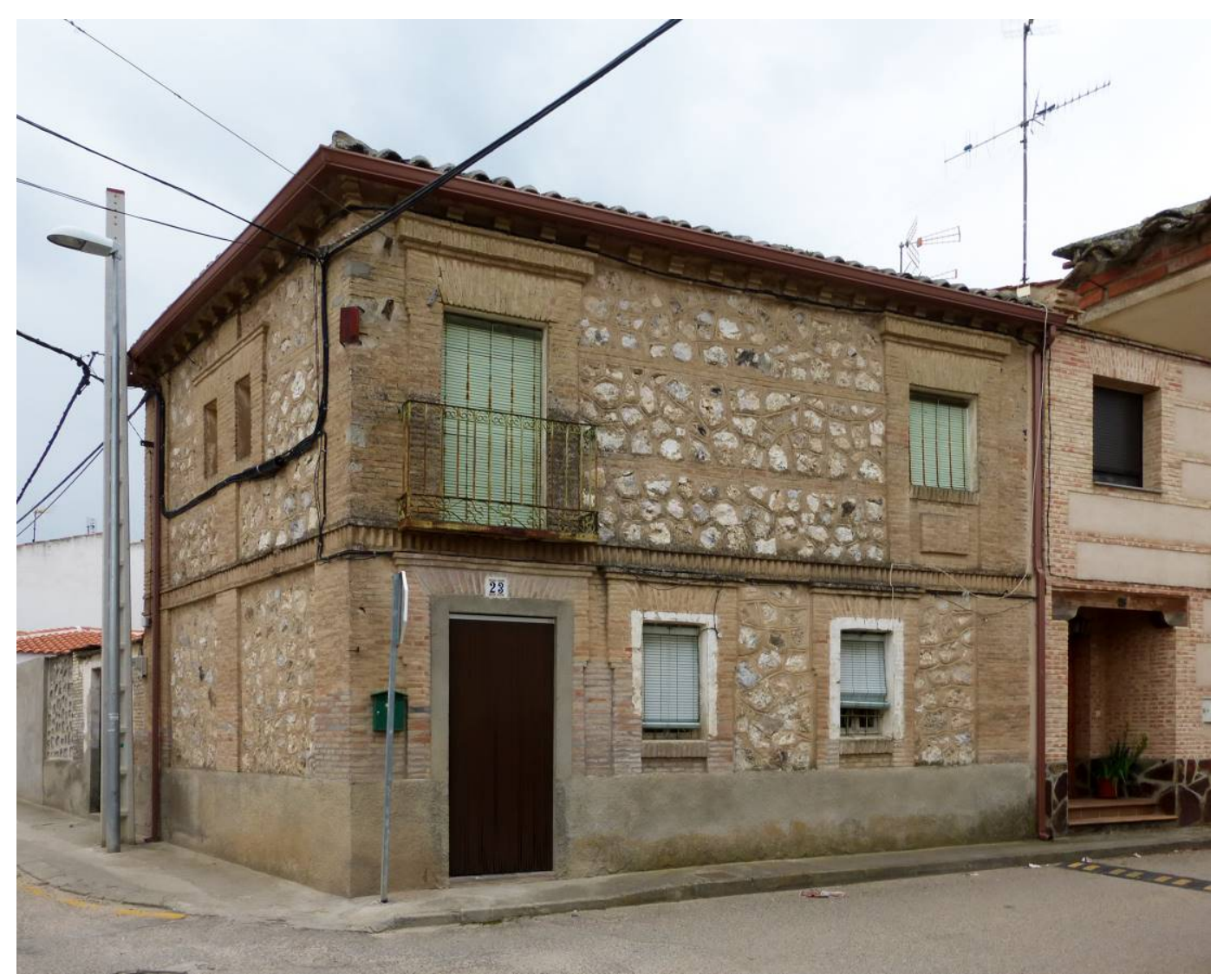

Ejemplo de arquitectura popular en Yunclillos, La Sagra, Toledo, a la que, sin embargo, difícilmente podría aplicarse la etiqueta de "arquitectura sin estilo", ya que incorpora diversos elementos propios de la arquitectura “culta” (fotografía del autor, abril de 2015) 


\subsubsection{Arquitectura vernácula}

Por vernáculo en español se entiende aquello que es propio o nativo de un determinado lugar. Arquitectura vernácula es, por tanto, en nuestra lengua, la que es propia de una determinada región o lugar. Sus particulares caracteres pueden orientarnos así sobre su pertenencia a un clima, un área geográfica o un entorno cultural específicos.

Según esto, una arquitectura vernácula podrá o no ser popular, ya que, como se ha explicado previamente, también una arquitectura "culta" o "de autor" puede incorporar rasgos que nos permitan asociarla a un determinado lugar, y de hecho tradicionalmente solía hacerlo.

Pero esto no sólo es aplicable a arquitecturas pretéritas, sino que es también un recurso de uso común en la arquitectura contemporánea. Así, por ejemplo, podemos reconocer una determinada arquitectura como propiamente neoyorquina sin que ésta sea en absoluto popular. Se aproxima así esta definición, como veremos, al uso del término "vernáculo" más extendido en Norteamérica.

Conviene señalar también que los rasgos vernáculos son determinados por su vinculación con una determinada identidad local, y que esa identidad asociada a un lugar concreto puede o no tener su origen en una tradición, pudiendo haber sido también planificada o generada por otros medios. Es decir, lo vernáculo puede así mismo ser o no tradicional.

En caso de serlo, son los elementos que sobreviven a la evolución constante que la tradición impone los que determinan precisamente ese carácter vernáculo. Podría afirmarse que lo vernáculo dentro de una tradición está constituido por el núcleo más estático de la misma, aquello de más lenta evolución o transformación, sin que éste haya de ser necesariamente algo inmutable. De hecho, cuando Chueca Goitia acuña el término "invariante" para hablar de esos rasgos característicos que definen lo vernáculo, y pese a al carácter ineludiblemente equívoco de esta denominación, trata de desmarcarla en todo momento del estatismo que pudiera atribuírsele, pareciéndole mucho más adecuado "usar el término invariante con toda su flexibilidad y fluidez que el de constante, cuya rigidez contraviene el vagaroso fluir del proceso histórico" (Chueca Goitia 1971, 29). Esta matización resulta importante, pese a poder ponerse en duda la mayor "flexibilidad y 
fluidez" de la palabra elegida, al haber sido ese segundo término, el de "constante", el preferido con fines semejantes por otros autores españoles del momento (Almagro 1955). Así, por ejemplo, un tipo de chimenea puede ser un elemento arquitectónico vernáculo, propio de una determinada tradición local, y, sin embargo, haber sufrido un proceso de lenta pero constante transformación a lo largo del tiempo.

Otro aspecto de lo vernáculo que ha de destacarse es que puede hallarse descontextualizado, manteniendo, sin embargo, su poder de evocación del lugar al que pertenece. Son también arquitecturas vernáculas aquellas arquitecturas que encontramos replicadas en contextos diversos a aquellos de los que son propias. Así, su origen continúa siendo, sin embargo, identificable.

Esta última afirmación parece tambalearse ante muchos rasgos arquitectónicos considerados vernáculos por parte de la crítica arquitectónica, pero que son, sin embargo y en esencia, meras abstracciones pretendidamente vernáculas. De ahí la importancia de establecer un correcto uso de esta terminología. La defendida conexión de muchos de esos rasgos con un lugar concreto se limita en realidad a su asociación con un determinado autor. De este modo, se afirma con frecuencia, por ejemplo, que las curvilíneas formas representativas de algunas de las más conocidas obras de Alvar Aalto se han erigido en rasgo vernáculo de lo finlandés. Sin embargo, “cuanto más son utilizadas por Richard Meier esas sensuales curvas de Aalto, menos tendemos a recordar su inspiración finlandesa" (Speck 2007, 79). La diferencia entre lo verdaderamente vernáculo y lo que lo es sólo de forma circunstancial queda evidenciada cuando, por el contrario, no por reproducir una y otra vez motivos propios de una pagoda china en cualquier barrio chino de una gran ciudad dejaremos de identificar el lugar de origen de esa arquitectura.

Ahondando en esta última cuestión, podría también afirmarse que, generalmente, cuando nos encontramos ante una arquitectura vernácula descontextualizada, si su verdadero origen nos resulta familiar e identificable, y contra lo que se ha afirmado hasta la saciedad durante las últimas décadas, esto no nos causa rechazo. De este modo, por ejemplo, hallándonos frente a una arquitectura vernácula oriental en un jardín inglés, ante un pequeño pueblo ruso en Potsdam, o ante un edificio de inspiración montañesa en la ciudad de Madrid, normalmente, y salvo que nos encontremos frente a un vulgar sucedáneo, no sólo no lo encontramos problemático, sino que comúnmente resulta divertido e inspirador. 


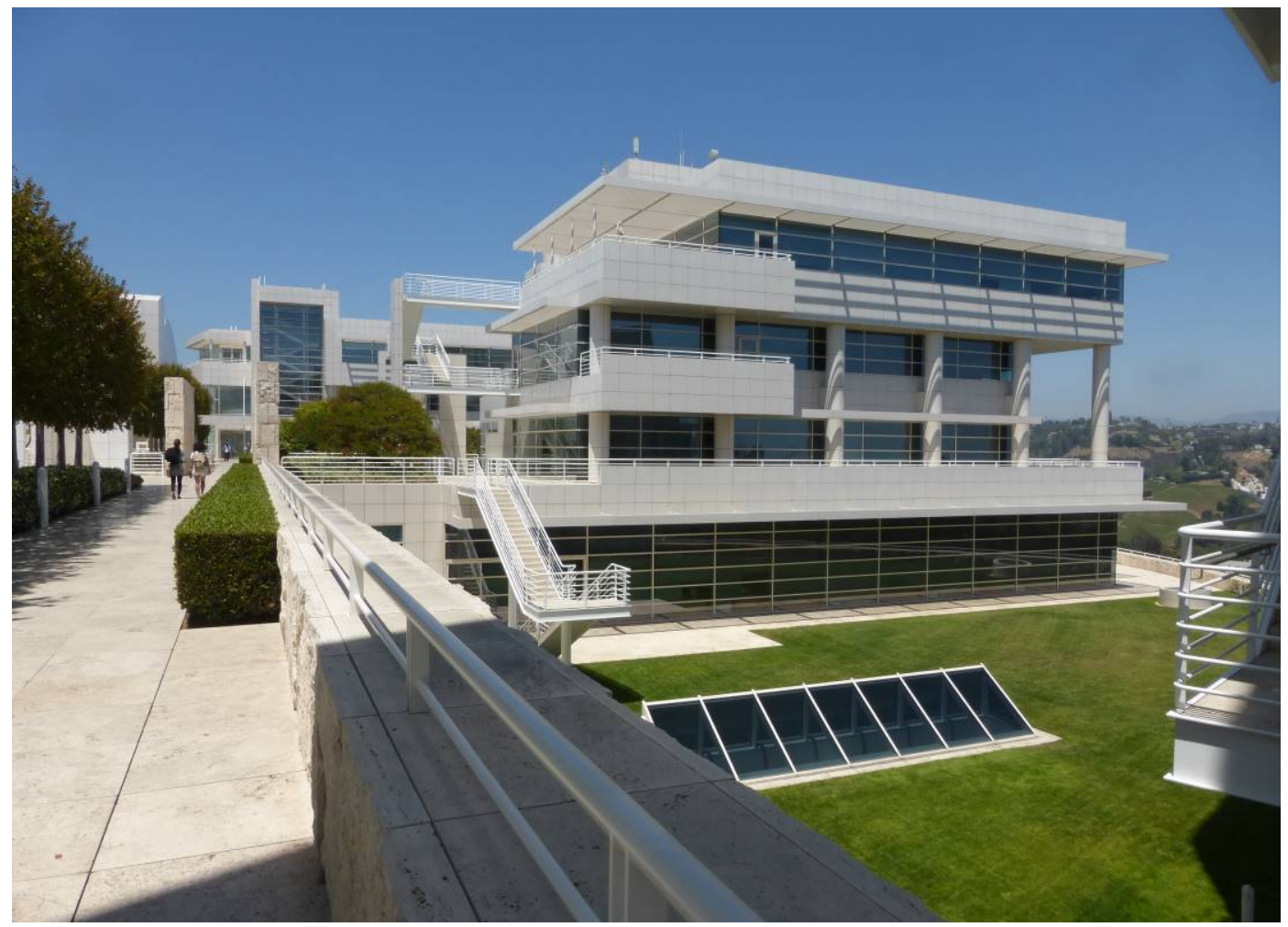

Edificios en lugares y contextos por completo diversos en los que se hace uso de idénticos lenguaje, soluciones arquitectónicas y materiales de construcción: el Centro Getty en Los Ángeles y Museo del Ara Pacis en Roma, ambos obra del arquitecto norteamericano Richard Meier (fotografías del autor, mayo de 2016 y marzo de 2010)

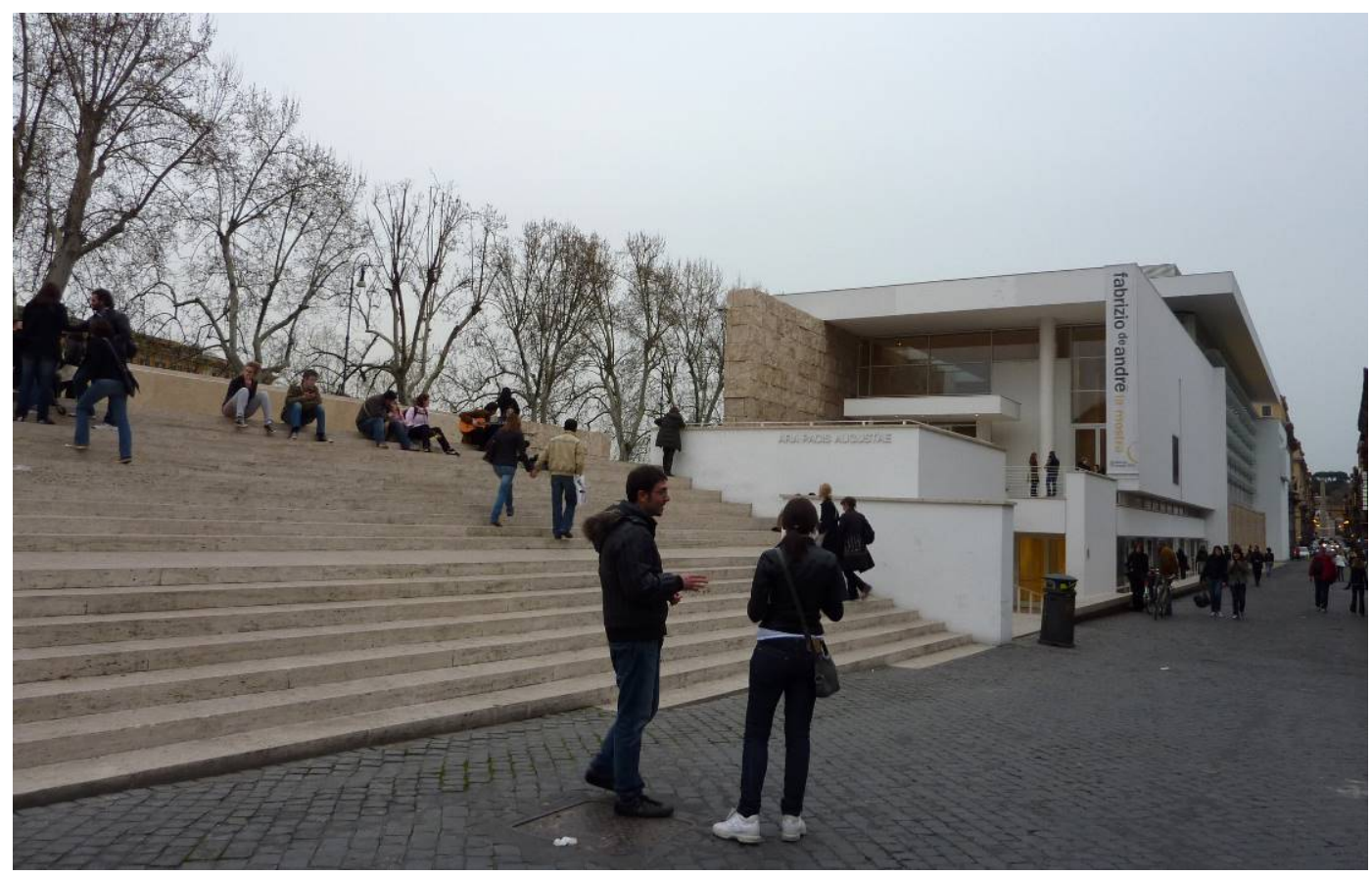




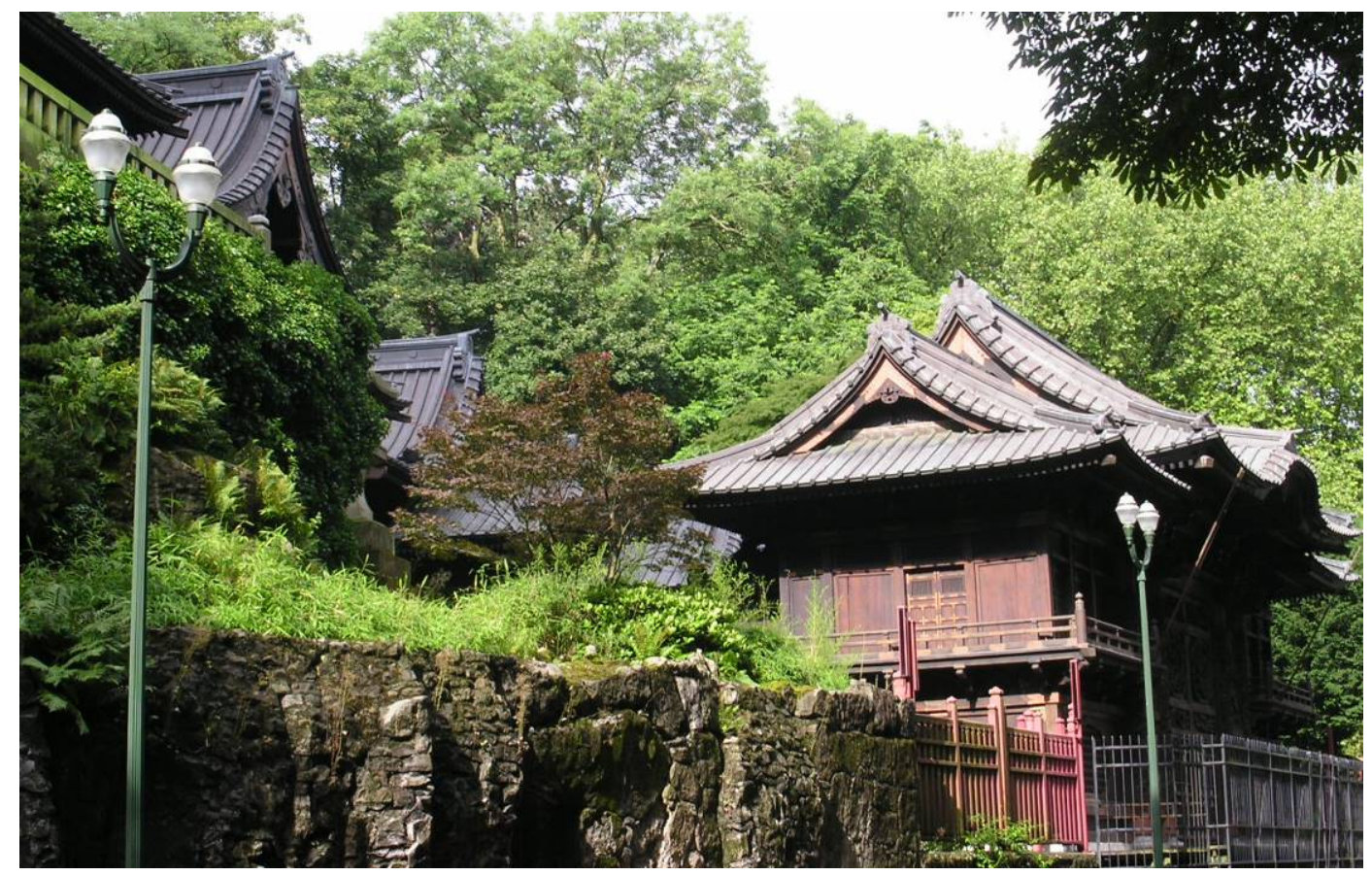

$\mathrm{La}$ arquitectura vernácula se comprende y valora incluso en ocasiones en las que se encuentra descontextualizada: vista de algunas de las construcciones japonesas que hoy forman parte de los Museos del Extremo Oriente en Bruselas, y casa de tradición rusa en el barrio de Alexandrowska, Potsdam (fotografías del autor, julio de 2005 y diciembre de 2014)

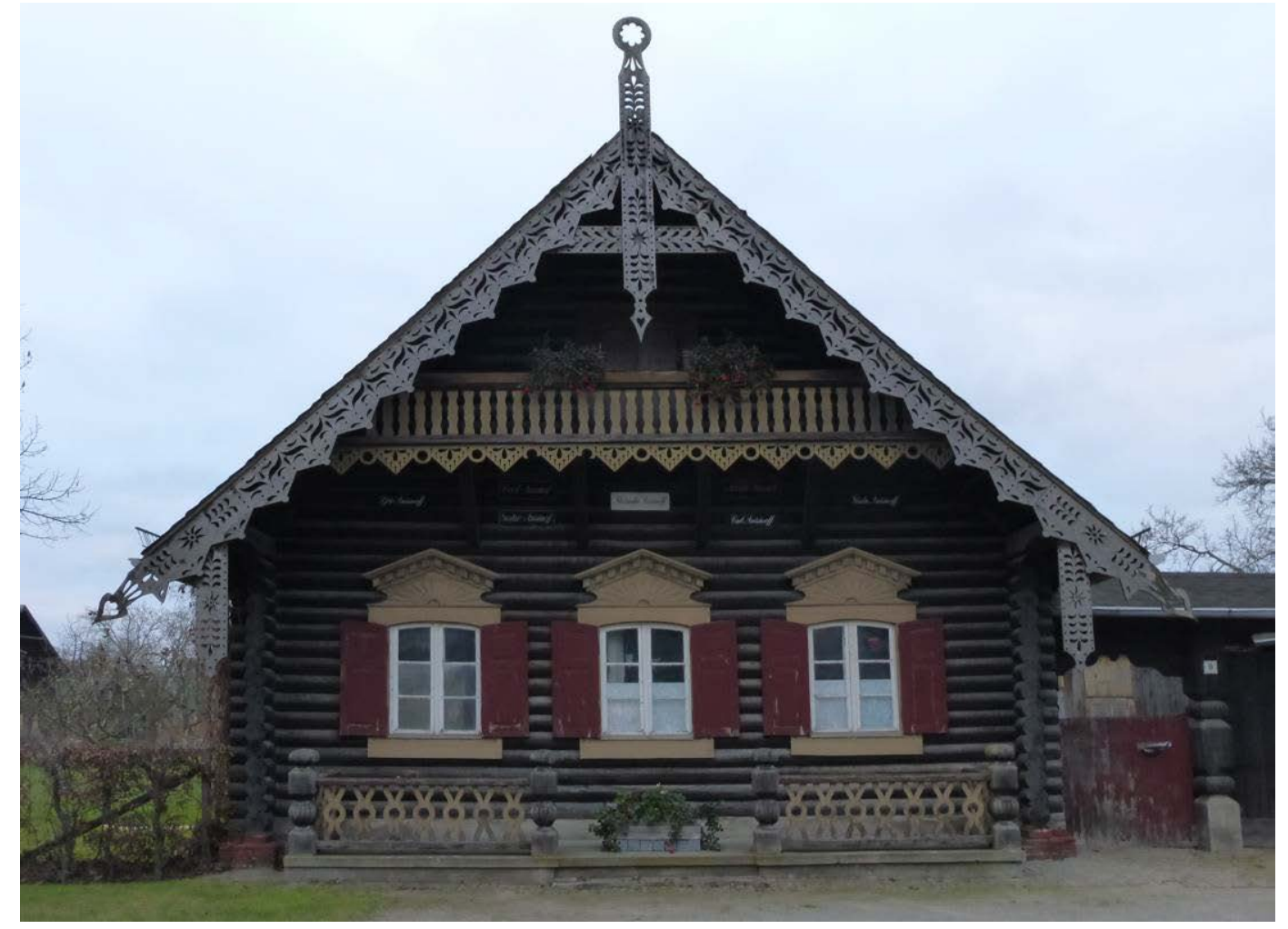


Podría afirmarse, por tanto, que aquellas arquitecturas ligadas a una determinada identidad local, pertenecientes a una tradición reconocible, son apreciadas en sí mismas, a diferencia de lo que ocurre con frecuencia con las arquitecturas más "genéricas", y con independencia de que se encuentren o no en el lugar con el que se corresponden, siempre y cuando no se trate de una vulgarización de las mismas.

En todo caso, nuevamente la confusión entre los conceptos de arquitectura popular, tradicional y vernácula ha hecho que con frecuencia lo vernáculo no sea bien comprendido o reconocido. Sirva como ejemplo el núcleo urbano de Esquivel, que diseñara Alejandro de la Sota en 1952, dentro de la política repobladora del Instituto Nacional de Colonización. Su arquitectura no es, desde luego, popular, pero es, sin embargo, vernácula, recogiendo en su composición numerosos elementos de las tradiciones locales. Una vez más, podemos ver cómo en el capítulo introductorio de Arquitectura popular española Carlos Flores, al hablar de obras como ésta sin haber establecido una división clara entre estos tres conceptos, se ve obligado a plantear ciertas dudas sobre su definición, zanjando finalmente el problema concluyendo que se trata de arquitecturas que sólo son populares en apariencia, pese a sus claras analogías con lo popular (1973 - 1977, vol. 1, 9-61).

Y si la confusión entre los términos tradicional, popular y vernáculo se produce en ocasiones dentro de nuestra misma lengua, aún resulta más complejo consensuar esta terminología a nivel internacional. Paul Oliver señaló ya las múltiples dificultades terminológicas a las que tuvo que hacer frente para la elaboración de The Encyclopedia of Vernacular Architecture of the World, la principal referencia internacional sobre la materia, donde hubo de coordinar el trabajo de más de 750 personas procedentes de más de 80 países diversos (2006a, 27-31). Pese a ello, podría decirse que lo que en español denominaríamos arquitectura popular tradicional equivale de forma aproximada a lo que en el área germánica se denomina Heimat y a lo que en el mundo académico de lengua inglesa recientemente parece haberse consensuado como vernacular architecture, buscando internacionalizar una definición de compromiso entre las existentes en diversas áreas culturales. Sin embargo, la siguiente definición fue la propuesta por Oliver con esta intención, con motivo de la redacción de la mencionada enciclopedia, acercándose en parte a lo que en esta investigación denominaremos arquitectura popular tradicional: "la arquitectura vernácula comprende viviendas y cualquier otra construcción del pueblo. 


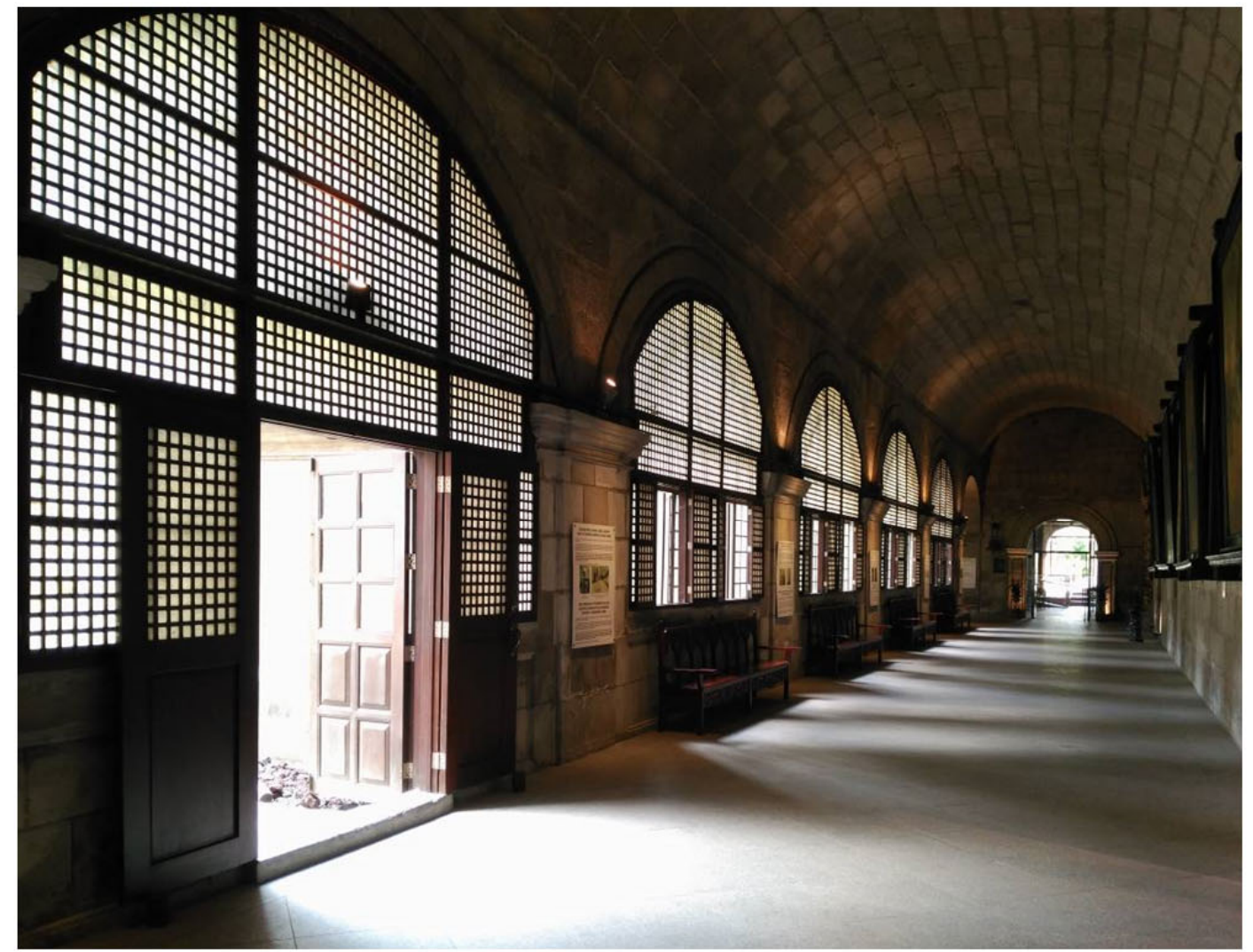

Ventanales de "capiz" (Placuna placenta), uno de los diversos rasgos vernáculos que pueden hallarse en el claustro del Convento de San Agustín en Manila, y detalle de una de estas ventanas (fotografías del autor, mayo de 2017)

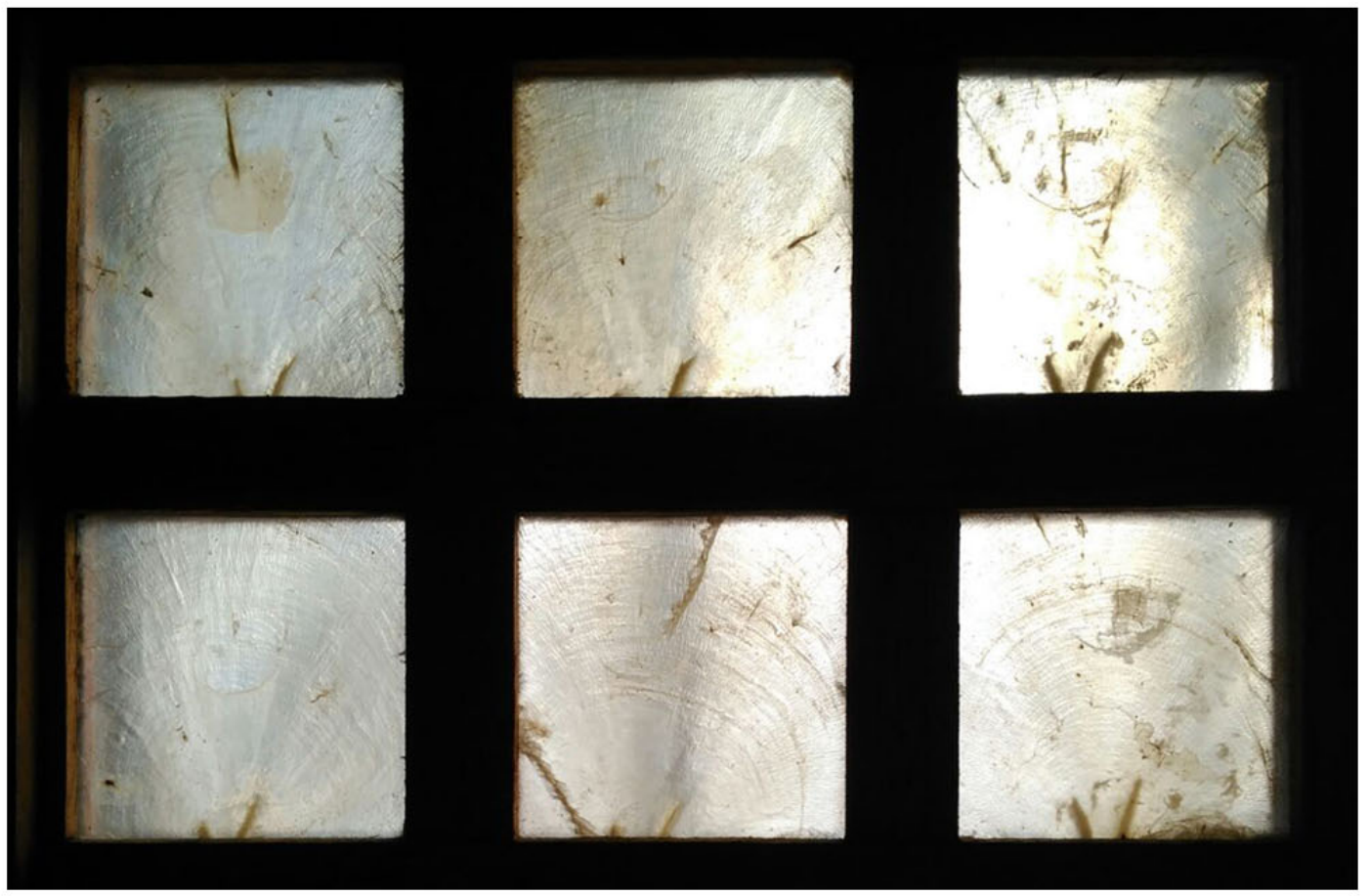


Relacionada con su contexto ambiental y con los recursos disponibles, es construida normalmente por su propietario o por la comunidad, utilizándose para ello tecnología tradicional. Cualquier forma de arquitectura vernácula está construida para satisfacer necesidades, acomodándose a los valores, la economía y las formas de vida de las culturas que la producen".

Siguiendo a Oliver, el mismo término se ha utilizado también en esta versión restringida e internacionalista, equivalente, como se ha dicho, a lo que aquí denominaremos arquitectura popular tradicional, en la Carta Patrimonio Vernáculo Construido de 1999, el más reciente documento internacional sobre la materia, producto de la Duodécima Conferencia del ICOMOS, celebrada en la localidad mexicana de Morelia.

Sin embargo, vernacular architecture en lengua inglesa suele usarse en realidad de modo diverso, en un sentido más extenso y regionalmente variable, siendo por lo común válido también para arquitecturas no tradicionales, y aproximándose así al uso que en nuestra lengua se hace de lo vernáculo en su sentido más amplio. En los EEUU, además, se utiliza también para hablar de aquellos edificios que, aunque diseñados por arquitectos, cuentan con características propias de la arquitectura popular tradicional, lo que prácticamente haría equivaler su significado al que, como trataremos, le otorgamos a lo vernáculo en nuestra lengua. Popular architecture, por otra parte, se utiliza en inglés comúnmente para referirse a arquitecturas diseñadas y construidas para el pueblo, y no tanto por el propio pueblo, de lo que deriva el uso de la palabra pop para calificar un determinado estilo. Se aleja así por completo del uso que hacemos en español del mismo. Pero esta terminología inglesa se ha extendido, en cualquier caso, a muchas otras lenguas, principalmente desde mediados del siglo XX y ha aumentado con ello la confusión existente entre los tres términos analizados. 


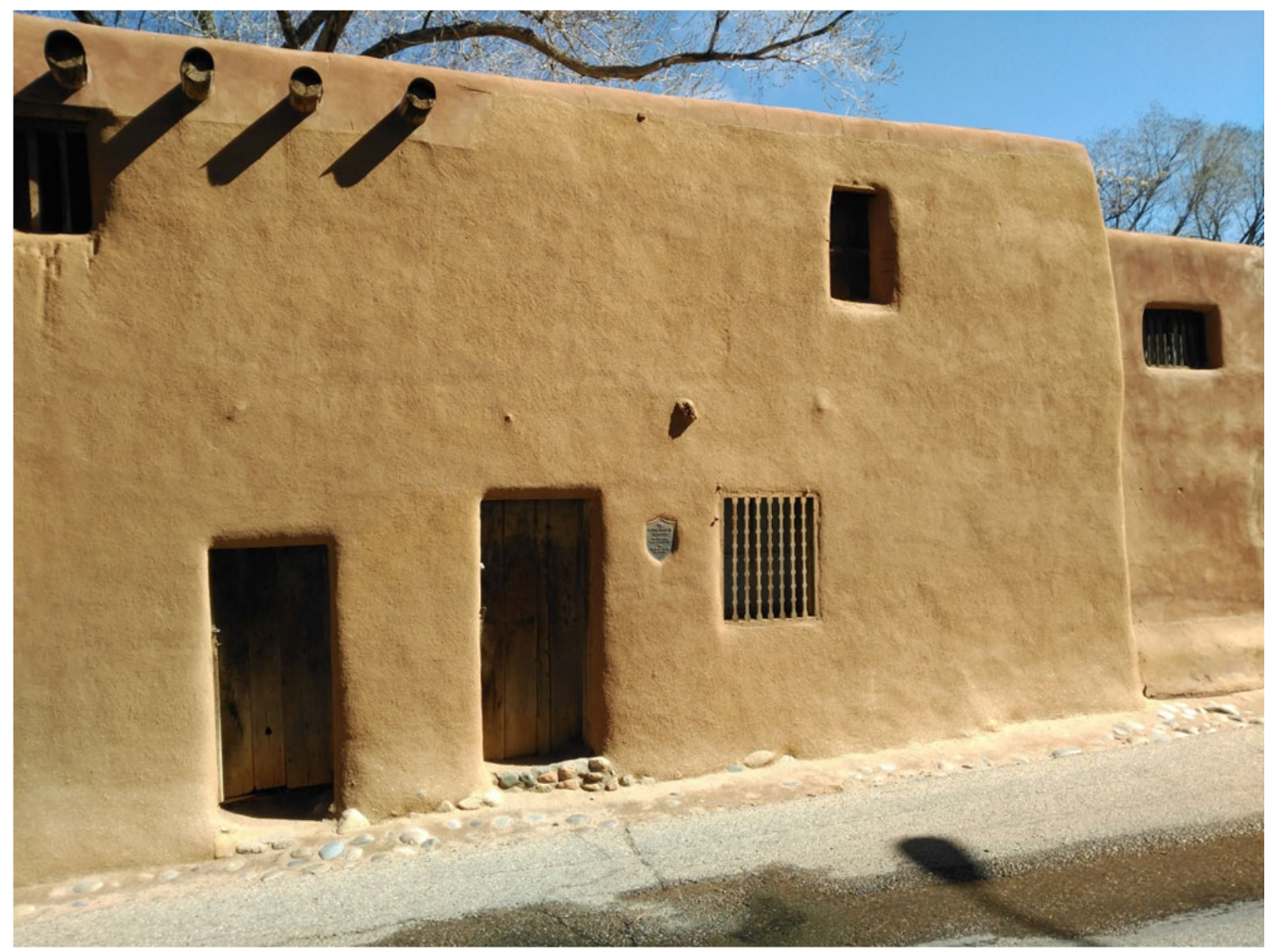

Dos ejemplos de arquitectura vernácula de Santa Fe, Nuevo México: una de las pocas casas populares que se han conservado, en la Calle De Vargas, y el Museo de Arte de Nuevo México, diseñado por Isaac Rapp en 1917 (fotografías del autor, marzo de 2018)

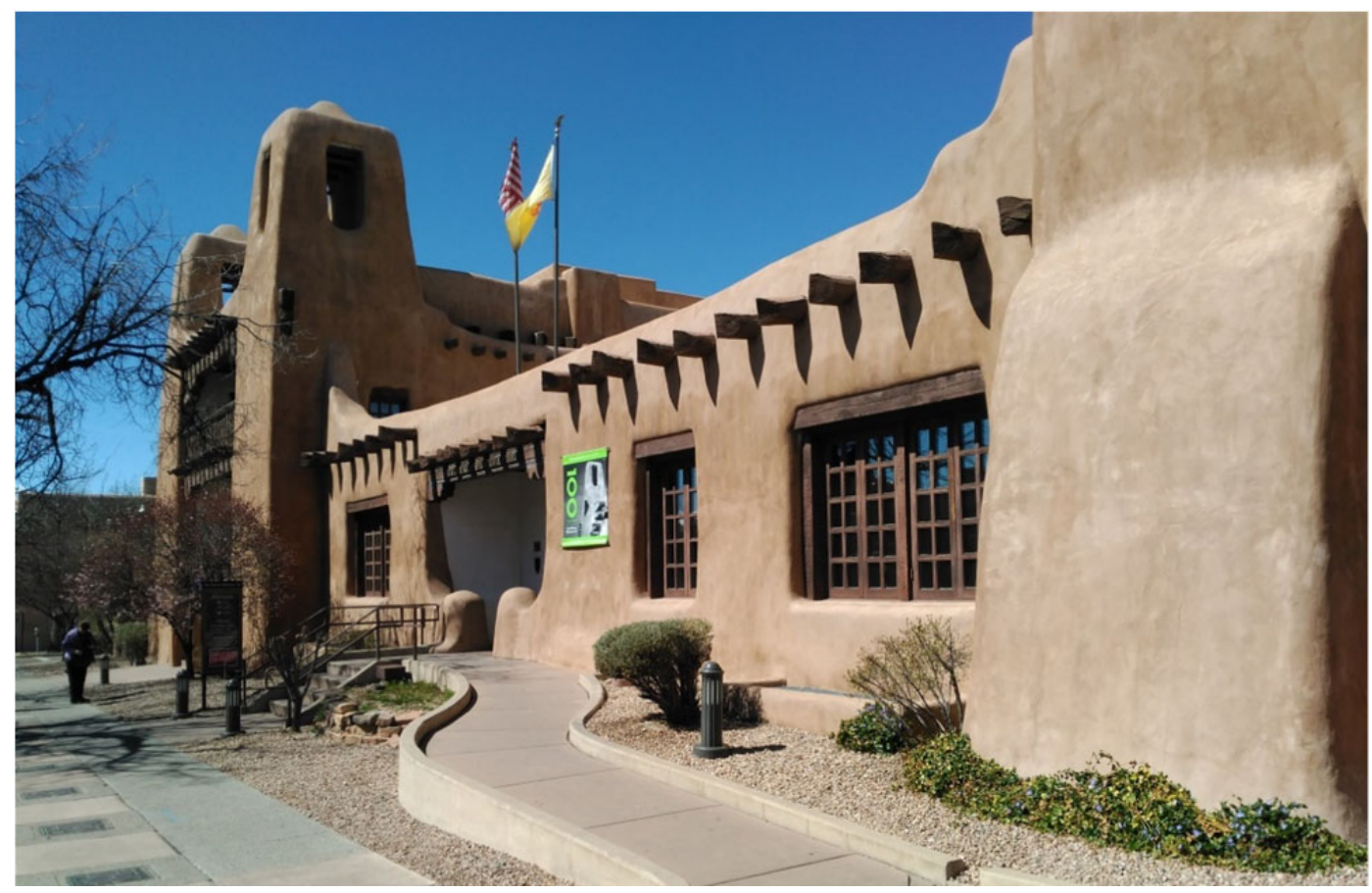




\subsection{CONSIDERACIONES SOBRE LA PRESERVACIÓN DE LAS TRADICIONES CONSTRUCTIVAS, ARQUITECTÓNICAS Y URBANÍSTICAS PARA EL DESARROLLO DE ESTA INVESTIGACIÓN}

Una tradición verdadera no es el testimonio de un pasado caduco; es una fuerza viva que anima e informa el presente. Lejos de implicar la repetición de lo que fue, la tradición supone la realidad de lo que perdura.

Igor Stravinsky. 1952. Poética musical

La problemática a la hora de abordar la preservación de la identidad tradicional de un determinado lugar se extiende hasta la extendida indefinición de qué es lo que se pretende mantener o conservar, qué motivos pueden aducirse para hacerlo, a qué amenazas está sometido y qué herramientas pueden utilizarse para contrarrestarlas.

\subsubsection{La tradición como proceso de imitación e innovación}

Una tradición es algo dinámico, en constante cambio y evolución, pero caracterizado también por una relativa estabilidad, consecuencia a su vez de la relativa estabilidad de lo que, como se explicaba en el apartado anterior, Amos Rapoport denominó "fuerzas primarias" y "factores secundarios o modificadores" (1969, 46-47). Siendo así, cualquier intento de conservarla en un estado particular de su propio devenir podría contravenir precisamente la intención de preservarla a largo plazo.

Architectural Design dedicaba en 1988 una monografía al tema de la tradición como proceso de transmisión de conocimiento basado en la innovación y la imitación titulada Imitation \& Innovation, partiendo en ella de la defensa de la naturaleza imitativa de cualquier creación artística humana que realizara, siguiendo a autores clásicos como Demócrito, Lucrecio o Vitruvio, Antoine Chrysostôme Quatremère de Quincy en su ensayo De l'Imitation (1823), y en conformidad con la definición de tradición aportada en 
el apartado anterior de esta tesis. Tal como afirma Vincent B. Canizaro en la introducción a su conocida compilación de artículos sobre el Regionalismo, Architectural Regionalism. Collected Writings on Place, Identity, Modernity and Tradition (2007, 22), "es la práctica de la imitación la que se considera que aporta continuidad cultural".

Entre las diversas aproximaciones a la cuestión incluidas en esta compilación, resulta singularmente útil para una mejor comprensión del funcionamiento de los procesos tradicionales de transmisión del conocimiento la diferenciación entre imitación, copia y pastiche planteada por Lucien Steil $(1988,9)$. Según ésta, imitación se refiere a un proceso creativo e innovador, pero que toma como base unos modelos precedentes que se adaptan o reinterpretan para adecuarlos a unos condicionantes que difícilmente pueden ser los mismos que los de los modelos imitados. Por tanto, se entiende esa imitación como un proceso empírico desarrollado en el seno de una tradición, en un mecanismo "crítico, selectivo e inventivo". Sin embargo, la copia resulta de la búsqueda de una mera reproducción de un modelo pretérito, una réplica donde la creatividad se ha postergado, pero que aún puede ser exitosa, y denomina pastiche, finalmente, a la copia imperfecta, a la reproducción superficial y simplificada. Siendo así, la imitación requiere formación, dominar unas reglas sobre las que poder trabajar, así como la capacidad para hacer uso de ellas en toda su flexibilidad; la copia, una artesanal habilidad para replicar algo con éxito; y el pastiche, la capacidad para recrear las principales impresiones o los efectos producidos por el modelo imitado, pese a tratarse de una versión imperfecta o incompleta del mismo ${ }^{4}$.

Según esta diferenciación, queda más claro cómo la vitalidad de los procesos tradicionales en la arquitectura depende al mismo tiempo de la continuidad de la voluntad de innovar en base a la imitación y de la formación necesaria para poder hacerlo. Sin embargo, si estos procesos se quedaran en la mera y estática copia, o se limitaran al parcial pastiche, la tradición estaría condenada a desaparecer, pues anularía su capacidad para adaptarse a los siempre cambiantes requerimientos del momento (Ricoeur 2007, 50).

\footnotetext{
${ }^{4}$ Atendiendo a las categorías utilizadas en el análisis pormenorizado de las transformaciones sufridas por la tradición arquitectónica de La Sagra recogido en esta investigación, es el pastiche lo que se ha descrito como una imitación incorrecta de la tradición.
} 
Discriminar entre estos tres conceptos será clave para el objeto de esta investigación. Por tanto, y salvo que se indique lo contrario, cuando en esta investigación se haga referencia a la preservación de las tradiciones constructivas, arquitectónicas o urbanísticas de un lugar, no se hará entendiéndola como réplica de unos modelos prefijados, sino como una forma de trabajar en la que cualquier innovación se fundamente en la imitación, trabajando sobre el estudio de los logros previamente alcanzados, en el conocimiento acumulado a base de experiencias pretéritas.

Tal como se explicaba anteriormente, cuando una tradición deja de funcionar como tal, es decir, cuando deja de transmitirse el conocimiento y ya no se trabaja en base a él, la tradición deja de ser un proceso vivo para convertirse en un conjunto de reglas fijadas en un momento concreto de su evolución y que pertenecen a un tiempo pasado, con circunstancias y requerimientos diversos de los actuales. Por ello, a menudo, cuando se habla de su conservación o de su recuperación, realmente se trata no de revitalizar la auténtica tradición como proceso, sino de seleccionar una serie de elementos característicos de ese momento pretérito, en ese particular estado evolutivo, y convertirlos en elementos normalizados, estáticos. La arquitectura de este modo orientada responderá inevitablemente a las categorías previamente definidas de copia o pastiche. A largo plazo lo preservado por esta vía puede llegar a ser, a lo sumo, una copia más o menos lograda de un momento concreto en la evolución de aquello que se pretendía mantener. Esto, que puede resultar valioso o interesante per se, no equivale a la preservación de una tradición. 


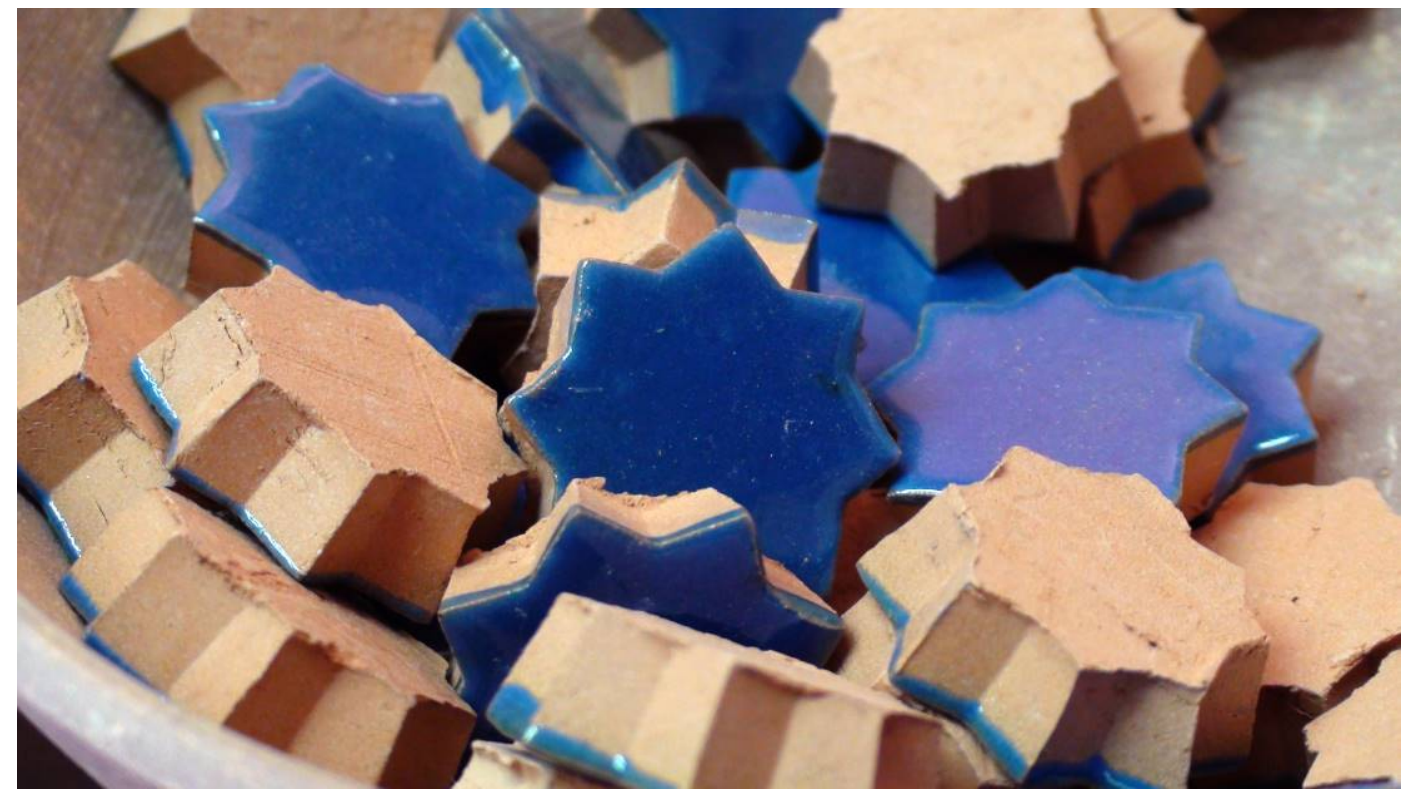

Fátima Quesada es una maestra ceramista dedicada a los mosaicos de azulejería. En su trabajo ha introducido algunas actualizaciones en el corte y la cocción de los azulejos que produce. Estos cambios han facilitado diversos procesos, pero ha velado por que éstos no resten en ningún caso calidad al producto final ni riqueza a su cromatismo. Así, la tradición no sólo se mantiene, sino que se está contribuyendo a hacer más viable su continuación por la vía de su actualización (fotografías cedidas por Fátima Quesada)

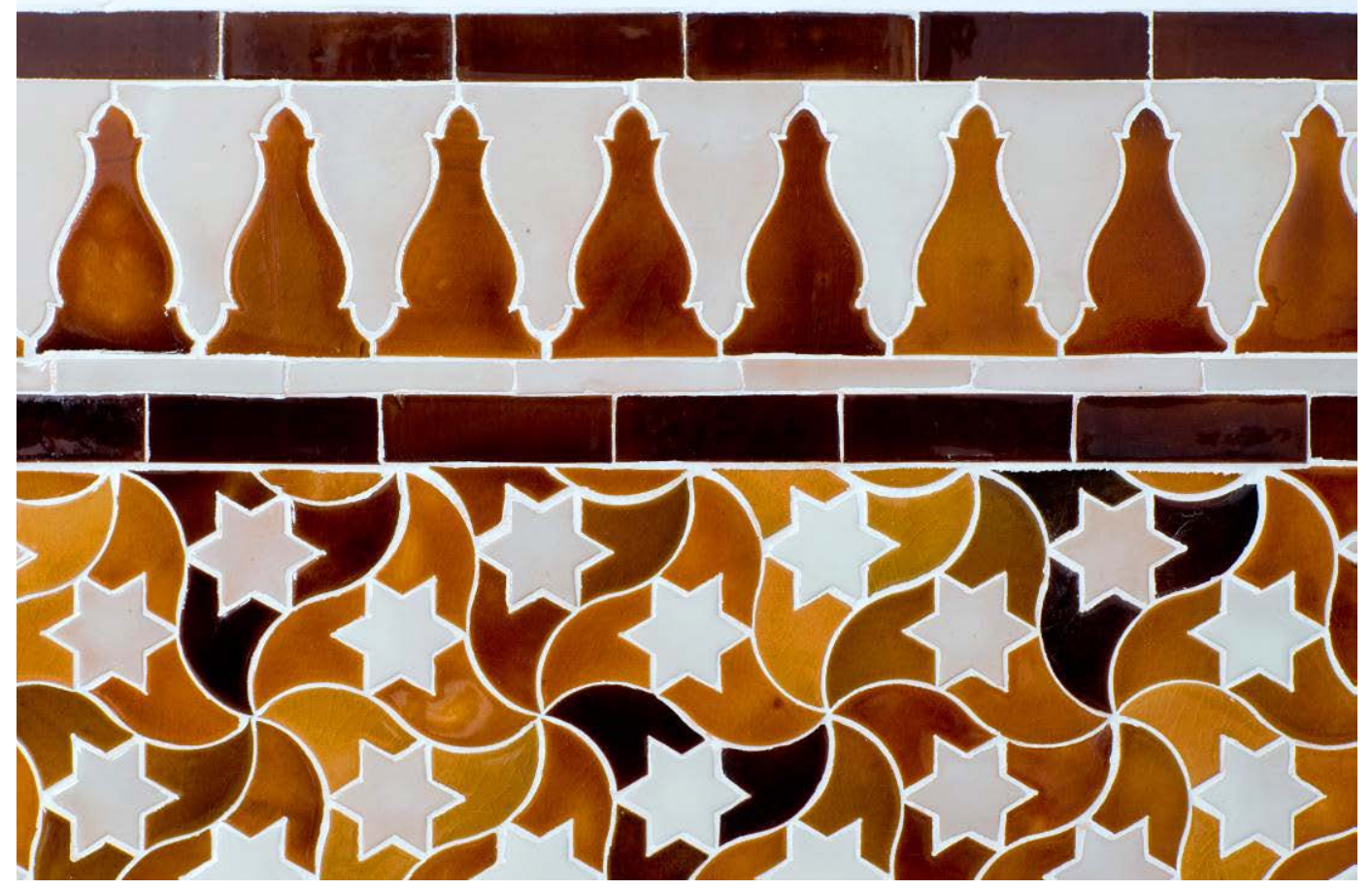




\subsubsection{Valores atribuidos a la identidad local tradicional y objetivos implícitos en su conservación}

Los fines perseguidos al trabajar en la preservación de la identidad local tradicional tampoco están siempre claros. Al ser un problema de gran complejidad, con múltiples ramificaciones, ha sido común su instrumentación en la persecución de otros fines diversos, viéndose utilizado de un modo u otro por ideologías políticas de diversa índole que lo han abanderado o rechazado, o desacreditado en busca de beneficios económicos, a menudo enmascarándolos asociando esa identidad a proteger con limitaciones para un pretendido desarrollo o para una supuesta reducción del desempleo.

Eric Hobsbawm en The Invention of Tradition (1983, 8-9) enumera tres habituales motivos para intentar recuperar o para pretender incluso "inventar" una tradición: establecer o simbolizar la cohesión de un grupo o comunidad, sea ésta real o artificial; establecer o legitimar instituciones, relaciones de autoridad o de estatus social; e inculcar o promover valores, creencias o comportamientos convencionales. Sin embargo, los argumentos que pueden buscarse para la conservación de la tradición arquitectónica local son en realidad mucho más amplios y numerosos.

Dado que el facilitar la creación o el mantenimiento de los lazos comunitarios es una de las principales consecuencias del mantenimiento de la identidad local tradicional, y en atención a su complejidad, se tratará de él con singular detenimiento en el siguiente apartado.

En todo caso, si bien la búsqueda de una arquitectura basada en la identidad local tradicional ha estado frecuentemente vinculada a la intención de preservar la identidad de una comunidad y a muy diversos fines políticos o socio-económicos, tal como afirma Hobsbawm, también lo ha estado a la promoción de valores como la construcción sostenible, la voluntad de redescubrir en ellas valiosas soluciones técnicas o arquitectónicas o la búsqueda de referencias para recuperar una relación más estrecha de lo artificial con lo natural (Oliver 2006a, 23-24, 42), objetivos todos ellos que han dirigido y condicionado muchos de los planteamientos a los que se hace referencia en posteriores apartados de esta investigación. 
De hecho, entre los principales valores que reconocemos hoy en la conservación estas tradiciones locales están precisamente su vínculo con el uso sostenible del medio en el que se han desarrollado o su riqueza como fuente de soluciones prácticas ante determinados problemas que pueden darse igualmente en el presente o en el futuro. Al ser depositarias de una extensa experiencia sobre cómo gestionar y habitar un determinado lugar, las tradiciones arquitectónicas y constructivas se erigen en una fuente de indudable riqueza para la investigación y el progreso efectivo en este ámbito. Se entiende, por tanto, su importancia como reflejo o consecuencia de un amplio conocimiento empírico con gran valor de actualidad. La amplia mayoría de las iniciativas y estudios que desde el ámbito de la arquitectura han analizado o puesto en valor estas identidades locales se han aproximado a ellas, de hecho, atraídos precisamente por este aspecto. En él han centrado buena parte de su atención, descuidándose a menudo, sin embargo, los múltiples factores de índole cultural implicados en su conservación, como pueden ser los citados por Hobsbawm o su relación con el mantenimiento de una determinada estructura socioeconómica (Rapoport 1969, 135; Oliver 1969; Asquith y Vellinga 2006, 19).

Sin embargo, este último aspecto en particular constituyó una de las principales reivindicaciones de las primeras voces que se alzaron, desde Gran Bretaña, contra la pérdida o deterioro de las identidades locales tradicionales, ya que fueron pioneros en destacar los beneficios sociales y económicos que el mantenimiento de la tradición arquitectónica supone para el artesano libre, o, en términos actuales, para la clase media autónoma. El temprano desarrollo de la construcción industrializada en su país había supuesto unas mayores división y jerarquización del trabajo, reduciéndose considerablemente con ello tanto la necesidad de trabajadores cualificados como su grado de control o responsabilidad sobre el resultado final del mismo, con la consiguiente pérdida de calidad. Además, había llevado a la deslocalización de la producción y de buena parte del trabajo, resintiéndose con ello las economías locales. La mecanización del trabajo permitía, al igual que hoy, producir materiales y elementos constructivos competitivos a grandes distancias, pero también prescindía del conocimiento acumulado por la mano de obra local sobre los propios medios de su entorno. Autores como John Ruskin (2004, 85-88) o William Morris (2012a, 164-191; 2012b, 255-263) denunciaron esta situación como el origen de una importante degeneración de la arquitectura y del paisaje no sólo por sus consecuencias estéticas o cualitativas en el resultado final de cualquier obra de edificación o de transformación de un lugar, sino también por sus 
consecuencias humanas. Habían visto cómo la generalización de una arquitectura más industrializada se había convertido en cómplice del deterioro de la situación económica y social de buena parte de la población de su país en aquel tiempo o bien era consecuencia del mismo. Los costes de producción se abarataban y las clases más desfavorecidas tenían así acceso a productos y servicios antes fuera de su alcance. Sin embargo, sus condiciones de vida y de trabajo y, sobre todo, su estatus social, empeoraban progresivamente ${ }^{5}$.

La deslocalización de la producción industrial, implantada ahora principalmente en lo que se denominan "países en vías de desarrollo", ha hecho hoy este desequilibrio menos perceptible, al convertirse la desigualdad denunciada por estos autores ingleses en transnacional y reducirse con ello la consciencia de la misma. Pero, al mismo tiempo, en un momento en el que la despoblación del mundo rural constituye una de las principales amenazas para el patrimonio cultural, la capacidad de la recuperación de las tradiciones arquitectónicas y constructivas para regenerar o restaurar la estructura socio-económica de las regiones afectadas ha pasado de nuevo a un primer plano. Se multiplican en la actualidad las experiencias que lo adoptan entre sus principales objetivos. Buenos ejemplos entre los muchos existentes serían la propia labor en el sur de Marruecos de la ONG que codirijo, Terrachidia, que, como se ha mencionado ya, inició su actividad en el año 2012, la de la Fundación por el Patrimonio de Afganistán, encabezada por Yasmeen Lari, o la de la fundación Turquoise Mountain en Kabul.

Continuando con aquellos valores de la preservación de las identidades locales tradicionales a los que menos atención se ha prestado desde el campo de la arquitectura, otra cuestión a tener en cuenta es el potencial económico que supone el patrimonio arquitectónico tradicional, no sólo por su fortalecimiento del tejido económico local, sino también por el atractivo turístico que suele llevar aparejado. Cuanto más se deterioran y difuminan las distintas identidades locales tradicionales, más atractivas y apreciadas resultan las de aquellos lugares en los que mejor se han preservado, sean cuales sean los factores que han contribuido a su mantenimiento.

\footnotetext{
${ }^{5}$ Esta cuestión se desarrolla de forma más extensa en el apartado 3.2. de este estudio.
} 
Tampoco se ha dedicado en los debates arquitectónicos un cuidado suficiente al hecho de que las identidades locales tradicionales constituyan además uno de los principales reflejos de la existencia de diferentes culturas, siendo un aspecto clave para la preservación de la diversidad cultural o, dicho de otro modo, de las diversas formas de entender y habitar el entorno construido.

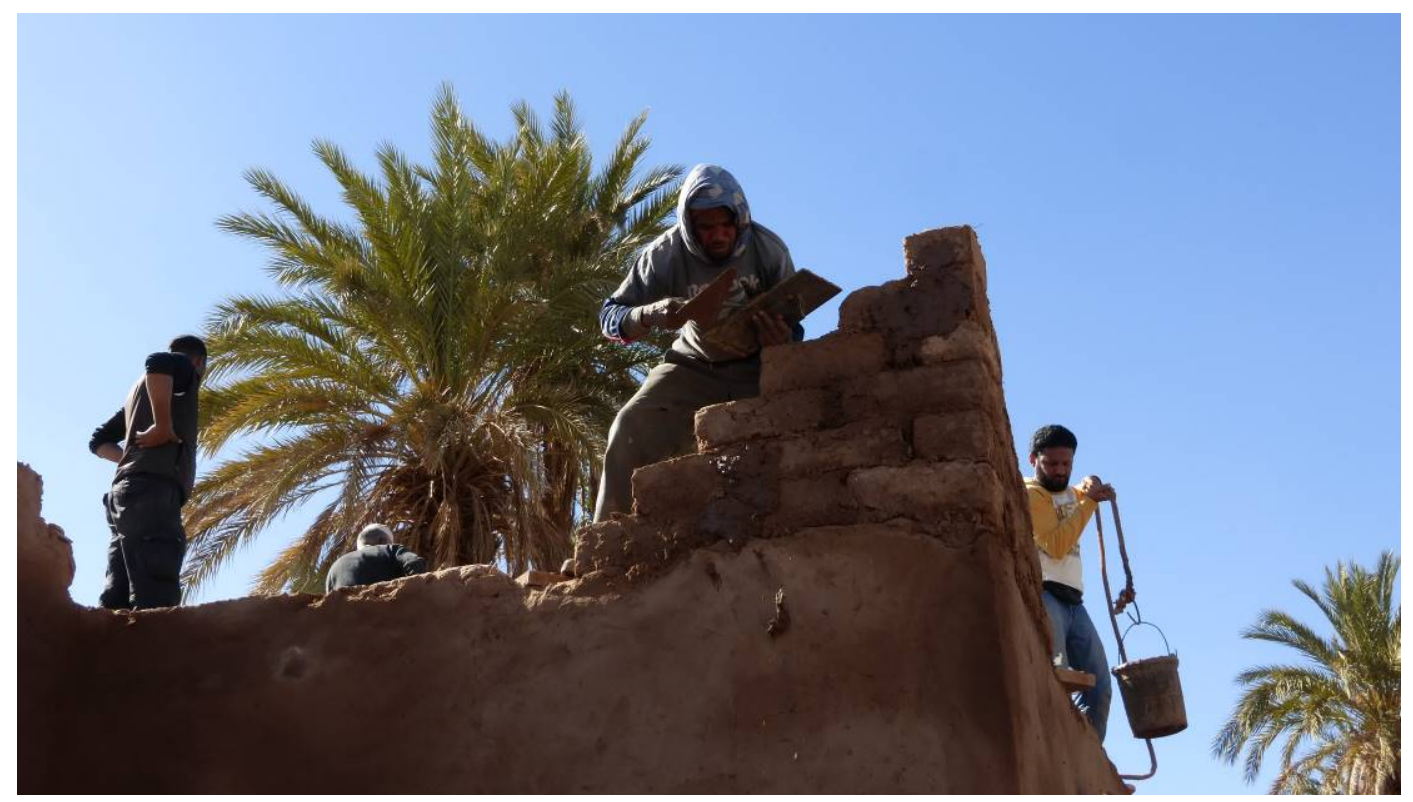

Trabajos restauración mediante técnicas tradicionales de construcción desarrollados por

Terrachidia en las puertas fortificadas de Ouled Mhia y de Ouled Driss, ambos en el Oasis de

Mhamid, Zagora, Marruecos (fotografías del autor, enero de 2015 y abril de 2017)

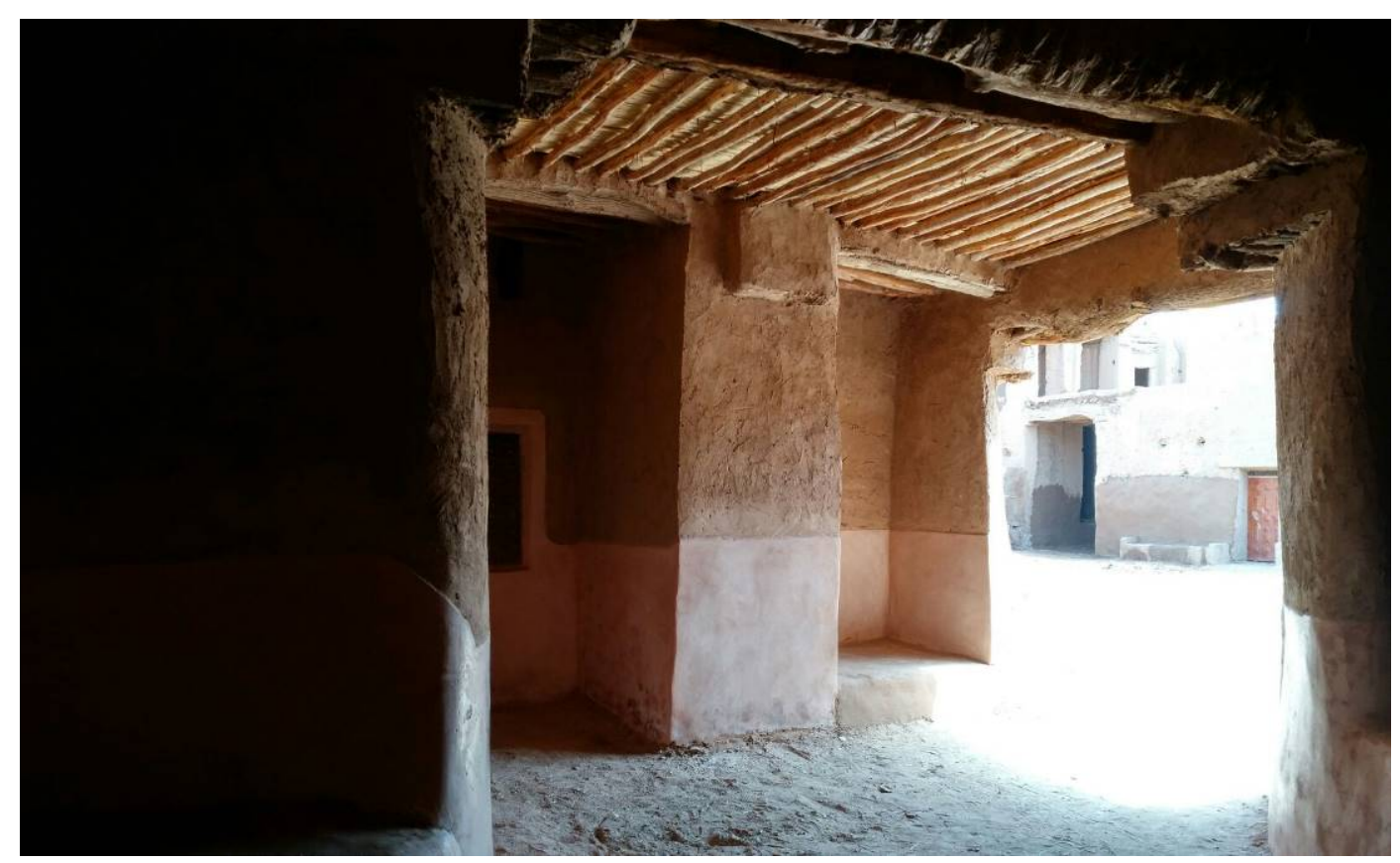


Finalmente, y sin pretender ser exhaustivos, no menos importante entre estos valores de la tradición arquitectónica menos considerados hasta fechas recientes es el que podríamos denominar artístico relativo, recurriendo a una de las categorías establecidas por Aloïs Riegl en 1903 en su seminal trabajo Der moderne Denkmalkultus. Sein Wesen und seinen Entstehung, (2008, 91-99). La arquitectura tradicional es y ha sido también muy admirada por su belleza, por su sencillo y natural atractivo. Esta preferencia estética está estrechamente relacionada con lo que Ruskin denominaba "cantidad de vida" depositada en su elaboración, es decir, con la idea de cultura material como reflejo de quienes la han producido y utilizado (Ruskin 2007, 133, 151). Y lo está también con la "preferencia por lo primitivo" cuya extraordinaria vigencia en el tiempo estudiara Ernst Gombrich (2003). Si bien, tal como explicara Riegl, los valores artísticos son mutables, varían con el tiempo y también lo hacen en el espacio, entre una cultura y otra. Lo que una obra pretérita tiene en común con la voluntad de arte actual "sólo pueden ser algunas facetas", aspectos de ella que son especialmente valorados hoy en día frente a otros que no lo son o lo son en menor grado (Riegl 2008, 92). Estas relatividad y selectividad pueden rastrearse en lo que desde el mundo de la arquitectura se ha declarado valorar de la arquitectura tradicional a lo largo del tiempo.

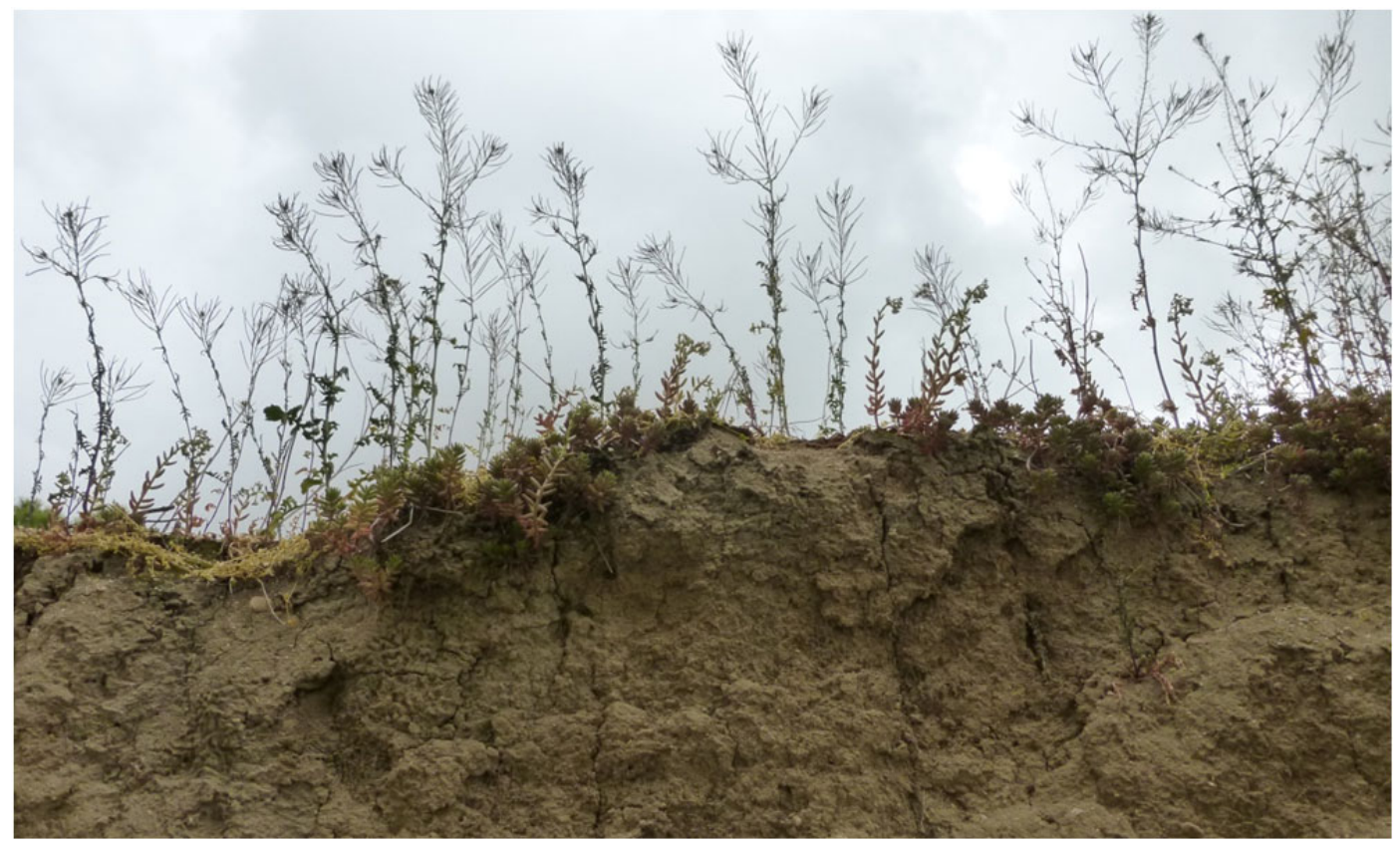

Vegetación creciendo sobre un muro de tapial abandonado en Lominchar, La Sagra, Toledo. Su prácticamente nula generación de residuos no biodegradables y el ser completamente reciclable son dos de las cualidades hoy más estimadas de la arquitectura tradicional (fotografía del autor, abril de 2015) 


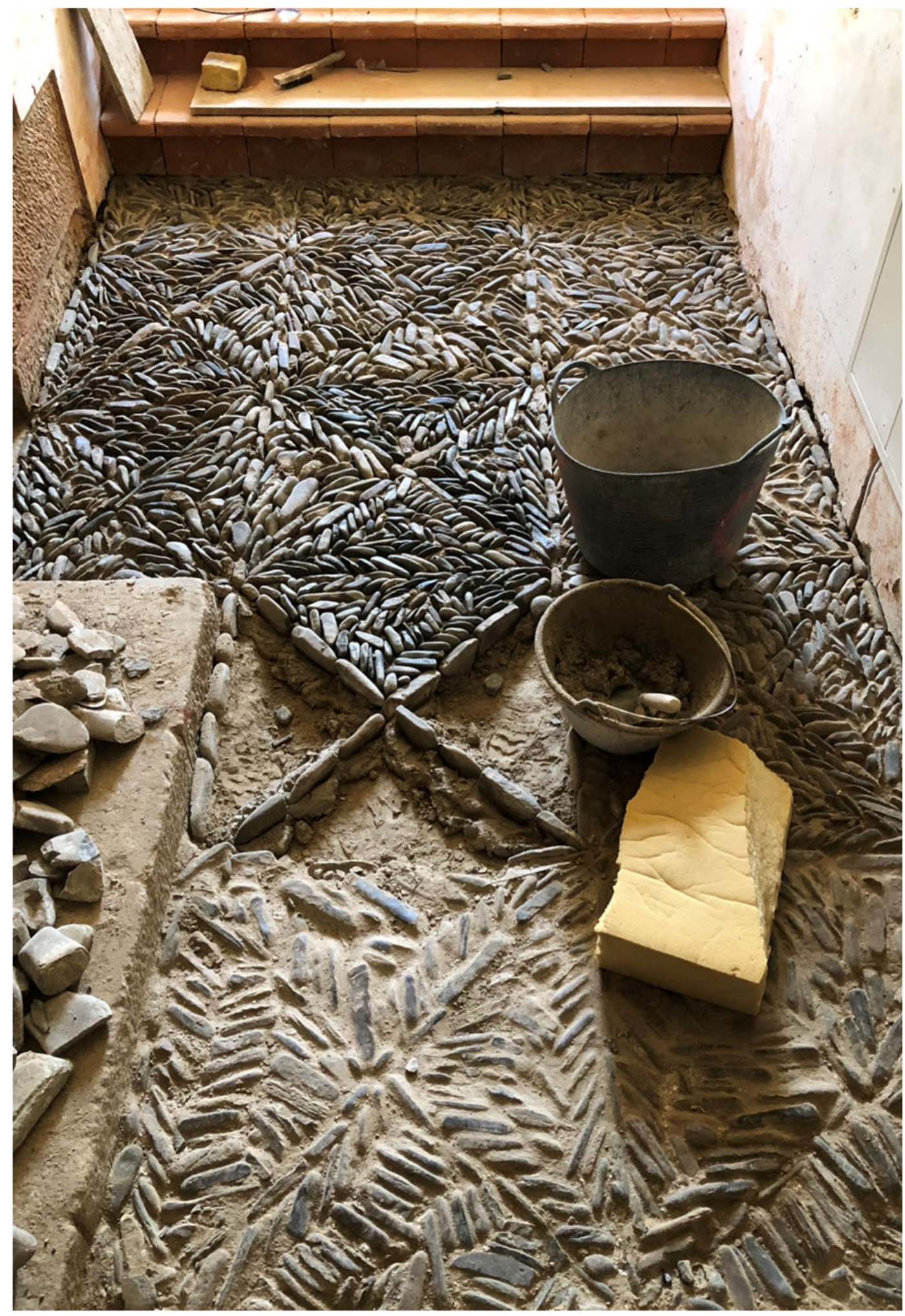

Empedrado o enchinado tradicional en proceso de ejecución por Carlos Martín, buen ejemplo de la "cantidad de vida" que elogiaban John Ruskin y sus seguidores como principal medida de la belleza de las creaciones humanas (fotografía cedida por Carlos Martín, abril de 2018) 


\subsubsection{Naturaleza de los procesos que amenazan la pervivencia de las tradiciones arquitectónicas y constructivas}

Si complejos son los motivos que pueden esgrimirse para la preservación de la identidad local tradicional, no lo son menos los problemas a los que ésta ha de enfrentarse. Requieren, por ello, algunas aclaraciones para la mejor comprensión de las posibles vías para combatirlos.

Una completa enumeración de los riesgos identificados en nuestro país para la conservación de las tradiciones arquitectónicas y constructivas ha sido incluida en el Plan Nacional de Arquitectura Tradicional elaborado por el IPCE (2014, 22-25). A ella puede remitirse cualquier interesado en la materia.

Ahora bien, es de utilidad analizar también la naturaleza de los motivos por los que estas tradiciones fueron y continúan siendo abandonadas. Reflexionar sobre el por qué se interrumpen los procesos de invención en base a la imitación ayuda esclarecer las bases de esta investigación.

Algunos autores han asociado el abandono de la tradición con la aparición de una mayor capacidad de elección por parte de una sociedad al adoptar formas no orales de difusión del conocimiento, defendiendo el vínculo entre alfabetización y deterioro del saber tradicional (Goody y Watt 1968, 65-67; Lowenthal 1985, 369; Anderson 2005, 164-165). Y vinculada a las formas escritas de transmisión del saber está la tendencia hacia la estabilización de lo que se considera tradicional o hacia la ralentización de sus procesos internos de adaptación y cambio, necesarios para su propia subsistencia. Otros autores, por el contrario, han señalado una mayor tendencia al estatismo en esos mismos procesos de transformación tradicionales a causa de las limitaciones para transmitir el conocimiento que impone la tradición oral (Dobrowolski 1958).

Sea como sea, aunque aceptemos la importante incidencia de este hecho, que no ha de subestimarse, la experiencia demuestra que las tradiciones generalmente no pierden vitalidad por la extensión de la alfabetización per se, sino que se trata de un proceso complejo en el que otros factores, sobre todo socioeconómicos, juegan un papel más relevante. Así, vemos hoy en casi cualquier región del mundo que presentan un grado de 
alfabetización creciente o completo cómo muchas tradiciones no sólo no se abandonan, sino que ganan vitalidad ${ }^{6}$.

Entre los posibles factores socioeconómicos que inciden en el abandono de la tradición, una parte de ellos conduce de forma directa, a diferencia del anterior, no a la transformación, sino a la completa desaparición del vehículo transmisor de la propia tradición: el artesano. En este grupo se encuentran la mecanización de la producción de materiales y de la construcción, con la aparición de la gran industria y el abaratamiento de las energías fósiles. Y también puede considerarse como uno de ellos la extensión a un mundo global del liberalismo económico sin restricciones, que reduce fuertemente la competitividad del trabajo cualificado realizado por el artesano de la construcción, al menos en las regiones económicamente más favorecidas por este sistema. La cantidad y el coste inmediato se imponen con ello de forma general sobre la calidad y la durabilidad. Ya se ha mencionado anteriormente la temprana denuncia de las consecuencias humanas de este hecho por parte de autores como Morris o Ruskin. No menos importante para dificultar la labor del artesano de la construcción es la hipertrofia de normativas y regulaciones relativas a la construcción y a la extracción y la producción de los materiales destinados a ésta, salvo en aquellos lugares donde se establecen condiciones excepcionales para el desarrollo del trabajo de estos profesionales.

Estos factores se encuentran entre los principales mecanismos de deterioro a los que hacemos frente cuando trabajamos por la preservación de la identidad local tradicional. Son, además, los más difíciles de combatir, pues sólo pueden equilibrarse desde instancias políticas, recurriendo a complejas medidas de protección de la economía y el tejido social locales. Pese a ello, los posibles beneficios socioeconómicos que su implementación podría suponer, en especial para las áreas rurales, pueden reducir el idealismo de tales planteamientos.

En cualquier caso, además de los mencionados factores socioeconómicos, existen otra serie de causas para el abandono de las tradiciones cuyas raíces son exclusivamente culturales, sin relación alguna con contingencias prácticas. A diferencia de las causas

\footnotetext{
${ }^{6}$ La situación actual de los oficios tradicionales de la construcción en el Reino de Marruecos, por ejemplo, donde existen ya altas tasas de escolarización y alfabetización, es buena muestra de ello.
} 
referidas previamente, al tratarse de motivaciones culturales, también puede ser puramente cultural cualquier posible herramienta dirigida a contrarrestar su efecto.

Este segundo tipo de problemas es especialmente fácil de identificar cuando se trabaja en contextos donde la economía continúa siendo de subsistencia, con mano de obra muy barata en relación con el precio de los productos de la industria, y donde, por tanto, los materiales y labores de construcción más competitivos siguen siendo principalmente tradicionales. Sin la incidencia de esos condicionantes en situaciones de este tipo, podría pensarse que la identidad local tradicional apenas se vería amenazada. Sin embargo, la realidad indica lo contrario. En tales lugares puede igualmente verificarse con frecuencia la irrupción y progresiva extensión de prácticas arquitectónicas completamente ajenas a la tradición, el clima y los recursos del lugar. Se aprecia en muchos de ellos cómo también en estos casos se tiende a experimentar con materiales, técnicas y estilos apenas conocidos o dominados. Éstos se introducen, aun siendo con frecuencia más costosos y menos funcionales, sencillamente por considerarse más sofisticados, más urbanos, o propios de clases privilegiadas.

A través de la experiencia de Terrachidia, por ejemplo, hemos podido constatar cómo, principalmente por cuestiones de estatus social, en regiones con una economía de subsistencia pueden introducirse sucedáneos de estilos arquitectónicos foráneos y técnicas como el hormigón armado sin que exista la necesidad práctica de los mismos, asumiéndose su mayor coste y desconociéndose incluso los rudimentos más básicos de su funcionamiento estructural. Así, un caso paradigmático es la extendida práctica en los oasis del sur de Marruecos de introducir pilares de hormigón armado en muros de tapial preexistentes, careciendo por tanto de una función estructural racional y a pesar del elevado coste relativo de los materiales utilizados. También es frecuente el recurso a pastiches de tradiciones apenas conocidas y comprendidas, con frecuencia sin que exista verdadera consciencia de su carácter foráneo ni de su sustancial distanciamiento del modelo que se pretende copiar. Es interesante señalar que con frecuencia el origen de estos modelos no se encuentra en el entorno, más allá de algún ejemplo de arquitecturas proyectadas desde las administraciones públicas o promovidas por las clases más pudientes, sino en las zonas urbanas, cuyos usos y costumbres poseen a menudo un fuerte atractivo para los habitantes de las zonas rurales. 
Debe recordarse nuevamente aquí, por resultar esclarecedora, la ya explicada separación que establecía Amos Rapoport entre "factores secundarios o modificadores" y "fuerzas primarias" entre los posibles condicionantes de la evolución de una tradición (1969, 4647). Señalaba con ello cómo los materiales y técnicas constructivas disponibles pueden producir alteraciones en la arquitectura tradicional, pero no determinar su forma, destacando que ésta es en última instancia una elección cultural.

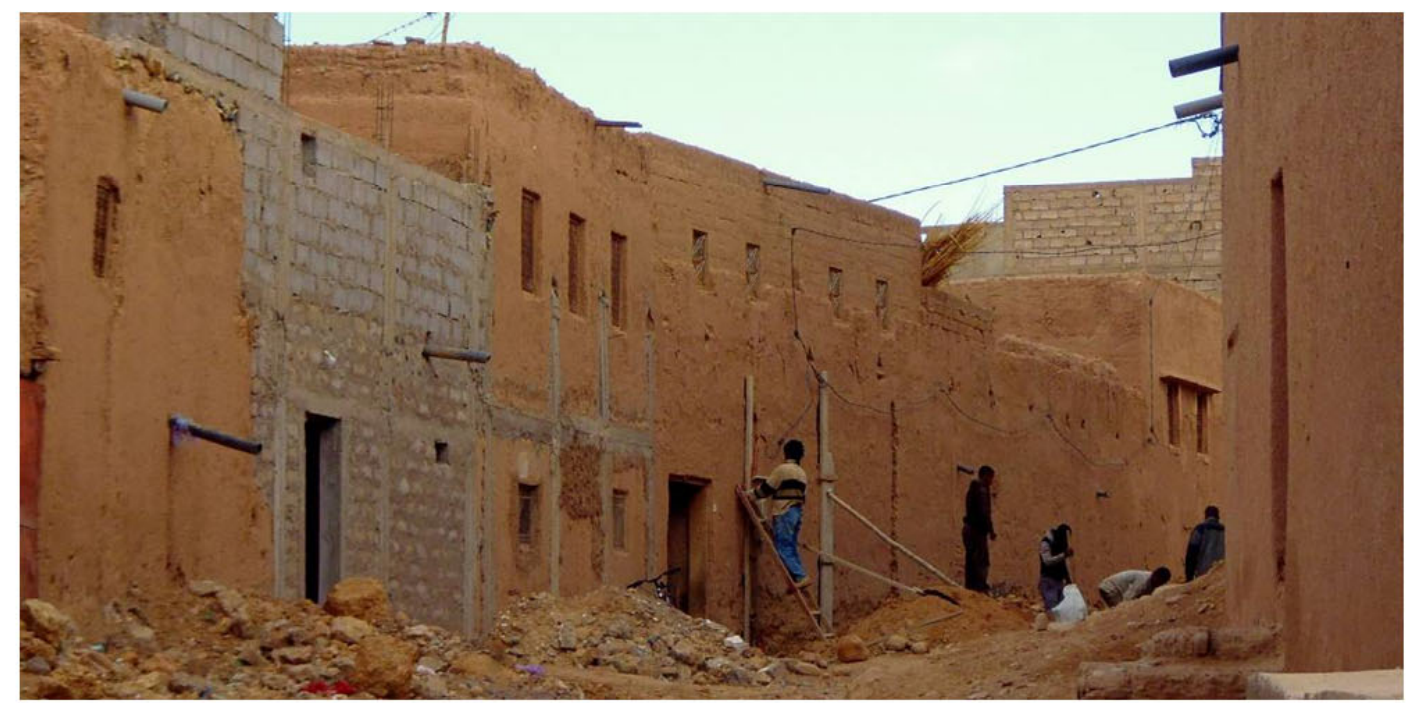

Edificios construidos con muros de tapial sobre los que, encofrando a una sola cara, se está vertiendo hormigón en Tamegroute, Zagora, Marruecos. De este modo, el edificio aparenta contar con una estructura de pórticos de hormigón armado, pese a no trabajar ésta en modo alguno. En la segunda imagen se aprecia un balcón tradicional diseñado por Donald Gray para una nueva casa en

Granada (fotografías del autor, enero de 2014 y agosto de 2015)

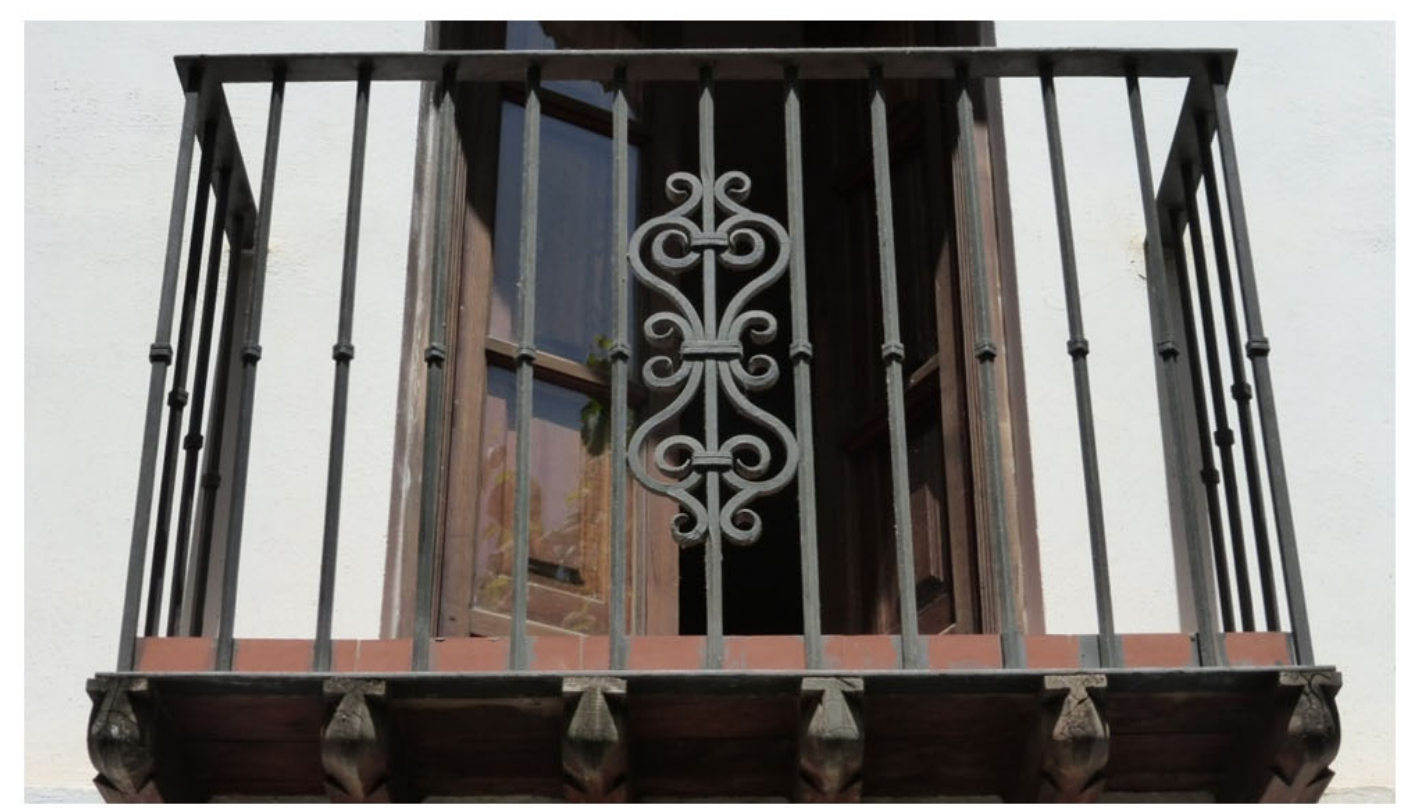


Hobsbawm se refiere también a estos factores puramente culturales en The Invention of Tradition $(1983,8)$, afirmando que, aun cuando suela aducirse que el abandono de la tradición local se produce cuando ésta ya no está disponible o ya no es viable desde un punto de vista práctico, la realidad es que suele sobrevenir antes de que esto ocurra, cuando deja de ser utilizada y actualizada de forma deliberada. Sin negar la mayor dificultad de adaptar prácticas preindustriales a los requerimientos de sociedades industrializadas, atribuye su abandono a corto plazo al propio rechazo ideológico a la tradición "por quienes la ven como obstáculo al progreso o, aún peor, como su adversario militante"

La idealización del progreso se convierte así en uno de los principales problemas a los que la arquitectura tradicional se enfrenta. El "mito del progreso infinito" fue identificado por Mircea Eliade como la ideología que domina e inspira la cultura contemporánea, como el dogma propio de nuestro tiempo $(2016,186)$. Según este dogma "el verdadero cometido del hombre consiste en cambiar y transformar la Naturaleza", ya que "está capacitado para obrar mejor y más aprisa que la Naturaleza", y "está llamado a convertirse en dueño de ésta".

Con el progreso, se idealiza también con frecuencia la tecnología y, sobre todo, de la imagen de la misma, es decir, de la apariencia tecnológica. Esta admiración por las sugestivas imágenes del progreso y la tecnología ha sido una constante no sólo en la historia de la arquitectura del siglo XX, sino en la de su cultura en general. Sin embargo, ha estado siempre al mismo tiempo bajo sospecha, convirtiéndose en el blanco de las críticas de un creciente número intelectuales, novelistas, cineastas, arquitectos y otros personajes del mundo de la cultura. A esta cuestión dedicamos, de hecho, el segundo número de la revista Teatro Marittimo, dedicada a la teoría y crítica de la arquitectura a través del cine y la cultura popular.

La visión idealizada del progreso supone una hoy muy cuestionada visión de la historia como desarrollo lineal hacia un grado de perfeccionamiento progresivamente más elevado. La ciencia y la cultura han ido progresivamente apartándose de esta ideología

\footnotetext{
${ }^{7}$ Las conclusiones tanto de Rapoport como de Hobsbawm aquí expuestas quedan refrendadas por los resultados obtenidos en esta investigación, al haber permitido cuantificar las notables divergencias en la transformación de la tradición local en función de parámetros puramente socioculturales.
} 
desde hace décadas (Boas 1955; Carlo Baroja 1983, 229-239; Caro Baroja 1996, 12-15; Siegel 2004; Cenicacelaya y Baganha 2005, 24-38; Krier 2013, 81-88; Harari 2014), pero está fuertemente arraigada aún en nuestros días, y parece estarlo en mayor medida precisamente en aquellos contextos donde la industrialización ha llegado de forma más tardía y parcial. Sigue estando particularmente extendida igualmente en el campo de la arquitectura, cuya historiografía moderna ha estado dominada por este principio, y donde es frecuente aún encontrar un firme rechazo por todo material, sistema constructivo o forma tradicional o popular, ya sea por considerados anticuados, primitivos o inferiores o por el propio hecho de no ser símbolo de progreso. La historia de la arquitectura sigue asimismo narrándose en ocasiones asumiendo el modelo lineal de perfeccionamiento evolutivo, perfeccionamiento que conduce en todo caso al progresivo surgimiento y después a la expansión de las arquitecturas de estilo vanguardista que inspirarían las tendencias actuales.

De esta forma, el uso actual de una chimenea de ladrillo propia de la tradición de una determinada zona, por ejemplo, será frecuentemente rechazado per se por un gran número de profesionales, considerando más adecuada para nuestro tiempo cualquier solución que, por encima de cualquier otra consideración, rompa con la tradición, con ese pasado ya superado. Algo similar ocurre con los materiales y técnicas tradicionales, por lo que técnicas como el ladrillo de adobe o el tapial son con mucha frecuencia consideradas primitivas, inferiores e impropias de nuestro tiempo. También suelen considerarse poco sólidas o poco duraderas, mientras numerosos productos sintéticos químicamente inestables, y tendentes por ello a una pronta degradación y alteración de sus propiedades, no son juzgados de modo semejante.

El arquitecto norteamericano Samir Younés ha denominado a esta forma de tratar de diseñar con la novedad como objetivo primario, dentro de la exaltación del progreso por el propio progreso, inventio ex nihilo (2012a, 21-22), contraponiéndolo con ello al tipo de invención propio de la tradición, que, tal como se ha expuesto, está fundamentado en la imitación.

El colectivo de los arquitectos se convierte por esta vía en un importante agente ideológico en el deterioro de las identidades locales tradicionales. Sin minusvalorar el papel del resto de agentes implicados en los procesos de transformación sufridos por 
nuestro entorno, los resultados del estudio de los casos seleccionados en esta investigación resultan esclarecedores. En los núcleos analizados, en una amplia mayoría de las intervenciones arquitectónicas recientes existe una clara preferencia, si no por la tradición local, sí al menos por una arquitectura que aparente formar parte de ella, lo que contrasta con el muy generalizado rechazo hacia este tipo de arquitectura por parte de los profesionales de este campo.

En este sentido, el 9 de julio de 1909, con el título La Arquitectura, Azorín publicaba en diario $A B C$ una tan breve como dura crítica a la degradación del paisaje rural, que achacaba sin ambages a la extensión de la actividad del arquitecto a entornos cuya esencia arquitectónica ignoraba, desdeñando aquellas reglas fundamentales que, consagradas por centenarias tradiciones, habían ido forjando su imagen (Azorín 1909, 6):

En pueblos pequeños en que la "acción" del arquitecto se ha dejado sentir, yo he tenido ocasión de ver construcciones que, en medio de caserones viejos y nobles, destacaban de un modo deplorable (...). ¿Se podrá tolerar el espectáculo de estas viviendas presuntuosas y llamativas en que con pobreza y desmañadamente se quiere imitar los edificios fastuosos de las grandes capitales? No; dejemos que el genio local de alarifes y albañiles se desarrolle libremente y según la tradición.

El arquitecto comenzaba a verse ya entonces como uno de los agentes destacados en la difusión de este género de mitificación del progreso, en la exaltación de la ruptura con la tradición como herramienta de desarrollo. De hecho, sin que exista contacto alguno entre ambos autores, encontramos una visión semejante casi por las mismas fechas en uno de los más famosos textos del arquitecto moravo Adolf Loos, Arquitectura, publicado en $1910(1993,23-35)$ :

¿Puedo conducirles a la orilla de un lago de montaña? El cielo es azul, el agua verde y todo descansa en profunda paz. Las montañas y las nubes se reflejan en el lago, y así las casas, caseríos y ermitas. No parecen creadas por mano humana. Están como salidas del taller de Dios, como las montañas y los árboles, las nubes y el cielo azul. Y todo respira belleza y silencio... ¡Eh, qué es aquello! Un tono equivocado en esa paz. 
Como un ruido innecesario. En medio de las casas de los campesinos, que no las hicieron ellos sino Dios, hay una villa. ¿Proyecto de un buen o de un mal arquitecto? No lo sé. Sólo sé que ya no hay paz, ni silencio, ni belleza.

No en vano Loos fue en aquel tiempo uno de los más fervientes críticos del afán de novedad por la propia novedad, lo que le llevó a enfrentarse a cada una de las diversas corrientes arquitectónicas que fueron poniéndose de moda a lo largo de su carrera, propugnando siempre, al menos en sus escritos, la evaluación crítica de cualquier transformación propuesta sobre lo ya avalado empíricamente por la tradición (1993, 7778).

Sin embargo, no es correcto responsabilizar de este problema en exclusiva a los arquitectos, sino que, tal como se ha dicho, el resto de agentes implicados en la construcción, incluyendo a los propios clientes, han compartido con ellos la extendida ideología que asocia tradición con atraso o pobreza. Los prejuicios hacia la tradición han existido y existen de forma generalizada. De hecho, prescindir hoy del arquitecto en la construcción de un edificio en raras ocasiones conllevaría un retorno a la tradición perdida. En el mejor de los casos, los trabajadores encargados de la ejecución del edificio acometerían un intento probablemente fallido de copiar una tradición que desconocen, en la que no han sido ya por lo general formados, resultando de ello un vulgar pastiche. No menos probable sería que ocurriera, como lamentaba ya Hassan Fathy reflexionando sobre este mismo problema $(1976,21,34)$, que, abandonada "la segura guía de la tradición", se lanzaran intentar reproducir "arquitectura de arquitectos", conocida tan sólo de segunda o tercera mano, y resultando edificios "con todos los defectos y ninguna de las ventajas del trabajo del arquitecto".

A la hora de abordar este arraigado problema cultural, habría que tener en consideración, por tanto, que para combatirlo con éxito la formación en este ámbito no debería limitarse a las escuelas de arquitectura, sino tratar de alcanzar un público más general, llegando sobre todo a la totalidad de los oficios de la construcción. Su introducción en el ámbito académico, en cualquier caso, sería un buen fundamento para la difusión y mejores comprensión y valoración generales de la tradición arquitectónica y constructiva. El arquitecto, al igual que ha venido siendo un importante agente en el alejamiento de la 
tradición local, podría erigirse en un importante referente para su recuperación. El propio Paul Oliver ha señalado la urgente necesidad de que haya estudiantes de arquitectura con una educación completa en el campo de la arquitectura tradicional, subrayando también la necesidad de que ésta sea marcadamente intercultural e interdisciplinar (Oliver 2006a, 43; Davis 2006; Latter 2006).

Ahora bien, analizados los diversos factores que conducen al deterioro de la identidad local, también es importante señalar cuáles no lo hacen y, sin embargo, suelen aducirse como tales, de forma que no añadan confusión y complejidad al ya dificultoso tema estudiado.

Es común encontrar argumentos, de nuevo muy extendidos entre los profesionales de la arquitectura y la edificación, que consideran necesario el abandono de la tradición por otros motivos. Se entiende a menudo que la "superación" de la misma es un objetivo ineludible. Entre estos planteamientos, es frecuente encontrar justificaciones de esta determinación en base a cambios en los requerimientos de confort de nuestro tiempo, a la aparición de nuevas técnicas o materiales o al surgimiento de nuevos tipos de edificios.

El análisis de los hechos muestra que no son éstos, sin embargo, tan determinantes para el abandono de la tradición, al igual que, como se ha explicado, no lo son en su génesis. Pese a que es claro que condicionan el proceso estudiado, su abandono resulta en última instancia una cuestión de índole cultural, una cuestión de elección. Queda en mayor medida determinado por la propia ideología que los considera aspectos determinantes. De esta forma, a lo largo de la historia se han sucedido los cambios en los requerimientos de confort, el desarrollo de nuevas técnicas y materiales y la aparición de nuevos tipos arquitectónicos sin que nada de ello haya conducido al abandono de las tradiciones locales, sino a su transformación, a su adaptación a esas nuevas circunstancias o posibilidades. De este modo, en un mismo pueblo castellano, por ejemplo, podrá verse cómo una casa medieval, una casa del siglo XVI y una casa del siglo XIX son completamente diversas $\mathrm{y}$, sin embargo, se mantienen dentro de una tradición.

Pese a ello, este tipo argumentos se propagó enormemente en el ámbito de la arquitectura, y en especial a partir de lo que Reyner Banham denominó en 1960 Primera Era de la Máquina, siendo muchos de ellos recogidos por el propio autor (1985). Hacía con ello 
referencia al primer tercio del siglo $\mathrm{XX}$, aunque argumentos similares a los de entonces habían sido esgrimidos ya, y lo siguen siendo aún con frecuencia en la actualidad, para descalificar la construcción, la arquitectura y el urbanismo tradicionales.

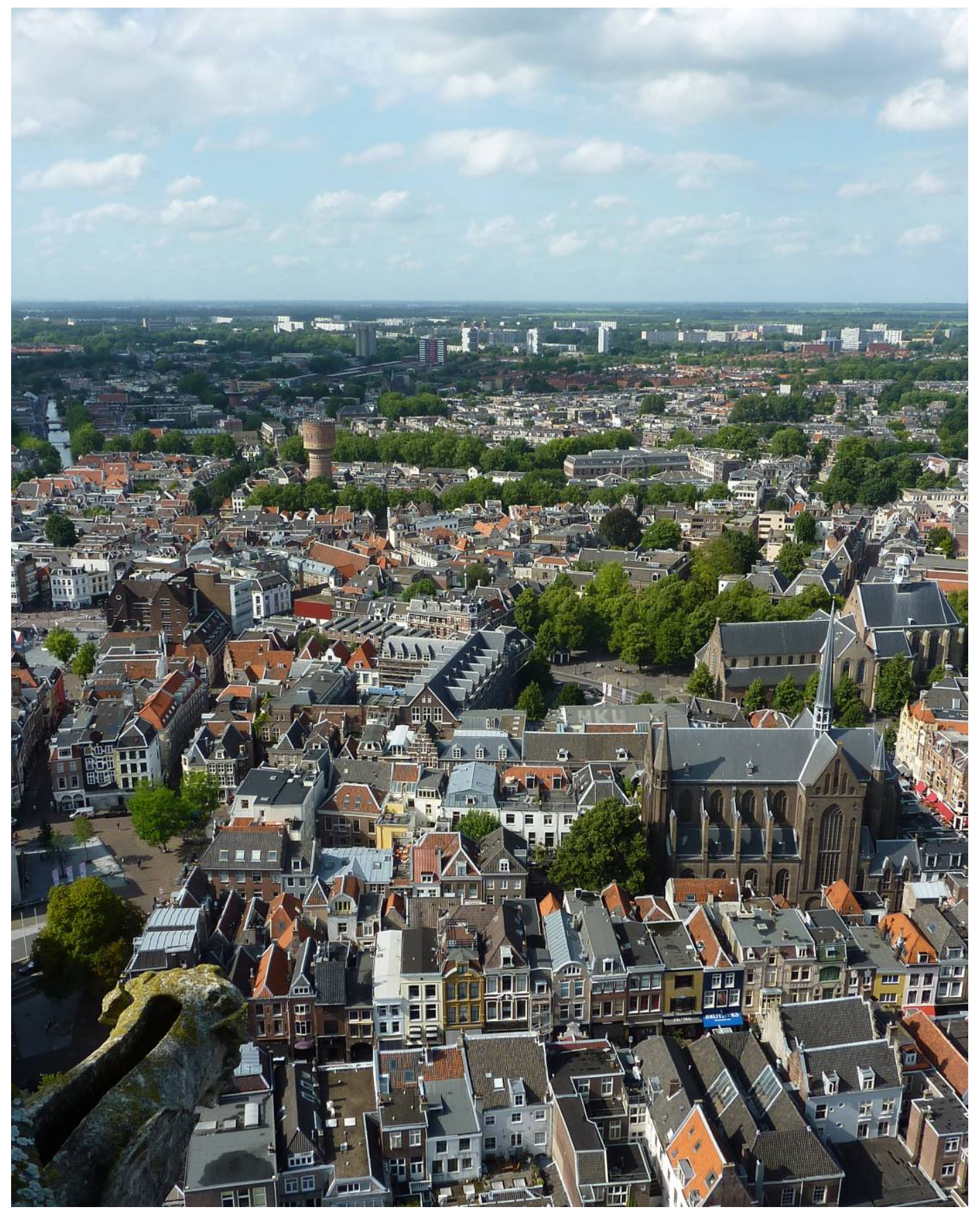

Multitud de tipos y estilos arquitectónicos han ido conformando con el tiempo la característica identidad del centro histórico de Utrecht. Los sucesivos cambios en su tradición arquitectónica local nunca supusieron un menoscabo de ese peculiar carácter

(fotografía del autor, agosto de 2012) 


\subsubsection{Herramientas para la preservación de la identidad local tradicional}

Para hacer frente a esta problemática existen multitud herramientas, todas ellas de probada utilidad, pero ninguna suficiente por sí misma.

Sobre la legislación desarrollada en España con este objetivo, se incluyó un exhaustivo capítulo en el Plan Nacional de Arquitectura Tradicional desarrollado por el IPCE (2010, 74-148), al igual que sobre los diversos inventarios elaborados hasta la fecha en cada una de las diversas comunidades autónomas (149-280). Además, a nivel municipal existen numerosos catálogos de inmuebles a proteger en mayor o menor grado y normativas urbanísticas destinadas a la preservación de algunos rasgos de la tradición local, mejor o peor identificados, tanto en edificios existentes como en obras nuevas.

La mayor parte del trabajo realizado hasta hoy se ha centrado en la protección de la materialidad de elementos arquitectónicos producidos por la tradición, así como en limitar las posibles alteraciones que puedan sufrir los conjuntos que conforman. Es decir, se ha desarrollado desde planteamientos que desatienden casi por completo su naturaleza procesual, reduciendo esa tradición a una condición estática que no ha hecho sino agravar su ya crítica situación. Y a menudo, además, han adolecido de un conocimiento insuficiente de la riqueza y complejidad de las tradiciones que se pretenden mantener, que quedan en ocasiones reducidas a una serie de rasgos, más o menos simplificados, que se consideran particularmente típicos.

Sin embargo, como se ha dicho, una tradición, para mantener su vitalidad, requiere siempre de un vehículo transmisor, de un depositario de ese saber que sea a su vez capaz de transmitirlo. Es decir, aunque la identidad local tradicional está definida por un conjunto de elementos materiales, su conservación no depende únicamente de la preservación de suficientes ejemplos de los mismos, sino también del patrimonio inmaterial que permita no sólo cualquier adaptación que su continuidad requiera, sino también producir otros nuevos.

Se ha explicado ya el término tradición y su carácter creativo y cambiante, así como el lento sistema de decantación que conduce a la definición de los rasgos vernáculos que determinan la identidad. Aunque pueda resultar sorprendente, hasta fechas recientes, 
desde el mundo de la arquitectura y de la conservación del patrimonio, al tratar este campo, se ha trabajado mucho sobre la preservación de los productos de la tradición y muy escasamente sobre el mantenimiento del conocimiento que los ha generado y la continuidad de su transmisión.

Como se tratará con mayor precisión más adelante, esta idea constituía uno de los pilares sobre los que se apoyaba la que fue la primera teoría global sobre la preservación de la identidad tradicional: la desarrollada y puesta en práctica por el movimiento inglés de las Artes y los Oficios. Sin embargo, sería relegada progresivamente a un papel secundario, desapareciendo en la práctica de los principales debates de la arquitectura y la restauración tras la Segunda Guerra Mundial y hasta su renacimiento de la mano del reconocimiento o la revalorización de lo que se lo que iba a denominarse Patrimonio Cultural Inmaterial.

Esta revalorización del patrimonio inmaterial iba a producirse de forma progresiva. Ya en 1982 la UNESCO iba a convocar a un grupo de expertos en la materia que desarrollarían la Recomendación sobre la Protección de la Cultura Tradicional y Popular de 1989. Seguirían a este texto documentos como el Sistema de Tesoros Humanos Vivos de 1993 y la Proclamación de Obras Maestras del Patrimonio Oral e Inmaterial de la Humanidad de 1998. Todos ellos incidirían en la naturaleza procesual de ese patrimonio y en la necesidad de mantenerlo vivo, sin tratar de congelarlo, para su conservación efectiva. El programa de Tesoros Humanos Vivos, en particular, se creó con el objetivo de incitar a los Estados a otorgar un reconocimiento oficial a los más destacados depositarios de cada tradición, así como apoyarles en la transmisión de su saber a las nuevas generaciones. Finalmente, recogiendo todo este desarrollo, se celebró en 2003 la trigésimo segunda reunión de la UNESCO con el título Convención para la Salvaguardia del Patrimonio Cultural Inmaterial, certificando "la superación de la dicotomía material-inmaterial" y quedando reforzada la "idea de Patrimonio como Cultura (Alonso Ponga 2009: 56-60)".

En consecuencia, un año más tarde, en 2004, la UNESCO y la Agencia Japonesa sobre Asuntos Culturales celebran una conferencia en Japón, dedicada a la ciudad de Nara, de la que surge Declaración de Yamato sobre Enfoques Integrados para Salvaguardar el Patrimonio Material e Inmaterial, donde se adopta ya una visión común a la hora de tratar 
ambos patrimonios, asumiéndose la impropiedad de intentar trabajar sobre la preservación de cualquiera de estos patrimonios de forma independiente.

Esta visión, aunque permanece aún alejada hoy de los debates en torno a la nueva arquitectura, está ya muy extendida en el campo de la preservación del patrimonio. El ya citado Plan Nacional de Arquitectura Tradicional, desarrollado por el Instituto de Patrimonio Cultural de España, es buena muestra de este tipo de aproximaciones (2014, 11):

La arquitectura tradicional está íntimamente relacionada con el Patrimonio Cultural Inmaterial. Las manifestaciones culturales inmateriales en estos contextos arquitectónicos se corresponden con los conocimientos y las técnicas constructivas utilizadas, las funciones de los espacios en relación con las actividades domésticas, económicas o las celebraciones sociales, así como la organización, división y el significado de los mismos en función del grupo que lo habita. Por último, las creencias y prácticas asociadas tanto al uso como al mantenimiento de las construcciones, así como la valoración, la percepción y el significado local como espacio habitado, forman parte de la cultura inmaterial. A su vez, toda esta dimensión inmaterial asociada a la arquitectura se conecta con saberes ajenos a los técnico-científicos constructivos, como son la organización de un territorio con sus hitos de referencia, zonas productivas, sus áreas comunitarias, sus redes viarias, los conocimientos tradicionales relacionados con oficios artesanales, manejo de ganado, cultivos, aprovechamiento de los recursos de campo, meteorología, fauna, flora, es decir, sobre el entorno de estas construcciones tradicionales.

Pese a este lento proceso de reconocimiento, sin tener en cuenta el patrimonio inmaterial resulta imposible preservar o regenerar lo que denominamos identidad tradicional en un sentido estricto. Su desaparición lleva aparejada la de los mecanismos miméticos de actualización y adaptación continuas que mantienen viva la tradición y las consecuencias de esta extinción se extienden lentamente a sus vestigios materiales, condenados con ello a desaparecer antes o después. 


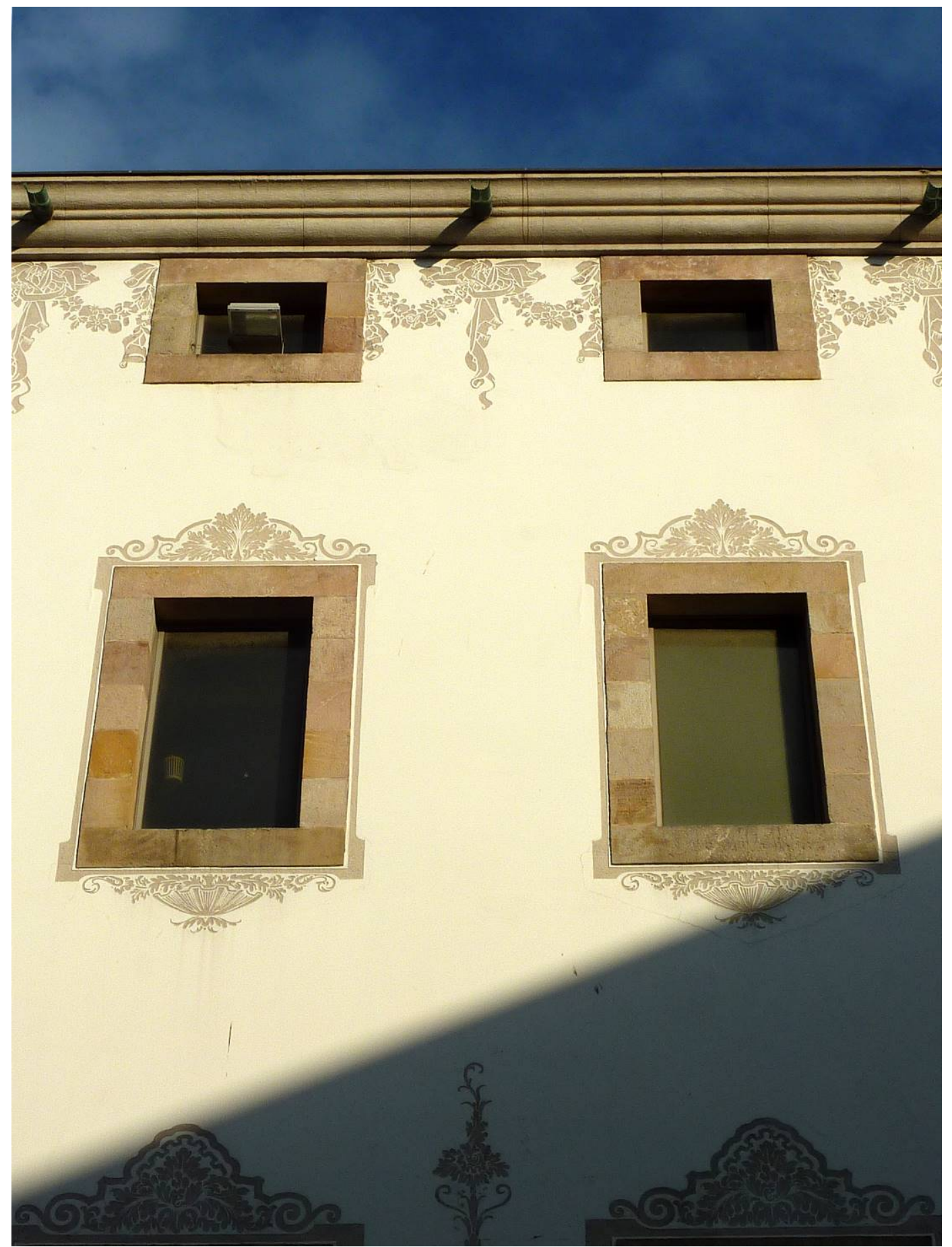

Esgrafiados en Barcelona. La identidad tradicional de esta ciudad difícilmente podría conservarse a largo plazo si desaparecieran los maestros del característico esgrafiado local (fotografía del autor, junio de 2012) 
Sin embargo, no en todas las culturas se ha producido un desequilibrio tan arraigado y duradero entre la valoración del patrimonio material y la del inmaterial. Así, en países como Japón o Corea la imposibilidad de considerar ambos patrimonios por separado tuvo un temprano reconocimiento. La protección del patrimonio inmaterial está ya muy desarrollada en ellos, existiendo desde hace décadas políticas específicas al respecto. Japón declaró sus primeros "monumentos vivos" en 1950, los denominados Tesoros Nacionales Vivientes. Hoy cuentan con multitud de "monumentos vivos" en cada uno de los dos países, pudiendo ser éstos tanto individuos como colectivos. Los Tesoros Nacionales Vivientes, además de prestigio y reconocimiento, reciben un soporte económico vitalicio a cambio de asumir la responsabilidad de transmitir su saber, ofreciéndose también financiación parcial para sus aprendices. Entre los muchos trabajos artesanales protegidos ocupan un importante lugar algunos asociados a las artes de la construcción, como la carpintería y el trabajo del metal.

Posteriormente, también se instituyó esta figura en otros países de Extremo Oriente, como Filipinas. En 1994, tomando como referencia el sistema japonés de los Tesoros Nacionales Vivientes, se creó en Francia el título de Maestro Artista. Los Maestros Artistas se escogen periódicamente entre los más destacados artesanos con el fin de transmitir sus conocimientos a aprendices. El proceso de aprendizaje tiene una duración establecida de tres años, durante los cuales el Maestro Artesano percibe una asignación económica anual.

En el caso español, no existe figura alguna de este tipo, pese a que ha habido iniciativas con el fin de su establecimiento, actualmente truncadas. Sí existe, sin embargo, algún tipo de protección para el patrimonio inmaterial en casi todas las legislaciones autonómicas al respecto. En nuestro país, "muchas son las fiestas protegidas (como si lo necesitaran) pero escasas las actividades profesionales, los conocimientos o las técnicas que hayan sido declaradas bien patrimonial de una u otra manera. Y lo cierto es que esos conocimientos, esas actividades, serían doblemente necesarios: desde un punto de vista patrimonial (la conservación y la transmisión de saberes tradicionales) y desde un punto de vista funcional: ¡cuántas restauraciones de patrimonio no se pueden realizar de manera conveniente por la falta de profesionales de oficios perdidos!” (Llop i Bayo 2009, 137). 
ind

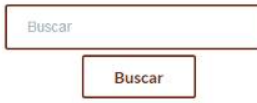

+ Categorias

- Provincias

Todas las provincias

Álava - Araba

Albacete

Alicante-Alacant

Almeria

Asturias

Ávila

Badajoz

Bes Balears

Barcelona

Burgos

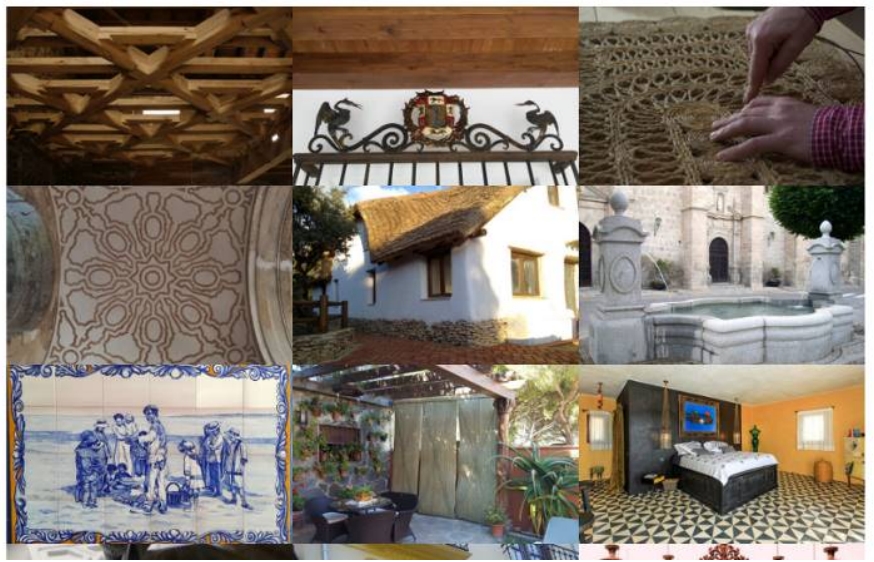

Imagen del directorio de artesanos hoy disponible de libre acceso en la página web de la Red

Nacional de Maestros de la Construcción Tradicional (www.redmaestros.com) y vista de una de las exposiciones con las que anualmente se difunde el trabajo de los maestros de la construcción galardonados con los Premios Richard H. Driehaus de las Artes de la Construcción, ambas iniciativas dirigidas a la promoción y el reconocimiento de estos oficios (fotografía cedida por

Carmen García Hermida, junio de 2017)

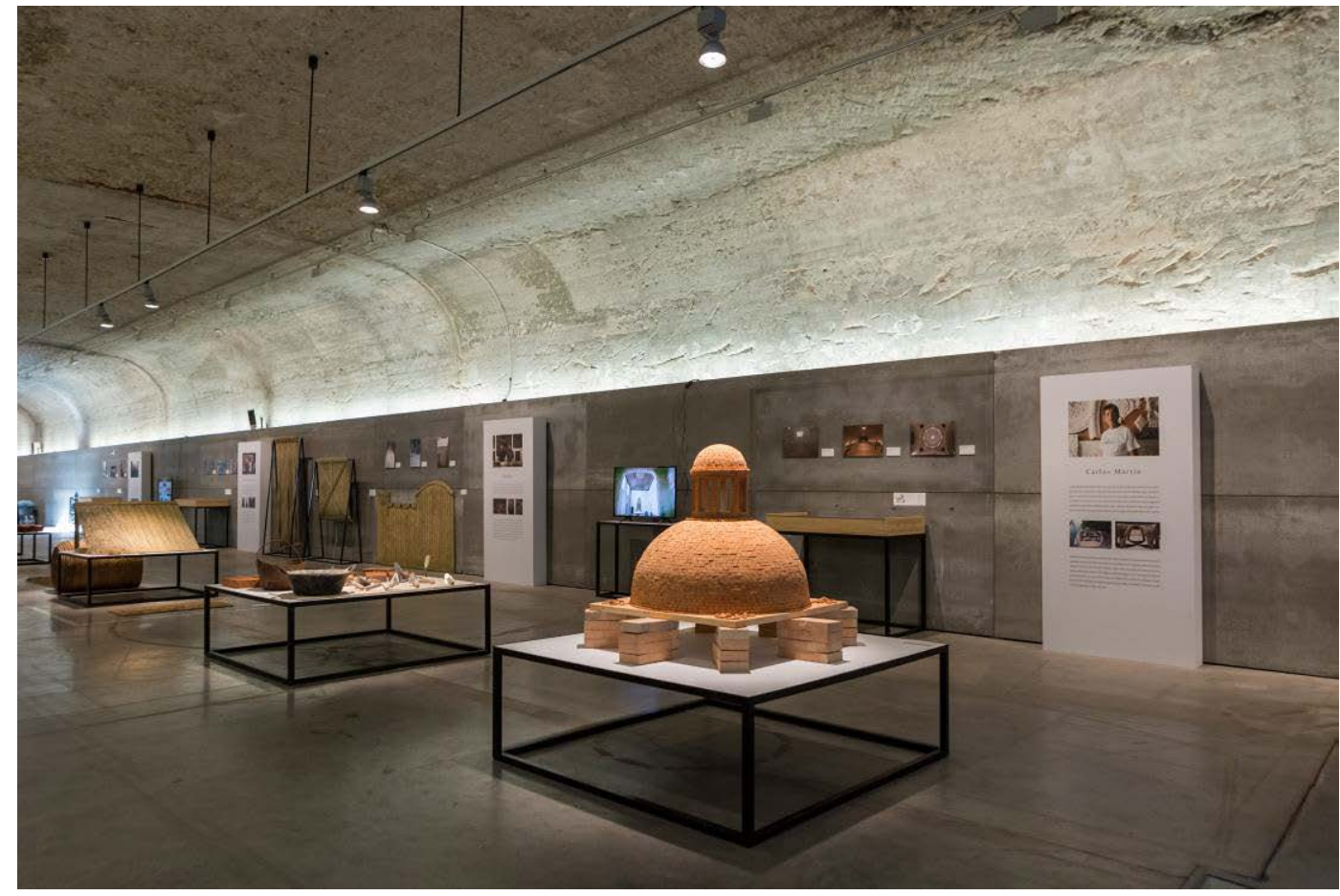


Sí se ha acometido, sin embargo, con motivo de la elaboración del Plan Nacional de Arquitectura Tradicional por el IPCE (Instituto de Patrimonio Cultural de España), un primer trabajo de inventariado de artesanos de la construcción tradicional, aunque se trata aún de una aproximación inicial a un campo que, pese a haber sido en gran medida ninguneado durante las últimas décadas, sigue siendo felizmente muy amplio. Como complemento a éste, he coordinado la puesta en marcha de un proyecto desarrollado por INTBAU (Red Internacional para la Construcción, la Arquitectura y el Urbanismo Tradicionales) en colaboración con el IPCE, gracias al apoyo económico del Richard H. Driehaus Charitable Lead Trust, que nos ha permitido crear un directorio web interactivo en el que los principales maestros de la construcción tradicional española pueden ser localizados tanto por oficio como por ubicación, mostrándose y explicándose su trabajo y aportándose sus datos de contacto: la Red Nacional de Maestros de la Construcción Tradicional. El modelo que inspiró su elaboración fue el creado por el Art Workers' Guild británico, fundado en 1884 por un grupo de arquitectos vinculados al movimiento Arts and Crafts y procedentes todos ellos del estudio de Richard Norman Shaw: William Richard Lethaby, Edward Prior, Ernest Newton, Mervyn Macartney y Gerald C. Horsley. Sigue funcionando hoy en día como una asociación de artistas, artesanos y diseñadores que cuenta con un directorio web que les proporciona una mayor visibilidad y oportunidades de colaboración y apoyo mutuos y les facilita el mantenerse informados sobre el trabajo realizado por el resto de miembros.

Pero por encima del inventariado, la protección y la promoción de estos oficios, está siempre la necesidad de facilitar su transmisión. Fue en el propio Reino Unido, tras la Exposición Universal de 1851, donde se determinó implantar un nuevo modelo de enseñanza técnica a través de las Escuelas de Artes y Oficios. Este sistema sirvió de modelo al español. En el propio Real Decreto de 5 de noviembre de 1886, destinado a regular la enseñanza técnica en nuestro país a través de este tipo de escuelas, se utilizaba el ejemplo británico como referencia (Durán Rodríguez 2009, 73-74). En todo caso, se había creado con anterioridad en Francia un sistema similar cuyos orígenes estuvieron en 1780, aunque recibieron el nombre de Écoles d'Arts et Métiers ya en 1803. En España, se fundaron este tipo de escuelas en prácticamente todas las capitales de provincia, así como la mayor parte de poblaciones con una notable actividad industrial. Muchas de ellas fueron creadas gracias a iniciativas locales, a menudo por las Sociedades Económicas de 
Amigos del País, siendo algunas incluso anteriores a su regulación a través del mencionado Real Decreto.

La enseñanza en estas escuelas fue evolucionando y, en muchas de ellas, desvinculándose progresivamente en las últimas décadas de la enseñanza de oficios, en especial de los vinculados a la construcción, y especializándose en las enseñanzas artísticas y el diseño. De hecho, hoy en día es frecuente en ellas la adopción del nombre de Escuelas de Arte. En cualquier caso, en muchas de ellas sigue enseñándose algún oficio de carácter más tradicional, tales como forja, ebanistería o cerámica, así como formación en conservación y restauración de bienes culturales.

La excepción la constituyen algunos centros locales o regionales que se han convertido en referentes nacionales en la conservación de determinados oficios de la construcción tradicional, tales como el Centro de los Oficios del Ayuntamiento de León, que imparte cursos de oficios tales como la carpintería, la cantería, la forja, la cerámica o el trabajo del vidrio, el Centro Albayzín de Granada, o la Escuela de Canteros de la Diputación de Pontevedra en Poyo, que ofrece una completa formación de tres años para la obtención del título de cantero, con posibilidad de ampliarla dos años más para recibir el de maestro cantero.

Pero hay otro formato de escuelas que, por su carácter eminentemente aplicado, han ido ocupándose principalmente del campo de la formación en los oficios de la construcción: las Escuelas Taller. Estas escuelas nacieron como empeños prácticamente personales, extendiéndose más adelante por todo el ámbito nacional. El programa de Escuelas Taller y Casas de Oficios fue creado por el Gobierno de España en 1985. Comenzó ese mismo año su andadura la Escuela Taller concebida inicialmente, gracias al impulso de José María Pérez "Peridis", para restaurar el Monasterio de Santa María la Real de Aguilar de Campoo. A partir de esta experiencia se conforma en 1994 la Fundación Santa María la Real, que extendería esta labor por diversas regiones españolas. Una de las primeras en seguir su ejemplo fue la Escuela Taller de Lebrija, que inició su actividad también en 1985, bajo la dirección del arquitecto de origen australiano Donald Gray. Funcionó, además de como institución formativa, como una plataforma para el desarrollo de la región y un centro de reinserción social de gente de la región. Sus cursos estuvieron dedicados a diversas disciplinas: albañilería, carpintería, forja, cerámica, jardinería y 
técnicas de restauración de edificios históricos. Pese a su éxito, el proyecto perdió su financiación en 1989. En 1992 la Agencia Española de Cooperación Internacional para el Desarrollo (AECID) extendió este tipo de programas a los países en los que estaba trabajando. En 1996 comenzó también a funcionar la Fundación Santa María de Albarracín, cuya Escuela Taller se convertiría en un referente internacional en el ámbito de la formación para la restauración del patrimonio.

Además, existen otras iniciativas en nuestro país que han contribuido también de modos diversos a sacar del ostracismo la construcción y la arquitectura tradicionales, tales como el Centro de Investigación de Arquitectura Tradicional (CIAT) de la Universidad Politécnica de Madrid en Boceguillas, fundado en 1996 y dirigido por Fernando Vela Cossío, donde se vienen impartiendo desde entonces cursos de toma de contacto con la construcción con tierra, la cantería o la carpintería, entre otros. En la misma universidad, un pequeño grupo de profesores ha contribuido en gran medida a la revalorización de las técnicas tradicionales de construcción, lo que ha llevado incluso a la creación de un Máster Universitario en Construcción y Tecnología de Edificios Históricos, coordinado por José Carlos Palacios. También deben señalarse los múltiples talleres y actividades académicas organizados por Fernando Vegas y Camilla Mileto desde la Universidad Politécnica de Valencia; los cursos de Artifex Balear, fundada en Mallorca en 2002; los del Museo de la Cal de Morón; la labor realizada desde el año 2012 por nuestra ONG, Terrachidia, introduciendo en pocos años a centenares de participantes de todo el mundo a la construcción con tierra; así como los trabajos del recientemente creado Grup de Recuperació i Estudi de la Tradició Arquitectònica (GRETA) de la Demarcación de Gerona del Colegio de Arquitectos de Cataluña. Finalmente, y sin pretender ser exhaustivos, hay que señalar la labor realizada en España desde el mismo 2012 gracias al filántropo norteamericano Richard H. Driehaus, financiando múltiples actividades de cuya coordinación me encargo, entre otras: el Premio Rafael Manzano de Nueva Arquitectura Tradicional, el Concurso de Arquitectura Richard H. Driehaus, y diversos cursos y seminarios para la promoción de la arquitectura y la construcción tradicionales contemporáneas. Fundamentales para dotar de mayores reconocimiento y visibilidad a los vehículos transmisores de la tradición, los artesanos, pueden ser también los Premios Richard H. Driehaus de las Artes de la Construcción, que hemos organizado desde INTBAU en colaboración con el Ministerio de Fomento y el Ministerio de Cultura, y que premian anualmente a maestros de la construcción en cuatro categorías distintas, que se 
corresponden con otros tantos grupos de oficios, otorgando además una beca formativa anual a uno de los ganadores para formar a un aprendiz, quien resulta igualmente becado durante ese año.

Queda, sin embargo, mucho que hacer en España para cumplir con los objetivos a los que viene comprometiéndose a instancias de diversos organismos internacionales. En febrero de 2017 el Comité de Ministros del Consejo de Europa adoptó la Recomendación del Comité de Ministros a los Estados Miembros sobre la Estrategia para el Patrimonio Cultural Europeo para el siglo XXI, que se lanzó oficialmente en Limassol, Chipre, en abril de 2017 y que es buen ejemplo de ello. En la recomendación D10 recogida en este texto $(2017,19)$, "Utilizar el patrimonio cultural como un medio para dotar a cada región de un carácter distintivo y hacerla más atractiva y mejor conocida", se habla de recuperar las actividades económicas tradicionales y de destacar cualidades del patrimonio como su uso de recursos, suministros y redes de distribución locales, mientras que en la K7, "Asegurar la transmisión del conocimiento y las habilidades propios de los oficios del patrimonio", se incide en que la continuidad de éstos es esencial para la conservación del patrimonio, pero su fragilidad los hace susceptibles de desaparecer en una generación, y en cómo para asegurar y garantizar su transmisión ha de apoyarse a los propios artesanos y empresas artesanas de diversas formas, incluyendo mecanismos para la promoción y el fomento de su trabajo, ayudas a la formación de jóvenes y centros formativos dedicados a los oficios tradicionales.

La situación en otros países europeos parece ser similar, aunque en algunos, como en Francia, la enseñanza de los oficios tradicionales goza de una salud envidiable. En el caso francés, las diversas agrupaciones de los Compagnons mantienen una estructura formativa mucho más rica y pautada que la que puede encontrarse en España, donde hemos de hablar siempre de iniciativas eminentemente aisladas y dispersas. Entre estas sociedades de Compagnons hay tan solo ligeras diferencias, que sin embargo han impedido hasta la fecha su unificación bajo una única organización. Su sistema de transmisión del conocimiento fue declarado en sí mismo Patrimonio Cultural Inmaterial de la Humanidad por la UNESCO en el año 2010. Las principales agrupaciones existentes hoy en día son: la Union Compagnonnique des Compagnons du Tour de France des Devoirs Unis, fundada en 1889; la Fédération Compagnonnique des Métiers du Bâtiment (FCMB), creada en 1952 agrupando varias asociaciones; y la Association Ouvrière des 
Compagnons du Devoir et du Tour de France (AOCDTF), fundada en 1941. La memoria de actividades del año 2015 de la tercera de ellas muestra con sus cifras el éxito alcanzado por esta vía: diez mil jóvenes en formación en veintinueve oficios diversos en tan solo ese año.

Otro caso singular es el del Reino Unido, donde un tipo de trabajo semejante se desarrolla a través de varias instituciones independientes, como la Carpenters' Company, de cuya existencia y actividad existen referencias desde 1271 y de la que depende el Building Crafts College de Stratford, fundado a su vez en 1893 y donde se enseñan hoy un gran número de oficios. También son desempeña una amplia labor la Prince's Foundation, donde existen dos programas principales de enseñanza de oficios: el Building Craft Apprenticeship, de ocho meses de duración, y el Young Heritage Apprenticeship, de doce meses.

Finalmente, otro interesante método o complemento para el aprendizaje de los oficios tradicionales, pervivencia de costumbres medievales, se ha conservado en Alemania, donde además de la formación en sus prestigiosas Escuelas de Artes y Oficios, los artesanos mantienen aún vivo el conocido como Wanderjahre. Se trata de una tradición formativa en la que el estudiante pasa varios años de aprendizaje viajando por el país, teniendo así ocasión de conocer de forma más extensa los trabajos propios de su oficio. Cada año siguen emprendiendo este viaje cientos de alemanes y la UNESCO lo declaró Patrimonio Cultural Inmaterial de la Humanidad en el año 2015.

Además de la enseñanza de los oficios, la orientación de la docencia de la arquitectura puede también influir de forma notoria en la preservación de la tradición arquitectónica. Se han citado ya las experiencias que vienen desarrollándose en la Universidad Politécnica de Madrid y en la Universidad Politécnica de Valencia, a las que cabe añadir la progresiva reorientación de los estudios de arquitectura de la Universidad Alfonso X el Sabio hacia la preservación del patrimonio y la arquitectura tradicional, en la que estamos actualmente trabajando. A nivel internacional existen escuelas de arquitectura que centran su formación en el estudio de la arquitectura tradicional, o que al menos la incluyen como parte de sus programas, teniendo sus alumnos durante sus estudios la posibilidad de proyectar edificios basados en la tradición, lo que aún es complicado o imposible en buena parte de las escuelas de arquitectura de todo el mundo. Entre estas 
escuelas, destacan por su continuidad y años de experiencia en este ámbito las escuelas de arquitectura de la Universidad de Notre Dame y la Universidad de Miami. También existen hoy programas de grado o posgrado de este tipo o donde se incluye al menos esta cuestión entre las materias impartidas en las de la Universidad de Yale, la Universidad de Judson, la Universidad de Colorado, la Escola Superior Gallaecia, la Universidad Oxford Brookes, la Universidad de Oxford, la Universidad de Buckingham y la Universidad de Gales Trinity Saint David.

Una vez perdida la posibilidad de la transmisión directa de estos saberes, la conservación de al menos parte del conocimiento puede servir de base para futuros proyectos de recuperación de los mismos. En este sentido, existen trabajos centrados en la documentación detallada de las prácticas tradicionales de construcción, tales como las entrevistas y grabaciones que viene desarrollando Félix Ángel Rivas a artesanos del Pirineo aragonés, o los múltiples reportajes sobre oficios tradicionales que Eugenio Monesma Moliner ha estado y está realizando por todo el país.

Para concluir, hemos de hacer mención a la importancia que tienen hoy las publicaciones en la transmisión del conocimiento sobre la tradición constructiva, en especial los tratados de técnicas de construcción, reparación o restauración y los manuales de soluciones y detalles constructivos. Sobre esta cuestión se recomienda consultar el completo artículo al respecto escrito por Camila Mileto y Fernando Vegas y publicado en el octavo número de la revista Patrimonio Cultural de España, dedicado a la arquitectura tradicional (2014, 67-78). Clasifican en él este tipo de textos en: tratados, guías y líneas guía, recetarios de materiales y técnicas tradicionales, prontuarios y códigos, atlas y otros manuales didácticos, y manuales.

A lo expuesto en el mencionado texto de Mileto y Vegas puede añadirse que han jugado un papel particularmente importante en la transmisión de determinadas soluciones tradicionales los manuales de detalles constructivos, por contener precisamente el tipo de documentación de mayor utilidad como referencia práctica tanto para los artesanos como para los arquitectos. Aunque los tratados que incluyen manuales de construcción entre sus contenidos han existido desde el propio tratado de Vitruvio, es durante los siglos XVIII y XIX cuando proliferan especialmente los tratados de construcción en general o de determinadas técnicas en particular. Entre los primeros tratados en fijar su atención 
específicamente en la arquitectura y la construcción "rurales" estarían los de los franceses François Cointeraux (1790 en adelante) y Léon de Perthuis (1810) y el del inglés William Barber (1805). Muchos otros les seguirían, especialmente en Francia, donde la arquitectura rural se convirtió en una disciplina con gran desarrollo.

Sería más adelante, sin embargo, tras las difusión de las ideas del movimiento Arts \& Crafts, cuando aparecerían los manuales específicos sobre la arquitectura y la construcción de regiones concretas. En España el primero de este tipo parece haber sido el estudio realizado por Leonardo Rucabado sobre la arquitectura tradicional montañesa, que incluyó no sólo planos de edificios, sino también múltiples detalles constructivos característicos de los artesanos de la zona: desde trabajos de carpintería hasta elementos de forja, fijando su atención incluso en la cerrajería de la región.

Especial interés tienen también los muchos trabajos norteamericanos sobre la arquitectura de nuestro país que se publicarían en las dos primeras décadas del siglo XX. Estuvieron precedidos por la impresionante labor de Arthur Byne y Mildred Stapley, quienes hicieron de guías para muchos de los autores posteriores y se les adelantaron elaborando y publicando catálogos de fotografías y dibujos de edificios, muebles, patios o detalles de forja de tradición española. Algunos de estos trabajos, como su Spanish Ironwork, con su prolijidad de detalles fotografiados o dibujados, bien pueden ser utilizados como manuales de soluciones constructivas. Tras ellos, animados en muchos casos por la voluntad de revivir las tradiciones arquitectónicas hispanas en las áreas de antigua influencia española, y especialmente en California, llegarían obras como las de Austin Whitelesey, con textos de Bertram Grosvernor Goodhue (The Minor Ecclesiastical, Domestic and Garden Architecture of Southern Spain, 1917); William Lawrence Bottomley (Spanish Details, 1924); Soul Winsor, con textos de Ralph Adams Cram (Spanish Farm Houses and Minor Public Buildings, 1924); Samuel Chamberlain (Sketches of Northern Spanish Architecture in Pen, Pencil and Wash, 1926); y Gerstle Mack y Thomas Gibson (Architectural Details of Southern Spain, 1928, y Architectural Details of Northern and Central Spain, 1930). Entre ellas, por la abundancia de dibujos y detalles técnicos, debieron ser de singular utilidad para el propósito buscado la de Bottomley y las de Mack y Gibson. 

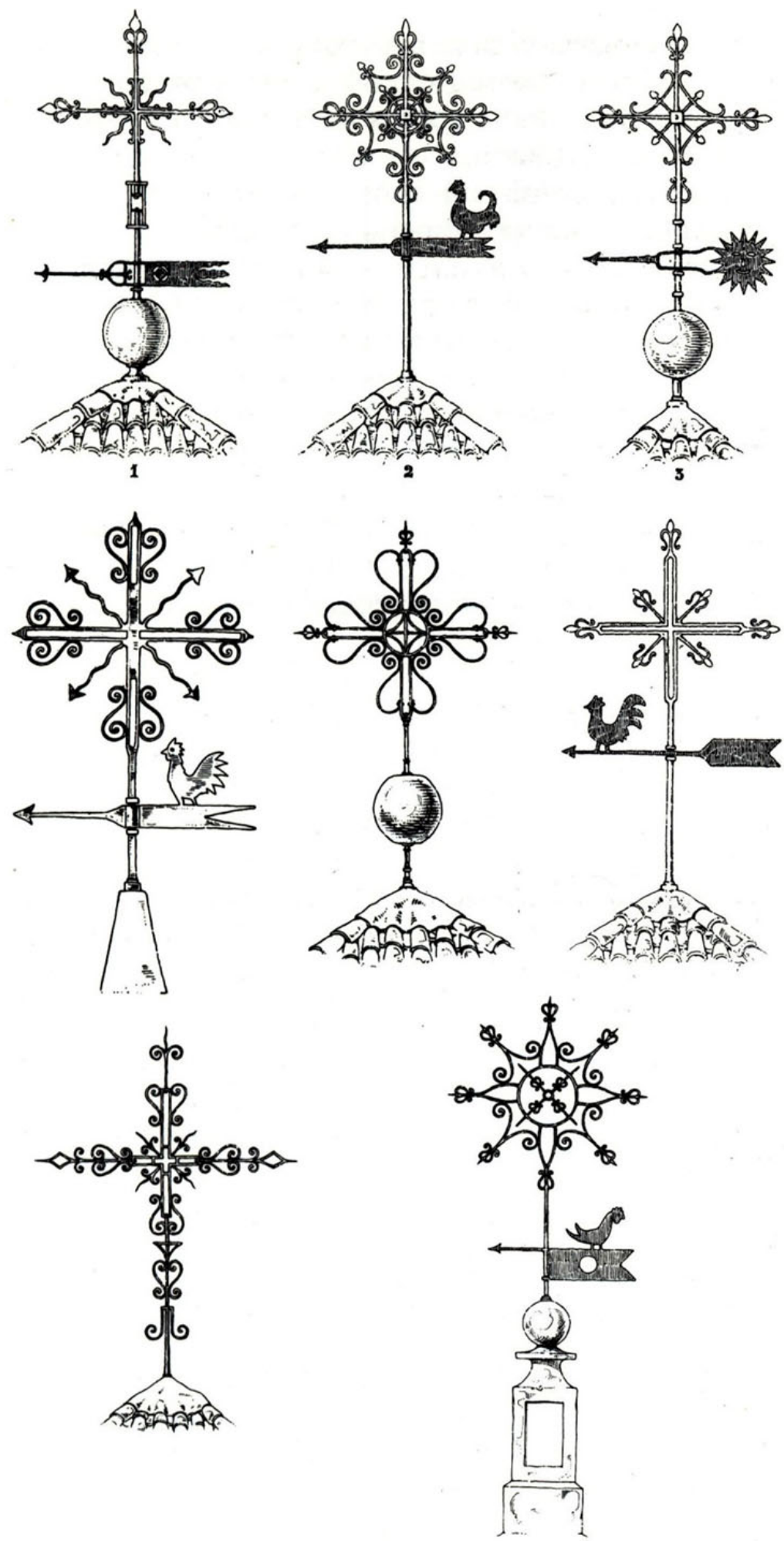

Detalles de coronación de cubiertas propios de la arquitectura tradicional montañesa, recogidos por Leonardo Rucabado en sus influyentes estudios sobre la misma (Ordieres 1987, 74) 
Otro manual de este tipo que iba a convertirse en una obra de referencia, y que destaca por su atención a una inusual diversidad de aspectos de la tradición local de las regiones sobre las que trata, es el realizado por el arquitecto francés Albert Laprade sobre la arquitectura de distintos lugares de nuestro país. Las láminas en las que condensa los muchos detalles recogidos en los viajes que se publicaron sin encuadernar, recogidas todas ellas en un cuaderno que permitía su fácil manejo y reproducción, bajo el título Croquis: Portugal, Espagne, Maroc. Pese a su tardía publicación, en 1958, sus viajes iniciales, de los que datan las primeras láminas, comenzaron a partir de 1915.

En cuanto a la aportación española a este género de catálogos de detalles constructivos y arquitectónicos, destaca particularmente la ingente labor realizada desde la revista Reconstrucción, publicada por la Dirección General de Regiones Devastadas y Reparaciones desde 1940 hasta 1953.Posteriormente, ya en 1976, y utilizando en ellos un grafismo análogo al utilizado en dicha publicación periódica, José Claret Rubira publicó sus Detalles de arquitectura popular española.

Mucho más adelante surgirían los manuales dirigidos a la recuperación de la tradición en lugares específicos, entre los que destacan los Manuali del Recupero italianos. Los primeros de ellos fueron desarrollados para las ciudades de Roma, Cittá di Castello y Palermo gracias al impulso de Paolo Marconi. Les seguirían muchos otros, en su mayoría desarrollados por discípulos directos o indirectos de Marconi, Se ilustran en ellos con múltiples detalles constructivos y muy completas axonometrías los diversos elementos que componen la arquitectura del lugar. Igualmente significativos han sido los manuales elaborados por la asociación RehabiMed bajo la coordinación de su presidente, Xavier Casanovas, para la conservación y rehabilitación de distintos lugares del Mediterráneo, desde países como Siria (2004) o Líbano (2004) hasta ciudades como Kairuán (2008) o Marrakech (2008). La misma asociación ha publicado también un manual más general con el fin de que otros puedan desarrollar proyectos similares en base a su metodología: Método RehabiMED: Arquitectura tradicional mediterránea (Casanovas 2007). Semejante en lo que respecta a las técnicas de representación utilizadas en estas experiencias anteriores sería el manual desarrollado bajo la dirección de Fernando Vegas y Camilla Mileto para orientar la restauración de la arquitectura tradicional valenciana, Aprendiendo a restaurar. Un manual de restauración de la arquitectura tradicional de la Comunidad Valenciana (2011). Esta obra, pionera en su género en nuestro país, puede 
servir como referencia para el desarrollo futuro de trabajos semejantes dirigidos a la preservación de la arquitectura tradicional del resto de regiones españolas, que los necesitan con creciente urgencia.

Los propios Mileto y Vegas elaboraron también el manual Renovar Conservando. Manual para la restauración de la arquitectura rural del Rincón de Ademuz (Vegas y Mileto 2007). Menos técnico que el anterior, es, sin embargo, mucho más accesible para el público general, al que estas herramientas han de dirigirse también. Se logra este objetivo con la inclusión de un apartado con gran poder de comunicación, en el que se muestran fotografías de diversas situaciones en las que se señala, recurriendo a ejemplos reales, cómo sería adecuado, mejorable o impropio restaurar o conservar cada elemento. Se trata, por tanto de una técnica muy semejante a la innovadora metodología popularizada por Paul Schultze-Naumburg a través de su revista Kulturarbeiten, publicada durante un largo período que se extendió entre los años 1900 y 1929. En ella, su autor trataba de detener lo que consideraba una grave devaluación de la arquitectura, el paisaje y, en general, de la identidad tradicional de Alemania y recurría para ello a oposiciones de fotografías en las que mostraba ejemplos positivos y negativos. Siguiendo a SchultzeNaumburg, esta técnica fue más adelante ampliamente explotada en la propaganda del Movimiento Moderno, que paradójicamente había sido el blanco de algunas de sus críticas.

También recurriría a este tipo de oposiciones el ya mencionado Donald Gray en La construcción tradicional en La Alpujarra granadina (2014). Se contraponen en él soluciones propias e impropias de la tradición local, precedidas de un minucioso estudio de cada uno de los elementos constructivos que componen la tradición constructiva de la zona, en el que se ofrecen las medidas y el trazado de hasta el último de sus detalles, desde sus chimeneas y alhacenas hasta los clavos de sus puertas, lo que enlaza este trabajo con el método que inaugurara en nuestro país Leonardo Rucabado.

Más allá de nuestras fronteras, son de gran interés publicaciones como Get your House Right. Architectural Elements to Use \& Avoid, de Marianne Cusato, Ben Pentreath, Richard Sammons y Leon Krier (2008), o los manuales desarrollados por Steven A. Mouzon para diversas comunidades norteamericanas (Key West, Bienville, Mooresville, St. Augustine...), o el que publicara junto a Susan M. Henderson bajo el título Traditional 
Construction Patterns. Design \& Detail Rules of Thumb (2004), que además de un catálogo de soluciones constructivas propias del léxico arquitectónico local, contienen compilaciones de lo que el autor denomina "dos and don'ts".

Otro campo en crecimiento, y que había sido abandonado durante largo tiempo, son los manuales de materiales, oficios y técnicas tradicionales. Las referencias recientes en nuestro país son múltiples y se incrementan cada año. Especialmente significativa fue la contribución de Enrique Nuere, al haber impulsado con sus investigaciones y trabajos la recuperación de todo un oficio perdido: la carpintería de lo blanco. Poco a poco van apareciendo publicaciones sobre el trabajo de la cal (Gárate 1993), el yeso (Gárate 1999), los esgrafiados (Ruiz Alonso 2001), etc.

Para terminar con los diversos tipos de publicaciones que están contribuyendo a conservar el patrimonio arquitectónico y constructivo tradicional, otra iniciativa pionera en su género fue la publicación del primer diccionario existente sobre la construcción tradicional, y en particular sobre la construcción con tierra: el Diccionario de Construcción Tradicional. Tierra, obra de Jaime de Hoz, Luis Maldonado Ramos y Fernando Vela Cossío (2003).

Todas estas herramientas para la preservación de la identidad local tradicional, precisamente aquellas que centran su atención en la transmisión del saber que la conforma, se hallan en España, como se ha expuesto, en un estado de desarrollo aún incipiente, que presenta además grandes desigualdades entre unas regiones y otras y entre unos campos de trabajo y otros. 


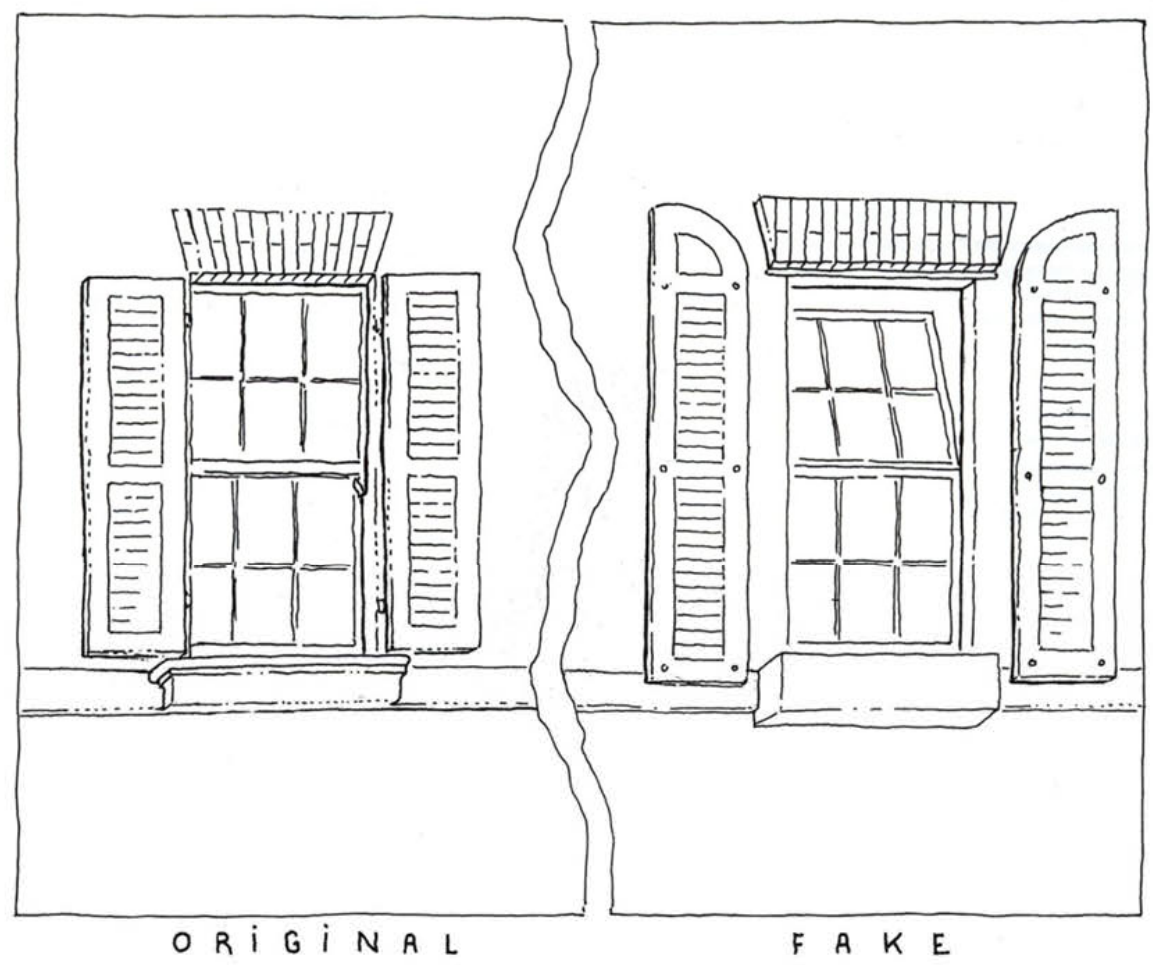

El tipo de ilustraciones incluidas en Get your House Right. Architectural Elements to Use \& Avoid, de Marianne Cusato, Ben Pentreath, Richard Sammons y Leon Krier, está concebido para orientar de forma sencilla y muy visual a todos los implicados en los procesos de construcción y diseño de edificios tradicionales $(2008,86,102$ y 103 . La primera de las ilustraciones es obra de Leon Krier)

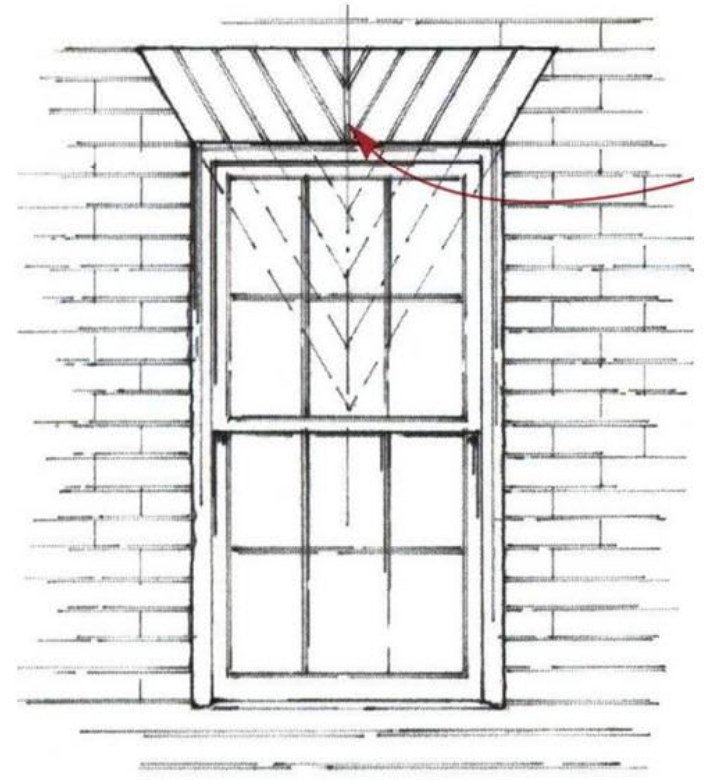

AV०ID

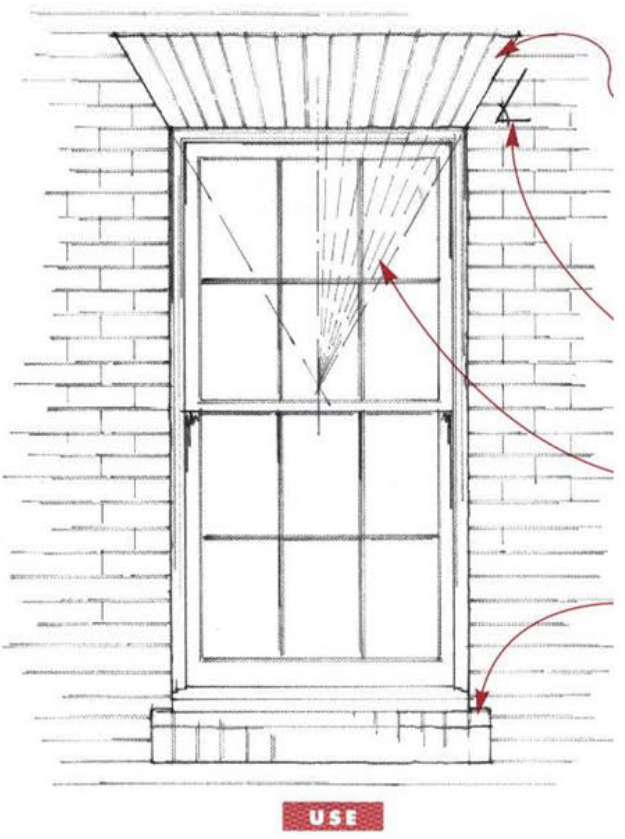




\subsection{GLOBALIZACIÓN E IDENTIDAD LOCAL. CONSECUENCIAS EN EL ÁMBITO DE LA ARQUITECTURA Y EL URBANISMO}

Junto con el patrimonio natural, hay un patrimonio histórico, artístico y cultural, igualmente amenazado. Es parte de la identidad común de un lugar y una base para construir una ciudad habitable. No se trata de destruir y de crear nuevas ciudades supuestamente más ecológicas, donde no siempre se vuelve deseable vivir. Hace falta incorporar la historia, la cultura y la arquitectura de un lugar, manteniendo su identidad original. Por eso, la ecología también supone el cuidado de las riquezas culturales de la humanidad en su sentido más amplio. De manera más directa, reclama prestar atención a las culturas locales a la hora de analizar cuestiones relacionadas con el medio ambiente, poniendo en diálogo el lenguaje científico-técnico con el lenguaje popular. Es la cultura no sólo en el sentido de los monumentos del pasado, sino especialmente en su sentido vivo, dinámico y participativo, que no puede excluirse a la hora de repensar la relación del ser humano con el ambiente.

Papa Francisco, 2015. Carta Encíclica Laudato si’: Sobre el cuidado de la casa común.

El hecho de que la máxima autoridad eclesiástica católica aborde la cuestión del deterioro de la identidad local tradicional en una de sus primeras cartas encíclicas no tiene precedentes, dando idea de la alarma generada por este problema en nuestro tiempo. Se escriben ríos de tinta sobre este fenómeno y la globalización y sus consecuencias se han convertido en un lugar común tanto en la prensa generalista como en la bibliografía especializada. Sin embargo, y tal vez por ello mismo, nuevamente estamos ante conceptos que requieren una correcta definición, acotando de forma precisa sus verdaderas implicaciones en el campo que nos ocupa en particular, el de la arquitectura, antes de poder trabajar sobre ellos ${ }^{8}$.

\footnotetext{
${ }^{8}$ Los apartados siguientes han servido de base para el artículo del autor "Tradición Arquitectónica, Identidad y Globalización: el problema de la homogeneización del paisaje construido", publicado en la revista Estoa (2018b).
} 


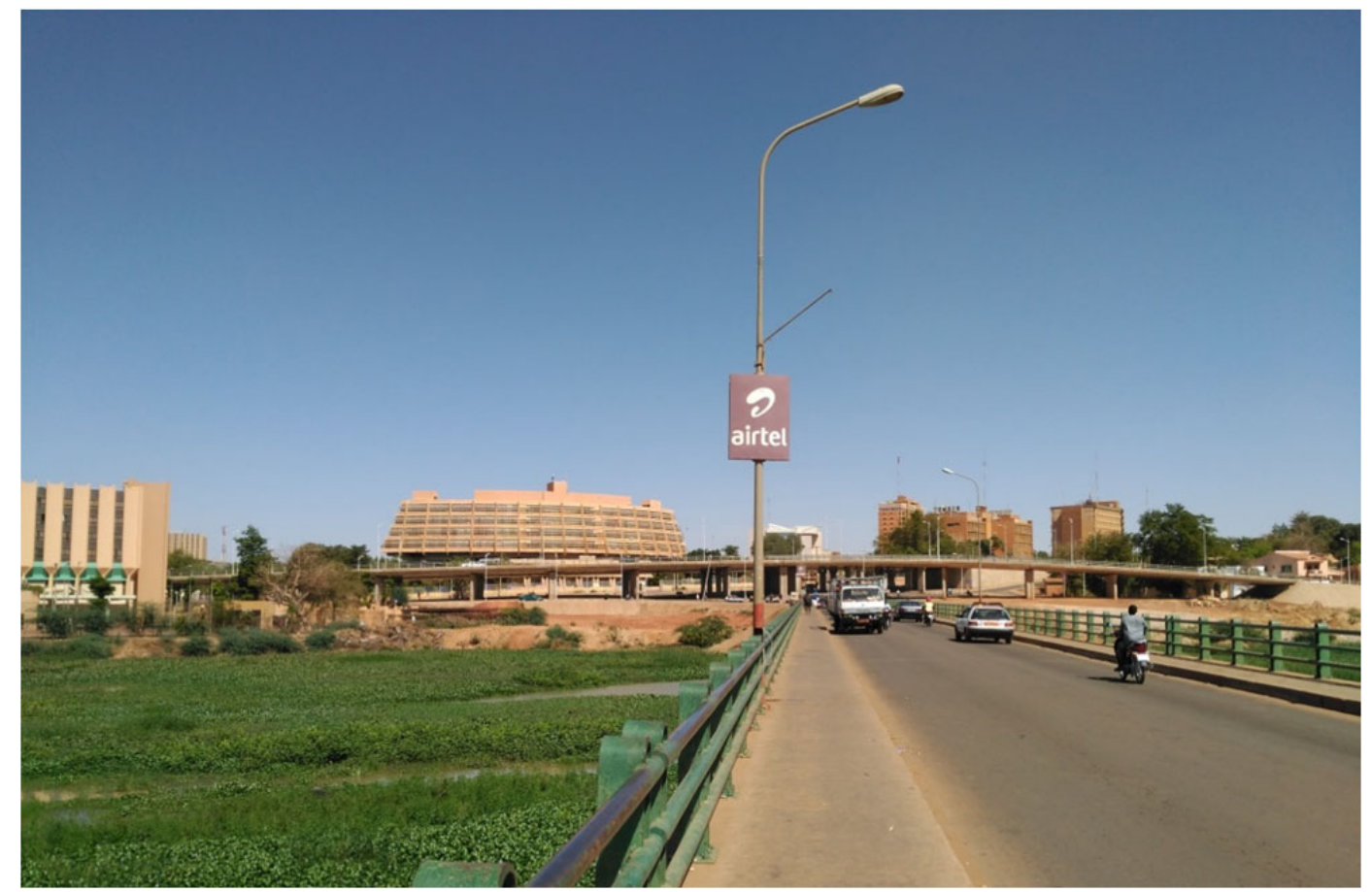

El paisaje urbano de Niamey, Níger, salpicado de megaestructuras de hormigón armado semejantes a las de muchas otras ciudades de todo el globo, es parcialmente "vernacularizado" por sus propios habitantes al poblar de asentamientos informales los espacios libres existentes entre ellas (fotografías del autor, diciembre de 2017)

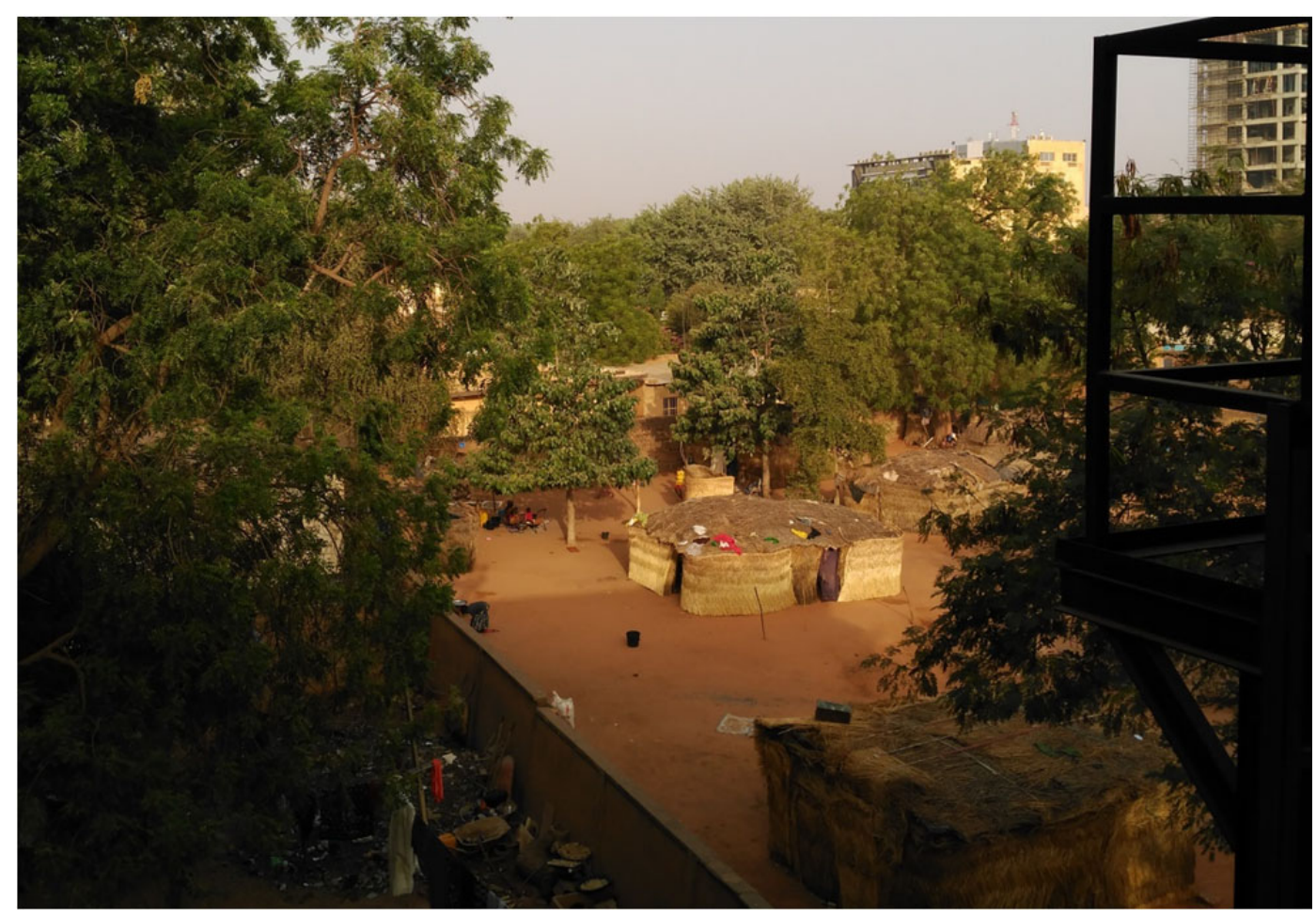




\subsubsection{Globalización}

La contemporaneidad ha visto nacer un fenómeno nuevo, o al menos nuevo en la importancia que ha adquirido, y que ha ido expandiéndose y agudizándose desde su aparición: la percepción de este proceso por una parte significativa de la población mundial como "una uniformización empobrecedora y una amenaza contra la que han de luchar para preservar su cultura propia, su identidad, sus valores" (Maalouf 2016, 120).

Se ha asociado con frecuencia la globalización a términos como Occidentalización, Americanización e incluso "Manhattanización", pero conviene señalar que, más allá de que los Estados Unidos o la propia Nueva York se hayan identificado durante décadas como modelo y símbolo de desarrollo y progreso, la identidad local de las diversas regiones de Occidente, de Estados Unidos, o de la propia isla de Manhattan han sufrido igualmente los efectos de la globalización, diluyéndose progresivamente muchos de sus rasgos distintivos, por lo que ha de ponerse en cuestión dicha asociación.

La palabra globalización se hizo primero común en la jerga económica durante la década de los 60 del pasado siglo, mientras que la popularización de su uso podría datarse en la década siguiente, apareciendo ya con profusión en declaraciones y documentos oficiales durante los años 80 . Los detalles sobre el origen y evolución del uso de este término pueden consultarse en el libro The Globalisation of Modern Architecture. The Impact of Politics, Economics and Social Change on Architecture and Urban Design since 1990, escrito por el arquitecto británico Robert Adam $(2012,59)$. La Recomendación sobre la protección y el papel contemporáneo de las áreas históricas, presentada por la UNESCO en Nairobi en 1976, fue el primer documento internacional sobre el patrimonio arquitectónico en abordar este problema, aunque se refería a él con los términos despersonalizar y estereotipar.

En todo caso, la globalización no es un fenómeno nuevo, sino que desde la aparición de las primeras civilizaciones han existido procesos de mestizaje, asimilación y diferenciación culturales. "La Nueva Era Global es solamente la última manifestación de un proceso de interconexión global que se ha estado desarrollando desde el amanecer de la humanidad" (Adam 2012, 7). 
De este modo, hechos como la romanización de la cuenca mediterránea o la hispanización del continente americano podrían entenderse como grandes impulsos hacia la globalización. Sin embargo, tales procesos de homogeneización han estado históricamente acompañados por procesos de diferenciación o "vernacularización”, y al igual que, por ejemplo, el castellano hablado en México o Argentina adquirió una identidad propia, adaptándose a un contexto cultural diverso, lo mismo ha sucedido siempre con la arquitectura, siendo fácilmente comprobable cómo las tradiciones arquitectónicas hispanas se diversificaron al mezclarse con las tradiciones locales del Nuevo Mundo. Del mismo modo, también hoy asistimos a similares casos de progresiva diferenciación, tal como ha ocurrido, por ejemplo, con las costumbres socio-religiosas en amplias regiones del mundo islámico, o con las lenguas regionales en diversos lugares de Europa.

Ahora bien, qué es pues lo que hace singular esta etapa concreta de este proceso histórico de sucesivas o paralelas homogeneizaciones y diversificaciones culturales y cuáles son sus particulares efectos sobre nuestro entorno construido.

Joseph Stiglitz, Premio Nobel de Economía del año 2001, define la globalización como "la integración más estrecha de los países y los pueblos del mundo, producida por la enorme reducción de los costes de transporte y comunicación, y el desmantelamiento de las barreras artificiales a los flujos de bienes, servicios, capitales, conocimientos y (en menor grado) personas a través de las fronteras" $(2002,34)$. Según esta definición, nos encontramos ante un fenómeno de progresiva convergencia política, económica y cultural. Tanto es así, que, según el propio Stiglitz, el propio concepto de nación-Estado ha sido trascendido por fuerzas económicas cuyo poder y ámbito de actuación superan ampliamente su capacidad para gobernarlas.

Relaciones comerciales, flujos migratorios, intercambios de ideas, etc. no constituyen una novedad de nuestro tiempo, si bien su impacto se ha disparado con el triunfo del capitalismo y el libre mercado. Tales fuerzas de cambio no han de ser pues lo que diferencie este momento de los anteriores, lo que haya convertido la globalización en una preocupación internacional de primer orden. Estos flujos culturales han existido siempre, conllevando, como se ha dicho, tanto procesos de homogeneización como procesos de diferenciación. Las tradiciones locales no han dejado nunca de adaptarse a ellos, cambiando y evolucionando conforme a las necesidades y la mentalidad de la sociedad a 
la que han dado servicio. Así, si una determinada cultura se implantaba en un nuevo territorio, se veía naturalmente abocada a adaptarse a ese nuevo contexto, desarrollando caracteres propios vinculados tanto a la base cultural previa que allí encontraran, en caso de existir ésta, como al propio medio físico existente, con su clima, sus recursos, su geografía, etc.

Para comprender este fenómeno, basta comprobar cómo incluso en los casos más extremos, en aquellos cuya historia nos habla de una superposición constante de oleadas de pobladores, costumbres e influencias culturales heterogéneas, la arquitectura tradicional ha proseguido su particular evolución. Sirvan como ejemplo ciudades como la palestina Hebrón, una tierra en permanente disputa, en la que numerosos pueblos y culturas diversas han ido dejando su huella y en la que, sin embargo, la tradición arquitectónica local no ha hecho sino ir incorporando cada nueva aportación, adaptándola a sus particulares caracteres. Se superponen así en ella armónicamente tanto antiguos edificios de cronología difícil de determinar, como posteriores aportaciones arquitectónicas que incorporan algunos rasgos mamelucos primero y otomanos más adelante.

Dicho lo cual, incluso si aceptáramos la hipótesis de que estuviéramos realmente en los albores de una convergencia cultural absoluta y obviáramos pues la existencia de los procesos diferenciadores que acompañan a estos movimientos convergentes, ésta no implicaría una progresiva convergencia del medio físico.

La homogeneización del entorno construido no es una consecuencia directa de una homogeneización cultural. Un buen ejemplo de ello fue expuesto por Julio Caro Baroja en 1946 en Los pueblos de España (2003, vol. 2, 18-22), donde contrastaba el progresivo desplazamiento hacia el norte de la cultura y la lengua vascas desde el siglo XVI ante el avance de las castellanas con la notable estabilidad de las fronteras entre los diversos tipos arquitectónicos tradicionales durante el mismo período. Casos como éstos pueden encontrarse en distintos momentos históricos en casi cualquier región del mundo. Tal como afirma Marcel Vellinga (2006, 87-90), a pesar de que "la indigenización o vernacularización dinámicas de influencias culturales externas (modernas, formales, globales) ha sido ampliamente ignorada", toda tradición, y todo edificio, se han transformado y actualizado a lo largo de su historia, al igual que lo han hecho su función, 
utilización y significado, sin que por ello hayan dejado de ser tradicionales. Así pues, difícilmente puede ser únicamente la homogeneización cultural, por muy intensa que ésta esté siendo, lo que esté conduciendo hoy a una homogeneización de nuestro entorno construido sin precedentes, ya que procesos de este tipo han sido una constante histórica.

Para prescindir de la construcción y la arquitectura tradicionales, esto tiene que ser, además, factible. Factores como la mecanización y la abundancia de recursos energéticos disponibles tienen que hacer antes posible avanzar en esa dirección. Para dejar a un lado la guía que éstas suponen, recurriendo a una conocida afirmación de Milton Friedman, Premio Nobel de Economía en 1976, debe poderse primero "fabricar un producto en cualquier lugar, utilizando recursos de cualquier lugar, por una empresa localizada en cualquier lugar, para ser vendido en cualquier lugar" (Adam 2012, 78).

Sin embargo, el hecho de que sea factible el abandonar una tradición tampoco lo convierte en necesario. Es decir, en última instancia, para que este cambio se produzca, para que la "mecanización tome el mando", se requiere, además, además de que sea posible, un marco ideológico que lo sancione. Es en este punto donde la búsqueda del "progreso" como fin en sí mismo juega un papel decisivo en el proceso. Sin este aval ideológico, la Nueva Era Global no conduciría ineludiblemente a una arquitectura global, sino que únicamente facilitaría la propagación y posterior vernacularización de determinados modelos culturalmente más aceptados.

Leopoldo Torres Balbás narraba con bellas palabras cómo "el artesano, concienzudo y lento, no puede luchar con las producciones de la fábrica", y añadía: "Su humilde clientela desdeña además por anticuados los muebles fuertes y pesados de los abuelos, los lienzos ásperos y eternos, tejidos en casa, los cacharros hechos por los alfareros del lugar, y las casas viejas en las que vivieron sus ascendientes. Prefieren todas esas cosas frágiles, pretenciosas y efímeras, que tienen una apariencia de lujo burgués y que admiran tras los escaparates de las tiendas ciudadanas (...)”. Sin embargo, este desdén no es algo ineludible ni necesario. Prosigue Torres Balbás lamentando cómo al mismo tiempo "sus productos son acogidos por las clases acomodadas y la moda de lo primitivo y regional impónese. Los objetos mobiliarios cambian de cuadro y pasan a decorar las habitaciones de la burguesía. Anticuarios y chamarileros despojan las casas aldeanas de los fuertes muebles tradicionales, de los lienzos y tejidos transmitidos de generación en generación, 
de las humildes joyas y preseas con que se engalanaban las mujeres en días señalados" $(1988,159-161)$.

Tal como se desprende de este relato, la cultura material tradicional sigue siendo adaptable a las necesidades del presente, y así ha ocurrido siempre con cualquier tradición. Además de una situación que lo posibilite, es necesaria una deliberada voluntad de abandonarla para que se precipite su desaparición progresiva.

La búsqueda de la originalidad como un fin en sí mismo es por ello considerada por diversos autores como una de las principales causas para la desaparición de la tradición. Este proceso fue explicado con notables extensión y rigor por Amos Rapoport (1969: 7), quien señaló también cómo este afán carece de motivaciones prácticas o funcionales, siendo únicamente un impulso cultural.

Siendo pues un fenómeno cultural, podemos volver a afirmar que podría llegar a combatirse, o que podrían paliarse al menos parte de sus efectos, por medio de herramientas también eminentemente culturales. Sin adoptar políticas culturales en esta línea, y en especial medidas formativas, difícilmente cualquier otro tipo de medidas podrán resultar exitosas a largo plazo. Tal como se ha expuesto en el apartado anterior, sin una mentalidad favorable a la conservación y adaptación a nuestro tiempo de una tradición viva, la homogeneización arquitectónica incide y seguirá incidiendo incluso en aquellas regiones donde la continuidad con la tradición es aún hoy la alternativa más sencilla y asequible para edificar. 


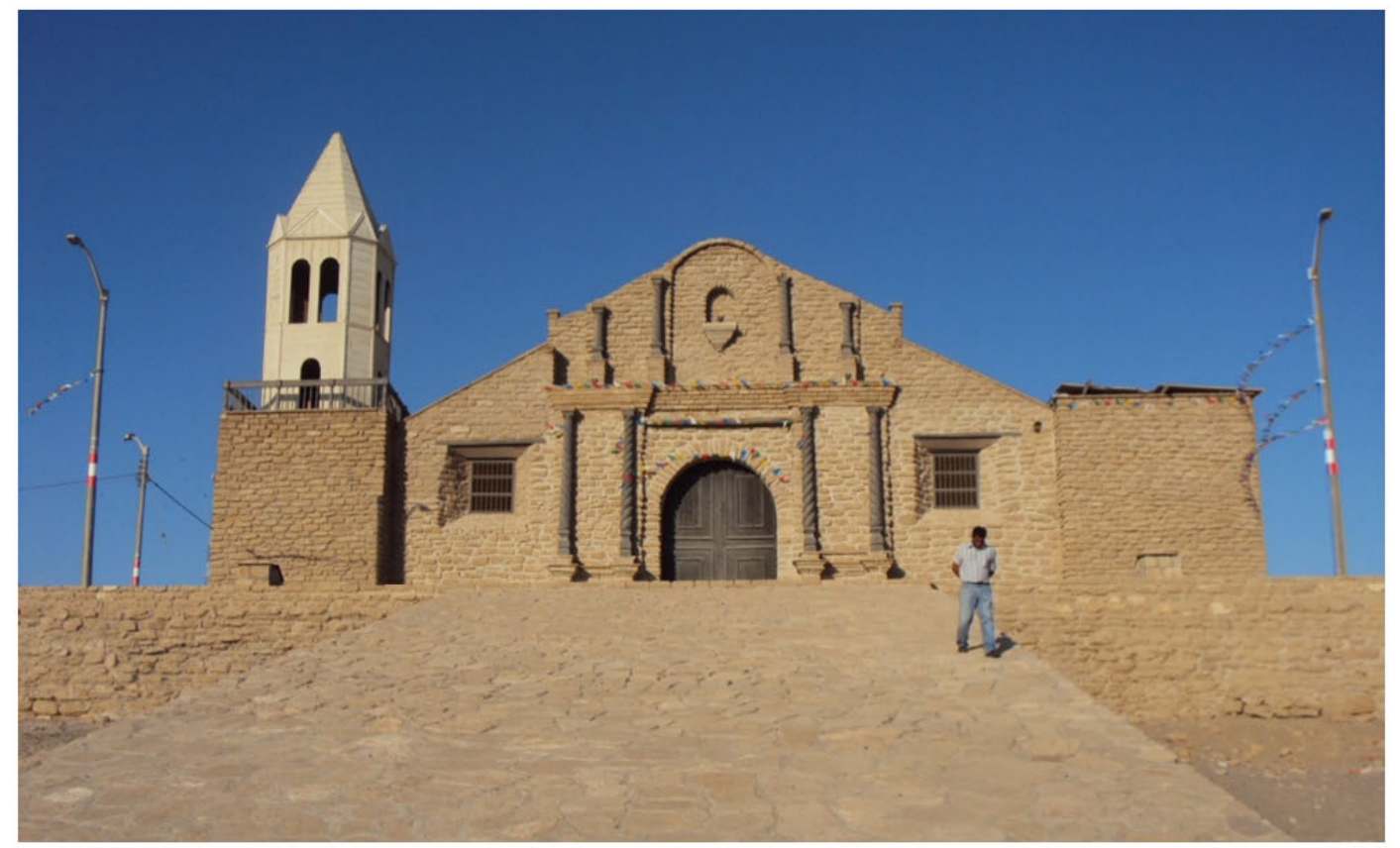

Iglesia de San Lucas de Colán, Piura, Perú, edificada en 1535, y hospedaje rural "Los Horcones" en Túcume, Lambayeque, también en Perú, obra del año 2002 de los arquitectos Jorge Burga Bartra y Rosana Correa: ni las aportaciones culturales foráneas ni la aparición de nuevas funciones y requerimientos prácticos conducen necesariamente a un deterioro de la identidad local (fotografias del autor, agosto de 2011)

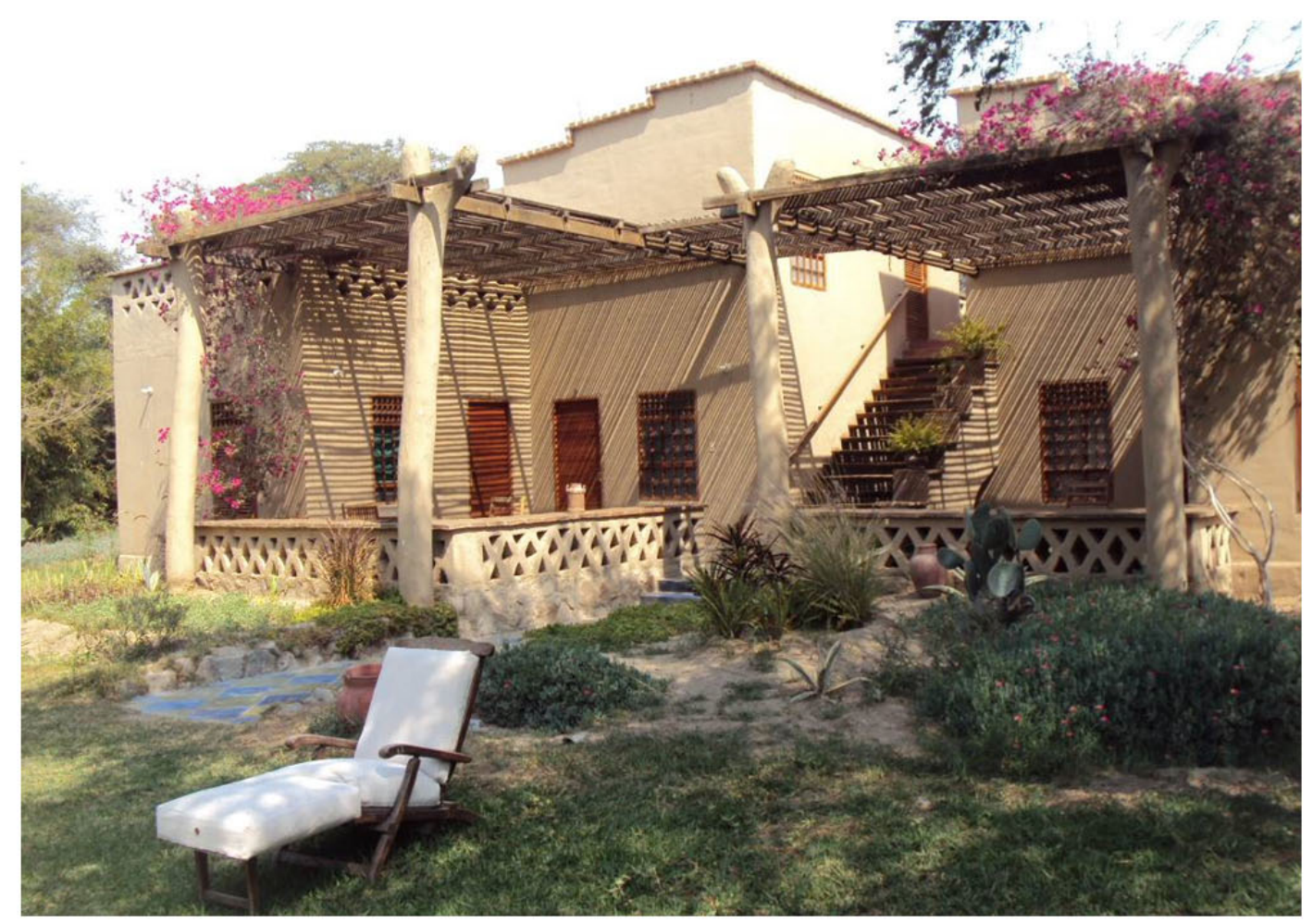




\subsubsection{Identidad}

El concepto de identidad, así como las consecuencias humanas de su deterioro, suelen quedarse al margen de los debates arquitectónicos. Requieren, sin embargo, un análisis detenido, al ser la base de la cuestión estudiada y no ser fácilmente identificables ni cuantificables los efectos negativos producidos por su posible degradación.

El arquitecto noruego Christian Norberg-Schulz, quien a lo largo de su obra se ha ocupado singularmente del estudio del concepto de lugar, lo define como una totalidad compuesta de cosas concretas que determinan su particular esencia: el carácter del lugar, que él denomina genius loci (1976, 3-10). Tomaba este término de los espíritus que en la Antigüedad clásica se asociaban a cada lugar según su particular carácter, aunque en numerosas culturas han existido prácticas similares. En la esencia del lugar encuentra dos funciones psicológicas fundamentales: orientación e identificación, la primera con un significado puramente topológico, la necesidad de saber dónde se está, y la segunda como capacidad para definir la identidad de la persona a través de su identificación con determinados lugares. La función de la orientación fue magistralmente estudiada por Kevin Lynch (2008), siendo comúnmente materia de estudio en las escuelas de arquitectura. La de identificación, sin embargo, no ha tenido hasta hoy la atención que se merece, pese a ser la más importante de las dos, según el propio Norberg-Schulz, para quien, además, esta disfunción ha conducido a la proliferación de arquitecturas alienantes, incapaces de convertirse en lugares en un sentido pleno.

Tal como afirma el arquitecto noruego, en los lugares que podemos considerar como tales reconocemos numerosas referencias que contribuyen a definir nuestra propia identidad, tanto en la configuración general como en los más pequeños detalles de los mismos. Puede añadirse también que estas referencias pueden ser de carácter individual o de carácter colectivo.

Mientras que las referencias individuales dominan el espacio privado, las que sirven al individuo para comprenderse a sí mismo, en entornos urbanos tienen preeminencia las colectivas, al ser las que dan servicio a toda una comunidad. Éstas responden a grupos sociales de distinta escala, desde naciones o ciudades completas, hasta miembros de una pequeña comunidad o vecindario, pasando por grupos más difíciles de delimitar, como los 
practicantes de una determinada religión o los seguidores de unas ideas políticas concretas.

Además, estas referencias pueden ser físicamente patentes, bien existiendo materialmente o siendo huellas de otras destruidas, estar más o menos estratificadas, resultar más o menos legibles: desde edificios, monumentos o partes de ellos, hasta reminiscencias de anteriores tramas urbanas o configuraciones espaciales pretéritas. Pero también pueden subyacer en el paisaje urbano, subsistiendo únicamente en la memoria colectiva, que puede llegar o no a asociarlas, de forma consciente o subconsciente, a un determinado lugar.

Entre estas referencias subyacentes, podríamos también aún establecer una nueva diferenciación. Por un lado, tenemos aquéllas que, pese a su historicidad, han dejado de existir de forma aparente, como pueden ser los recuerdos de ciertos sucesos. Por otro, aquéllas que, aun formando parte de lo mitológico o legendario, o deformada su memoria por el transcurso del tiempo, desempeñan un papel análogo al de las anteriores.

En La idea de la ciudad, publicado en 1963, Joseph Rykwert trata ampliamente del papel de las referencias colectivas al analizar tanto la ciudad romana como sus paralelos en otras culturas, mostrando "la ciudad como un símbolo mnemónico total o, en todo caso, como un complejo de símbolos en que el ciudadano, a través de ciertas experiencias palpables, como procesiones, fiestas estacionales y sacrificios, se identifica con su ciudad, con su pasado y sus fundadores" $(2002,209)$.

La arquitectura tradicional, en concreto, tal como se expone en el ya citado Plan Nacional de Arquitectura Tradicional (2014, 8-9): “es una de las principales señas de identidad de los diversos colectivos que les han dado vida. Cada una de estas arquitecturas constituye un testimonio único e inherente de la comunidad que la ha producido, por ello unifican colectivos y refuerzan vínculos de identidad compartida. La enorme diversidad de matices que cada área geográfica conlleva se manifiesta en lo construido. Ello hace que cada lugar tenga una personalidad arquitectónica propia, y en su conjunto todas ellas reflejen la gran variedad y riqueza cultural de nuestro territorio. La naturaleza de esta arquitectura se basa en una serie de principios que le otorgan un valor relevante para la memoria colectiva del ser humano". Es decir, se trata de referencias colectivas que poseen valor a escala global. 
Por ello, un europeo, por ejemplo, será capaz de reconocer y valorar la arquitectura tradicional de un determinado pueblo tunecino, por alejado culturalmente que pueda estar de sus habitantes, y tales reconocimiento y valoración contribuirán al mismo tiempo a la definición de su propia identidad como europeo.

Si bien es cierto que lo popular tradicional está siempre limitado en cuanto a los recursos o soluciones de los que puede hacer uso, su versatilidad y adaptabilidad a cada particular circunstancia dan lugar a que generen rasgos específicos para cada lugar. Son, por otra parte, estas limitaciones, las que permiten articular una identidad determinada. Para que una arquitectura sea capaz de integrarse en una identidad tradicional, de comunicar un carácter vernáculo, es necesario comprender las consecuencias de esas limitaciones. Y para poder alcanzar ese objetivo, en palabras de Amos Rapoport, es necesaria una predisposición a aprender y utilizar el lenguaje de un lugar, lo que implica la aceptación de su autoridad, la confianza en él, y el uso de un vocabulario común $(1969,5)$.

El sociólogo polaco Zygmunt Bauman ha analizado ampliamente el complejo concepto de la identidad, publicando importantes textos sobre la materia como Modernidad líquida, La ambivalencia de la modernidad o sus conversaciones con Benedetto Vecchi, reunidas en castellano bajo el título de Identidad. Expone en ellos tanto la relevancia que la cuestión de la identidad ha adquirido en nuestro tiempo, como la problemática a la que ha de hacer frente.

Para Bauman, la globalización ha tenido importantes consecuencias sociales, lanzándonos a un perpetuo estado de fragilidad, al haber minado la antigua estabilidad de nuestra identidad.

La definición de esta última es condición indispensable hacer referencia a nuestras relaciones con el resto de la sociedad, pero el proceso globalizador ha hecho que los vínculos que nos conectan a los demás se vuelvan cada vez más inestables, siendo difícil confiar en su pervivencia a largo plazo. Lo que Bauman denomina "estilo consumista" mina progresivamente la durabilidad de la identidad, que sólo una minoría privilegiada puede elegir a voluntad. Explica el sociólogo polaco cómo la oferta de identidades se multiplica imparablemente para esa minoría: la ciudad, el paisaje, la comunidad, la familia, el amor o el trabajo se están convirtiendo en algo mudable, resultando cada vez 
más arriesgado esperar de ellos estabilidad. Este "estilo consumista" supone que todo, siempre que podamos permitírnoslo e independientemente de que se trate de parejas, hogares u objetos, haya de satisfacernos de forma instantánea, requiriendo para hacerlo una constante búsqueda de la novedad (Bauman y Vecchi 2007, 137). Por ello, afirma que hemos pasado de una fase de "modernidad sólida" a otra "fluida", "líquida", que denomina de este modo por analogía con los fluidos, que no pueden "conservar su forma durante mucho tiempo $\mathrm{y}$, a menos que se les vierta en un contenedor ceñido, siguen cambiando bajo la influencia de incluso la menor de las fuerzas" (Bauman y Vecchi 2007, 111-112).

"La herramienta pasada de moda la tiramos a la basura", escribía Le Corbusier en 1923 en Hacia una Arquitectura, llamando a los arquitectos a librarse de la "acumulación bochornosa de viejo detritus" $(1986,13,288)$. Este tipo de discurso, característico de las vanguardias artísticas que más se han afanado en la búsqueda de la novedad, refleja fielmente la exaltación de la "liquidez" de la que habla Bauman.

El afán de cambio y novedad de ese "estilo consumista" hace que los lugares, previamente asociados a tradiciones culturales particulares, con el sentido de continuidad que ello comporta, se transformen progresivamente en los "no lugares" que en 1992 identificara Marc Augé como productos originales de nuestro tiempo, aquellos carentes de una identidad propia ligada a ellos (2008, 83-85). Tradicionalmente espacio y lugar eran conceptos ampliamente coincidentes, mientras que en la actualidad cada vez menos espacios pueden considerarse propiamente lugares (Giddens 1993, 17). Otros antropólogos, entendiendo este proceso en este mismo sentido, lo han denominado “deterritorialización” (Kearney 1995, 553; Hernández Martí 2006). Lo local se desvanece. Nuestras ciudades van convirtiéndose de forma progresiva en las "ciudades genéricas" que aclama el arquitecto holandés Rem Koolhaas (2008a), quien no ha hecho sino plasmar en sus escritos la realidad de la particular cruzada que buena parte de la vanguardia arquitectónica libra desde hace décadas contra los lugares de identidades sólidas. Koolhaas defiende en sus escritos la inevitabilidad de asumir los dictados de la era de lo que él mismo ha denominado "espacio basura" (2008b).

Para la "modernidad líquida" de la que habla Bauman, los productos del pasado, como la propia arquitectura tradicional, sólo parecen aceptables y disfrutables cuando son 
"congelados, catalogados y empaquetados en un buen diseño a la moda" que subraye que han sido ya apartados de su uso cotidiano, que su desarrollo ya se ha detenido (Augé 2008, 83; Bauman y Vecchi 2007, 156). Desecharlos, o rotularlos y "momificarlos" cual objetos de museo se convierten en las soluciones usuales para ellos bajo los dictados de esta ideología. Lo estable, o lo que como la tradición evoluciona tan sólo lentamente, se opone de este modo a lo que se considera el éxito, resultando por ello frecuentemente menospreciado y, sin embargo, por paradójico que resulte, crecientemente anhelado.

La sociología se ha ocupado ampliamente de este problema, planteando que esta paradójica relación se debe a que tendemos a definir nuestra propia identidad no sólo con nosotros mismos, sino también a través de nuestros vínculos sociales y de nuestros lazos con determinados lugares (Relph 1976; Anholt 2009, 157). Por ello, tal como en 1903 explicaba el sociólogo germano Georg Simmel, al tiempo que el hombre ha ido olvidando progresivamente sus tradiciones y renunciando a sus principales referencias locales, ha surgido en él un creciente temor a la pérdida de su identidad, tanto colectiva como individual, ya que sentirse arraigado es quizá una de las más importantes y menos reconocidas necesidades humanas (Simmel 1971; Weil 1952, 41; Arendt 1958, 95-96). Lo que permanece, lo que perdura más allá de la fugacidad la propia vida humana, es fundamental para dotar de solidez al mundo que nos rodea. Los entornos que conservan su condición de lugares se convierten por ello en uno de los más importantes recursos para fundamentar esa solidez, ese arraigo. De ahí que su progresiva desaparición refuerce al mismo tiempo este papel.

En consecuencia, mientras el llamado por Bauman "estilo consumista" continúa destruyendo identidades locales y generando lugares e individuos genéricos, la necesidad que nos mueve a conservar, enriquecer o incluso a inventar estas referencias es tan poderosa que impulsa la realización de enormes esfuerzos intelectuales y materiales con tales fines. Por ello, afirma Hobsbawm, cualquier sociedad, ante la carencia o eliminación de la identidad que le es propia, busca crearla ex profeso, invirtiendo enormes esfuerzos en su preservación, su potenciación o incluso su invención (1983, 8-9).

Un buen ejemplo de ello lo encontramos en lo ocurrido en multitud de lugares donde, tras la destrucción ocasionada por guerras, atentados o catástrofes naturales, por lo general se ha buscado a toda costa restituirles la identidad perdida. 
Esta última cuestión introduce un nuevo concepto en el problema estudiado que requiere también un cuidado análisis previo: el de la autenticidad. Sobre él trata el siguiente apartado.

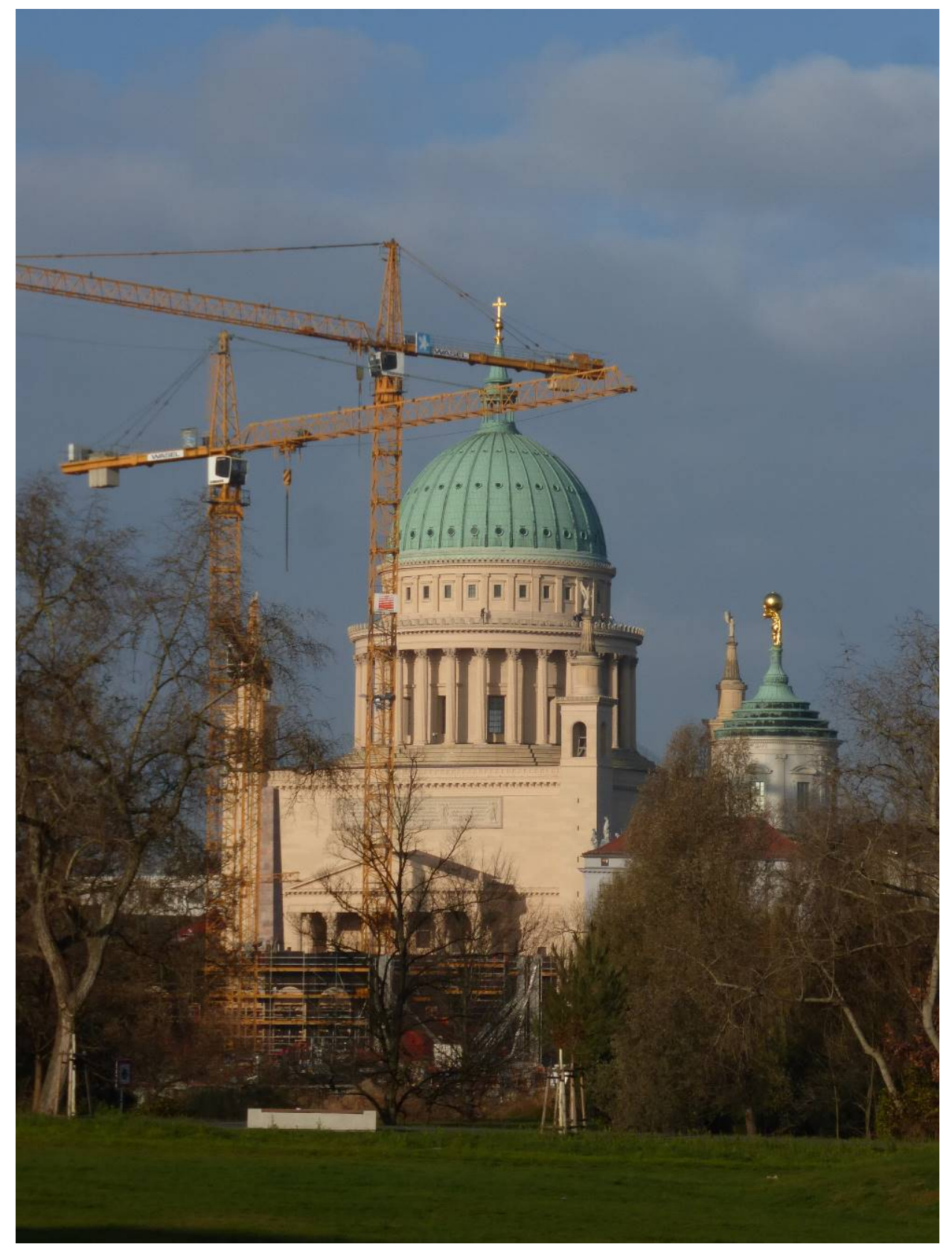

Obras de reconstrucción de la ciudad de Potsdam aún en curso en el entorno de la Iglesia de San Nicolás y el Alter Markt (fotografía del autor, diciembre de 2014) 


\subsection{LA AUTENTICIDAD EN LA ARQUITECTURA TRADICIONAL}

Cuando el arquitecto actual trabaja en entornos donde existe una tradición arquitectónica local con un estado de salud relativamente bueno, apenas se genera debate alguno sobre la validez de optar por la continuidad con esa tradición. Así, han sido unánimes, al menos en Europa, el reconocimiento y admiración ante intervenciones continuadoras de las tradiciones locales más vivas, como pueden ser las de la arquitecto Salma Samar Damluji en Hadramut (Yemen) o las de la también arquitecto y doctora en antropología Salima Naji en Guelmin (Marruecos).

Sin embargo, la polémica en torno al tema de la autenticidad es sumamente frecuente en los casos en los que el arquitecto se enfrenta a contextos cuya tradición arquitectónica se encuentra más degradada o incluso ha llegado a interrumpirse y, como reflejo de ello, las nuevas arquitecturas que tratan de revitalizarla o que simplemente incorporan determinados rasgos vernáculos propios de ella se encuentran ante grandes dificultades para alcanzar el pasado dominio de los recursos del entorno y la hoy a menudo empobrecida técnica que les daba forma.

Pese a ello, de no existir propuestas con una voluntad firme por recuperar la tradición local, adaptándola, como es propio de ella, a las presentes circunstancias, o de continuar utilizando al menos parte de sus caracteres vernáculos, la tradición arquitectónica estaría definitivamente condenada a desaparecer por completo y, a largo plazo, ni siquiera sería posible contemplar sus ya maltrechos vestigios materiales. Conviene analizar, por tanto, cuáles son la naturaleza y las causas de este problema, así como sus consecuencias en el ámbito estudiado.

Las principales críticas sobre la autenticidad de las nuevas arquitecturas desarrolladas desde la tradición o incluso sobre el mantenimiento de arquitecturas tradicionales preexistentes recurriendo a técnicas semejantes a aquéllas con las que fueron ejecutadas están relacionadas con: la ausencia en lo nuevamente edificado de uno de los aspectos más valorados en la cultura europea desde el Romanticismo, el de la "antigüedad material" (Riegl 2008, 49-56); la suposición de que incurren en un falseamiento de la historia; y su hipotética falta de originalidad o de novedad, censurándose estas propuestas como muestras de estatismo o desviaciones de lo que sería apropiado para nuestro tiempo. 
Se consideran así con frecuencia estas actuaciones como retrógradas, anticuadas y, en ocasiones, incluso inferiores en una cadena evolutiva de un progreso asumido como netamente lineal e ineludible.

La última de ellas, la falta de originalidad o de novedad, está estrechamente relacionada con el "mito del progreso infinito", con la ideología de la exaltación del "progreso por el progreso" o de la "novedad por la novedad", de la que ya se ha tratado en apartados anteriores. Sin embargo, se ha expuesto también ya el carácter mutable y dinámico implícito en el propio concepto de tradición, por lentos y sopesados que sean estos cambios, lo que conlleva cuestionar su asociación con la idea de estatismo9.

En este tipo de ataques a la autenticidad de la arquitectura que toma como referencia a la tradición se parte de que éste tipo de obras son siempre una copia o un pastiche. Pero no se producen sólo sobre la que trata de replicar con mayor o menor fortuna edificios del pasado, la que efectivamente entraría dentro de las nociones de copia y pastiche expuestas en apartados anteriores ${ }^{10}$, sino que se hace extensiva a toda arquitectura que trate de trabajar dentro de la tradición, de situarse en continuidad con ella. Por ello, generalmente será etiquetado del mismo modo un edificio completamente original que sencillamente busque entroncarse con la tradición local. Sin embargo, es importante diferenciar entre ambos géneros, discriminando entre la arquitectura continuista y la réplica histórica (Marconi 2007, 133; Adam 2008, 122-123; Younés 2016) o, puesto en términos Unamunianos, entre la Tradición Eterna y lo producido por la tradición en un tiempo y un lugar concretos.

La originalidad que se le niega desde estas opiniones críticas a aquellas arquitecturas que buscan sus referencias en la tradición local no suele negársele, aunque pueda parecer incoherente, a aquéllas que buscan su inspiración en arquitecturas que se hayan alejado ya de la propia tradición. Por ejemplo, un proyecto arquitectónico contemporáneo inspirado en trabajos pretéritos de Mies van der Rohe no será comúnmente censurado por su falta de originalidad, mientras que lo será con frecuencia una arquitectura contemporánea que trate de adaptar a las necesidades actuales la tradición local de, por ejemplo, un pueblo alcarreño, haciendo uso de recursos habituales en ella. Tal contradicción resulta

\footnotetext{
${ }^{9}$ Véase a este respecto especialmente el apartado 2.2.3. del presente estudio.

${ }^{10}$ Tema desarrollado ya en el apartado 2.2.1.
} 
particularmente esclarecedora, mostrando que este rechazo hacia una falta de originalidad o de adecuación a nuestra época de la arquitectura tradicional continúa escondiendo hoy, en realidad, una proscripción ideológica de cualquier obra que se distancie en exceso de los cánones marcados por la vanguardia arquitectónica.

La defendida ruptura con el pasado no es una ruptura con cualquier arquitectura del pasado, sino exclusivamente con las que con mayor claridad busquen dar continuidad a la tradición. Esta limitación no se establece tanto por el uso de una tecnología u otra o de unos materiales u otros, sino principalmente por su imagen. Un edificio contemporáneo cuyas formas, pese a recurrir a determinadas técnicas o soluciones constructivas preindustriales, entren dentro de una imagen que pueda asociarse a novedad o experimentación, rompiendo suficientemente con las características de la tradición, escapará fácilmente a este tipo de críticas. Un buen ejemplo de ello podrían ser los trabajos del arquitecto Francis Kéré, elogiados por la crítica arquitectónica a pesar de recurrir con frecuencia a materiales y soluciones constructivas tradicionales, al ser utilizados por él para generar formas ajenas a esas tradiciones.

En cuanto a los dos primeros grupos de los antes referidos motivos por los cuales una arquitectura tradicional contemporánea es habitualmente tachada de falta de autenticidad, es decir, los relativos a los valores históricos y de antigüedad, son éstos, si cabe, más complejos. Han suscitado, tal vez por ello, constantes debates, sobre todo en el campo de la restauración de monumentos. El dar una respuesta general a estas cuestiones, en caso de ser esto posible, escapa a los objetivos de esta investigación. Sin embargo, conviene esclarecer también las implicaciones de este debate en el ámbito que nos ocupa y, sobre todo, las consecuencias que tiene para el modo de afrontar el mantenimiento de la identidad local tradicional.

Sobre este tema no existen soluciones globales. La primacía del valor histórico o del valor de antigüedad en las intervenciones contemporáneas sobre lo preexistente no es en absoluto universal, ya que, como afirma el arquitecto italiano Giovanni Carbonara, refiriéndose en concreto a las intervenciones de restauración, hoy es comúnmente aceptado que cada una "constituye un caso en sí mismo, no encuadrable en categorías y que no responde a reglas fijadas previamente, pero que debe ser estudiado a fondo cada 
vez, caso por caso, sin asumir posiciones dogmáticas o alineadas respecto a la entera gama de problemas y soluciones que la restauración suscita" $(1998,18)$.

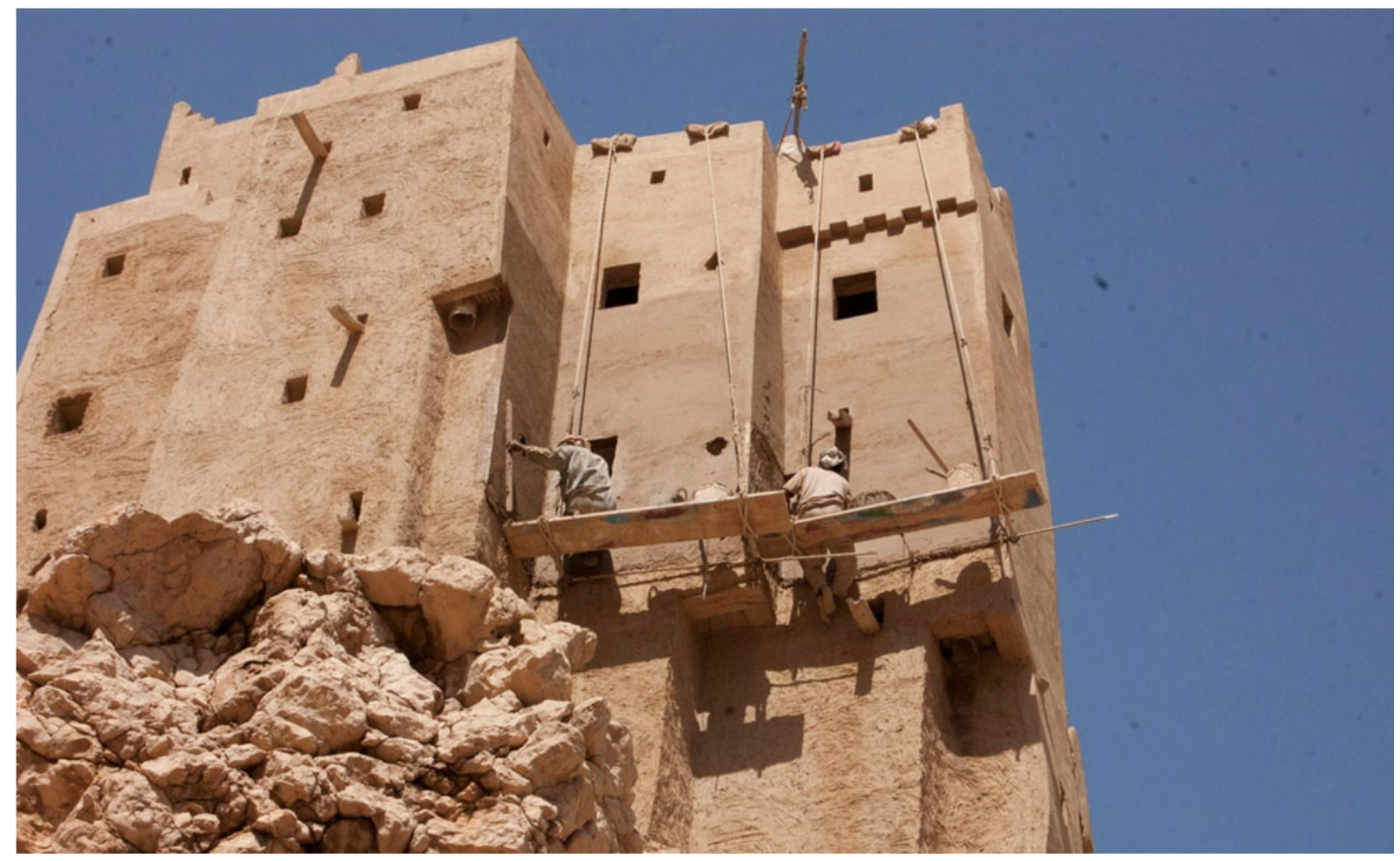

Obras de restauración de la fortaleza Qarn Majid en Dawan, Hadramut, Yemen, según proyecto de Salma Samar Damluji para la Dawan Architecture Foundation y el Prince Claus Fund (fotografía cedida por Salma Samar Damluji), y obras de restauración dirigidas por el autor en uno de los acueductos del Canal de Cabarrús, cerca de Patones, Madrid (fotografía del autor, noviembre de 2015)

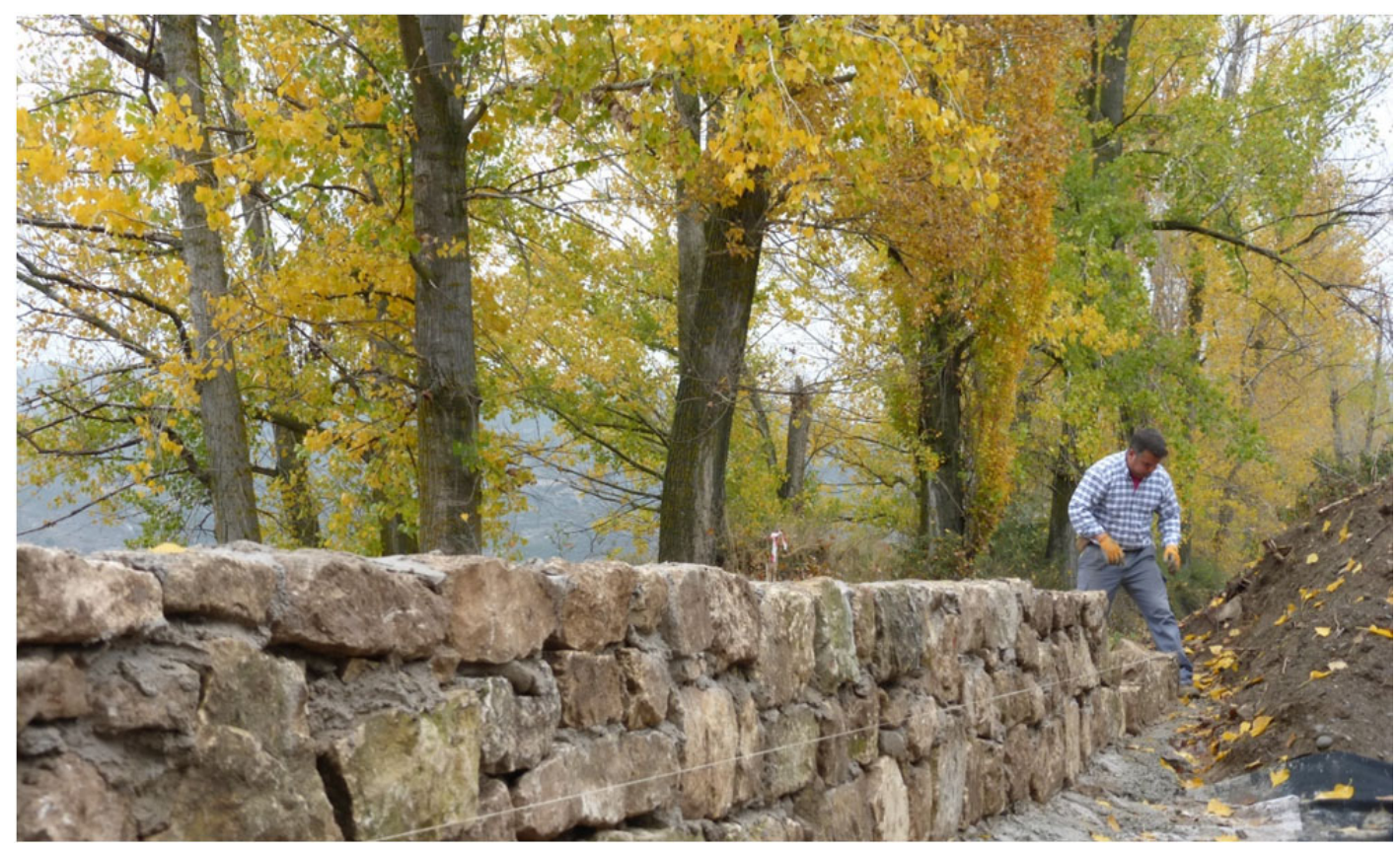


En cualquier tipo de restauración, con frecuencia, para lograr la reintegración de un elemento, la materia perdida o degradada ha de sustituirse por nuevos aportes. Estas ausencias se conocen como "lagunas". Una "laguna" puede ser cualquier materia desaparecida, desde un sillar o la carpintería de una ventana hasta un edificio completo. La Carta de Atenas de 1931 postuló que estas "lagunas", una vez rellenas o restituidas, habían de diferenciarse materialmente con claridad del "original", entendido éste como algo ya cerrado, perteneciente al pasado. Se entendía así cualquier intervención en el patrimonio como una actuación sobre elementos con los que se ha producido en todo caso una ruptura definitiva. La arquitectura tradicional es, sin embargo, en su conjunto, un patrimonio que, para poder ser conservado, necesita permanecer "vivo", ser permanentemente renovado, actualizado y utilizado. La Carta de Atenas recomendaba además utilizar en toda restauración las más novedosas tecnologías, llegando incluso a mencionar expresamente la conveniencia de recurrir al hormigón armado. Iba a menoscabar con ello la continuidad de muchas técnicas y oficios tradicionales, que estaban aún desempeñando un importante papel en el ámbito de la restauración.

Tras la Segunda Guerra Mundial, la rotundidad de estos postulados, que impedían recuperar lo que realmente se valoraba de gran parte del ingente patrimonio perdido durante la contienda, motivó su revisión. Surgieron entonces los teóricos de la denominada "restauración crítica", con Cesare Brandi a la cabeza, quienes comenzarían a matizar estas prescripciones. El propio Brandi en 1963, en su Teoría de la restauración, trataba ya de dar solución a algunos de los problemas a los que habían dado lugar (Brandi 2007,22-23):

La reintegración debe ser reconocible siempre y con facilidad; pero sin que por esto haya que llegar a romper esa unidad que precisamente se pretende reconstruir. Por ello, la reintegración deberá ser invisible desde la distancia a la que la obra de arte ha de contemplarse, pero inmediatamente reconocible, y sin necesidad de instrumentos especiales, en cuanto se acceda a una visión apenas más próxima (...).

Una laguna, en lo que se refiere a la obra de arte, es una interrupción del tejido figurativo. Pero, contrariamente a lo que se cree, lo más grave 
respecto a la obra no es tanto lo que falta cuanto aquello que se inserta indebidamente (...).

Llevado al campo de la preservación de la identidad local, este último comentario resulta especialmente significativo. Basta comprobar lo acontecido en numerosos espacios urbanos de nuestra geografía para confirmar lo acertado de estas palabras. Con frecuencia, un solo edificio que rompa con la tradición local puede dañar gravemente la totalidad del paisaje urbano de una plaza o una calle. Recurriendo a la terminología utilizada por Brandi en el trabajo citado, estos edificios, en lugar de integrarse en la composición en la que han sido insertados, se erigen en figura destacada sobre la misma, pasando lo preexistente a convertirse en un mero fondo que simplemente contribuye a subrayar el carácter diverso y rompedor de lo recién añadido.

La Carta de Venecia de 1964, recogiendo esta herencia, matizaba las contundentes prescripciones de la Carta de Atenas, dando ya prioridad a las soluciones técnicas tradicionales. Sin embargo, el legado de este documento anterior puede observarse aún en su muy debatido artículo noveno, que en su versión final en inglés volvía, incoherentemente y contra la intención de al menos parte de sus principales redactores (Houbart 2014), a enfatizar la necesidad de que cualquier intervención contemporánea lleve "el sello de nuestra época", dando pie a interpretaciones en abierta contradicción con las revisiones críticas anteriores. Los efectos negativos de la mala interpretación que puede hacerse de este artículo noveno han sido expuestos por numerosos autores, incluyendo al principal redactor de la Carta de Venecia, Raymond Lemaire, fundador junto a Piero Gazzola del ICOMOS (International Council for Monuments and Sites) y secretario general y presidente del mismo durante sus primeras décadas, quien lamentaba la redacción final del artículo en cuestión y "los muchos errores que se han perpetrado en su nombre" (Lemaire 1995, 192), cuando la intención inicial del mismo, presente en los borradores previos de la famosa Carta, era hacer precisamente notar que los añadidos que se hicieran al patrimonio habrían de realizarse en sintonía con sus propias formas y materiales, y que pese a ello llevarían inevitablemente también "el sello de nuestra época" (Houbart 2014, 227). Este polémico artículo ha dado lugar a interminables debates e intentos de revisión, los más tempranos de ellos protagonizados por sus propios redactores poco después de su adopción. Un interesante compendio de revisiones críticas de este documento puede consultarse en The Venice Charter Revisited: Modernism, Conservation 
and Tradition in the 21st Century, editado por Matthew Hardy y publicado en 2008. También es de interés la matización del texto de Venecia propuesta desde la International Network for Traditional Building, Architecture and Urbanism (INTBAU): The INTBAU Venice Declaration on the Conservation of Monuments and Sites in 21st Century, consensuada y ratificada por los miembros de la red internacional en el año 2007.

Tal como planteara Antoni González Moreno-Navarro, quien fuera Jefe del Servicio de Patrimonio Arquitectónico Local de la Diputación de Barcelona (1997, 22), desde la generalización de las teorías de la conocida como "restauración crítica" se reconoce internacionalmente la existencia de una dualidad entre la "autenticidad arquitectónica" y la "autenticidad material", estando siempre ambas en un difícil equilibrio.

Esto no viene sino a dar continuidad a la antigua Paradoja de Teseo, según la cual los antiguos atenienses se plantearon esta misma dicotomía al enfrentarse al siguiente dilema: el viejo barco en el que Teseo había regresado a Atenas se conservaba como una reliquia en la ciudad. Con el paso del tiempo, sus piezas fueron deteriorándose y muchas hubieron de ser reemplazadas por otras análogas. La forma barco seguía siendo la original, pero no lo era ya su materia. La cuestión planteada fue si, dada esta circunstancia, se trataba o no del mismo barco. Las respuestas a ella resultaron ser irreconciliables y parecen seguir siéndolo en la actualidad.

Sin embargo, el propio González llamó la atención sobre el impacto negativo del modo en que, desde la extensión de los planteamientos de la Carta de Atenas, se venía dando prioridad generalizada a la primera de las categorías por él diferenciadas, la "autenticidad material", frente a la segunda, la "autenticidad arquitectónica" (1997, 22). Abogando por equilibrar ambas, afirmaba que "son más auténticos un muro de carga o una bóveda que trabajen tal y como fue previsto originalmente, aunque todos sus ladrillos, mampuestos o dovelas sean nuevos, que un muro o una bóveda cuyos elementos hayan sido materialmente conservados pero que hayan perdido su capacidad mecánica (...)", y hacía hincapié en que "los valores genuinos de una arquitectura (forma, espacio, sistema estructural, materiales, texturas, etc.) que hayan sido acreditados mediante la investigación científica como originales pueden ser tenidos por auténticos y merecen ser conservados (o recuperados, si se perdieron), y transmitidos a las futuras generaciones. Y al igual que la recuperación de la autenticidad documental del monumento, puede 
plantearse la de la autenticidad funcional o significativa, casi siempre estrechamente relacionadas".

Esta ampliación del concepto de autenticidad favorece el posible desarrollo de cualquier proyecto de recuperación o revitalización de la arquitectura tradicional, pero se enfrentaría aún a la resistencia de los defensores de la ruptura con el pasado, entre los que han de destacarse los autodenominados conservacionistas. Sus objeciones anti-restauradoras encuentran aún su reflejo en algunas normativas y declaraciones, incidiendo en gran medida en el problema estudiado. Su crítica no se dirige contra cualquier intervención que altere la forma y el significado del patrimonio arquitectónico, sino exclusivamente contra aquellas que pretendan continuar una tradición que consideran en todo caso extinta y cuya recuperación es para ellos un falseamiento de una historia, que ha roto de forma definitiva con cualquier continuidad con la arquitectura del pasado (Dezzi Bardeschi 2006). Mientras la introducción de un elemento que utilice el lenguaje o las técnicas constructivas de los precedentes es considerado por ellos reprobable, la única alternativa válida es para la mayoría de ellos introducir elementos marcadamente rupturistas e indudablemente contemporáneos, alteren o no éstos, en mayor o menor medida, la composición y el significado de lo preexistente, y sin reparos en que, siguiendo de nuevo la terminología de Brandi, lo preexistente pase a convertirse en fondo sobre el que destaque la figura de estos nuevos añadidos.

Este género de argumentos se reivindican comúnmente como herederos ideológicos del inglés John Ruskin, por lo que conviene acometer un estudio detenido de las teorías de este último sobre la tradición arquitectónica y la conservación del patrimonio, aunque se tratará con mayor amplitud de su visión general de la arquitectura más adelante.

Para John Ruskin, cuyas ideas sentarían las bases para el surgimiento del movimiento de las Artes y los Oficios, la belleza de una obra residía en la cantidad y calidad del esfuerzo físico e intelectual vertidos en ella, por lo que cualquier alejamiento del trabajo artesanal suponía un grave deterioro de la misma. Así lo entendieron también sus más directos seguidores. Su noción de compromiso social pasaba por favorecer el recurso a los oficios tradicionales, a los que propugnaba insuflar nueva vida adaptándolos a los requerimientos de su tiempo (Ruskin 2004). Pero, para Ruskin, la calidad de un trabajo, no dependía sólo de la cantidad de "sacrificio" o de "vida" vertidos en él, sino también del dominio previo 
de la tradición. En su Lámpara de la Obediencia defendió la importancia de trabajar e innovar según los dictados de lo avalado por ella, resaltando que cualquier adición o cambio sobre la tradición no ha de ser nunca un objetivo en sí mismo, ya que esos cambios "son mucho más obra del tiempo y de las multitudes que de inventores individuales" (2007, 180-184).

Es claro, por tanto, que la mayor parte de las intervenciones que proclaman ser "conservacionistas", introduciendo en entornos tradicionales elementos de marcada apariencia tecnificada e industrial en base a ello, habrían sido consideradas por Ruskin el extremo de la degradación y la inhumanidad.

Por otra parte, sin embargo, tal como aducen quienes reivindican al inglés para respaldar la defensa de la ruptura con el pasado, éste rechazó sin ambages las restauraciones que pretendían recuperar pasadas glorias, al considerar que carecían del espíritu y de la maestría de los artesanos que habían dado lugar a ellas. Reclamaba, por el contrario, la restauración de ese espíritu y esa maestría para las obras de su tiempo, que esperaba que algún día pudieran alcanzar la elevación espiritual y el nivel de dominio de los oficios artesanales que los poderosos gremios del Medioevo habían llegado a desarrollar.

Contra lo que suele pensarse, Ruskin nunca criticó las obras del arquitecto francés a quien se cita habitualmente como su antítesis, Eugène-Emmanuel Viollet-le-Duc ${ }^{11}$. Sí atacó, por el contrario, otras muchas obras coetáneas, pero siempre en los mismos términos, censurando la bajeza del trabajo artesanal realizado al contrastarla con el que se pretendía replicar. De esta manera, podrían entenderse los radicales postulados de Ruskin como una de las más extremas reivindicaciones hasta la fecha de la necesidad de recuperar los procesos de imitación e innovación propios de la tradición, siendo precisamente esto lo que le llevó a rechazar la copia parcial y vulgarizada de modelos pretéritos. Según su singular criterio, la copia debía considerarse sólo una vía hacia el aprendizaje y la reinstauración de los conocimientos perdidos, y realizarse, en sus propias palabras, "sin admitir una sola alteración de un caveto, en la anchura de un filete. Más adelante, una vez que la vista esté acostumbrada a las formas y ordenaciones gramaticales, una vez el

${ }^{11}$ De hecho profesó una gran admiración por él, al menos en categoría de intelectual, y le citaba con frecuencia, en especial en sus últimos escritos, llegando a dedicarle un extenso elogio en The Pleasures of England (1908). 
pensamiento esté familiarizado con todas ellas, cuando podamos hablar con naturalidad esta lengua muerta y aplicarla a cualesquiera ideas que queramos exteriorizar, es decir, a todo propósito práctico de la vida; entonces, y sólo entonces, se podrían permitir licencias; cabría conceder a la autoridad individual cambios o añadidos en las formas recibidas, siempre dentro de ciertos límites" (Ruskin 2007, 183-184).

Así pues, reivindicar las ideas de Ruskin para defender la proscripción de la tradición arquitectónica implica una vulgarización o incomprensión de sus ideas. Se adoptan con frecuencia así para avalar precisamente lo que tanto él como sus seguidores trataron de combatir con mayor ahínco: la sustitución del hombre por la máquina en la génesis de la cultura material.

Por otra parte, el absoluto rechazo mostrado por Ruskin a la intervención en el patrimonio, hoy por hoy, dada la amplitud de la concepción actual del mismo, conllevaría una problemática muy diversa a la de aquel tiempo. Entre otras diferencias fruto de la evolución del concepto de patrimonio, implicaría hoy un extensivo inmovilismo. Esto, enfrentaría dos aspectos de sus propias ideas, su rechazo a la "restauración" chocaría contra una de las principales aspiraciones del propio autor inglés: la de la revitalización del trabajo artesanal tradicional. Tal como afirma Marcel Vellinga (2006, 92), plantear que los edificios tradicionales no se alteren o actualicen en modo alguno, abogando por su rígida conservación y condenando cualquier cambio $\mathrm{o}$ adaptación como una contaminación o adulteración de los mismos, es convertir a estas tradiciones en algo destinado a desaparecer.

Al margen de ello, es claro que la constitución material, técnica e incluso en ocasiones el funcionamiento estructural de una intervención arquitectónica contemporánea difícilmente puede llegar a ser una réplica exacta de las utilizadas en momentos pretéritos (Jokilehto 1999, 2-3), por mucho que esa fuera la voluntad de su autor. Una arquitectura contemporánea basada en una tradición local tendría sumamente complicado el llegar a ser una reproducción fiel de la de otro tiempo. Se trata de algo inherente al propio concepto de tradición. La materialidad y la forma de una obra actual que busque seguir una determinada tradición no serán las mismas que las de las obras realizadas hace uno o dos siglos, al igual que tampoco fueron las mismas en las intervenciones de hace uno o dos siglos que en las de diez o doce siglos antes. Es decir, una casa tradicional del siglo 
XVIII, por ejemplo, no era una réplica idéntica de su equivalente en el siglo XII. Y no sólo no pretendía serlo, sino que no hubiera podido alcanzar tal objetivo. Las condiciones eran diversas. Su funcionamiento necesariamente también lo era. Y, sobre todo, la cultura de sus diseñadores y ejecutores era ya otra. A esto precisamente se refería la ya citada redacción original de la Carta de Venecia, tergiversada en su versión final.

La tradición se ve siempre reinterpretada por nuestra cambiante mirada hacia ella. Seleccionamos constantemente lo que de ella queremos fijar, preservar o potenciar, lo que queremos restaurar y lo que queremos sustituir. Cuando se busca trabajar conforme a una tradición, se trata siempre de una tradición relativa, condicionada tanto por nuestra cultura actual como por las que nos han precedido, es decir, de una tradición viva, en constante transformación.

Cualquier conjunto tradicional, al igual que todo edificio histórico, con el paso del tiempo y tras sucesivas decisiones de conservación y restauración, no deja de ser hasta cierto punto también una interpretación contemporánea de la herencia del pasado. Como planteaba el arquitecto Aldo Rossi, "la forma de la ciudad es siempre la forma de un tiempo de la ciudad" $(1982,104)$. O, como lo describió en 1985 el historiador David Lowenthal, en su reconocida obra The Past is a Foreign Country: "el pasado no está ahí atrás, en un separado y extraño país; es asimilado en nosotros mismos, y resucitado en un presente permanentemente cambiante" (410-12).

Independientes del desarrollo de las teorías de la restauración, las tradiciones han seguido mutando y evolucionando, adaptándose a los también cambiantes condicionantes del contexto histórico-geográfico en el que se desarrollaban. El común mantenimiento de cualquier edificio o artefacto ha requerido siempre, además, actuaciones sucesivas para adaptarlos a los cambiantes requerimientos de cada época.

No existe un modelo estático de arquitectura tradicional, no existe un "original", sino que lo que ha llegado hasta nosotros es el resultado de diversas aportaciones que han ido moldeándola durante siglos, dando lugar a diversos resultados en cada momento, y a obras que recogían el legado de un sinnúmero de transformaciones que reflejan esa misma evolución. Así pues, no por el hecho de haber cambiado, por el hecho de haber sido siempre diversa al precedente, sucesivamente mejorada o empobrecida respecto a él, o por 
muy continuistas que fueran las intervenciones sufridas, dejaba de ser auténtica, ni se considera hoy que no lo sea. Como se señalaba al comienzo de este apartado, en los casos en los que existe una crítica hacia la falta de autenticidad de una tradición arquitectónica, ésta se limita únicamente a las arquitecturas contemporáneas que tomen como base una tradición ya debilitada o incluso desaparecida.

Sin embargo, es fundamental poner en este punto de relieve que el rechazo a que una arquitectura contemporánea pueda tomar como base para su desarrollo tradiciones arquitectónicas en estado ya precario implica también, atendiendo a lo expuesto en anteriores apartados de esta investigación, el rechazo a poder preservar a largo plazo la identidad local tradicional de una importante parte de las regiones del mundo, con la consiguiente pérdida cultural que ello implica.

Ni siquiera una postura que podría considerarse tan extrema en este aspecto como fue la de John Ruskin negaba esta posibilidad. Es más, como hemos visto, era para él, por el contrario, una urgente necesidad el comenzar a trabajar de nuevo en base a la tradición.

La aceptación de la necesidad de desarrollar una arquitectura tradicional contemporánea para garantizar su preservación futura no implica que se rechacen otros valores de este patrimonio. Tampoco que se consideren prescindibles o reemplazables los cada vez más escasos ejemplos de él que del pasado hemos podido conservar. De hecho, cada uno de esos vestigios se ha erigido hoy en un valioso depósito de conocimientos sobre el habitar un determinado territorio, atesorados hasta en el menor de los detalles de su constitución. La preservación de estos elementos sería pues igualmente prioritaria si se pretendiera acometer con éxito la recuperación progresiva de al menos parte del saber del que son depositarios. Una vez perdida la tradición oral, sólo las muestras heredadas de la cultura material producida por medio de ella pueden servir como fuente de conocimiento para intentar recuperarla, o recuperar al menos algunos de sus principales valores.

Sea como sea, compatibilizar la noción de autenticidad con la continuidad que la arquitectura y los oficios tradicionales requieren para su conservación efectiva a largo plazo parece ineludible. Habrá de respetarse por principio la integridad del patrimonio material heredado, pero sin rechazar al mismo tiempo las operaciones que aseguren la continuidad de la tradición que lo produjo. 
En otras culturas y otras arquitecturas este debate sobre la autenticidad es prácticamente inexistente, principalmente en aquellas cuyo patrimonio es por lo común materialmente menos duradero, como puede ser el construido en madera. Cuando el patrimonio a conservar requiere más frecuentes restituciones, se produce una indiscutida primacía de la "autenticidad arquitectónica" sobre la "autenticidad material" (Larsen 2000; Vegas y Mileto 2002, 14-41). Tampoco se producen fuertes disensiones en el campo de la restauración de jardines históricos, cuya materia es esencialmente efímera, e incluso apenas existen en el ámbito de la restauración de la arquitectura del Movimiento Moderno, por lo general igualmente más perecedera (Rivera Gámez 2012, 215-225).

Tales contrastes han conllevado una nueva revisión crítica del problema, tal como refleja el abierto concepto de autenticidad recogido en el Documento de Nara sobre la Autenticidad de 19994. Definida ahora como "esencia" del patrimonio, trata dar cabida así a otras realidades y sensibilidades, trascendiendo la idea de la preponderancia de la "autenticidad material" y apartándose de pasadas restricciones "conservacionistas":

Dependiendo de la naturaleza del patrimonio cultural, su contexto cultural, y su evolución a través de tiempo, los juicios de autenticidad pueden relacionarse a la validez de una gran variedad de fuentes de información. Los aspectos de las fuentes pueden incluir forma y diseño, materiales y substancia, uso y función, tradiciones y técnicas, la localización y contexto, espíritu y sentimientos, y otros factores interiores y exteriores.

La aceptación expresa de todas estas concepciones diversas de la autenticidad encontraría su reflejo en diversos documentos internacionales posteriores, que irían por lo general matizando el mencionado artículo noveno de la Carta de Venecia y reconociendo progresivamente la importancia del papel de la conservación del patrimonio inmaterial en el entendimiento del problema de la autenticidad.

Consecuentemente, numerosas asambleas y documentos internacionales iban a reflejar esta nueva sensibilidad hacia la cultura inmaterial y, con ella, hacia las identidades tradicionales. Además de los textos ya citados en anteriores apartados, se sucederían así documentos como la Declaración Universal de la UNESCO sobre la Diversidad Cultural 
de 2001, la Convención para la Salvaguardia del Patrimonio Cultural Inmaterial de 2003 o la Convención sobre la Protección y la Promoción de la Diversidad de las Expresiones Culturales de 2005. En 2008, con motivo de la XVI Asamblea General de ICOMOS, celebrada en la ciudad de Quebec, se adoptó la Declaración de Quebec sobre la Preservación del Espíritu del Lugar, en la que se afirma que "el patrimonio cultural inmaterial otorga un significado más enriquecedor e íntegro al patrimonio como un todo; y debe ser tomado en cuenta en todas las legislaciones relacionadas con el patrimonio cultural, y en todos los proyectos de conservación y restauración", y reconoce "que esencialmente las personas son quienes transmiten el espíritu del lugar y que esa transmisión es parte importante de su conservación”, así como que son las comunidades locales las que "están en mejores condiciones para salvaguardarlo y deberían estar directamente involucradas en todos los esfuerzos que se realicen".

Pese a ello, sigue manteniéndose la vigencia la Carta de Venecia como la más conocida referencia internacional sobre la materia, sigue resonando aún su artículo noveno, y la revisión y matización de sus principios se traslada sólo lentamente a leyes, normativas y administraciones encargadas de velar por el patrimonio, por lo que la transmisión de los nuevos conceptos expuestos tanto hacia el campo de la práctica arquitectónica como hacia la sociedad en un sentido más amplio es aún relativa. 


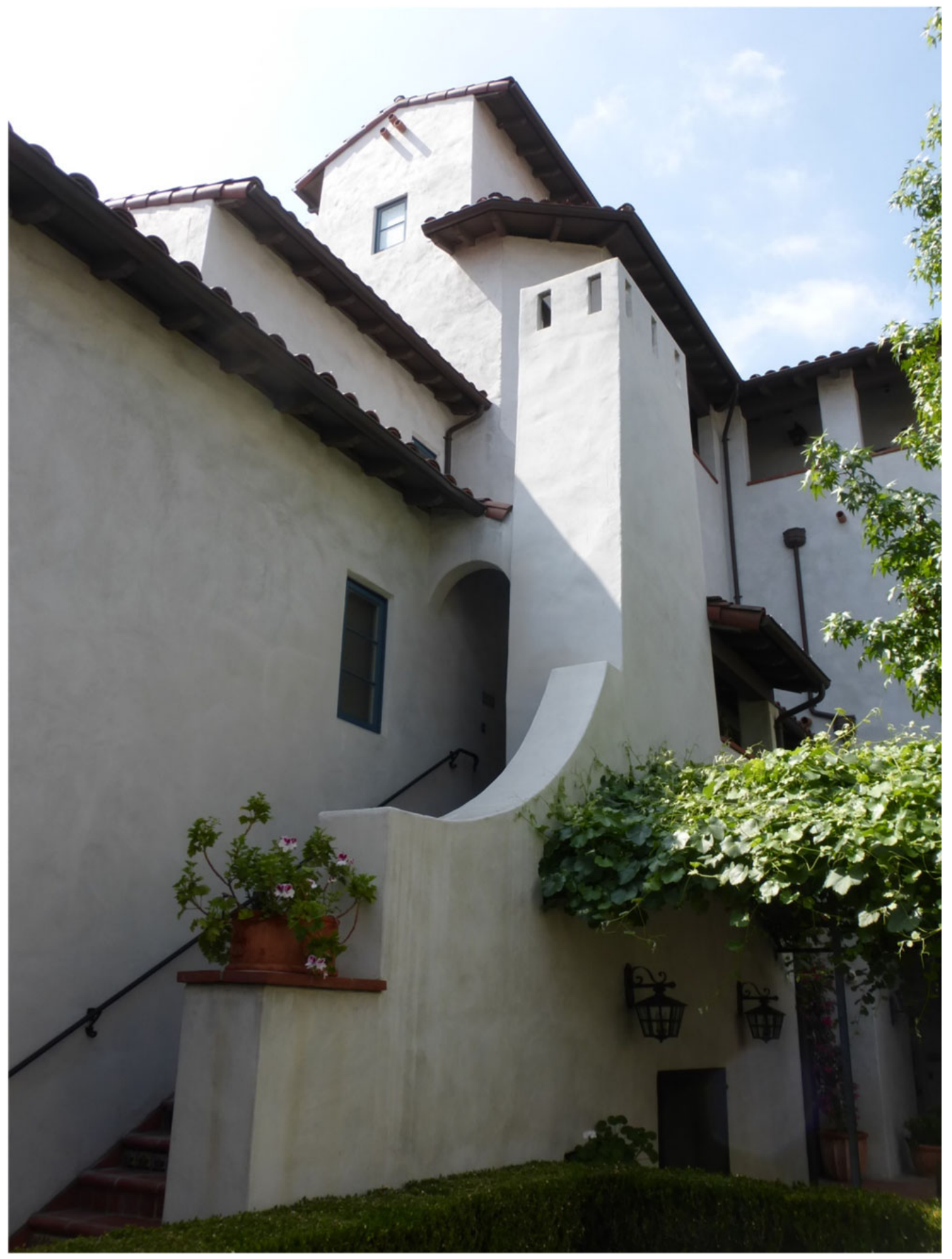

Arquitectura vernácula californiana contemporánea: Granada Court, Pasadena, California, obra de Moule \& Polyzoides (fotografía del autor, mayo de 2016) 


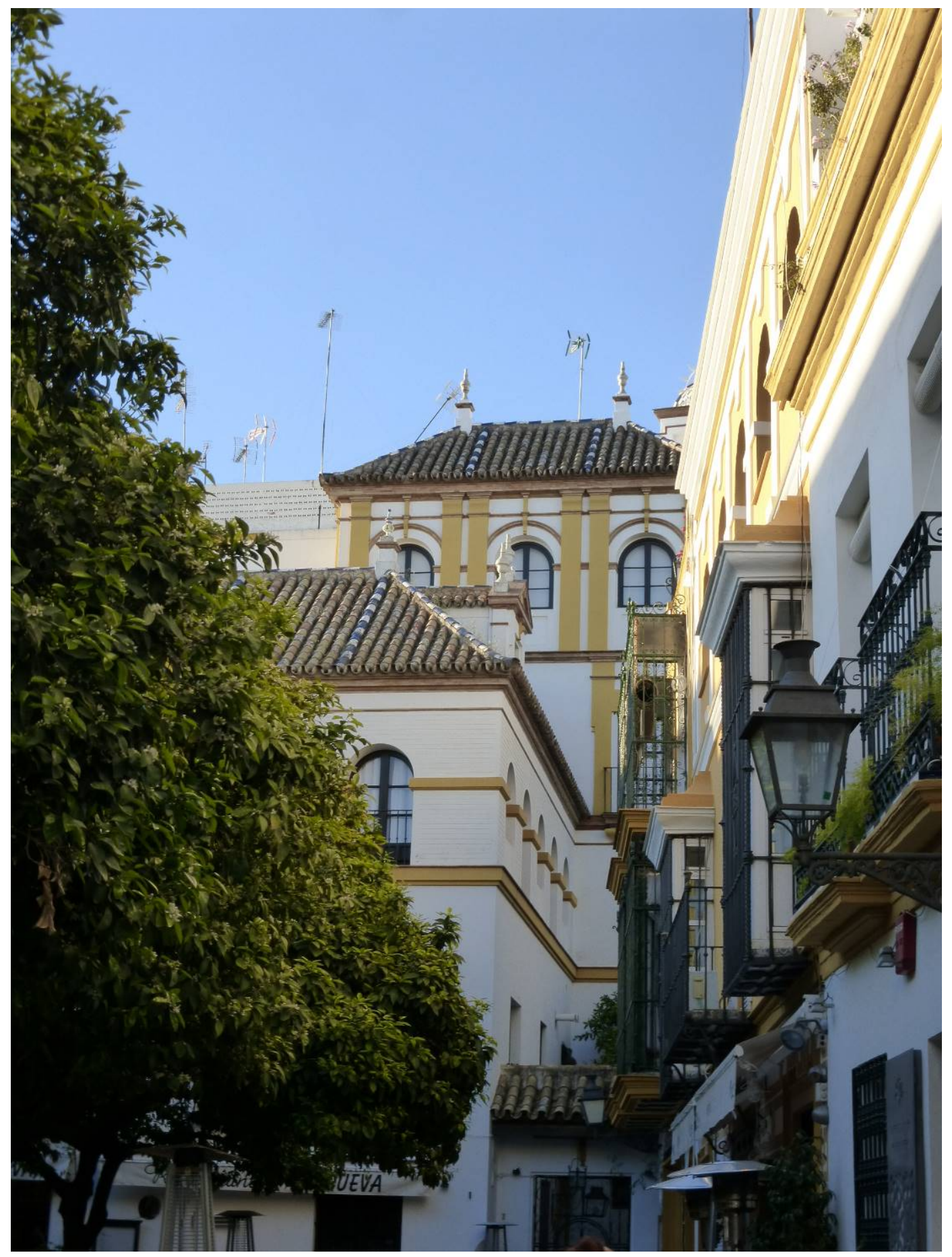

Arquitectura vernácula sevillana contemporánea: Casa de Fernando Chueca Goitia, Sevilla, obra de Rafael Manzano Martos (fotografía del autor, marzo de 2016) 


\section{DESARROLLO DEL PROBLEMA DE LA PRESERVACIÓN DE LA IDENTIDAD LOCAL $Y$ SU RELACIÓN CON OTRAS REIVINDICACIONES DE LA RECUPERACIÓN DE LA TRADICIÓN ARQUITECTÓNICA}

Llegué a una aldea donde no vi (ni lo esperaba ver en aquel momento) ningún edificio moderno, aunque muchos de ellos eran casi nuevos, sobre todo la iglesia, que era inmensa y cuya belleza, elegancia y finura me dejaron embelesado. El coro y el presbiterio eran tan nuevos que el polvo de la piedra todavía permanecía blanco sobre la hierba veraniega que crecía debajo de las esculturas de las ventanas. Las casas estaban construidas prácticamente de una estructura de roble recubierta de una mezcla de arcilla, paja y yeso encalado, aunque algunas de ellas tenían los pisos inferiores hechos de mampostería y las ventanas y las puertas de piedra caliza. En todas ellas había curiosas esculturas que, aunque en buena parte ya estaban viejas y desgastadas, tenían la misma apariencia de limpieza, pulcritud e incluso de belleza que había encontrado en cada detalle de los campos cercanos. El tejado de las casas estaba cubierto de ripias de roble, ya envejecido y gris como la piedra, aunque había uno recién construido que aún conservaba su color amarillo y pálido.

William Morris reflejaba así en el Sueño de John Ball (2007, 13-14), publicado en 1888, su propia visión idealizada de la ciudad preindustrial, entendiendo ésta como un conjunto dotado de la salubridad, la funcionalidad y la belleza de las que carecían las modernas creaciones urbanas de su tiempo. Para él, el origen de estas cualidades residía en la vigencia en ellas de sus tradiciones constructivas, arquitectónicas y urbanísticas. $\mathrm{Su}$ temprana mirada hacia el pasado en busca de soluciones para los problemas que afectaban a la arquitectura y, con ella, a la sociedad de su tiempo no ha perdido actualidad. Por el contrario, se trata de una tendencia en auge, al estar estrechamente relacionada con los profundos cambios sufridos por nuestro medio físico. Existe un creciente interés por perpetuar su diversidad. Sobre los medios para lograrlo se han desarrollado múltiples teorías, habiéndose puesto ya algunas en práctica con mayor o menor éxito. 
Aún hoy no hemos despejado la incógnita de cómo acometer este problema de forma satisfactoria. Sin embargo, varias décadas de investigaciones, polémicas y aplicaciones prácticas de posibles soluciones nos preceden. Su exposición y análisis generales constituyen una cuestión de gran utilidad profesional y ha de preceder al estudio pormenorizado objeto de esta tesis. Si las formas de entender la tradición arquitectónica han sido muy diversas, también lo han sido los mecanismos propuestos para su preservación o para la restauración de algunas de las cualidades que se le atribuyen.

Así, por ejemplo, el arquitecto Heinrich Tessenow planteaba en 1919, con gran pesimismo, que, para que la ciudad tradicional pueda imponerse de nuevo, tal como él mismo anhelaba, quizá fuera necesario que nuestra civilización sufra "algo así como una lluvia de azufre, y su próximo florecimiento sólo sea posible dentro de un esplendor que tal vez ahora sólo podemos comprender vagamente y que requiere, probablemente, de pueblos que hayan transitado a través del infierno" $(1998,149)$. Los detractores de la tradición arquitectónica, sin embargo, han negado siempre la existencia de este problema. Este pensamiento ha sido característico de un gran número de arquitectos durante ya prácticamente un siglo. De este modo, reputados profesionales, como Le Corbusier, sostenían que esta clase de aproximaciones ven "dilema y necesidad de optar entre armonía (asegurada) y aventura (riesgo) cuando precisamente la historia humana, y más precisamente la de la arquitectura, nos presenta en todos los lugares del mundo la evitación del dilema precisamente cuando la armonización está presidida por el espíritu de la época" $(1980,50)$.

Ante esta disparidad de visiones, en los albores del siglo XXI, sumidos en el actual contexto de crisis energética, económica y, sobre ellas, de nuestra identidad, los diversos argumentos al respecto sostenidos hasta el momento, así como los resultados de su aplicación, merecen ser ponderados de forma crítica o, al menos, expuestos de forma comparada, antes de avanzar en este estudio.

En este apartado de la investigación se realizará un recorrido general por la evolución histórica del problema de la preservación de la identidad local tradicional a nivel internacional: cómo y dónde se plantea por vez primera, quiénes son los principales actores implicados en su definición, cuáles son las principales conclusiones obtenidas por ellos y en qué modos éstas han sido puestas en práctica. 
Paralelamente, hay que señalar que existe una preocupación creciente por el desarrollo de arquitecturas y técnicas constructivas más comprometidas con el ahorro energético y la utilización sostenible de los recursos materiales disponibles. Este hecho está favoreciendo también la multiplicación de propuestas de algunos de los tipos analizados, pese a lo cual la preservación de la identidad local puede no estar entre sus objetivos o no serlo de manera primordial, mezclándose en ocasiones con otros propósitos que pueden, en cualquier caso, ponerse en relación con el objeto de este estudio.

Se analizará también finalmente la cuestión desde los principales documentos y directrices internacionales que inciden de un modo u otro en la cuestión estudiada.

Este recorrido general se entiende como un paso previo necesario para el mejor desarrollo y comprensión de este estudio y no ha pretendido ni podido por ello ser exhaustivo. 


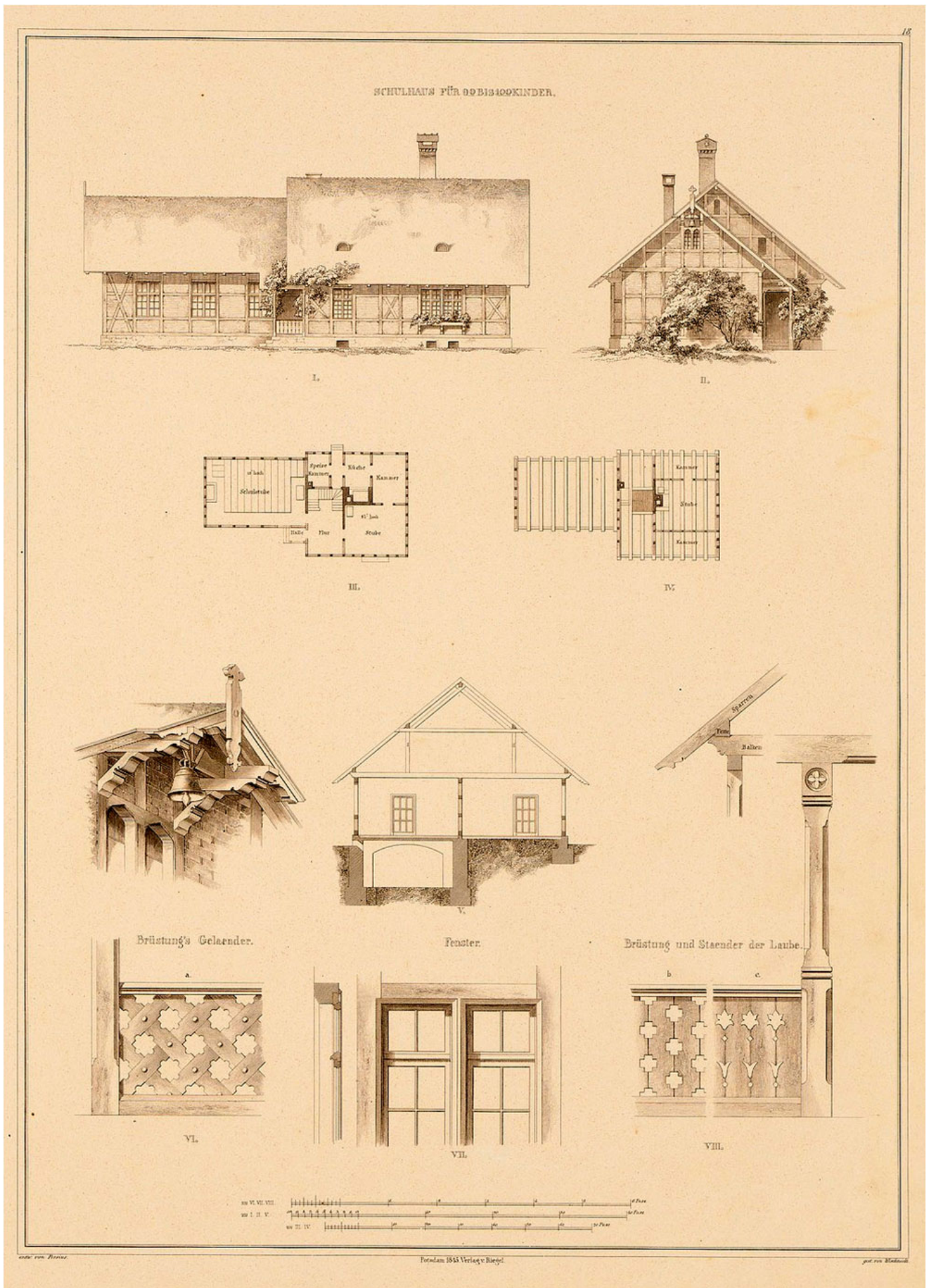

“Escuela para entre 90 y 100 niños”, diseñada por Ludwig Persius en 1845 (Museo de Arquitectura de la Universidad Técnica de Berlín) 


\subsection{EL NACIMIENTO DEL INTERÉS POR LA PRESERVACIÓN DE LAS TRADICIONES CONSTRUCTIVAS Y ARQUITECTÓNICAS LOCALES}

Las nuevas tecnologías y el progreso han despertado siempre la suspicacia humana. Las transformaciones del entorno natural provocadas por la propia Civilización se han ligado tradicionalmente a un sentimiento de pérdida y de culpa que reflejaban ya los más antiguos mitos. Así, en la tradición bíblica fue Caín el primero que "construyó una ciudad y la llamó Henoc; como el nombre de su hijo" (Gn 4 17).

Sin embargo, ha sido desde la Revolución Industrial, con las consecuencias estéticas y sociales que ésta trajo aparejada, cuando esta desconfianza se ha convertido con frecuencia en vigoroso rechazo. Naturalmente, fue en su cuna, Gran Bretaña, donde con mayor antelación y arraigo se denunciaron sus efectos adversos. Mientras la bucólica campiña inglesa desaparecía ante el avance de la industrialización y se volvían insostenibles las condiciones de vida de las clases sociales más desfavorecidas, ahora apiñadas en los suburbios de las grandes ciudades, la arquitectura, el arte y la literatura comenzaban a reflejar el malestar ante este proceso. Ejemplares de militancia contra él son, entre otros muchos, las novelas de Charles Dickens, los versos de William Blake o los grabados londinenses de Gustave Doré.

Surgen también en esta época nuevas ideas estéticas que avalarían esta naciente preocupación por la pérdida de las tradiciones locales y del paisaje que éstas conformaban. En buena parte de la literatura de viajes de cualquier tiempo pueden encontrarse referencias al exótico paisaje urbano que el viajero hallaba fuera de su patria, pero sería a partir de la generalización de estos viajes, con la popularización del Grand Tour y de la peregrinación hacia las antiguas ruinas que poblaban las orillas del Mediterráneo, cuando la mentalidad romántica comenzaría a fijar su atención en las arquitecturas vernáculas de aquellos parajes. Un buen ejemplo de ello es el testimonio dejado por Johann Wolfgang von Goethe de su determinante viaje a Italia.

En 1796 Wilhelm Heinrich Wackenroder, en su texto Desahogos de un monje amante del arte, planteaba una idea que iba a servir de base a muchas de las posteriores teorías en 
defensa de la tradición local, que se tratarán más adelante: la de la obra de arte como reflejo del alma del artista (Gombrich 2003, 95).

En cercana fecha, Schiller, al comprobar que la sensibilidad de la época había llevado a la valoración de aspectos que escapaban a los cánones académicos pretéritos y que, sin embargo, estaban ya bien arraigados en el acervo popular, introdujo una nueva categoría de belleza: la de lo "cándido". Utilizó esta denominación para referirse a aquellas obras cuya belleza es alcanzada en base a una creación instintiva o natural. Contraponía esta belleza a la de lo que él mismo denominaba "sentimental", la de lo surgido de la reflexión abstracta (Gombrich 2003, 95). Esta valoración de lo espontáneo, de lo sencillo, iba a gozar de una creciente aceptación en fechas sucesivas, incrementándose a medida que tales obras iban siendo cada vez más escasas y encontrando su reflejo en los trabajos de numerosos arquitectos. Así, casi siglo y medio más tarde, Leopoldo Torres Balbás, refiriéndose a las arquitecturas populares tradicionales, afirmaba literalmente que "poseen el encanto de lo espontáneo y sencillo", alejándose de lo "sentimental" $(1988,151,155)$.

Ningún ejemplo de esta creciente valoración de lo popular puede ser más expresivo que el Hameau de la Reine que Marie-Antoinette encarga en 1783 a su arquitecto favorito, Richard Mique, y que constituye quizás el primer caso documentado de edificación a gran escala de un entorno vernáculo tradicional adaptado a unos requerimientos completamente diversos. Concebido en colaboración con el pintor Hubert Robert, a su vez creador de jardines románticos y productor incansable de fantasías arquitectónicas, el Hameau de la Reine introduce en la formalizada grandiosidad de los jardines y palacios de Versalles lo atávico, lo vernáculo, lo cotidiano, lo espontáneo, cambiante y orgánico, a través de una serie de edificios diseñados a imitación de la arquitectura popular tradicional (el molino, la granja, el cottage, el palomar) y situados de forma aparentemente casual en torno a un gran lago irregular. El refinamiento de este conjunto, hoy en día convertido en una gran atracción turística, incluye el manejo intencionado de materiales, sistemas constructivos, disposiciones y caracteres propios de la arquitectura popular tradicional.

Fruto de esta nueva sensibilidad hacia lo popular el arquitecto francés François Cointeraux diseñaría numerosos edificios vernáculos en áreas rurales, defendiendo además el recurso a técnicas tradicionales de construcción, y en especial a la construcción en tierra. Además publicaría una de tratados sobre arquitectura y construcción "rurales" a 
partir de 1790. Poco después, en 1810, Léon de Perthuis publicó su Traité d'architecture rurale, en cuyo discurso preliminar se lamentaba de que los arquitectos franceses no prestaran más atención a la arquitectura y las técnicas de construcción populares, en especial a la hora de trabajar en entornos rurales, para lo que daba en este tratado numerosas indicaciones.

Mientras tanto, se multiplicaban en Gran Bretaña las publicaciones sobre arquitecturas vernáculas, tales como Farm Buildings, de William Barber (1805), o Rural Residences, Consisting of a Series of Designs for Cottages, Decorated Cottages, Small Villas and Other Ornamental Buildings, de John Buonarotti Papworth (1818).

No muchos años después, entre 1824 y 1828 , el gran paisajista, arquitecto y planificador John Nash incorporaba lo vernáculo en su gigantesco esquema de urbanización del Marylebone (luego Regent's) Park: el conjunto llamado Park Village, compuesto de cottages de diferentes estilos y organizado en torno a un trazado de apariencia casual y evolutiva. Considerado por John Summerson "el ancestro de todos los suburbios pintorescos", Park Village era un enclave residencial real (y lo que ha quedado de él lo sigue siendo hoy en día) en cuyo seno sus habitantes podían recluirse en un contexto vernáculo, a sólo un paso del fragor y las transformaciones vertiginosas del Londres del siglo XIX. Ésta no era ni mucho menos la primera tentativa pintoresquista de Nash, quien en torno a 1798 había proyectado, por ejemplo, su Picturesque Village, un conjunto de arquitecturas soñadas completamente vernáculo, y en 1810 había diseñado junto a George Repton el conjunto residencial de Blaise Hamlet, cerca de Bristol, siguiendo un patrón pintoresco que imitaba la estética y la disposición de una modesta aldea tradicional y que pronto se convirtió en un lugar muy popular atrayendo a numerosos visitantes. David Watkin analizaba en The English Vision (1982) la permanencia y riqueza de la admiración inglesa por lo vernáculo, que encuentra su reflejo tanto en la arquitectura como en la disposición pintoresca de las ciudades, que tiene ya un teórico maduro en Uvedale Price, autor en 1794 de An Essay on the Picturesque, y que muestra un vigor envidiable a lo largo del siglo XX a través de los teóricos de la ciudad-jardín.

Poco después de la publicación del libro de Price el arquitecto prusiano David Gilly y, sobre todo, su hijo Friedrich Gilly difundían en su país estas ideas, siendo recogidas y puestas en práctica por, entre otros, Karl Friedrich Schinkel y sus seguidores. Buena 
muestra de esta nueva sensibilidad son los dibujos de pintorescos paisajes y arquitecturas populares realizados por Schinkel durante su viaje por Italia, entre 1803 y 1805, entre los que cabe destacar sus cuidadas representaciones de la arquitectura popular de la isla de Capri. Junto a Peter Joseph Lenné y, sobre todo, Friedrich Ludwig Persius, tendría ocasión de recrear conjuntos semejantes en sus trabajos en Potsdam. En los alrededores de esta ciudad alemana desplegaron juntos una hábil combinación de la arquitectura vernácula italiana con el exuberante paisaje germano que tiene entre sus mejores resultados el conjunto del Hofgärtnerei o Casa del Jardinero de la Corte y sus famosos Baños Romanos, construido entre 1829 y 1831, que integraría en una composición absolutamente pintoresca una maravillosa combinación de elementos tomados en su mayoría de la arquitectura popular. En el entorno cultural germánico esta admiración por lo vernáculo perviviría a lo largo del siglo XIX, encontrando su reflejo en las clasificaciones tipológicas establecidas por Gottfried Semper, fundamentales para comprender las ideas al respecto de las siguientes generaciones de arquitectos. Su Villa Garbald, erigida entre 1863 y 1865 en el Ticino suizo, es buen reflejo del interés de Semper por las arquitecturas más populares. Arquitectos posteriores como Joseph Maria Olbrich, Josef Hoffmann seguirían esta estela, fijando nuevamente su atención en la arquitectura vernácula en sus viajes por el sur de Italia. A su regreso, este último llegaría incluso a publicar un temprano estudio sobre la arquitectura popular tradicional de la isla de Capri, que había dibujado con gran interés (Hoffmann 1897; 13-14). Como reflejo del arraigo de esta corriente de interés en la cultura vienesa, sería, de hecho, el Archiduque Luis Salvador de Habsburgo-Lorena quien, en su obra Die Balearen, publicada en 1871, se ocuparía de una forma pionera en nuestro país de los oficios y arquitecturas tradicionales, estudiando minuciosamente las costumbres y el paisaje de las islas Baleares.

Este descubrimiento de lo vernáculo conduciría progresivamente a algunos arquitectos a preocuparse por la falta de correspondencia entre arquitectura y carácter local en buena parte de lo que comúnmente se edificaba en el momento. Así, en 1841, el arquitecto inglés Augustus Welby Northmore Pugin se preguntaba ya en The True Principles of Pointed or Christian Architecture por qué motivo se construían "casas italianas" en Inglaterra, cuando el clima de ambos países era tan diverso (1852, 46-47), mientras que en sus famosos Contrastes (1836) se lamentaba de lo que consideraba una intensa degradación del paisaje inglés. Unas décadas más tarde, Eugène-Emmanuel Viollet-le-Duc ponía en boca del arquitecto de su Historia de una casa una amarga protesta por la construcción de 
"villas italianas en el norte de Francia y de chalets suizos en Niza" $(1873,150)$. El propio Viollet-le-Duc, en la voz "casa" del sexto tomo de su Dictionnaire raisonné de l'architecture française du XIe au XVIe siècle (1854-68), dedica un apartado a las "maisons des champs" y en él explica cómo, mientras que la arquitectura urbana varía en gran medida a lo largo del tiempo, la arquitectura rural es menos susceptible a estos cambios, mas su fisonomía está más condicionada por el medio físico y, por tanto, es muy diversa entre unas y otras regiones (289-298). Viollet-le-Duc presenta además en él la que parece haber sido la primera clasificación tipológica de las distintas casas características de diferentes regiones, aportando descripciones y dibujos de ellas.

Las investigaciones etnográficas y, con ellas, los estudios sobre las tradiciones vernáculas, irían ganando profundidad a lo largo del siglo XIX. La pionera Folklore Society (FLS), dedicada al estudio de la cultura popular tradicional, fue fundada en Londres en 1878 y su equivalente norteamericana, la American Folklore Society, una década después. La revista de la sociedad británica, Folk-Lore Record, comenzó a publicarse en el mismo año de su fundación. Siguen hoy en activo tanto la sociedad como la publicación, rebautizada más adelante como Folk-Lore Journal. Esta iniciativa tuvo pronto consecuencias en España, donde se editó desde 1882 la revista El Folklore Andaluz, promovida por Antonio Machado y Álvarez, quien hacía uso del pseudónimo Demófilo.

La mirada hacia la arquitectura tradicional trascendía progresivamente la admiración de su imagen pintoresca y del atractivo de su sencillez, para reconocer en ella un conjunto más amplio de valores. Los avances de la etnografía y la apreciación de los aspectos sociales y culturales implícitos en las tradiciones vernáculas llevarían, primero en Gran Bretaña y poco después en el resto de Europa, a ver en ella también un elemento identitario, un patrimonio cultural, y una herramienta de regeneración social. Surgen así las primeras reivindicaciones de la tradición arquitectónica en su más moderno sentido. 


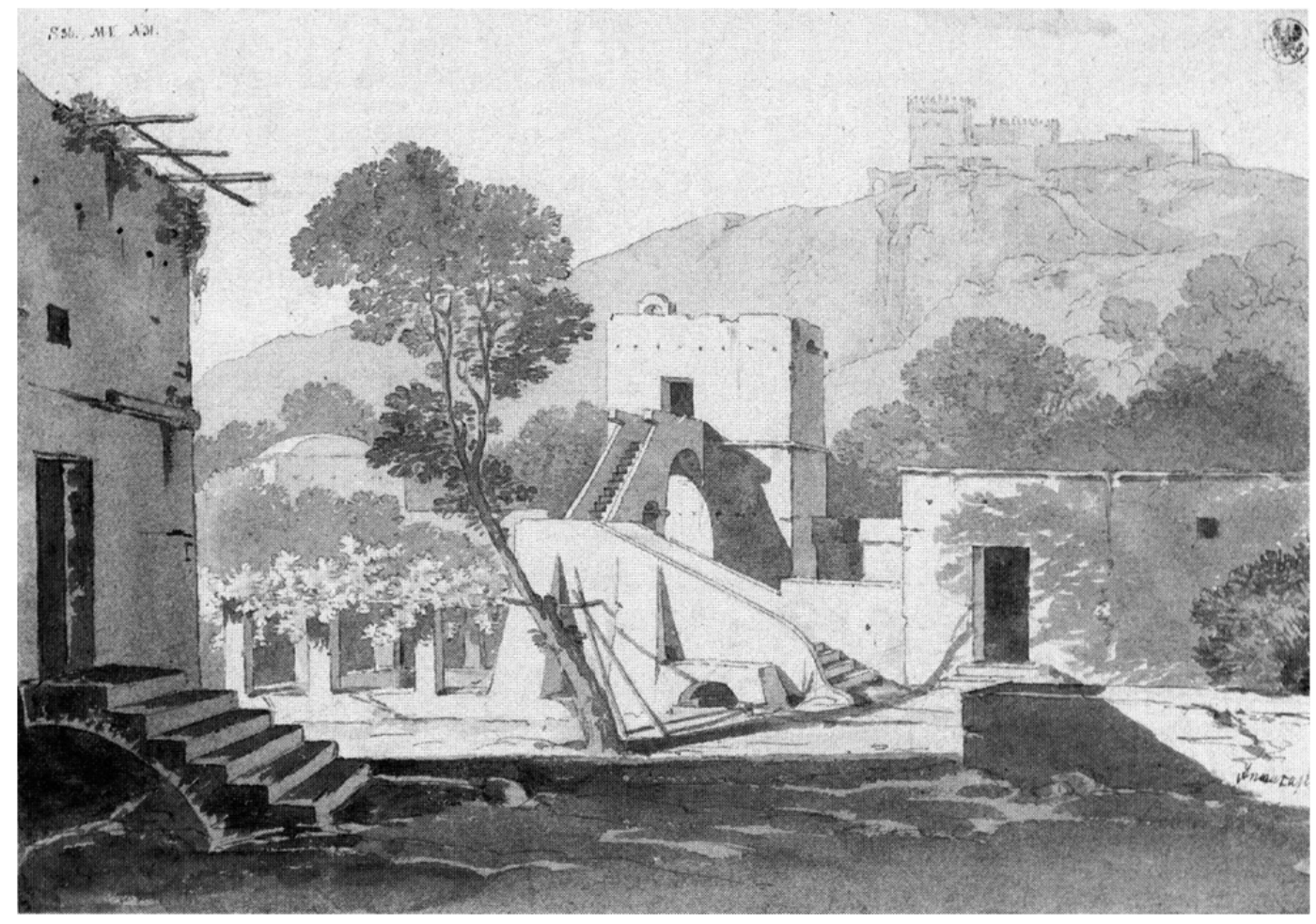

Casa de campo en Capri, dibujada en 1804 por Karl Friedrich Schinkel (Lejeune 2009, 72), y vista de la Casa del Jardinero de la Corte en Charlottenhof, Potsdam, diseñada por Karl Friedrich Schinkel y Ludwig Persius y construida entre 1829 y 1831, en una acuarela de Ferdinand Marohn de 1848 (Carter 1989, 127)

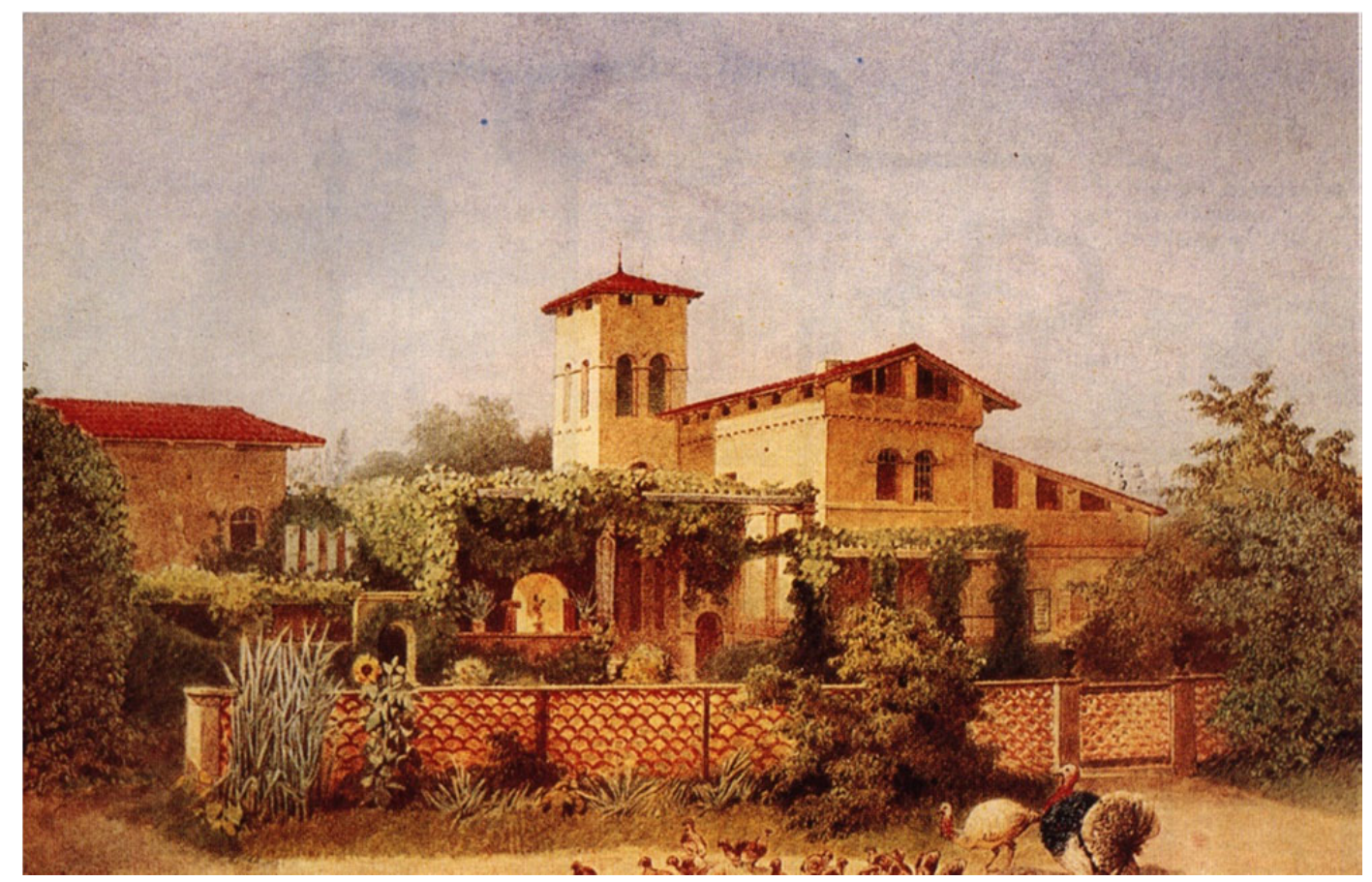




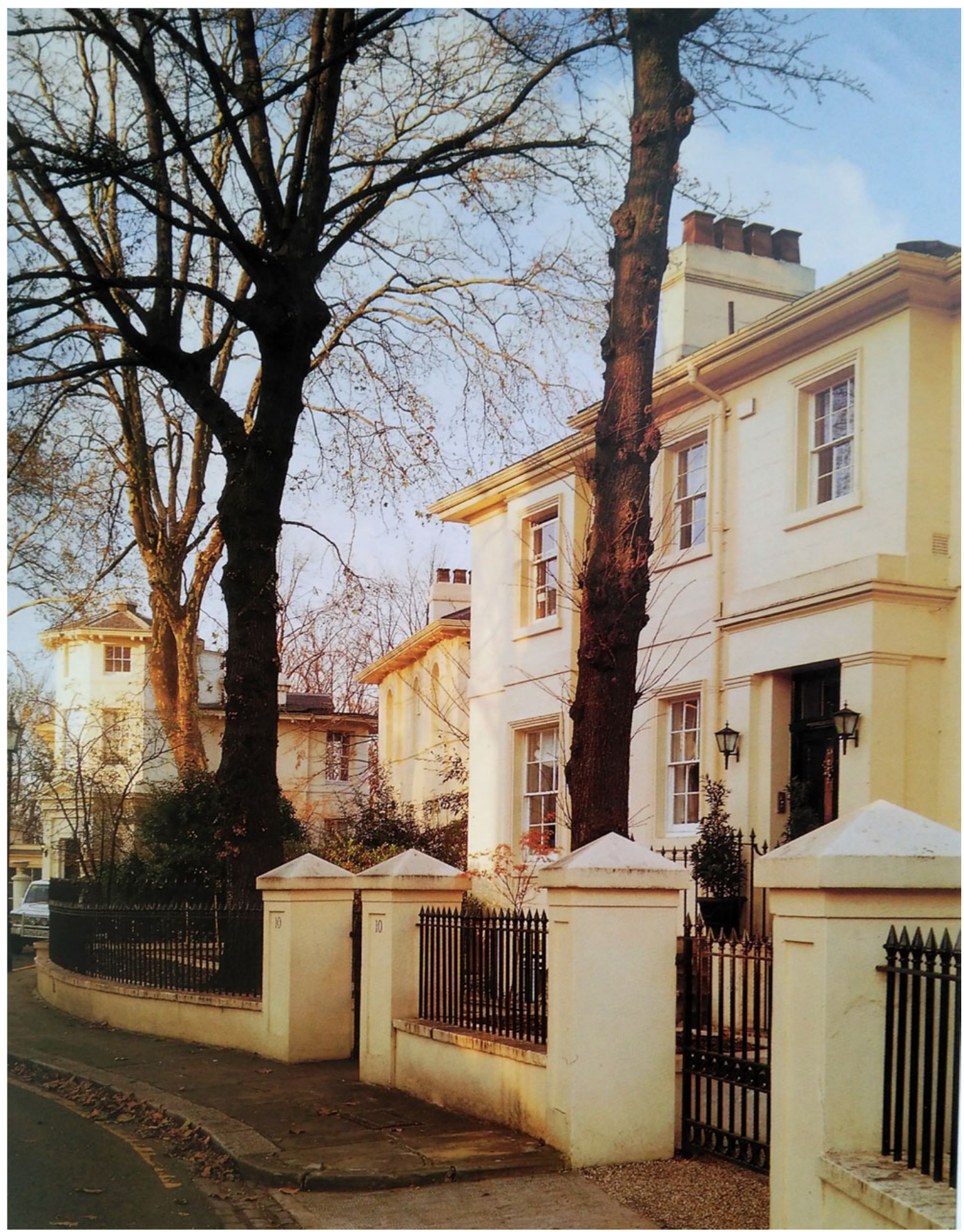

Park Village West, Londres, obra de John Nash y James Pennethorne, realizado entre 1824 y 1828 (Summerson 1988, 173) 


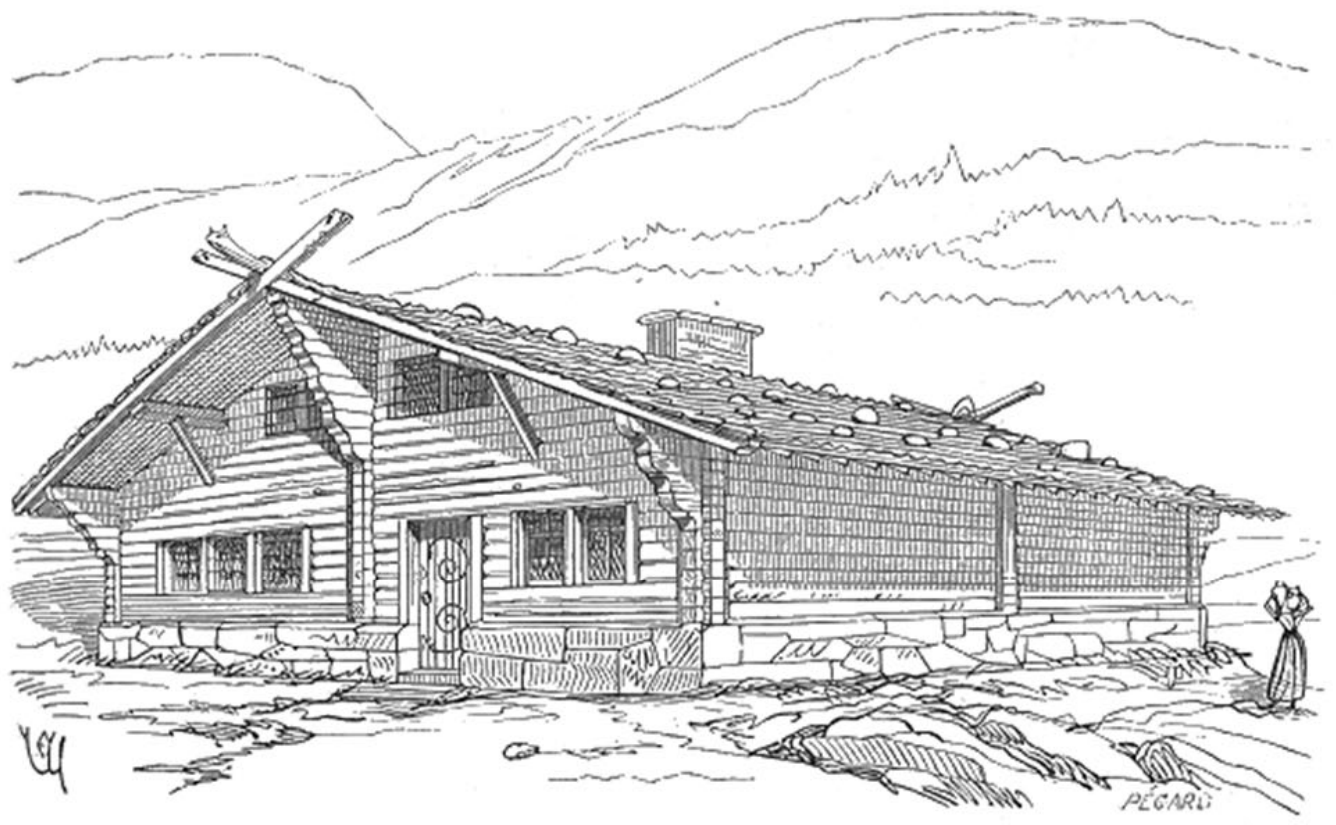

Casas tradicionales propias de las regiones francesas de los Vosgos y de las llanuras de Toulouse, recogidas por Viollet-le-Duc dentro del apartado que dedica a la vivienda rural en el tomo sexto de su Dictionnaire raisonné de l'architecture française du XIe au XVIe siècle, publicado entre 1854 y 1868 (295 y 296)

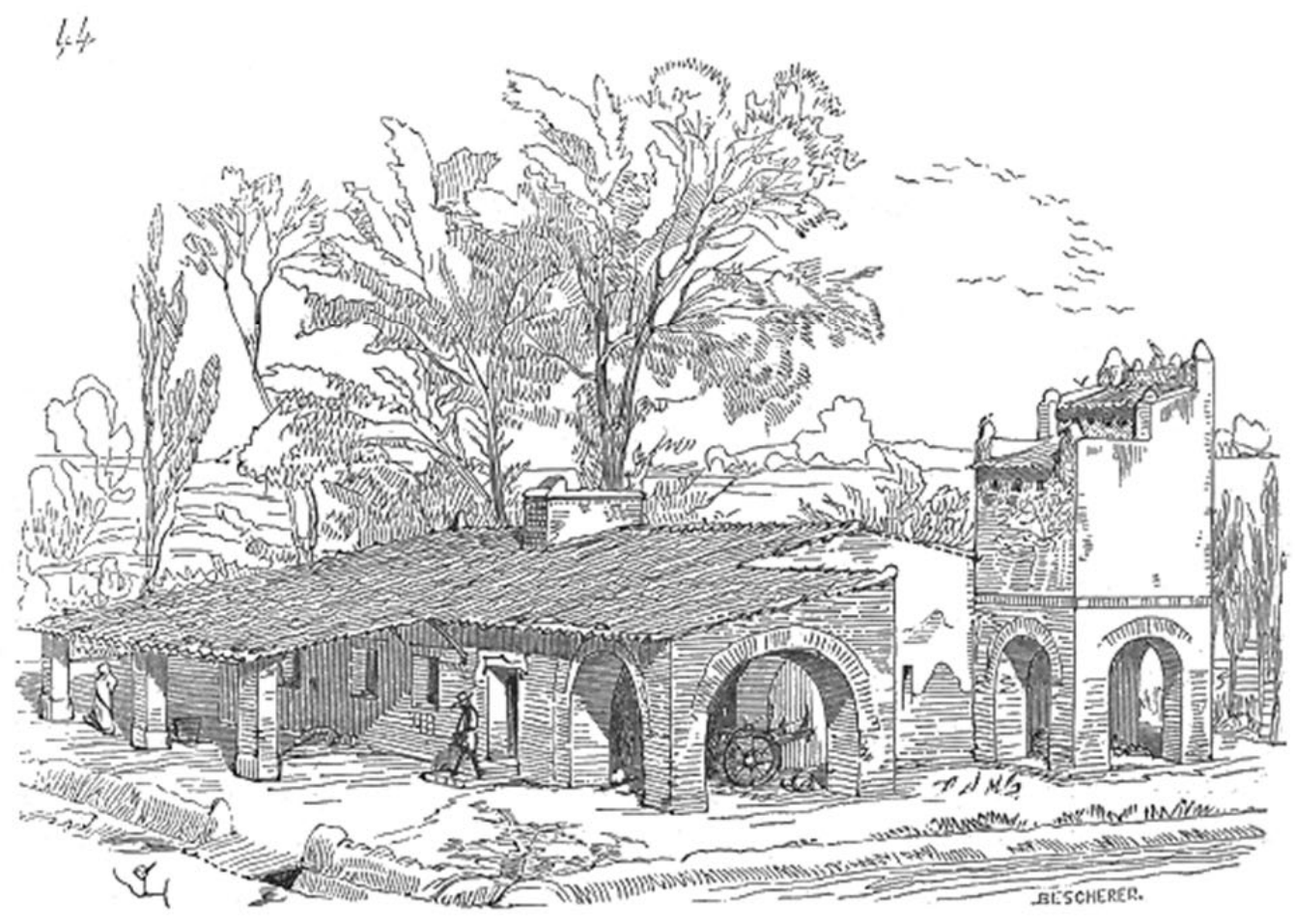




\subsection{EL PRIMER PLANTEAMIENTO INTEGRAL DEL PROBLEMA POR EL MOVIMIENTO DE LAS ARTES Y LOS OFICIOS INGLÉS. REIVINDICACIONES SOCIALES IMPLÍCITAS EN ÉL. REPERCUSIÓN INTERNACIONAL}

You must either make a tool of the creature, or a man of him. You cannot make both.

John Ruskin, The Stones of Venice, 1853.

William Morris denominaba a la tradición "intelligent tradition” (2016d, 81) y defendía que, por gran genio que un creador poseyera, sin el respaldo del trabajo dentro de esa tradición, cualquier obra suya carecería de valor. "El terreno que debe sembrar no es una pradera intacta, sino que ya ha sido fertilizado y mejorado por el trabajo de incontables generaciones" (2016d, 89).

En la segunda mitad del siglo XIX un influyente grupo de artistas e intelectuales volvió la vista hacia la tradición en pos de soluciones para los problemas de su tiempo, dando lugar en Gran Bretaña al movimiento conocido como Arts and Crafts, es decir, Artes y Oficios.

En aquel momento la noción de arquitectura tradicional resultaba aún, sin embargo, algo vaga, identificándose a menudo con lo medieval, entendido como lo anterior a la difusión de la más culta arquitectura "de autor". Este concepto iría enriqueciéndose con el tiempo, quedando al fin perfectamente definida en los albores del siglo XX, tras haberse multiplicado los estudios sobre las diversas costumbres y tradiciones populares.

En todo caso, la "intelligent tradition" que reivindicaba Morris no era ya un romántico revival del mundo preindustrial, ni una reivindicación de un pasado perdido, sino una sopesada búsqueda de herramientas válidas para la construcción de un futuro mejor.

En este movimiento británico se integraron numerosos artistas y artesanos, incluyendo arquitectos como Philip Webb y Charles Robert Ashbee y destacados pintores prerrafaelitas como Edward Burne-Jones y Dante Gabriel Rosetti. Pero serían William Morris y John Ruskin quienes se convertirían en los principales ideólogos inspiradores del 
movimiento. Las aportaciones teóricas de ambos serían fundamentales para la posterior evolución de la arquitectura, así como para la valoración de la arquitectura tradicional. En torno a sus figuras se desarrolló un complejo y completo sistema alternativo. No pretendían solamente reivindicar la legítima voluntad del hombre de vivir rodeado de auténtica Belleza, sino preservar una herencia paisajística y cultural que veían amenazada, devolver a una clase media de artistas y artesanos el papel que la producción industrial les había arrebatado y eliminar por esa vía, promoviendo dicha clase media, las diferencias sociales que el capitalismo había agudizado. Su programa ha de entenderse, por ello, como una propuesta unitaria, englobando aspiraciones artísticas, políticas y sociales en una única visión.

La raíz de sus ideas está en la noción que introdujo John Ruskin de obra manufacturada como reflejo de la cultura o las culturas que han trabajado en su producción o transformación, como documento en el que puede leerse la historia, la "vida" de quienes han intervenido en ella, con indiferencia de que se trate de arte o artesanía. No reconoce en la obra simplemente una manifestación del "Espíritu de la Época", como se ha malinterpretado con frecuencia, sino que la hace depositaria el aporte individual de sus creadores, de personas concretas que habitaron en fechas y lugares determinados. Para Ruskin, los objetos dependen "por lo que se refiere a dignidad y deleite, de la ardiente expresión de la vida intelectual que se ha ocupado de su producción" $(2007,133)$. Su verdadero encanto reside en si en ellos "descubrimos el registro de pensamientos, propósitos, pruebas y desmayos" $(2007,54)$ de los hombres que han intervenido en su ejecución y en sus ulteriores modificaciones. "El arte es la expresión de la felicidad que obtiene el hombre en su trabajo", afirmaba Morris. Según esta concepción, la obra de un ser humano es muy superior a la de la máquina, y, aunque el hombre puede llegar a tener que trabajar como una máquina, asimilándose la calidad de su trabajo a la del de éstas, "mientras trabajen como personas, poniendo el corazón en lo que hacen, mientras lo hagan lo mejor posible, no importa cuán malos trabajadores puedan ser, habrá algo en la manipulación que estará por encima de todo precio" $(2007,151)$.

Siguiendo a Ruskin, para los integrantes del movimiento de las Arts \& Crafts, cualquier labor que permita al hombre expresar su creatividad individual, siempre que esta creatividad se apoye en una tradición, en la herencia cultural de sus antecesores, puede producir obras de arte. De este modo, no sólo podrán producir objetos de gran belleza la 
escultura, la pintura o la arquitectura, sino que esa belleza podrá ser alcanzada también en la creación de cualquier objeto de uso doméstico, en la transformación de campos y ciudades, en la construcción de carreteras o caminos, o en la modificación, en definitiva, de cualquier aspecto del entorno en que vivimos (Morris 2012a). La humanidad tiene, según esto, la capacidad de rodearse de Belleza, de convertir el mundo en el que vive en lo que se conoce como una "obra de arte total", pero sólo puede avanzar en esa dirección cuando el tipo de trabajo que desarrolla y las condiciones en que lo hace son las apropiadas.

En consecuencia, la mercantilización del trabajo y la injusticia social, llevan, sin embargo, a la destrucción de nuestro entorno. Queda anulada con ellos la relación directa entre el trabajador y su obra, entre una cultura y su producción material, así como la satisfacción personal que ésta comportaba y, como resultado, desaparece también la Belleza. La tendencia a que ésta surja espontáneamente se debilita cuando el trabajo deja de ser algo personal, relacionado con las habilidades e intereses propios del individuo, para convertirse en parte de un proceso en el que apenas es partícipe y en el que, se esfuerce lo que se esfuerce quien lo ejecuta, percibirá un mismo salario y apenas tendrá control sobre su tarea. Tampoco las condiciones de vida del trabajador en un mundo ya mecanizado son las más apropiadas para que su felicidad le mueva a producir nada digno de ser considerado arte: “¿Hace falta que diga cómo vive? Alojado en un cuchitril sofocante, separado del campo más cercano por kilómetros de cuchitriles similares a eso que sarcásticamente llama 'suyo'. A veces, durante las vacaciones, se hacinará en un tren para captar un atisbo de esos campos, sólo para hacinarse otra vez en su regreso a su infierno particular del día" (Morris 2016a, 43).

La Belleza va así desapareciendo progresivamente del entorno, suplantada por rentables y estandarizados productos de consumo. El arte queda reducido al plano intelectual, fuera del alcance de la mayor parte de la sociedad. La arquitectura no puede ser ya una "obra de arte total", sino que su cualidad artística ha de replegarse únicamente al ámbito de lo conceptual. Con ello, deja de ser un arte para todos, convirtiéndose en un campo elitista, excluyente y ampliamente incomprendido (Morris 2012a).

Al artesano "la tradición le guiaba y le servía de ayuda en los usos y costumbres de su arte; por lo demás era libre" (Morris 2012a, 42). Sin embargo, su libertad se había visto 
truncada por la mecanización de la producción, con el precio de cuyos productos no podía competir. Mientras la búsqueda de calidad no se antepusiera a la demanda de cantidad, estaba condenado a desaparecer. La entonces incipiente sociedad de consumo tenía ya otras prioridades. Para Morris $(2008,8)$, las principales ideaciones de su tiempo eran los productos adulterados, los sucedáneos, las vulgares copias y simulaciones ("adulterations", "makeshifts", "mockeries", "shams") de los verdaderos productos, al convertirse éstos en un lujo al que sólo los más ricos podían acceder. Como el fabricante no puede obtener gran beneficio económico si lo que produce son pequeñas cantidades de productos de calidad, y el beneficio económico es su único objetivo, "lo que hace es fabricar un sucedáneo de lo que demanda el público, gracias a la espada de la baratura, como se ha dado en llamarla, no sólo puede imponérselo a los compradores, sino que puede impedir (y de hecho lo hace) que éstos obtengan el objeto auténtico; así que el artículo genuino deja de producirse cuando el sucedáneo triunfa en el mercado" (Morris 2016d, 86).

Morris estaba probablemente familiarizado con los textos en los que el francés Charles Fourier hacía una lectura análoga de la situación. Las palabras de Fourier, de significativa actualidad, parecen resonar en los escritos de Morris: "Lácteos, aceites, vinos, brandy, azúcar, café, harinas, todo se falsifica con impudicia. La multitud de pobres ya no puede obtener comestibles naturales. Sólo se les venden lentos venenos. Tales son los progresos que ha efectuado el espíritu comercial hasta en las aldeas más pequeñas" (Fourier 1901, 96).

Así iba a ocurrir con la arquitectura tradicional. Tal como se desprende de los resultados de la presente investigación, lo que hoy domina el paisaje urbano de nuestros pueblos es precisamente un sucedáneo de ella, y este sucedáneo no sólo es cada vez más demandado, sino que además se aleja progresivamente del modelo al que reemplaza.

Pero este proceso había comenzado ya en torno a las ciudades de la Gran Bretaña de aquel tiempo. Se citan aquí dos pasajes completos, uno escrito por John Ruskin y otro por William Morris, por su importancia para este estudio y la influencia que sus ideas iban a ejercer sobre muchos de los autores sobre los que trataran los siguientes apartados. 
Sobre la desnaturalización del paisaje y de la arquitectura, John Ruskin escribía ya en 1849 en su Lámpara de la Memoria (2007, 159-160):

Por ello, contemplo esas lastimosas concreciones de cal y arcilla que brotan, con marchita prontitud, de los amasados campos que circundan nuestra capital -esos delgados, temblorosos, descimentados caparazones de piedra imitada y madera astillada, esas horribles filas de menudencia formalizada, sin diferencias, sin confraternidad, tan solitarias como iguales-, no simplemente con aflicción por un paisaje profanado, sino con el doloroso presentimiento de que las raíces de nuestra grandeza nacional deben de estar muy corrompidas cuando tan poco ligadas están a su terreno natal; esas viviendas incómodas y deshonrosas son el síntoma de un grande y creciente sentimiento de descontento popular; pues marcan el instante en que el designio de todo ser humano debe estar en alguna esfera más elevada que la natural; en que su vida pasada es un escarnio habitual; en que, si edifican, es con la esperanza de abandonar los lugares que han edificado, $y$, si viven, es con la esperanza de olvidar los años vividos.

William Morris, preocupado también por la evolución de este mismo problema, se lamentaba de lo que el falso progreso había provocado en el paisaje de su país: "Ha cubierto los risueños prados con barracones de esclavos, devastado las flores y los árboles con gases ponzoñosos, convertido los ríos en cloacas" (2016c, 54). Y veía la común arquitectura de su tiempo como una agresión más a ese maltratado entorno (2016e):

Pensemos ahora en las casas en las que vivimos y en el tipo de sucedáneo que se ha construido durante los últimos cien años. Todos ustedes, incluyendo a quienes hagan poco uso de la vista, se habrán percatado de que las casas modernas son burdas en su concepción y feas de aspecto; que su amontonamiento en las grandes ciudades ha hecho que nuestras calles sean repulsivas y caminar por ellas, algo indignante; y que cuando las encontramos en el campo son como sarpullidos en medio de la belleza natural, así que las evitamos a no ser que estemos obligados a pasar por su lado. Y tampoco puede aducirse que al menos son útiles, dado el coste y el esfuerzo que ha supuesto construirlas. Eso es falso. Al contrario, de todas las paredes y techos que se han levantado para protegerse del viento y del mal tiempo, no hay ninguno que esté peor ideado o que sea más 
incómodo y disparatado; en una palabra, son casas estúpidas. Sin lugar a dudas, la mayoría de ustedes no tienen ni idea de cuán torpes son estos sucedáneos respecto a las casas que de verdad están hechas para hombres sobrios y sensatos. Como nunca habrán visto nada mejor, y estarán acostumbrados a las modernas, pensarán que son más o menos lo que tienen que ser, dado su tamaño y la riqueza de sus moradores, ya sean seis habitaciones pequeñas o sesenta grandes, ya ganen sesenta libras al año o roben sesenta mil. Pero créanme si les digo que han existido casas que embellecían las calles en que se erguían, que eran agradables para la vista y estimulantes para el espíritu; cuyo plano era práctico o razonable, acorde con los deseos de sus habitantes; que, lejos de empañar un paisaje bonito con su fealdad, constituían entonces - y en raras ocasiones aún hoy lo hacen - el adorno central del lugar; y que de hecho eran útiles, y no utilitarias, palabra que expresa más bien, me parece, una cualidad que viene a ser lo contrario de lo útil, y que significa algo cuya única utilidad es sacar dinero de las necesidades de los demás.

Ruskin, Morris y sus seguidores se implicaron activamente en las diversas causas en defensa del paisaje y la arquitectura tradicional y popular que surgían por todo el país. Son numerosos sus artículos de prensa y conferencias públicas en los que reaccionaban contra las actuaciones y propuestas que amenazaban este patrimonio, fueran demoliciones, construcciones inapropiadas o malentendidas restauraciones.

De igual modo, los ideales de este movimiento, al mismo tiempo artísticos, sociales y políticos, serían profusamente defendidos por medio de escritos y conferencias, siendo William Morris el más activo en esta materia. Entre los medios utilizados por él para difundir sus ideas al respecto destacan por su popularidad dos de sus novelas. Se trata en concreto de dos narraciones en primera persona. En ambos casos el protagonista despierta de un pesado sueño y se halla a sí mismo en una época distinta a la suya: El sueño de John Ball, publicada en 1888, y Noticias de Ninguna Parte, en 1890. La primera por medio del retorno a una aldea medieval y la segunda a través de un viaje a la ciudad del futuro exponen dos versiones semejantes de sociedades utópicas de artistas-artesanos que pueden llegar a habitar un mundo justo, bello y feliz. Los paisajes, ciudades, arquitecturas y objetos descritos en ambas novelas constituyen realizaciones plenas de los ideales estéticos de este movimiento. Son descritas como reflejo de la felicidad de las culturas e 
individuos que las han producido, pues han sido materializadas con orgullo y placer por sus habitantes, que han depositado en ellas sus esperanzas y desvelos.

Morris fue además un denodado defensor de un prácticamente extinguido género de socialismo libertario que marcó su vida y su obra y en el que jugaban un papel principal los oficios y artes tradicionales. De hecho, su Noticias de Ninguna Parte fue su particular reacción contra la entonces exitosa novela de Edward Bellamy Looking Backward, publicada poco antes, en 1887. Mientras esta última describe un futuro tecnológicamente avanzado y regido por un burocrático y totalitario Estado omnipresente y omnipotente en el que la propiedad privada ha desaparecido por la imposición de un materialista sistema igualitario, el alternativo "Ninguna Parte" es un mundo en el que, tras una revolución apenas recordada, el Estado ha dado paso a una suerte de democracia local autogestionada, un género de utopía en la que hallaban ciertas similitudes con algunas comunidades forales medievales y que era, sin duda, heredero de las ideas que previamente propugnara John Ruskin. En "Ninguna Parte", la gente vive en armonía por gracias a la satisfacción que su trabajo les comporta tras abolir el imperio de la máquina y el mercado. A diferencia de lo descrito en la obra de Bellamy, el individuo no ha sido anulado por la colectividad, obrando siempre con total libertad. Tanto para Ruskin como para Morris, la aceptación de la tradición no suponía una pérdida de libertad, sino que era precisamente aquello que permitía disfrutar plenamente de ella.

Inspiradas por las ideas de John Ruskin, varias comunidades cooperativas basadas en el trabajo artesanal fueron fundadas en Norteamérica. Todas ellas fracasaron en pocos años, asfixiadas por la presión de los mercados. Lo único que queda hoy de ellas es prácticamente el nombre, existiendo aún una localidad llamada Ruskin en Florida y otra en la Columbia Británica. La más floreciente fue Ruskin Colony, también conocida como Ruskin Commonwealth Association, que se fundó en Tennessee en 1894 y que en su punto álgido llegó a alcanzar una población de 250 "Ruskinitas" (Dearden 2004, 55), antes de su traslado a Georgia en 1899 y su disolución definitiva en 1901.

Además, el sistema gremial del Medioevo, como sistema que potenciaba el trabajo de sus artistas-artesanos, fue tomado como referente ideal para las diversas iniciativas cooperativas fundadas por los propios miembros del movimiento de las Artes y los 
Oficios: el St. George's Guild de Ruskin, el Century Guild de Arthur Heygate Mackmurdo, el Guild of Handicraft de Charles Robert Ashbee, etc.

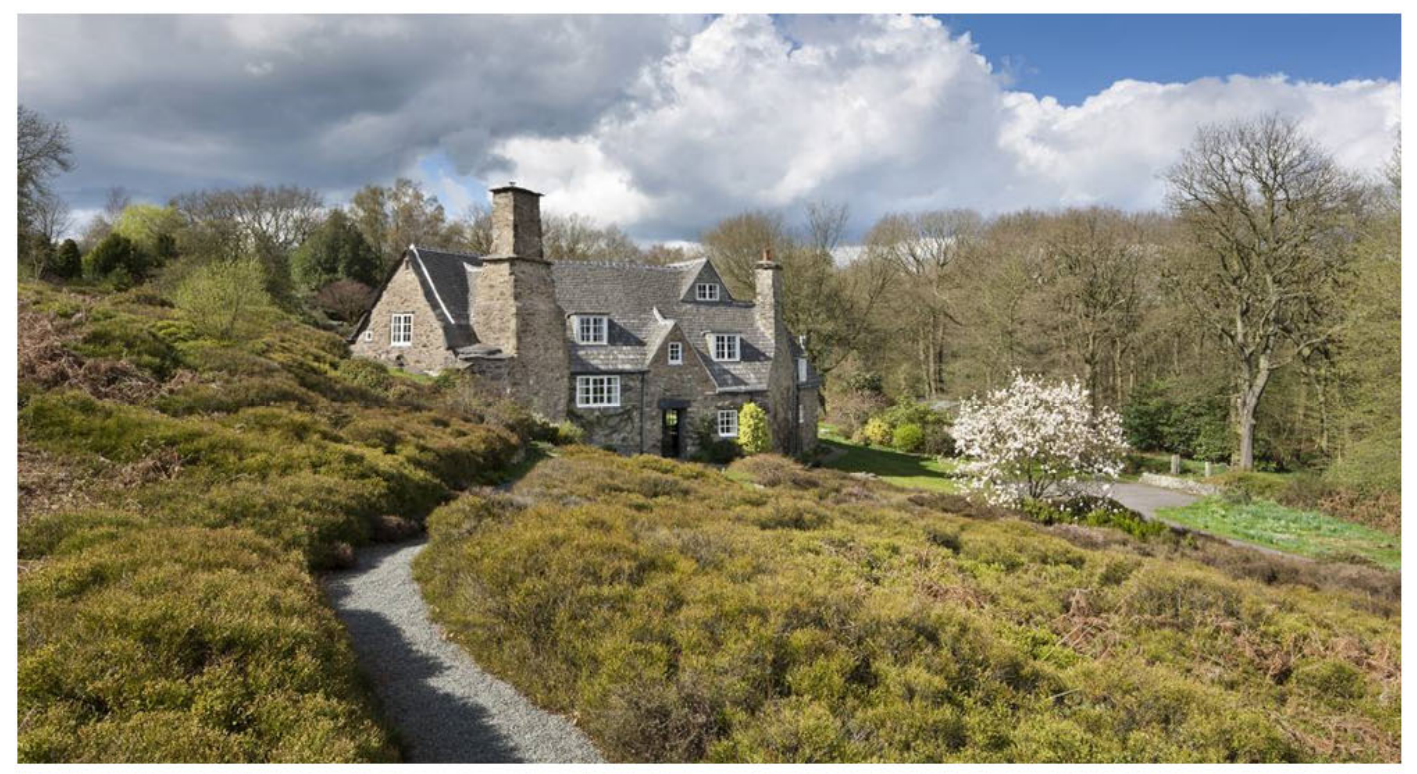

Stoneywell, Leicestershire, obra de Ernest Gimson realizada entre 1898 y 1899 (National Trust: fotografia de Andrew Butler), y la famosa Red House, Bexleyheath, diseñada por Philip Webb para William Morris y construida entre 1859 y 1860 (fotografia del autor, junio de 2012)

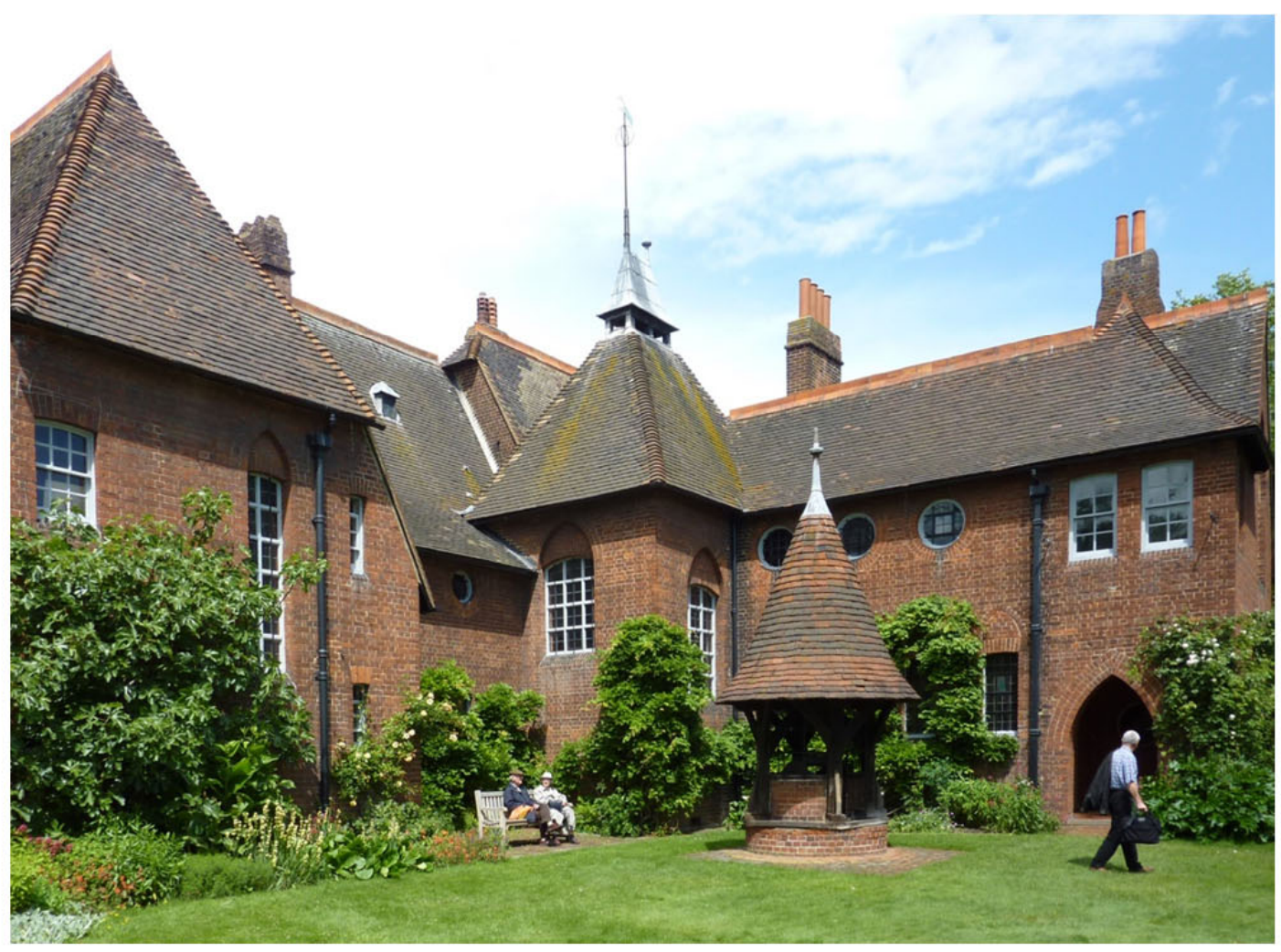


Sin embargo, estos autores no rechazaron la industria o las máquinas per se, sino su mala utilización. "Todo trabajo que realizado a mano es enojoso lo hacemos con máquinas muy perfeccionadas, y se hace sin máquinas el que puede ser agradablemente realizado a mano", declaraba uno de los habitantes de "Ninguna Parte" (Morris 2011, 147). Para Morris, por el esfuerzo y cuidado depositados en ellas, las máquinas eran los únicos "productos perfectos" de la era industrial, pero su fin era una "producción desmesurada de objetos inútiles y despreciables" (Morris 2011, 145). Combatían pues, no contra la máquina, sino contra el que éstas relegaran al individuo a servirlas, desempeñando un trabajo igualmente mecanizado y carente de incentivos. Esto fue explicado con gran claridad por el escritor Oscar Wilde, seguidor también de buena parte de estas ideas (2010, 13): ¿¿Pensáis, acaso, que nos oponemos a la maquinaria? Pues os diré que la reverenciamos, la reverenciamos cuando cumple con su trabajo propio, cuando releva al hombre en tareas innobles o desalmadas, pero no cuando pretende hacer aquello que sólo resulta valioso al ser producido por las manos y el corazón del hombre".

Si bien la realidad del mercado en el que tenían necesariamente que competir se impuso frente a sus más ambiciosos proyectos cooperativos, sus iniciativas fueron esenciales para el desarrollo de ámbitos tan destacados como el de la vivienda social. Fundamental fue, por ejemplo, la labor de Octavia Hill en este campo, quien fue cofundadora del National Trust, ayudó a salvar de la especulación inmobiliaria importantes áreas verdes de Londres, como Hampstead Heath, y colaboró estrechamente el propio Ruskin. Gracias a su sistema, miles de personas sin recursos disfrutaban de un hogar en el último cuarto del siglo XIX, en un esfuerzo que sólo tras haber alcanzado un amplio reconocimiento fue secundado y complementado por las administraciones públicas. Proyectos de vivienda social impulsados por ella, como el de las Red Cross Cottages, diseñado por Elijah Hoole, prueban que la arquitectura que propugnaba este movimiento distaba de ser tan exclusiva como tratarían décadas más tarde de caracterizarla sus detractores.

En todo caso, pronto algunos de sus miembros comenzaron a aceptar la necesidad de trabajar también para mejorar el diseño de los productos de la industria, renunciando así al pasado radicalismo. Así lo hicieron el propio Ashbee o el arquitecto William Richard Lethaby. Frank Lloyd Wright, admirador de los escritos de Ruskin y Morris, fundamentales para comprender su arquitectura, lanzó en 1901, en una conferencia organizada por la Chicago Arts and Crafts Society, una de las más conocidas críticas 
contra la encarnizada defensa de los oficios tradicionales por este movimiento. En esta conferencia, que se publicó con el título The Art and Craft of the Machine, Wright presentó una rotunda reivindicación de la máquina. Aunque la extrema posición defendida en ella entraba en contradicción con su propio trabajo como arquitecto, esta conferencia iba a convertirse en una referencia fundamental para los protagonistas de lo que Rayner Banham denominó la Primera Era de la Máquina.

Pese a estas críticas, la arquitectura de este movimiento gozó de gran éxito y aceptación hasta la llegada de la gran ruptura que supuso la Segunda Guerra Mundial, y no sólo entre las clases más acomodadas. Plataformas como la revista Country Life, publicada desde 1897 hasta la actualidad, le darían difusión internacional. Las obras e ideas de sus artífices influyeron durante décadas a arquitectos de todo el mundo, que tratarían de muy diversos modos de darles continuidad. Los escritos de Ruskin y Morris se publicarían en numerosos países. La historia de la arquitectura contemporánea quedaría definitivamente marcada por el debate entre la tradición local y las sucesivas modas internacionales.

En la obra que se convertiría el icono del movimiento, la Red House, proyectada en Bexley Heath (Kent) para William Morris por su compañero el arquitecto Philip Webb en 1859 , se encuentran ya muchos de los elementos que caracterizarían la arquitectura "Arts \& Crafts". Webb siguió ya entonces el principio de contar para su ejecución con cuantos materiales y artesanos locales fuera posible, tratando así que la casa se convirtiera en un elemento más del paisaje y la cultura característicos del lugar, entonces un entorno más rural de lo que es hoy en día. El arquitecto utilizó lo vernáculo como una herramienta que trascendía ya sus aspectos formales y compositivos.

Especialmente interesantes por su manejo de las tradiciones locales serán las obras de Ernest Gimson, tales como su Stoneywell Cottage, construida cerca de Leicester en 1897, o las casas que construyó en Devonshire, en las que utilizó sin reparo técnicas de construcción de la tradición local como los muros de tierra, erigidos en esta región con la técnica del "cob", o las cubiertas de pasto.

En fechas similares Richard Norman Shaw experimentaba con situaciones más complejas, trabajando con frecuencia en entornos urbanos donde el lenguaje arquitectónico que caracterizaba el paisaje urbano era más elaborado. La respuesta de Shaw, integrando 
elementos vernáculos y otros más "cultos" en un mismo diseño, de forma similar a como sucedía generalmente en cualquier tradición arquitectónica, sería llevado más adelante por Sir Edwin Lutyens hasta un grado de libertad y creatividad con escasos precedentes. Y, al igual que operaban de forma diversa en entornos rurales y urbanos, también trataban de adaptar su arquitectura a cualquiera que fuera el contexto cultural en el que trabajaran, de lo que resulta especialmente paradigmático la casa que Charles Francis Annesley Voysey diseñó en Asuán, Egipto, en 1905.

También se extendería el movimiento por Norteamérica, donde surgieron varias sociedades dedicadas a su promoción. Un personaje fundamental en el proceso fue Gustav Stickley, fundador de los Craftsman Workshops en Syracuse, Nueva York, cuyos productos se convertirían un referente estético en el espacio doméstico norteamericano de aquel tiempo. Fue también el creador de la revista The Craftsman, publicada desde 1901 a 1916, que contribuyó de forma decisiva a la difusión de estas ideas por el país. Sólo sobre estas bases puede comprenderse el nacimiento de otras corrientes que buscaban desarrollar una arquitectura que respondiera al particular paisaje en el que trabajaban, como la que se conocería como Escuela de la Pradera, integrada por arquitectos como Frank Lloyd Wright, George G. Elmsie, George Maher o William G. Purcell. Idéntica raíz se encuentra previamente en la obra de Henry Hobson Richardson. Y lo mismo puede apreciarse en el trabajo de los hermanos Charles Sumner Greene and Henry Mather Greene, quienes crearon verdaderos templos de las artes y los oficios, como sus conocidas obras en Pasadena, California, recreándose en el uso de la piedra, la madera, e incluso el adobe, como en la Walter L. Richardson House de Porterville, California, construida en 1929.

También tienen ese mismo origen la arquitectura conocida como Pueblo Revival, que se popularizó en Nuevo México en las décadas de 1920 y 1930, bien representada por trabajos como los de John Gaw Meem; o la que adoptaría el nombre de Mission Revival Style, que recurriría al lenguaje vernáculo de las antiguas misiones españolas en territorio norteamericano y que tuvo su momento de esplendor aproximadamente de 1890 a 1915, fecha a partir de la que fue evolucionando hacia lo que iba a conocerse como Spanish Colonial Style, y que fue también promocionada a través de The Craftsman (Smith 1983, 66). Esta última corriente fue imponiéndose gracias a los viajes y publicaciones que acercaron las tradiciones arquitectónicas españolas a los arquitectos estadounidenses. Esta 
arquitectura, inspirada en la tradición española pero de carácter netamente local, fue especialmente popular en antiguos territorios españoles como Florida y California, donde ese lenguaje local iría definiendo una serie de rasgos que conformarían finalmente el denominado California Style. Este giro hacia la arquitectura vernácula en la Norteamérica española sería protagonizado por arquitectos como Bertram Grosvenor Goodhue, George Washington Smith, Myron Hunt, Julia Morgan, Wallace Neff, Irving John Gill o Addison Mizner.

A su vez, esta influencia iba a extenderse igualmente por el continente europeo ${ }^{12}$, contribuyendo a conformar muy distintas respuestas al problema de la identidad local, desde identidades arquitectónicas de nuevo cuño, inventadas con fines nacionalistas, hasta muy distintas exploraciones de lo vernáculo y de su integración en la arquitectura del momento. Todo ello ha quedado relativamente desatendido en la historiografía arquitectónica, que frecuentemente se limita a recordar la oposición entre lo que se denomina regionalista o tradicionalista y la arquitectura de estilo moderno, tratando además de asociar de forma generalizada lo primero a lo reaccionario e incluso a lo totalitario.

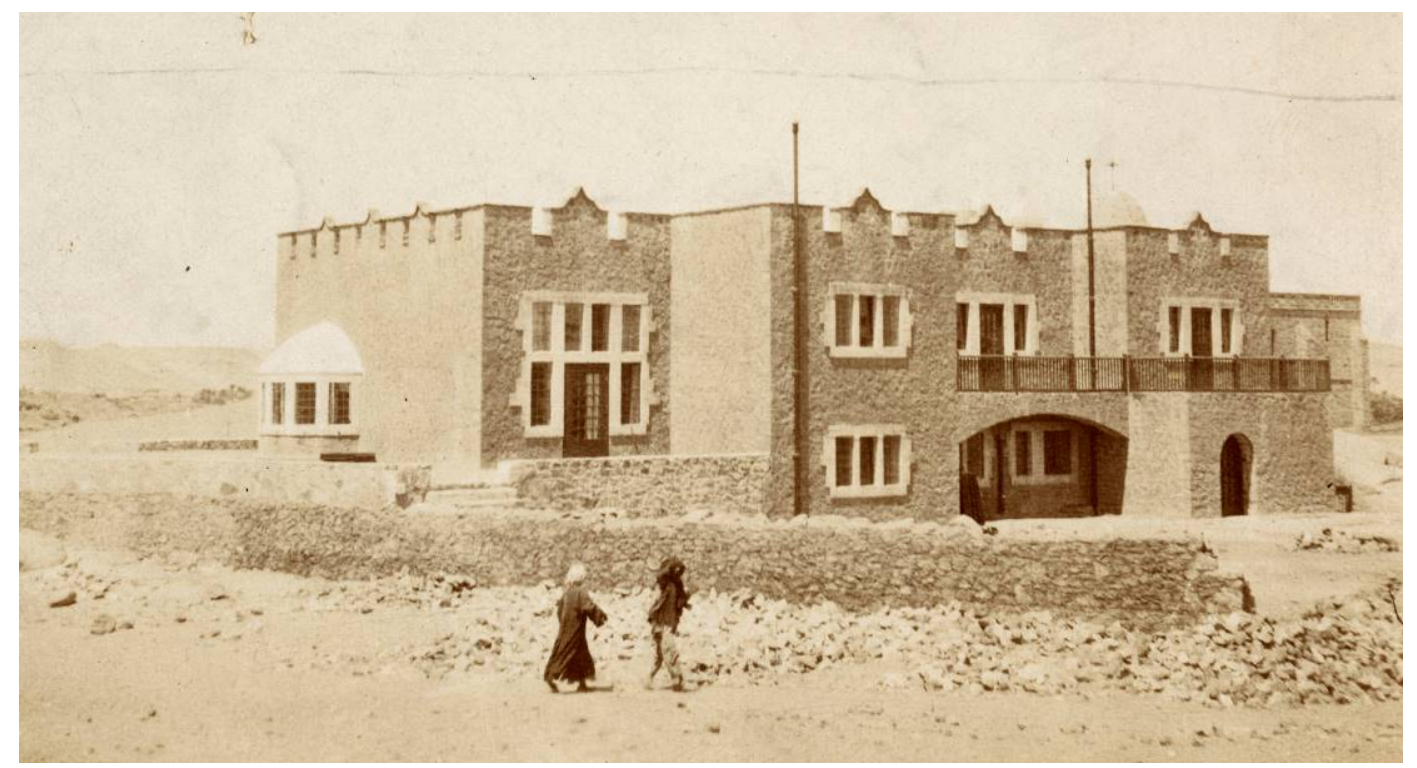

Casa diseñada por C. F. A. Voysey para Asuán, Egipto, en 1905 (Ref. web. suburbancitizen.files.wordpress.com, visitada el 1 de abril de 2017)

\footnotetext{
${ }^{12}$ Cuestión de la que trata el siguiente apartado.
} 


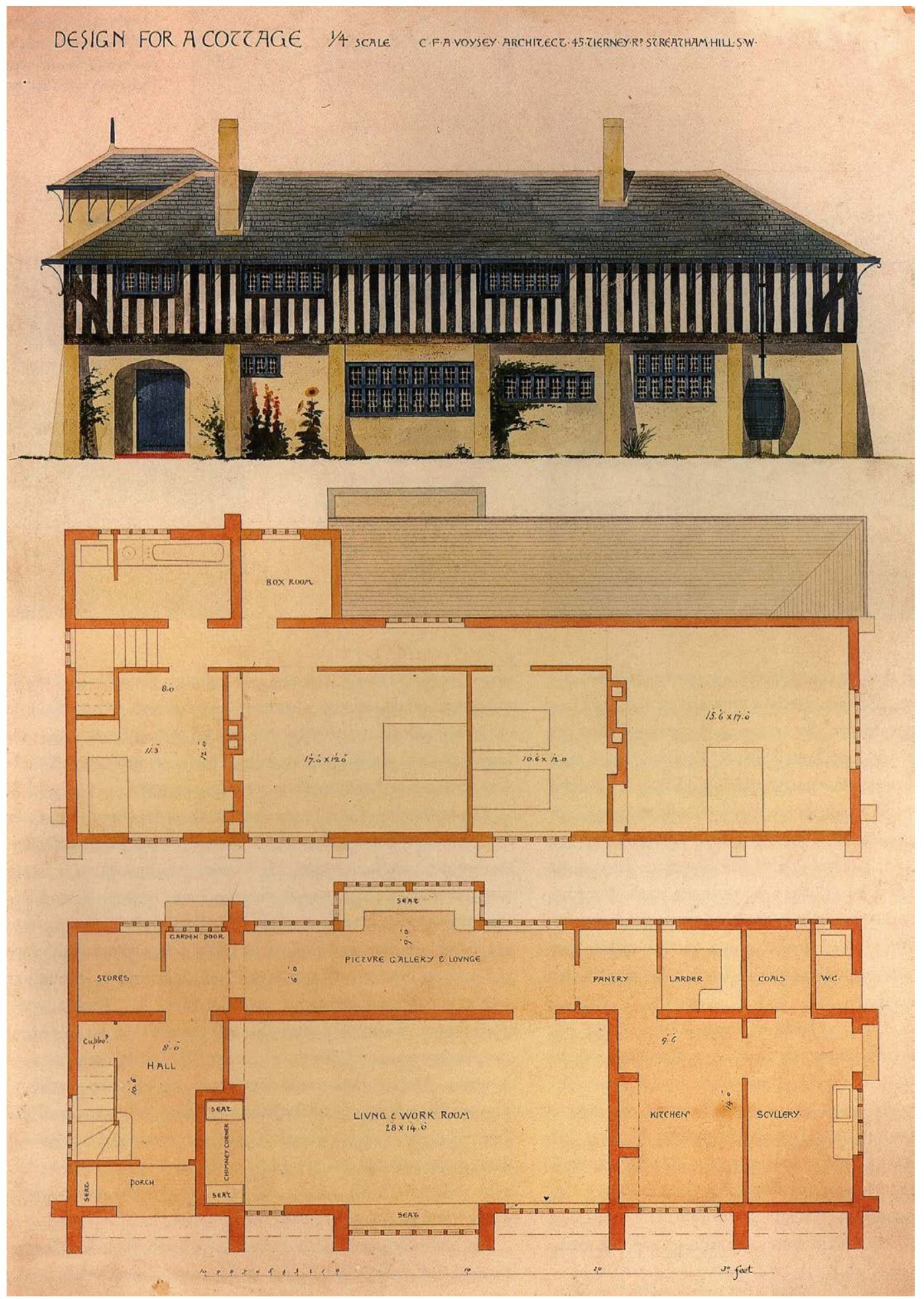

Diseño para una casa de entramado de madera realizado por C. F. A. Voysey en 1885 (Davey $1995,91)$ 


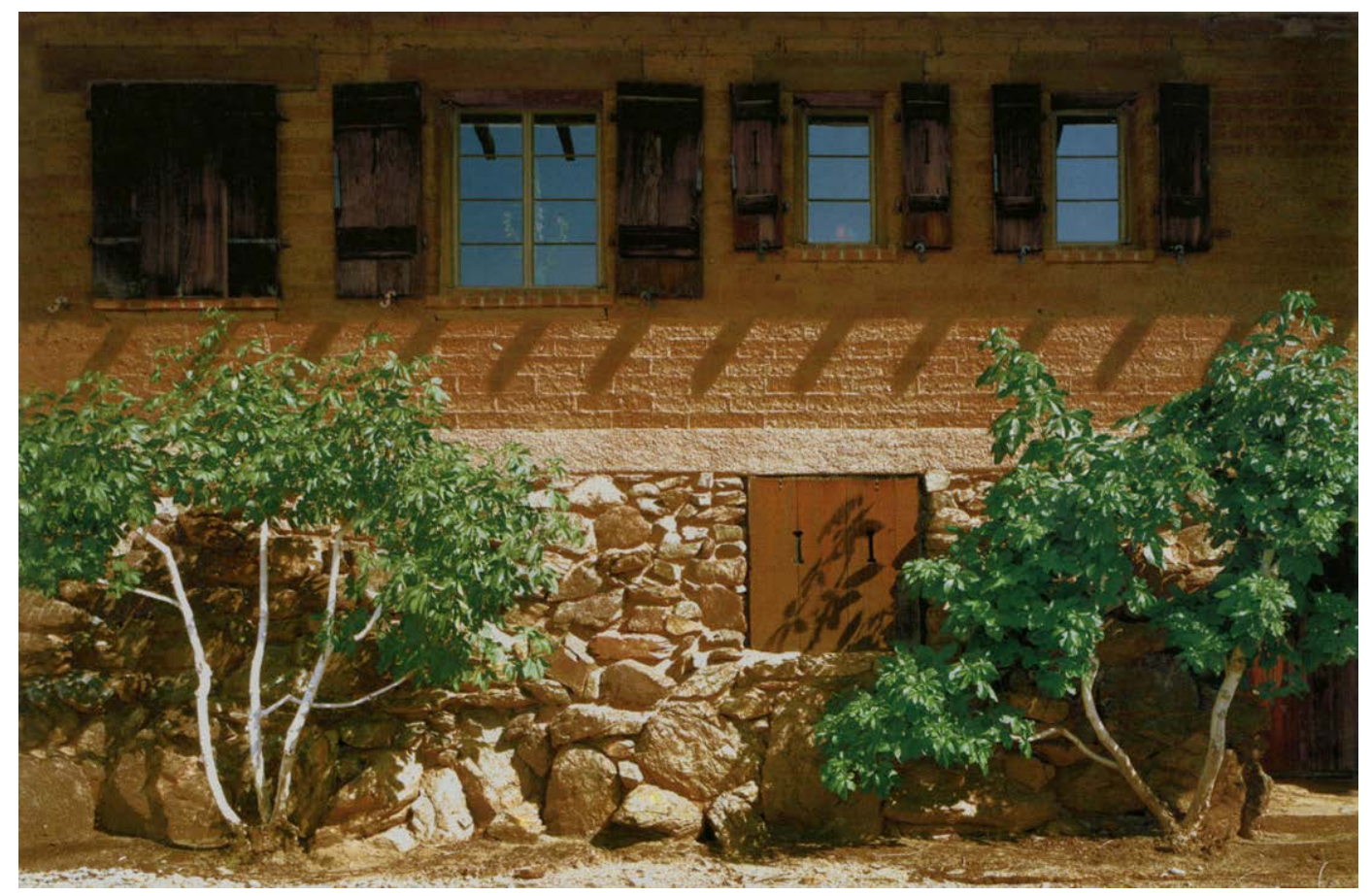

Detalle de la fachada de la Casa Walter L. Richardson, en Poterville, California, diseñada por Ch. S. Greene y H. M. Greene en 1929 y edificada en piedra, madera y abobe (Rand 2005), y vista de la Biblioteca Zimmerman de la Universidad de Nuevo México, Albuquerque, Nuevo México, diseñada por John Gaw Meem y realizada entre 1936 y 1938 (fotografía del autor, marzo de 2018)

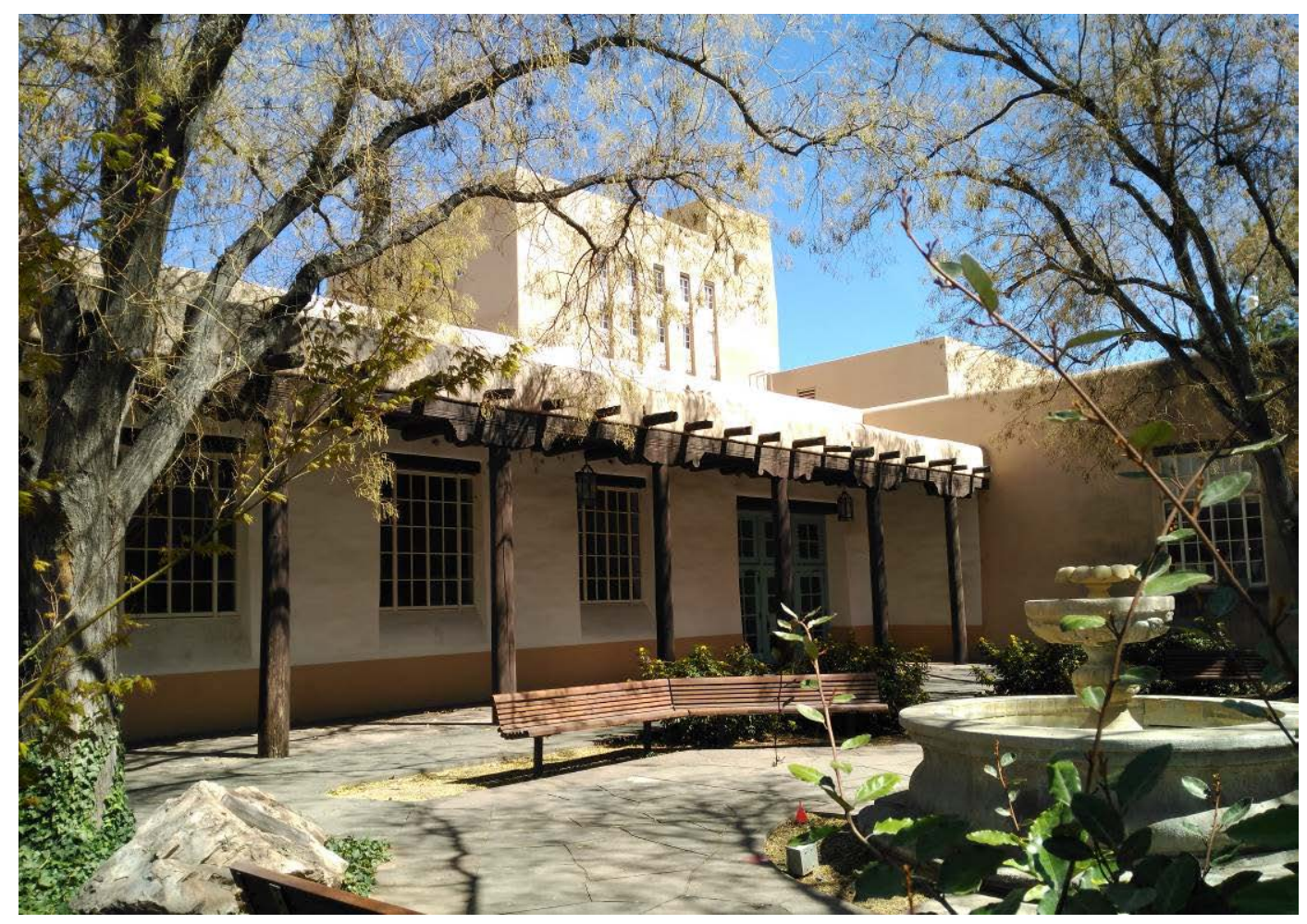




\subsection{NUEVAS EXPERIENCIAS DESARROLLADAS DESDE EL REGIONALISMO ARQUITECTÓNICO}

Hasta bien entrado el siglo actual se han construido en España casas de campo francesas, inglesas, suizas, pero muy pocas españolas. Cuanto más exótica, mejor le parecía a su propietario, quien ignoraba el triste papel que hacía pidiendo prestadas al extranjero las formas arquitecturales que el propio país brindaba en abundancia, incomparablemente mejores y mejor adaptadas a su clima.

La furia del exotismo empezó en la alta sociedad y fue ganando poco a poco la masa. Se olvidó por completo lo sugestivo y bello que es una solana, un portalón, una socarreña. Desapareció el valiente alero y hasta la teja morisca, la más española entre todas, tuvo que ceder ante materiales tan antiestéticos como la teja plana, impropios para el clima como la teja francesa y otros de este jaez.

Alfredo Baeschlin, Casas de campo españolas, 1930

La llegada de las ideas del movimiento Arts \& Crafts al Continente, a una Europa sumida en el proceso de creación y definición de sus identidades nacionales y regionales, iba a encontrar un fértil terreno para su arraigo y expansión. Además, los progresos de los estudios etnográficos, el redescubrimiento del mundo rural y del folklore, el desarrollo de la moderna concepción del patrimonio histórico-artístico y las inquietudes despertadas por la cuestión de la representación nacional y local en el marco de las exposiciones universales reforzarían este proceso. Lo mismo sucedería en otras naciones que habían ya comenzado a sufrir los efectos de la industrialización sobre su paisaje tradicional y su estructura social artesanal, como en el ya mencionado caso de Estados Unidos o en el de Japón, donde se vivía además un severo proceso de occidentalización y donde especialmente en las décadas de 1920 y 1930 se iba a desarrollar el "mingei", un importante movimiento de reivindicación de la tradición y las artesanías locales en torno a la figura del pensador Yanagi Sôetsu, también conocido como Yanagi Muneyoshi. 


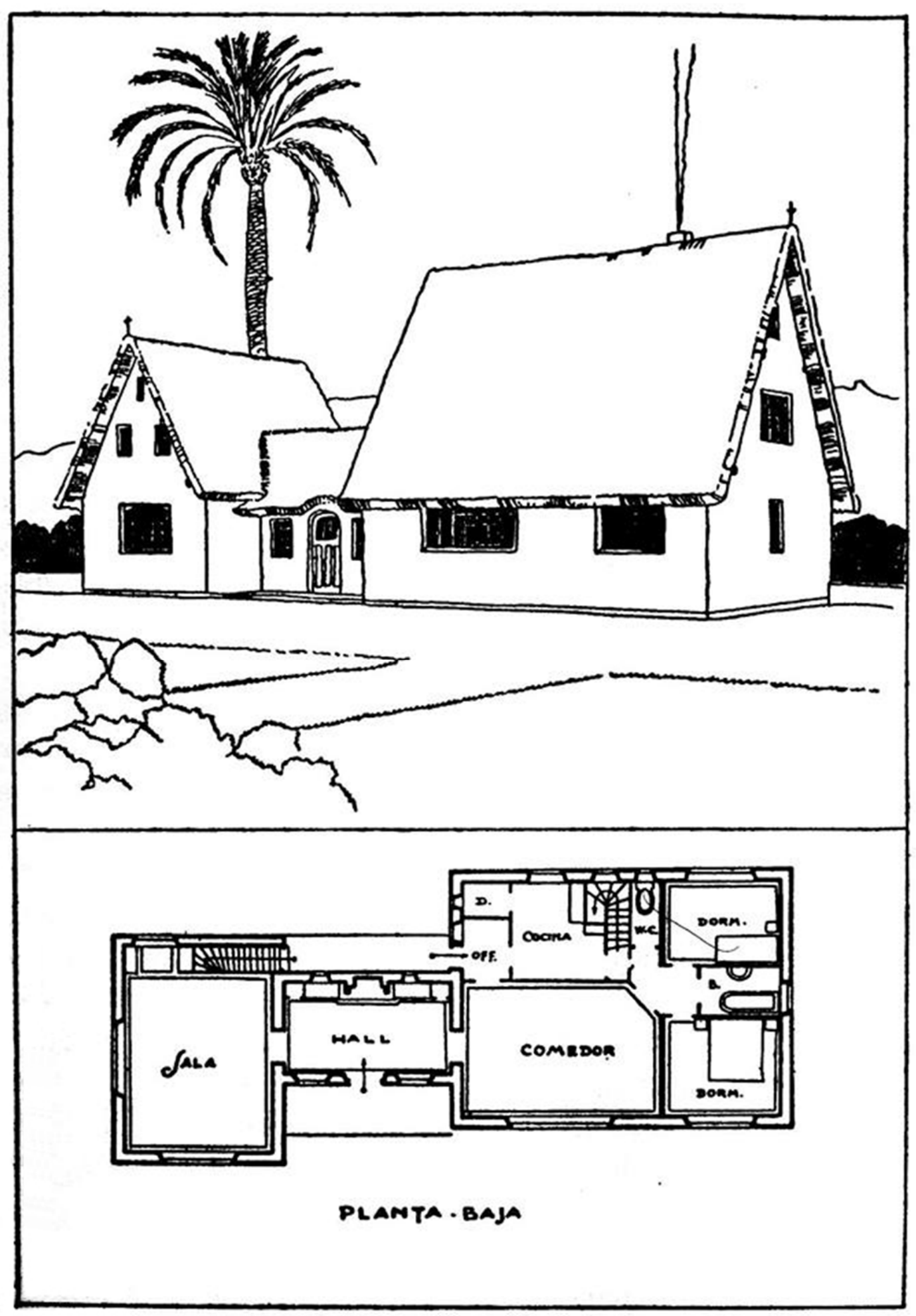

Propuesta de casa de campo por Alfredo Baeschlin, tomando como referente para su diseño la barraca valenciana (Baeschlin 1930a, 26) 
El debate sobre las identidades regionales se desarrolló fundamentalmente a partir de 1890, cuando el proceso de creación de las correspondientes identidades nacionales se había consolidado, y posiblemente como reacción ante el reduccionismo que éste había supuesto. La reciente construcción nacional se veía como una amenaza para las identidades locales. En política, esta reivindicación no buscaba atacar la unidad nacional, sino fortalecerla reconociendo y potenciando la diversidad existente en su seno. No en vano, una de las consignas regionalistas fue la estimulación de la variedad dentro de la unidad (Vigato 1994, 18-21; Storm 2010, 53).

De hecho, el regionalismo, al menos en sus primeras décadas, no se asoció a movimientos nacionalistas regionales. No sorprende, por ello, que una región como Cataluña, con una fuerte demanda de cuantos elementos contribuyeran a reforzar una identidad propia, buscara desarrollar una arquitectura particular más desde el modernismo que desde el regionalismo. Aunque ha de señalarse que parte de lo que a menudo la historiografía de la arquitectura ha encuadrado en el modernismo, y en espacial en sus comienzos, en lo que algunos han denominado el modernismo de la Renaixença, tiene un fuerte carácter autóctono y un discurso muy cercano, y ligeramente anterior, al que tendría luego el regionalismo. En todo caso, Pedro Navascués, uno de los historiadores de la arquitectura que más han estudiado la arquitectura de este período, llamó ya la atención sobre este hecho en su artículo "Regionalismo y arquitectura en España (1900-1930)", publicado en la revista $A \& V$ en 1985. Refuerza este argumento la repercusión que tuvo en Barcelona el movimiento de las Arts \& Crafts, que llevó a la cultura catalana del momento a tratar de revitalizar los oficios tradicionales de la construcción, fundándose la Asociación para el Fomento de las Artes Decorativas en 1877, así como agrupaciones gremiales semejantes a sus coetáneas británicas, como el Taller del Castell dels Tres Dragons (1889-93). Así como que algunos de los principales protagonistas de la arquitectura catalana del cambio de siglo, como Josep Puig i Cadafalch o Lluís Domènech i Montaner, estuvieran vinculados al nacionalismo político. Y que tanto Domènech i Montaner como Puig i Cadafalch abogaran por estudiar y adaptar a su tiempo las tradiciones arquitectónicas patrias, idea que, además de reflejar ambos en su obra, plasmaría el primero en 1878 en un texto titulado En busca de una arquitectura nacional. Consecuentemente, fueron tempranos estudiosos de la arquitectura popular tradicional. Por ello, Leoonardo Rucabado, quien fuera uno de los adalides del regionalismo español y estudió la carrera de arquitectura en Barcelona, se sentía en deuda con su maestro Domènech i Montaner 
por haber sido éste el primero que despertara su interés por lo regional, contando como en sus clases se prestaba atención a "la plateresca pompa de los palacios castellanos, los bermejos tonos de las fábricas aragonesas de ladrillo, la fastuosa lozanía de las góticas mansiones catalanas, algún churrigueresco prurito de posadas andaluzas, la runfante y blasonada apostura de la casa montañesa y hasta la poética simplicidad primitiva de las barracas de la Albufera valenciana" (1916, 1-9).

Lo que realmente se buscaba en esa recién descubierta diversidad regional era en ocasiones algo tan abstracto como hallar la esencia de un pueblo o una nación, sus verdaderas raíces, entendiendo generalmente que éstas podrían hallarse estudiando las tradiciones rurales más sencillas y primitivas. Otras veces, sin embargo, el objetivo era sencillamente mantener viva la riqueza cultural que esa diversidad comportaba.

Jean Charles-Brun, fundador de la Fédération régionaliste française (F.R.F.) en el año 1900, encontró además en el renacimiento de las regiones la solución para un problema social: el abandono del mundo rural por la necesaria emigración a las ciudades. El fortalecimiento de la pequeña industria local, potenciando lo artesanal, parecía ser la única vía para detener ese proceso (Vigato 1994, 19-21). Esta idea sigue vigente hoy en día, siendo el argumento esgrimido por un buen número de proyectos contemporáneos para el desarrollo rural. En todo caso, el regionalismo normalmente no se caracterizó por un rechazo absoluto de la producción industrial, como propugnaran Ruskin o Morris. Por el contrario, fue común el tratar de revitalizar los oficios artesanales estandarizando y optimizando sus procesos de producción para hacerlos más competitivos frente a la industria. Sobre este tema en particular resulta de gran interés el artículo "La normalización de la arquitectura vernácula. Un debate en la España de los veinte", escrito por Carlos Sambricio y publicado en la Revista de Occidente en el año 2000, así como el texto de Maiken Umbach “The Deutscher Werkbund and Modern Vernaculars” (2005, 114-140).

Finalmente, en el norte y centro de Europa, el regionalismo se relacionó además con frecuencia con otras corrientes reformistas, movimientos conocidos en Alemania como "Lebensreform" (reforma de los hábitos de vida). Muchos regionalistas compartían una especial apreciación de la naturaleza y la ecología y una fuerte admiración por lo "auténtico" y lo popular con grupos tales como promotores de la excursión al campo, 
organizaciones para la defensa del patrimonio construido o paisajístico, reformistas educativos, comunidades anti-maquinistas, nudistas, vegetarianas, etc. (Gutschow 2010, 154; Storm 2010, 96). En el caso español, sin embargo, tal vez por la escasa repercusión que había tenido aún la industrialización sobre el paisaje urbano, la arquitectura regionalista no se presentó generalmente como un movimiento reformista dirigido a propagar un estilo de vida más sano, natural o auténtico, aunque sí puede ponerse en relación con el Regeneracionismo.

El período que se extiende entre 1890 y 1939 fue la época del auge del movimiento regionalista, que se manifestaría en todos los ámbitos de la cultura. Tanto las humanidades como las artes, incluyendo la arquitectura, las letras o la música buscaron en lo vernáculo respuestas para las cuestiones de su tiempo. Sin embargo, a partir de la década de los 20 su predominio se vería amenazado por nuevas corrientes internacionalistas. La apropiación de algunas de las reivindicaciones del regionalismo por parte de algunos regímenes autoritarios como herramienta para combatir a sus adversarios ideológicos sería letal para el futuro de este movimiento. Durante las dos décadas que siguieron a 1945 esas corrientes internacionalistas fueron idealizadas como víctimas del autoritarismo. Al mismo tiempo, toda reivindicación de lo tradicional, fuesen cuales fuesen sus fines y argumentos, quedaría proscrita, siendo etiquetada como reaccionaria. En el caso español, esta condena llegaría casi diez años más tarde y de forma progresiva. El nacionalismo, las necesidades de la posguerra y la autarquía habían amparado la continuidad en nuestro país de algunos géneros de tradicionalismo, pero éstos no lograrían sobrevivir al advenimiento del desarrollismo y a las nuevas directrices ideológicas con las que el Régimen iba a impulsarlo.

Se trató, sin embargo, de un movimiento complejo, que presentó múltiples vertientes, con variaciones y particularidades en cada una de las áreas en las que se desarrolló. Los matices entre las diversas visiones de lo tradicional o de lo vernáculo a las que dio lugar se manifestaron en forma de irreconciliables debates entre ellas, siendo buenos ejemplos de ello lo acontecido en el ámbito de la arquitectura en España o en Alemania, tal como se explicará más adelante.

Además de la ya explicada aportación inglesa, fundamental para el desarrollo del pensamiento arquitectónico del momento sería así mismo el trabajo de Hippolyte Taine. 
En su Filosofía del arte (1957), publicada en varias entregas entre 1865 y 1882, explicaba cómo cualquier obra humana se encuentra determinada por la "raza", el "medio" y el "momento" de quienes la producen, es decir, condicionada por la cultura, el entorno físico y la época en que se ha producido. Los arquitectos, reflexionando sobre este método de análisis, podían comprobar cómo las obras producidas por la cultura de su tiempo efectivamente variaban con la difusión de cada nueva moda pero que, sin embargo, apenas existía diferencia entre los edificios diseñados para una u otra región. Así, el sistema de estudio propugnado por Taine iba a señalar a los arquitectos del cambio de siglo el elemento que parecía estar siendo ignorado por la arquitectura del momento: el lugar, lo vernáculo.

Esta idea pronto encontraría su réplica en España sirviendo de base durante las décadas siguientes para comprender y explicar el fenómeno de la arquitectura popular tradicional en nuestro país. Ángel Ganivet, en su Idearium español, publicado en 1897, hablaba de la "raza" y el "clima" como condicionantes de las creaciones humanas (1977, 63). Así, numerosos trabajos posteriores, siguiendo a Taine y a Ganivet, se refieren a la dependencia de la arquitectura tanto de factores puramente humanos - a los que se refieren como raza, pueblo, estilo, cultura o costumbres - como de factores del medio físico - enumerados éstos como país, tierra, clima, geografía, materiales o producciones - (Lampérez y Romea 1922, 35; Baeschlin 1930a, 11; Torres Balbás 1988, 149; García Mercadal 1930, 7-8; Cárdenas 1944, 7; Flores 1973 - 1977, vol. 1, 14). Lo mismo ocurriría con la noción hegeliana del Volkgeist, que con gran premura se trasladaría al pensamiento español como "espíritu del territorio" (Cruz Cruz 1998, 246-247) y que estaría detrás del concepto unamuniano de "intrahistoria" (Unamuno 2005, 264), la historia de lo cotidiano, de lo popular, de lo que mantiene su continuidad al margen de los grandes hechos históricos. Fue también Miguel de Unamuno quien introdujo el concepto de "tradición eterna", del que se ha hablado ya en el apartado correspondiente y que sería el principio sobre el que fundamentarían su trabajo muchos arquitectos durante décadas, citándolo explícitamente muchos de ellos al hablar de su trabajo prácticamente hasta nuestros días.

La citada obra de Ganivet, así como su texto Granada la bella (1896), en el que reivindicaba la preservación de la identidad tradicional de esta ciudad y planteaba ya algunos de los problemas que esa conservación implicaría afrontar, serían importantes 
referencias para la arquitectura regionalista española, junto con los numerosos escritos sobre el paisaje y el carácter españoles de Azorín y Unamuno, y en especial la obra que este último tituló En torno al casticismo (1895).

La influencia de las ideas de John Ruskin tanto en Ganivet como en Unamuno es significativa, sea ésta directa o indirecta, especialmente en su desconfianza en la máquina y en su condena al utilitarismo en la arquitectura (Ganivet 2011, 76-77, 122-123; Unamuno 2011, 159-164).

En el campo de la arquitectura la difusión del regionalismo llegó en un momento en el que los profesionales se hallaban ávidos por hallar una arquitectura que fuese apropiada para la época y el lugar en los que les correspondiera trabajar. También en su caso iban a buscar la respuesta a este problema en las arquitecturas de carácter más popular. El propio Ganivet lo planteaba en estos términos $(2011,119)$ : "Sin contar los estilos importados de fuera y modificados según las esencias locales, cada país tiene un estilo arquitectónico propio que se descubre en las construcciones pobres, en que lo natural está poco transformado por el arte. Para penetrar en el pensamiento íntimo de una ciudad no hay camino mejor que la observación de sus creaciones espontáneas; porque en las adaptaciones de lo extraño a lo local el espíritu trabaja sobre un tema forzado y no puede levantar el vuelo".

Sin embargo, el conocimiento que los arquitectos tenían de lo vernáculo no podía ser sino muy vago, pues carecían de formación al respecto y su estudio era aún un campo de investigación incipiente. Por ello, el regionalismo supuso la exploración de un ámbito completamente novedoso. Nos han llegado muchos testimonios que reflejan esta situación. El arquitecto Pedro Guimón, por ejemplo, en su introducción al libro del suizo Alfredo Baeschlin La arquitectura del caserío vasco (1930), nos cuenta cómo éste "vino primero en busca de documentación para una casa de estilo vasco que le habían encargado en Biarritz. Quedó sorprendido de lo poco que podía servirle lo comenzado a reunir por la Sociedad de Estudios Vascos en su hermosa biblioteca de San Sebastián, y asombrado de lo mucho que quedaba por hacer. Como ya hiciera en otras latitudes, se incrustó en el país -única forma de conocerlo a fondo- y se puso a estudiar sistemática y metódicamente la arquitectura rural" (1930b, 12). E Isabel Ordieres cita a Javier González de Riancho, amigo y seguidor de Leonardo Rucabado, contando cómo acompañaba a éste en "sus 
aventuradas excursiones en coche de caballos, y en algunos tramos más accidentados a pie, cargando con su pesada máquina fotográfica, trípode, bloc de dibujo, etc., recogiendo fotografías de casonas, palacios, capillas, torres, portaladas e innumerables detalles de aleros y solanas" $(1987,9)$.

La cultura europea se lanzó al redescubrimiento del mundo rural. En el caso español, instituciones como la Sociedad Española de Excursiones, fundada en 1893, y ‘personajes como Manuel Bartolomé Cossío, Elías Tormo, Vicente Lampérez o Manuel GómezMoreno, a los que se sumarían poco después otros como Leopoldo Torres Balbás o Teodoro Anasagasti, impulsaron a arquitectos e investigadores a salir al campo, a redescubrir un país en gran medida desconocido, a fotografiar, dibujar y documentar sus paisajes y arquitecturas, así como sus costumbres populares.

Imbricar su arquitectura en la tradición local implicó para los arquitectos regionalistas experimentar con muy diversas soluciones, siempre en busca de lograr enraizarla en la cultura material de cada lugar. No se trataba de copiar o replicar modelos del pasado. Tampoco estaban ya obligados por la necesidad a diseñar respetando los condicionantes del medio físico en el que trabajaban, tal como sucedía en gran medida con la arquitectura popular tradicional (Canizaro 2007, 20). Diseñaban, por el contrario, en base a elecciones conscientes y deliberadas en las que el arquitecto determinaba o no estudiar y respetar aspectos como el clima, los materiales, los sistemas constructivos, los trabajos artesanales o las formas que fueran propios de cada lugar, actualizándolos al mismo tiempo a través de novedosos diseños con los que al mismo tiempo intentaban dar respuesta a las necesidades de su época. Ya no se trataba de arquitecturas campesinas, concebidas para una sociedad y una economía de subsistencia, sino de edificios adaptados a los usos y costumbres del momento. En palabras del francés Léandre Vaillat, las nuevas construcciones no podían replicar, sino actualizar, la arquitectura del pasado, ya que sus habitantes no instalarán "un estercolero frente a su puerta, ni dormirán todos en la misma estancia, ni vivirán sobre tierra apisonada, nunca usarán horcas, ni comerán sólo gachas, no permitirán a las gallinas entrar a la cocina y no dormirán en catres" (1913, 284). Se hablaba de la tradición, una vez más, como algo siempre cambiante y en perpetua transformación, como un proceso que implica imitación e invención, lejos del estatismo propio de la réplica. Otro de los protagonistas de la arquitectura española de entonces, Luis María Cabello Lapiedra, explicaba en 1917 cómo "el estilo nacional debe surgir 
dentro de las características populares y regionales. Copiar por copiar los estilos de pasadas épocas será la muerte de lo que hemos dado en llamar Arte español” $(2009,14)$.

Este rechazo a la simple copia se extendía también al plano constructivo, donde se reaccionó a menudo contra la simulación de detalles de la tradición constructiva por medio de materiales de menor coste y calidad, es decir, contra los sucedáneos de los que hablaban Fourier y Morris. Para muchos de los arquitectos del regionalismo, la arquitectura tradicional era un modelo de autenticidad constructiva y persiguieron esa misma cualidad en sus propias obras. Por ello, el arquitecto francés Louis Sézille publicó un artículo en 1908 donde lamentaba que sólo una de cada ocho nuevas casas de carácter normando hicieran uso de verdaderos entramados de madera, mientras que en el resto no eran sino simulaciones realizadas con mortero (Storm 2010, 131). Años más tarde, en 1926, el español Joaquín de Yrizar rechazaba esta misma práctica en la revista $L a$ Construcción Moderna, al estar dando lugar a edificios que para acentuar su carácter vasco recurrían a entramados de madera fingidos en cemento pintado de verde o azul (Yrizar 1926, 37-42).

Criticaron también los regionalistas más ortodoxos el uso de lenguajes excesivamente populares o rurales en contextos urbanos en los que éstos nunca habían tenido cabida, con lo que deterioraban al actuar de este modo la particular identidad del campo y de la ciudad (Storm 2010, 92). Este concepto está relacionado con lo que los arquitectos y urbanistas norteamericanos Andrés Duany y Elizabeth Plater-Zyberk, fundadores del Nuevo Urbanismo, han denominado "urban-to-rural transects" o transiciones del carácter de lo urbano al de lo rural.

Otros regionalistas, como Paul Schultze-Naumburg, condenaron igualmente las obras que por su indiscriminado uso de fórmulas en ocasiones excesivamente elaboradas y en otras demasiado esquemáticas, conducían pérdida de jerarquía entre lo vernáculo y lo monumental, de forma que "las casas obreras parecían palacios, los palacios, chalets suizos, las granjas, prisiones, las prisiones, iglesias, y las iglesias, estaciones de tren" (1908, 123-125). Esta cuestión, publicada por Schultze-Naumburg en su conocida revista Kulturarbeiten, sería planteada en términos similares décadas después por Leon Krier en La arquitectura de la comunidad, y puede identificarse también entre las conclusiones de esta tesis. 
Sin embargo, estas ideas no fueron homogéneamente asumidas. La propia naturaleza investigadora y experimental de este movimiento conllevó un proceso de descubrimiento de la esencia de esas tradiciones que reivindicaban. Pedro Guimón se manifestaría pronto insatisfecho, por ejemplo, con la casa de carácter vasco que él mismo había realizado en Zumaya para uno de los más destacados pintores del regionalismo español, Ignacio Zuloaga, por haberse teñido su diseño de influencias foráneas que la habían alejado del "alma vasca" (1924, 168-172).

Reflejo de esta heterogeneidad es también el efecto inicial de la difusión de las ideas del movimiento Arts \& Crafts británico en numerosos arquitectos del resto de Europa. Muchos de quienes se convertirían en algunos de los principales exponentes de la corriente regionalista tomaron en ocasiones de forma literal su defensa de la revitalización de la tradición arquitectónica inglesa. Se diseñaron entonces por toda Europa edificios inspirados en la arquitectura vernácula inglesa: el Palacio Real de la Magdalena, de Javier González de Riancho y Gonzalo Bringas (1908-12), la casa para Maurice PillardVerneuil, del francés Pierre Sézille (1910), el Palacio de Artaza (1914), de Manuel María Smith Ybarra, o el Palacio de Cecilienhof (1914-17), del alemán Paul Schultze-Naumburg son buenos ejemplos de esta práctica, pese a ser todos sus arquitectos importantes representantes del regionalismo arquitectónico. En el equivalente francés a la revista británica Country Life, La Vie à la Campagne, que se comenzó a publicar en 1906, se publicó en el número de verano de 1909 un interesante debate sobre cómo podían los arquitectos tratar de integrar estas recientes aportaciones británicas en la tradición francesa.

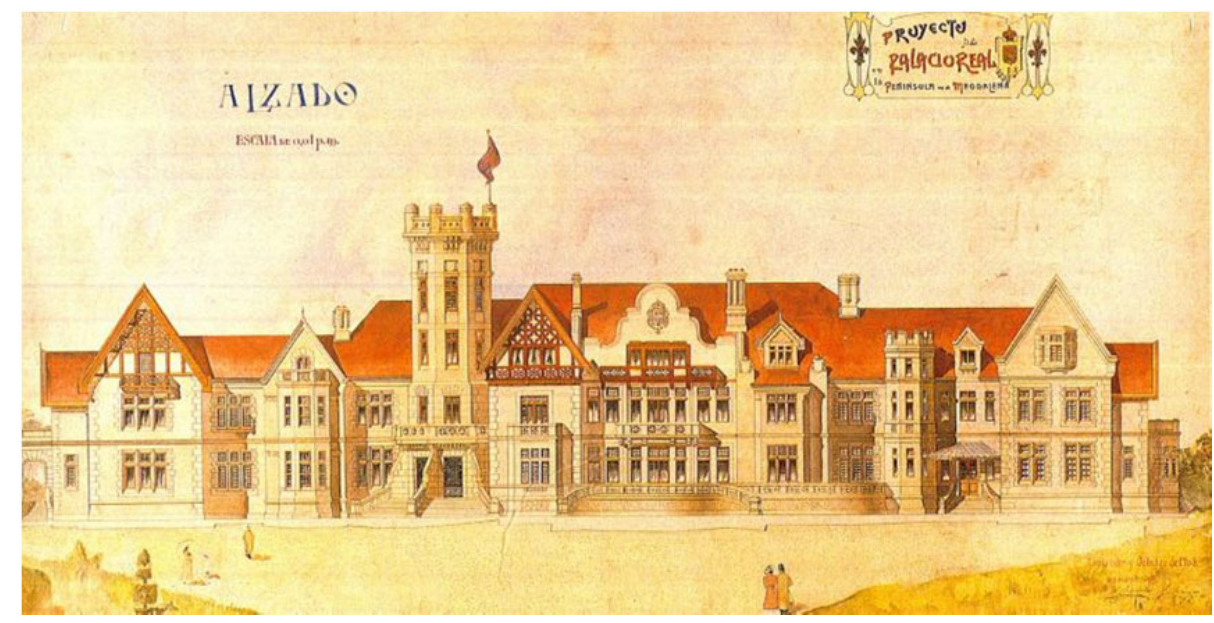

Palacio Real de la Magdalena, de Javier González de Riancho y Gonzalo Bringas (1908-12) 
Del mismo modo, las búsquedas de estilos pasados que, por ser característicos del país, pudieran representar a toda una nación, tan comunes durante buena parte del siglo XIX, convivirían en las primeras décadas del siglo XX con las nuevas ideas regionalistas, tanto con planteamientos en los que el estudio y actualización de las arquitecturas regionales existentes podría conducirles al desarrollo de unos anhelados nuevos estilos nacionales, como, más adelante, con propuestas en las que, con el análisis de la arquitectura tradicional, extrayendo de ella sus principios esenciales, y especialmente de sus ejemplos más populares, se pretendía principalmente crear arquitecturas que resultaran más apropiadas para los lugares en que se edificaban.

Así acontecía en la España de principios del siglo XX, donde se sucedían aún los intentos de buscar un estilo nacional, bien fuera en el mudéjar, bien en el plateresco, o bien en alguna de las recién descubiertas tradiciones regionales (Navascués Palacio 1985, 28-35; Hernández Martínez 2007, 33-34). Un buen ejemplo de estas tendencias es el pabellón español en la Exposición Universal de París de 1900, diseñado por José Urioste, quien recurrió al poder evocador del plateresco hispano. Mientras tanto, la búsqueda del espíritu de la nación en lo regional se muestra en las numerosas arquitecturas regionalistas diseñadas fuera del contexto del que eran originarias, pudiéndose encontrar así, por ejemplo, edificios de inspiración vasca o montañesa en muy distintas regiones españolas, práctica que sería duramente criticada por los regionalistas más ortodoxos.

Vicente Lampérez y Romea, cuyas enseñanzas y escritos tuvieron un papel fundamental en el desarrollo del regionalismo español, confiaba en que ese nuevo estilo nacional se conformara de forma progresiva, "por la adaptación sucesiva, lógica y ordenada de nuestras formas tradicionales, conservando en ellas lo que es inmanente: el genio de la raza sobrio y robusto en lo espiritual, y el país y el cielo, en lo material”. Para Lampérez, sólo "cuando a fuerza de adaptaciones se hayan modificado los estilos tradicionales, el estilo nuevo y nacional habrá surgido" (1911, 198-199). Otros arquitectos, sin embargo, y especialmente en la generación posterior a la suya, agrupándose en torno a la figura de Leopoldo Torres Balbás, considerarían que perseguir el objetivo de desarrollar una arquitectura nacional era un empeño inútil, al no haber existido nunca tal cosa. Para ellos, lo que caracterizaba la identidad de un país era una multiplicidad de tradiciones locales que se manifestaban tanto en la arquitectura de estilo como en la popular, pero de forma particularmente característica en esta última. 
Torres Balbás afirmaba que la arquitectura española se había caracterizado precisamente por un tradicionalismo tan vigoroso que había sido siempre capaz de convertir en algo propio y local cuantas influencias habían llegado del extranjero (1996a, 19; 1996b, 2325). Para él, era por ello urgente estudiar y conocer las arquitecturas populares de la tradición española, pues sólo comprendiéndolas y dominándolas podrían los arquitectos españoles seguir asimilando e integrando en su propia tradición aquellas corrientes cultas que siguieran llegando desde fuera. Acuñó para denominar esta última variedad de regionalismo, que promovería tanto en sus obras y escritos como a través de su importante labor docente, el término "sano casticismo". Creía que la incultura artística era lo que había llevado a que algunos profesionales cultivaran "estilos extraños a nuestra tierra" y, en consecuencia, en su conocido artículo "Mientras labran los sillares", publicado en 1918 en la revista Arquitectura, lanzaba la siguiente exhortación (1996a, 20):

Propaguemos este sano casticismo abierto a todas las influencias, estudiando la arquitectura de nuestro país, recorriendo sus ciudades, pueblos y campos, analizando, midiendo, dibujando los viejos edificios de todos los tiempos, no sólo los monumentales y más ricos, sino también, y tal vez con preferencia, los modestísimos que constituyen esta arquitectura cotidiana, popular y anónima, en cuyas formas se va perpetuando una secular tradición, y en la que podremos percibir mejor el espíritu constructivo de nuestra raza ${ }^{13}$.

\footnotetext{
${ }^{13}$ De este "sano casticismo" del que hablaba Leopoldo Torres Balbás podemos encontrar aún hoy nuevas manifestaciones en el área estudiada en esta investigación, si bien la proporción de nuevas edificaciones que pudieran encajar en dicha denominación no ha hecho sino disminuir en las últimas décadas, tal como se refleja en los resultados de la misma. El mencionado debate planteado por arquitectos representativos de este movimiento como Louis Sézille o Joaquín de Yrizar parece hoy, también a tenor de los mismos, más urgente que nunca.
} 


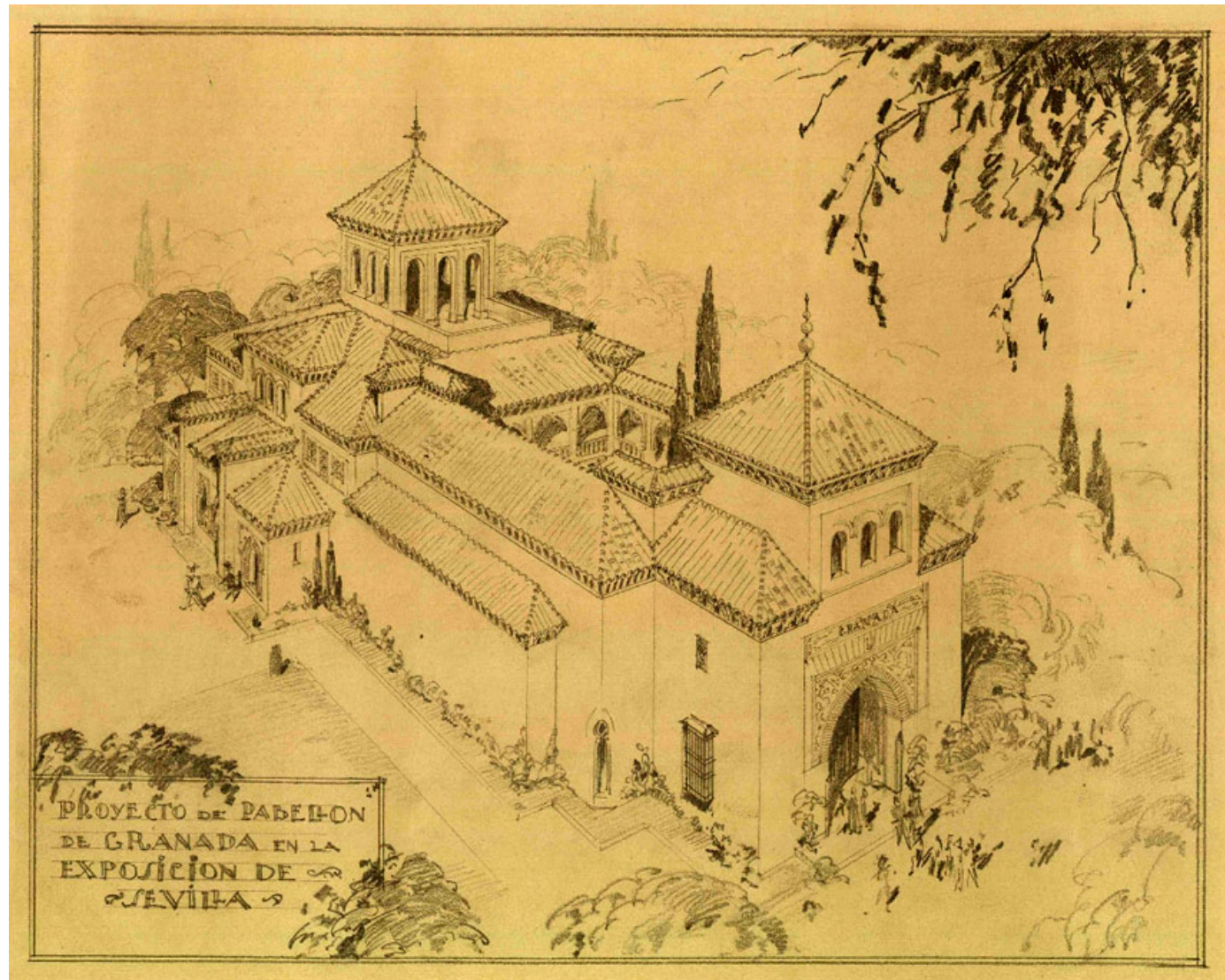

Pabellón de Granada en la Exposición Iberoamericana de Sevilla de 1929, obra de Leopoldo Torres

Balbás (Ref. web: exposicioniberoamericanadesevilla1929.blogspot.com.es, consultada el 31 de agosto de 2018) 


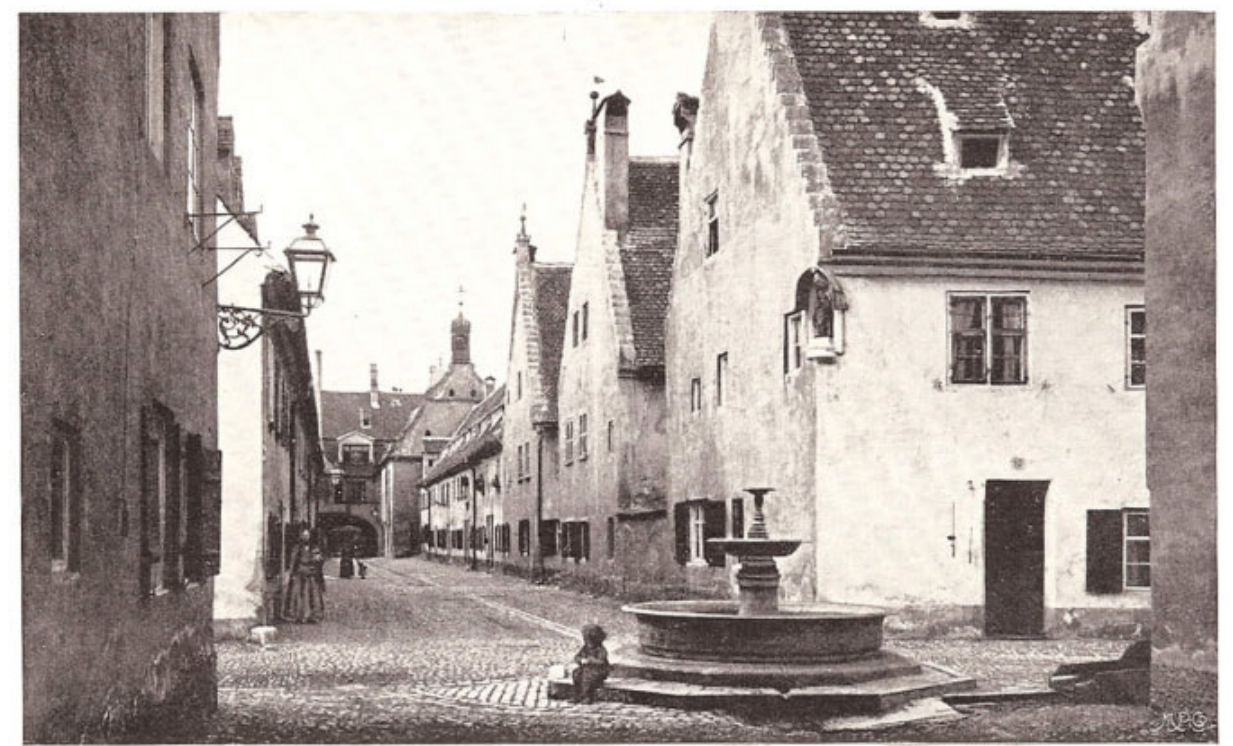

Abbildung 22

Strasse in Augsburg. Beispiel für gute gerade Strassenführung mit Abschluss

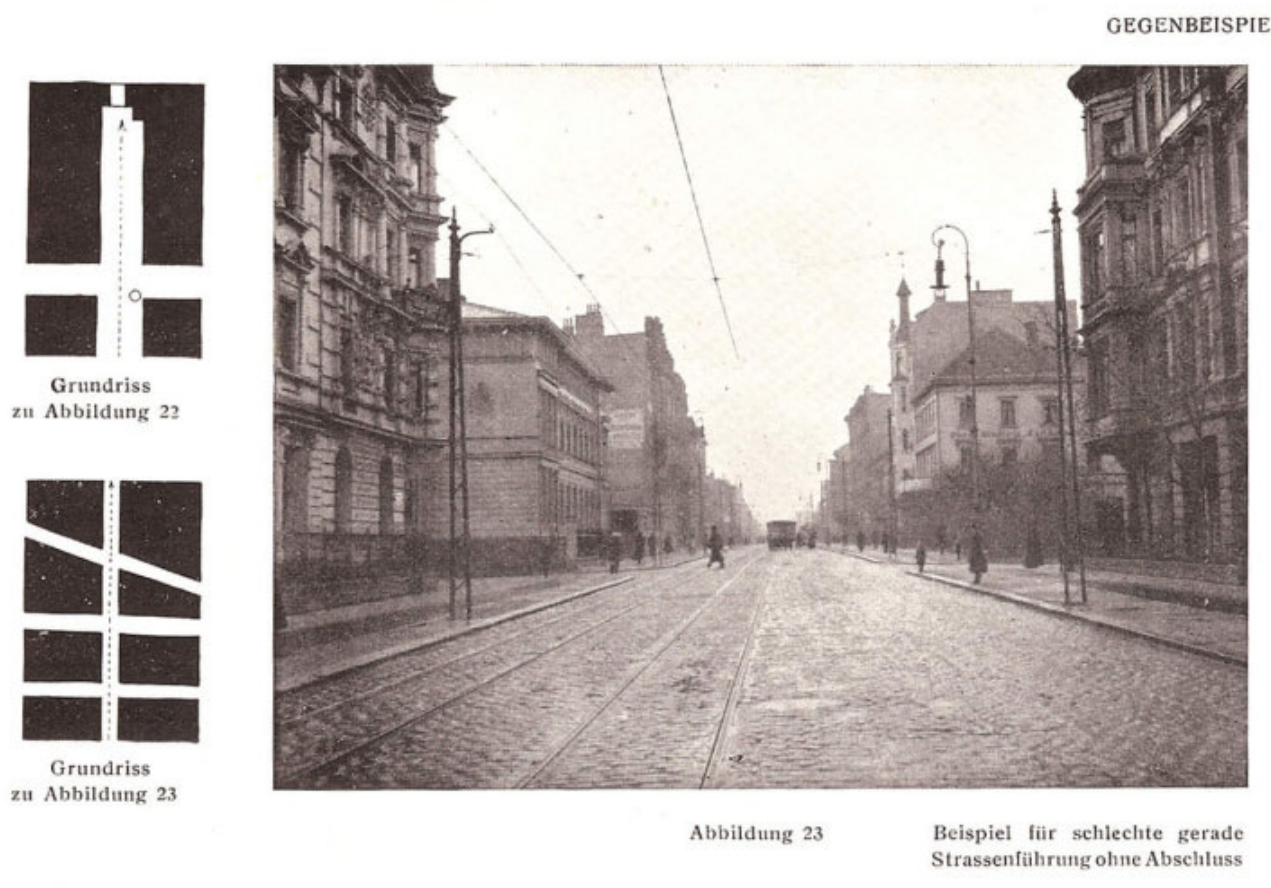

Comparación entre un diseño espacial que da lugar a una calle acogedora y otro que produce lugares carentes de interés, publicado por Paul Schultze-Naumburg en el número 4 de Kulturarbeiten en 1906 (Gutschow 2010) 
Es quizá Torres Balbás el arquitecto español del momento cuyas ideas se encuentren más próximas a las que se debatían desde pocos años antes en el campo de la arquitectura del ámbito germano. Como antes hicieran Adolf Loos o Paul Schultze-Naumburg, consideraba que el arquitecto no puede inventar "formas y disposiciones" de la nada, sino que éstas existen ya, son creadas por la tradición, y sólo conociéndolas y haciendo uso de ellas de modo personal podrá crear algo propio. Para ellos, las formas realmente prácticas, evolucionaron de año en año, de día en día, de hora en hora. "Ningún hombre, ni asociación, creó nuestros armarios, nuestras pitilleras y nuestras piezas de adorno. Las creó el tiempo", declaraba Adolf Loos en "La degeneración de la civilización”, publicado en 1908. Coincidían también los tres en ver en las máquinas y obras diseñadas por los ingenieros del momento esas mismas cualidades, idea que recogerían después los arquitectos vanguardistas.

En Alemania, estos conceptos fueron objeto de profundo análisis en el seno de la Deutsche Werkbund, fundada en 1907 por un grupo de artistas e industriales entre los que se encontraba el arquitecto Hermann Muthesius. Muthesius había sido enviado a Gran Bretaña en 1896 para informar a su regreso en su país sobre las nuevas corrientes arquitectónicas allí surgidas. Tras seis años de viajes y estudios, vuelve a Alemania, publicando un completo trabajo de tres volúmenes: Das englische Haus (1904-1905) y comenzando a promover las ideas del Arts \& Crafts británico por diversos medios, incluyendo su propio trabajo, y haciendo inicialmente uso en su arquitectura de elementos tomados de forma literal de la tradición vernácula británica, como sucediera a otros arquitectos del momento. Frente al anti-maquinismo Ruskiniano, los arquitectos alemanes iban a buscar en la tradición vernácula tipos que, avalados por el tiempo y conformados por la labor de sucesivas generaciones de artesanos, pudieran convertirse en estándares para mejorar el diseño de los productos alemanes. Arquitectos como Theodor Fischer, Bruno Paul, Richard Riemerschmid, Heinrich Tessenow, Fritz Schumacher, Paul Mebes, Paul Schmitthenner o el ya citado Schultze-Naumburg buscaron en la arquitectura tradicional alemana las fuentes para renovar la arquitectura de su tiempo. La ya mencionada revista Kulturarbeiten, publicada por Schultze-Naumburg, como se ha dicho, entre 1900 y 1929, se convertiría en el principal altavoz de muchas de sus ideas, así como la publicación de libros tales como Um 1800, de Paul Mebes (1908), o Trabajo artesanal y pequeña ciudad, de Heinrich Tessenow (publicado originalmente en 1919 y en versión castellana en 1998). Su forma de trabajar con las formas esenciales de la tradición, 
adaptando luego esos tipos al carácter de cada lugar, fue explicada de forma muy clara y visual por Paul Schmitthenner en Gebaute Form. Variationen über ein Thema mit Zeichnungen im Faksimil (La forma construida. Variaciones sobre un tema con sesenta dibujos en facsímil), publicado póstumamente en 1984. Este método y su concepto de "objetividad" ("Sachlichkeit") han sido analizados en España por el profesor José Manuel García Roig en su libro Paul Schmitthenner: Proyecto de arquitectura y Sachlichkeit, publicado en 2011.
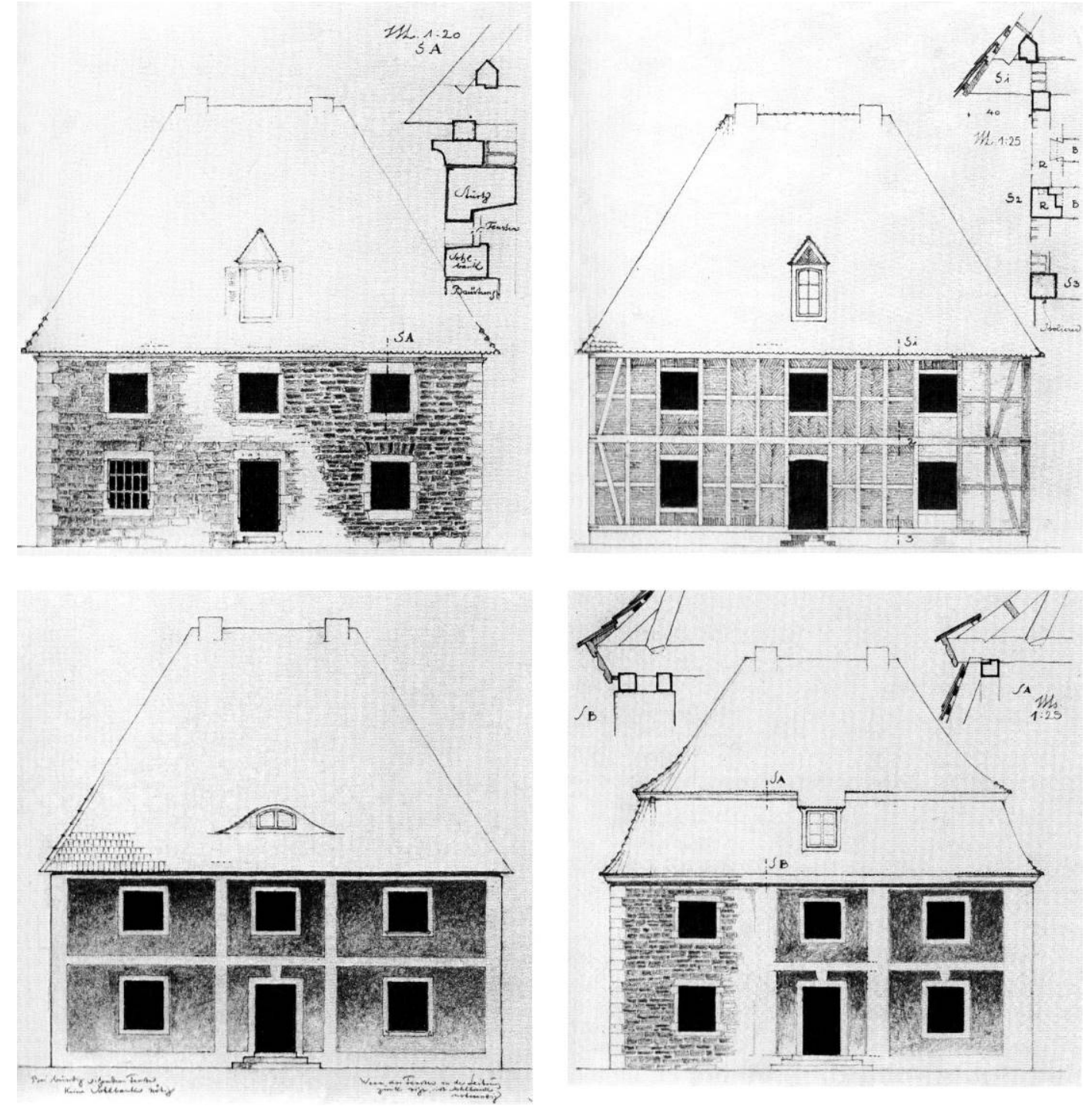

Variaciones de un mismo tipo arquitectónico, adaptándolo a la forma de construir propia del carácter de diversos lugares, Paul Schmitthenner (García Roig 2011) 
Para estos arquitectos, en definitiva, la historia de la arquitectura ofrecía, como afirmaba el propio Torres Balbás, "un caudal de formas depuradas por obra de una lenta selección", obras de la tradición intemporal o "eterna", mientras que el producto de las modas era sólo un capricho pasajero (1996d, 140; Schultze-Naumburg 1908, 32; Gutschow 2010, 158).

El suizo Alfredo Baeschlin, en su libro Casas de campo españolas, se alineaba también con algunos de estos principios, criticando la voluntad de crear nuevas formas para funciones que apenas habían variado, en lugar de dedicar esos esfuerzos a desarrollarlas cuando nuevos usos las demandaban, así como la degradación del paisaje que esta actitud generaba. Para Baeschlin, los defensores de la "arquitectura de vanguardia" iban uniformando todo, sin atender a las particularidades de cada región (1930a):

Los representantes de esta escuela opinan que los materiales modernos al alcance del arquitecto obligan a éste a crear formas nuevas (...). Es perfectamente admisible que para una idea nueva, para cosas modernas, como aeropuertos, estaciones, fábricas, etc., el arquitecto busque formas nuevas. Pero tratándose de una casa de campo, por ejemplo, cambia la cuestión por completo (...). El paisaje es de todos y no parece lícito destruir su hermosura sólo para satisfacer el capricho de moda. El mero hecho de posesión de unos cuantos palmos de tierra no puede autorizar a destruir todo un paraje con una edificación que lo afee”.

Y en términos similares se expresaba Secundino Zuazo (Flores 1968, 122-129): "Ahora empieza a hacerse entre nosotros una arquitectura igual a la de fuera, sin ningún interés. Creo que cuanto más se hace moderno más quedan prestigiadas las cosas de siempre”.

Ese "sano casticismo" propugnado por Torres Balbás, con su reivindicación del estudio de la tradición popular para lograr dotar de carácter local a las influencias llegadas de fuera, se presentó así como una vía alternativa a la excluyente dualidad entre tradicionalismo y exotismo que se venía discutiendo en los debates arquitectónicos españoles. La influencia extranjera no era para él negativa. Por el contrario, era un medio para enriquecer la cultura local. Lo negativo era no contar con la formación o las herramientas para poder asimilar las formas foráneas en conformidad con los caracteres esenciales de la tradición propia. 
Frente a lo defendido por Torres Balbás, Vicente Lampérez y Romea, en su artículo "La arquitectura española contemporánea. Tradicionalismos y exotismos", había planteado previamente esta dicotomía en los siguientes términos $(1911,195)$ :

El tradicionalismo es en arquitectura la devoción hacia los estilos que se usaron en otras épocas. (...) Las formas arquitectónicas que integran ciertos estilos históricos son la decantación, a través de los siglos y las generaciones, de principios y leyes, sin variables en un factor (las costumbres), perennes en otros (el espíritu de la raza, el espíritu del país). El estilo no es sólo una vestidura del Arte: cuando es bueno, es una razonada aplicación de principios constructivos y estéticos, que persisten aunque varíe la forma externa. El exotismo es la imitación, venga o no a cuento, con lógica o sin ella, conveniente o disparatada, de los estilos y las disposiciones extranjeras, contrarias las más de las veces a las necesidades, a los usos, a los materiales y al clima del país: todo por la suprema razón de que es moda.

El rechazo a lo que denominaban "exotismo" fue común entre los arquitectos regionalistas y a él se deberían polémicas como la surgida entre Demetrio Ribes y Leonardo Rucabado sobre esta cuestión. "No se considera que, si en otras épocas se pudieron hacer obras admirables sujetas a la influencia extranjera y reputadas actualmente como castizas, no hay razón para que actualmente se desdeñe realizar lo mismo", defendía Ribes $(1918,27)$, en respuesta al artículo de Rucabado "La tradición en la Arquitectura" (1917, 27-42), a su vez la reacción de éste ante la oposición de Ribes al breve manifiesto regionalista que, junto a Aníbal González Álvarez-Ossorio, el más reconocido arquitecto del regionalismo sevillano, había presentado en 1915 el VI Congreso Nacional de Arquitectura: "Orientaciones para el resurgimiento de una Arquitectura Nacional".

Pese a estas disensiones, la arquitectura española de este período sí se mostró unida en el estudio de la arquitectura tradicional, y en especial en el de sus ejemplos más populares. Manuel B. Cossío publicó en 1913 su "Elogio del arte popular". Vicente Lampérez y Romea dictó entre 1916 y 1922 distintas conferencias sobre la arquitectura popular y en 1917 dedicó su discurso de ingreso en la Real Academia de Bellas Artes de San Fernando a la arquitectura civil de las villas castellanas medievales. Resultado de estas y otras 
investigaciones, en 1922 publicó La arquitectura civil española de los siglos I al XVIII, en uno de cuyos capítulos se presenta por vez primera en España un estudio general de los tipos arquitectónicos populares del país. En 1923 Torres Balbás ganó el premio CharroHidalgo del Ateneo de Madrid con un análisis de la arquitectura popular tradicional de las distintas regiones de España. Un alumno suyo, Fernando García Mercadal, publicó en 1930 partes completas de ese trabajo en su libro La casa popular en España. Como consecuencia, al haberlo hecho sin citar a su autor original y sin el consentimiento de éste, Torres Balbás, publicó el trabajo completo en 1933, en el tercer volumen de Folklore y costumbres de España, bajo el título "La vivienda popular en España". Mientras tanto, en 1929, el también arquitecto Teodoro de Anasagasti ingresaba en la Real Academia de Bellas Artes de San Fernando con el discurso “Arquitectura Popular". Un creciente número de arquitectos e investigadores publicaban por esas mismas fechas artículos sobre las arquitecturas tradicionales de distintas regiones españolas. Las revistas Arquitectura, publicada desde 1918 y coordinada inicialmente por Torres Balbás, Cortijos y Rascacielos, publicada desde 1930 hasta 1954 y dirigida por el también arquitecto Casto Fernández-Shaw, y otras muchas, desempeñarían un importante labor en la difusión y valorización de este tipo de estudios. Tras la Guerra Civil, Gonzalo de Cárdenas, subdirector general de Regiones Devastadas, publicó en 1944 en La casa popular española, fundando además la revista Reconstrucción, que continuaría promoviendo este interés.

Basado en esta renovada apreciación de la tradición local, el legado arquitectónico del regionalismo español fue muy notable, contribuyendo en gran medida a definir y potenciar el particular carácter con el que hoy identificamos a muchas regiones españolas. En la Montaña, pese a la temprana muerte del principal impulsor de esta corriente, Leonardo Rucabado, se formó una importante escuela regionalista en torno a las figuras de, entre otros, Valentín Ramón Lavín Casalís, Emilio de la Torriente y, sobre todo, Javier González de Riancho. El regionalismo vasco estuvo representado por arquitectos como Pedro Guimón, Guillermo Eizaguirre y, principalmente, Manuel María Smith Ybarra y Ramón Cortázar. En el caso sevillano, el mejor estudiado gracias a Alberto Villar Movellán, el regionalismo tuvo sus mejores exponentes, además de en Aníbal González Álvarez-Ossorio, quizá el más popular arquitecto del regionalismo español, en Juan Talavera y Heredia, José Espiau y Muñoz, Antonio Gómez Millán, José Gómez Millán, Antonio Delgado Roig y Romualdo Jiménez Carlés, entre otros. La Exposición 
Iberoamericana de Sevilla de 1929 proporcionó a este grupo una especial repercusión. Además, muchos arquitectos se aproximaron también con su trabajo a lo que Torres Balbás denominaba "sano casticismo", pudiéndose destacar entre ellos a Secundino Zuazo, Gustavo Fernández Balbuena, Amós Salvador Carreras y, pese a la singularidad de su obra, Teodoro Anasagasti.

Los trabajos de Pedro Muguruza y, en general, la labor tanto de Regiones Devastadas como del Instituto Nacional de Colonización, darían continuidad tras la Guerra Civil a estas diversas sensibilidades hacia lo vernáculo, cuestión ya estudiada por Manuel Blanco Lage en su tesis doctoral Influencias formales en la configuración de la arquitectura española de la posguerra: la Dirección General de Regiones Devastadas (1987a).

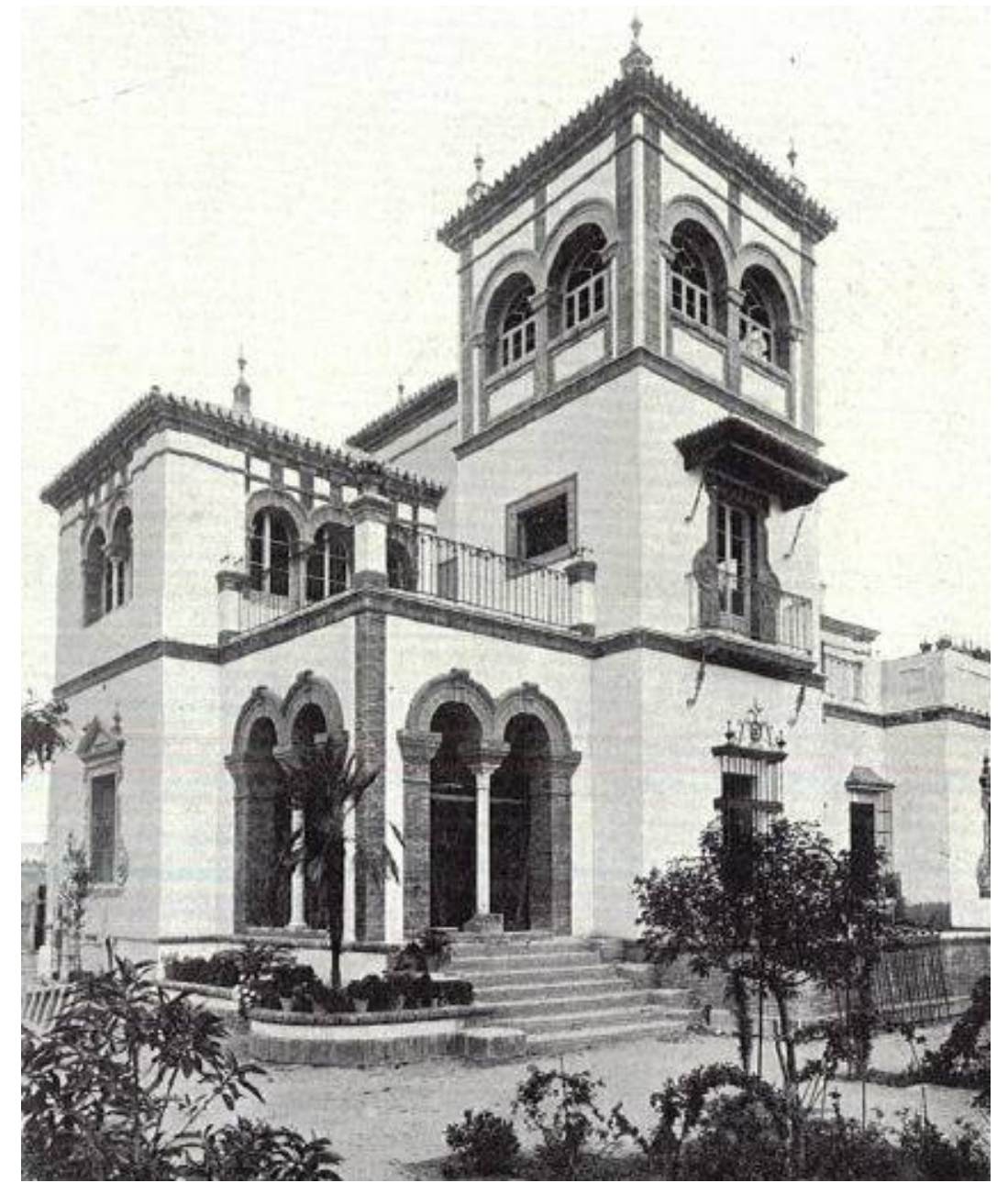

Quinta Carmen en la Calle Marqués de Nervión, Sevilla, obra de Juan Talavera y Heredia construida entre 1916 y 1917 y hoy desaparecida (Villar Movellán 1979, 259) 


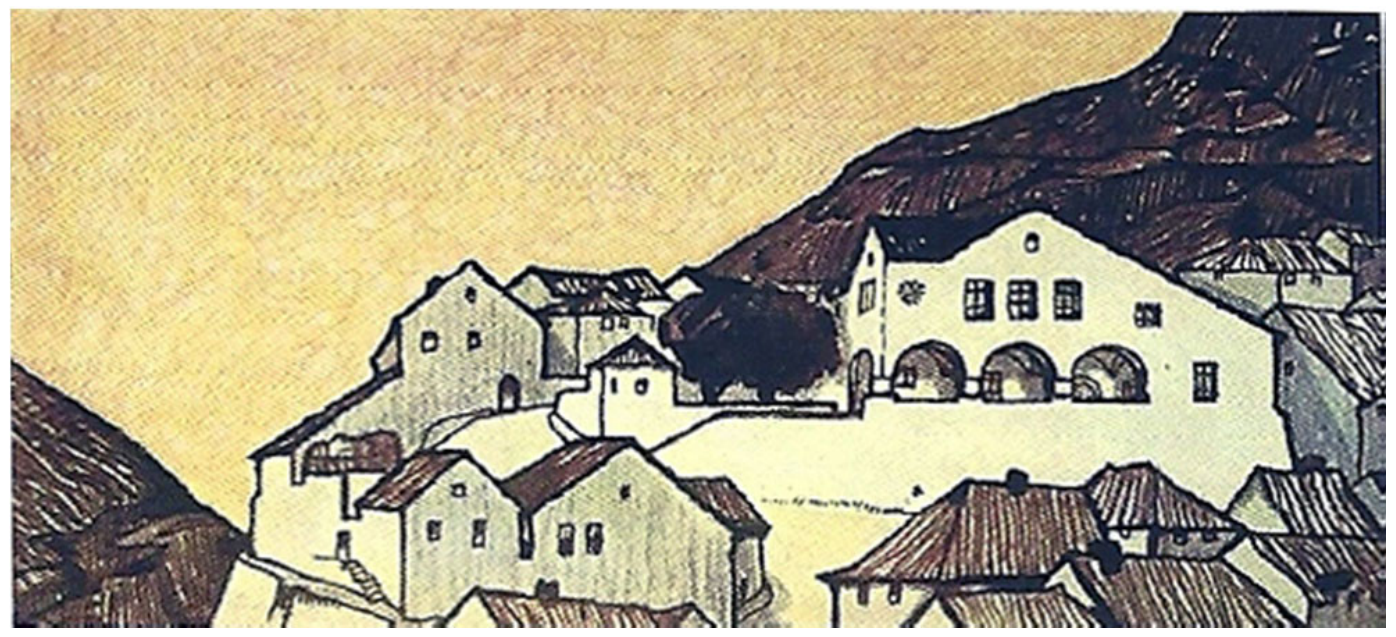

Ayuntamientos para las regiones francesas de Lozère y Alsacia, ilustraciones de Charles Letrosne incluidas en el primer volumen de su obra Murs at toits pour les pays de chez nous, publicada en tres volúmenes entre 1923 y 1926 (Culot 2005, 26)

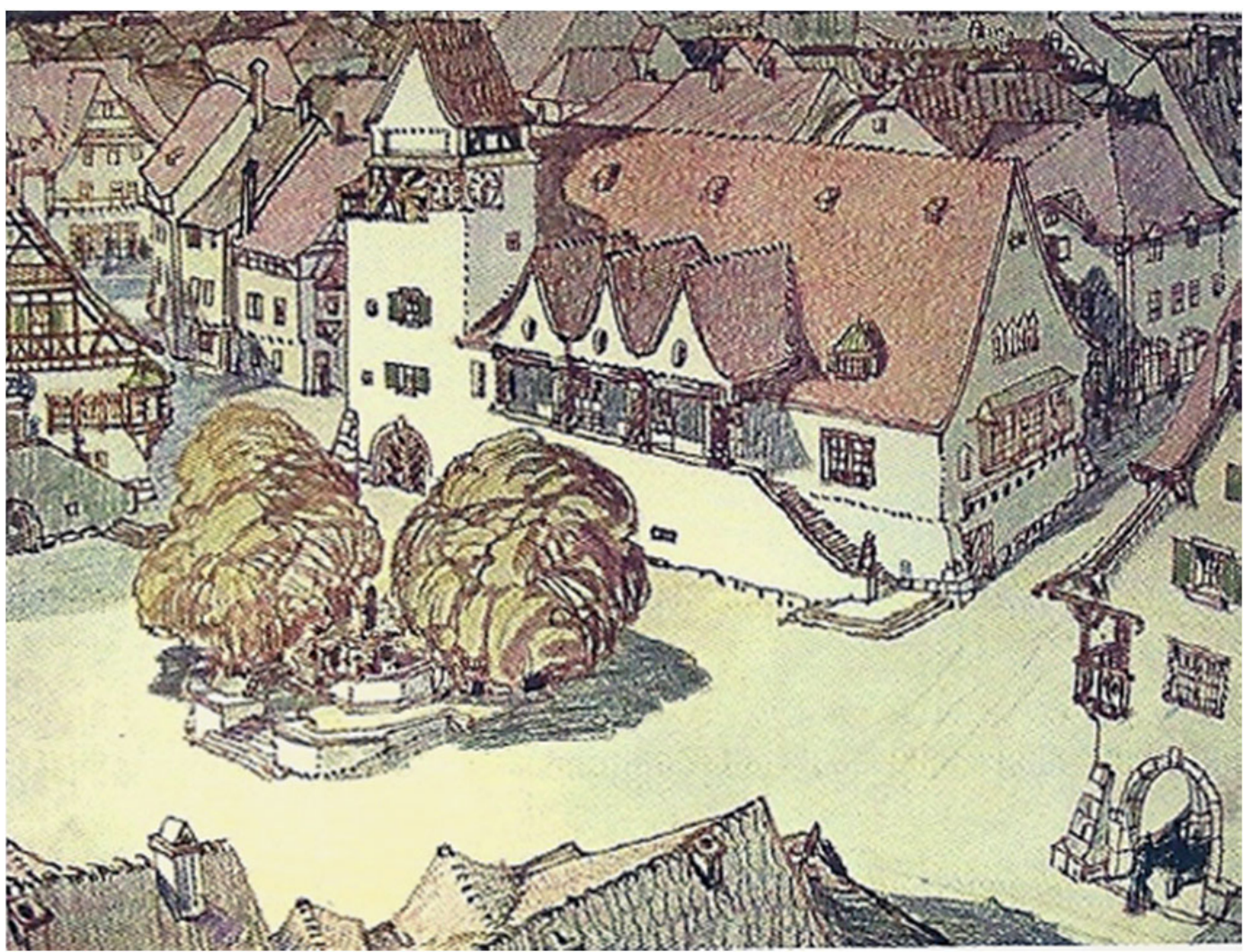


En el regionalismo francés, además del ya mencionado Louis Sézille, pueden destacarse, entre otros, los arquitectos Albert Tournaire, Louis Bonnier, Louis-Marie Cordonnier, Gustave Umbdenstock, Henri Godbarge, Charles Letrosne, quien publicó los tres volúmenes de Murs et toits pour les pays de chez nous entre 1923 y1926, considerado el principal manual del regionalismo francés. Y existieron también en Francia arquitectos de un regionalismo más racionalista, como André Pavlovsky. En Holanda, la arquitectura regionalista estuvo representada por arquitectos como Alexander Kropholler o los que integraron la denominada Escuela de Delft, que convivió con las escuelas de Ámsterdam y Róterdam, con las que compartió algunos de sus principales objetivos y, a diferencia de lo ocurrido en otros lugares en casos similares, constructivos debates. Los principales miembros de esta escuela fueron Marinus Jan Granpré Molière y Pieter Verhagen, integrándose también en ella arquitectos como Gijsbert Friedhoff, Bernardus Joannes Koldewey o Kees van Moorsel. En el caso portugués la figura fundamental fue la de Raul Lino. Y el regionalismo está también en la base de algunas de las nuevas arquitecturas vernáculas realizadas por Plinio Marconi en Italia y por Erik Gunnar Asplund o Sigurd Lewerentz en Suecia.

Frente a las narraciones históricas que han presentado y siguen presentando a los arquitectos del Movimiento Moderno como defensores de la democracia y los valores sociales y a quienes abogaron por una arquitectura contextual, fuera del tipo que fuera, como reaccionarios que propugnaban el autoritarismo, la realidad fue diversa. Si bien entre quienes propugnaban el nuevo estilo moderno fueron numerosos los arquitectos vinculados a la izquierda internacionalista, es ya bien conocido que entre los miembros de este grupo se albergaron ideas políticas de todo signo. También lo es que sucedió de igual modo en el seno del regionalismo, así como que entre ellos predominaron ideas políticas reformistas y los vínculos con el socialismo moderado, y en especial con el socialismo cristiano.

También, en general, la defensa regionalista de la identidad local y nacional frente a préstamos culturales foráneos fue abanderada por el fascismo. Pero los fuertes centralismo y colectivismo que lo caracterizaron, así como el culto a la violencia, al industrialismo y a la renovación de la nación, chocaron con los objetivos regionalistas. Podría esperarse que la irrupción del fascismo en el espectro político hubiera supuesto el auge del regionalismo 
y, sin embargo, supuso simplemente su instrumentalización política y, finalmente y como consecuencia de ésta, su ocaso (Umbach 2005, 117; Storm 2010, 12).

La defensa de la singularidad de cada región era contraria a la visión unitaria de la nación, y la valoración de lo artesanal y de los oficios tradicionales no podía encajar en la doctrina del crecimiento y la expansión continuos, de la idealización del progreso y el desarrollismo. El regionalismo estaba condenado a desaparecer frente a esos impulsos, como de hecho sucedió pronto en aquellos países donde los regímenes autoritarios lograron subsistir tras la Guerra (Umbach 2005, 136-139; Storm 2010, 275-279). E1 propio Albert Speer explicó cómo este cambio comenzaba ya ineludiblemente a operarse en Alemania durante el conflicto, aunque en ese caso en particular no pudo llegar a cuajar del modo en que lo hizo posteriormente en otros lugares. En cualquier caso, la arquitectura tradicional se mantuvo inicialmente como la principal referencia de muchos de los nuevos desarrollos urbanos en estas naciones, aunque predominando en ella la versión más estandarizada e industrializada de la misma. Se recurrió, por lo general, a tipos característicos de los que se eliminaba su verdadera complejidad local y temporal para aplicarlos sobre grandes áreas geográficas, como símbolos de las mismas, que quedaban así unificadas bajo una identidad común. Estos procesos estaban a menudo relacionados con la voluntad de reafirmar la unidad del pueblo y la nación, contribuyendo con ello a generar "una imagen estereotipada de la arquitectura popular" (García Grinda 1990, 432).

En Alemania, como reacción a la fundación del grupo Der Ring en 1926 y de los CIAM en 1928, concebidos para la promoción de la arquitectura y el urbanismo del Movimiento Moderno, en 1928 Paul Schultze-Naumburg, Paul Schmitthenner y otros arquitectos que abogaban por una modernidad basada en la tradición fundaron Der Block. Su oposición a las vanguardias arquitectónicas, la posterior proscripción de éstas por la Alemania nazi, y el apoyo a la causa nacionalsocialista de arquitectos como Schultze-Naumburg o Paul Bonatz determinarían el juicio histórico al que estas corrientes fueron sometidas en su conjunto tras la Guerra. Procesos similares se darían en el resto de naciones europeas. Incluso en aquellos países donde la vinculación de los arquitectos tradicionalistas con movimientos políticos reaccionarios fue nula, o en aquellos donde estas corrientes políticas ni siquiera tuvieron presencia alguna, cualquier arquitectura que difiriera de lo que vanguardia arquitectónica postulaba era susceptible de ser objeto de censura. 
La etapa del auge del regionalismo había dado paso a la era de la internacionalización de las formas arquitectónicas. Paradójicamente, el ya conocido como Estilo Internacional encontraría en el capitalismo y la economía global sus mejores promotores. Asociado ya a ellos, se convirtió en gran medida en símbolo del progreso, la libertad y la democracia, pasando a ser el lenguaje arquitectónico universalmente promovido por la práctica totalidad de las instituciones políticas internacionales cuya voluntad fuese proyectar esa imagen. Al mismo tiempo, la iniciativa privada iba a promover de forma creciente, y en especial en las áreas rurales, versiones cada vez más estereotipadas, si cabe, de la arquitectura tradicional. La Era del Sucedáneo de la que tempranamente prevenían Morris y Fourier no había hecho más que comenzar.

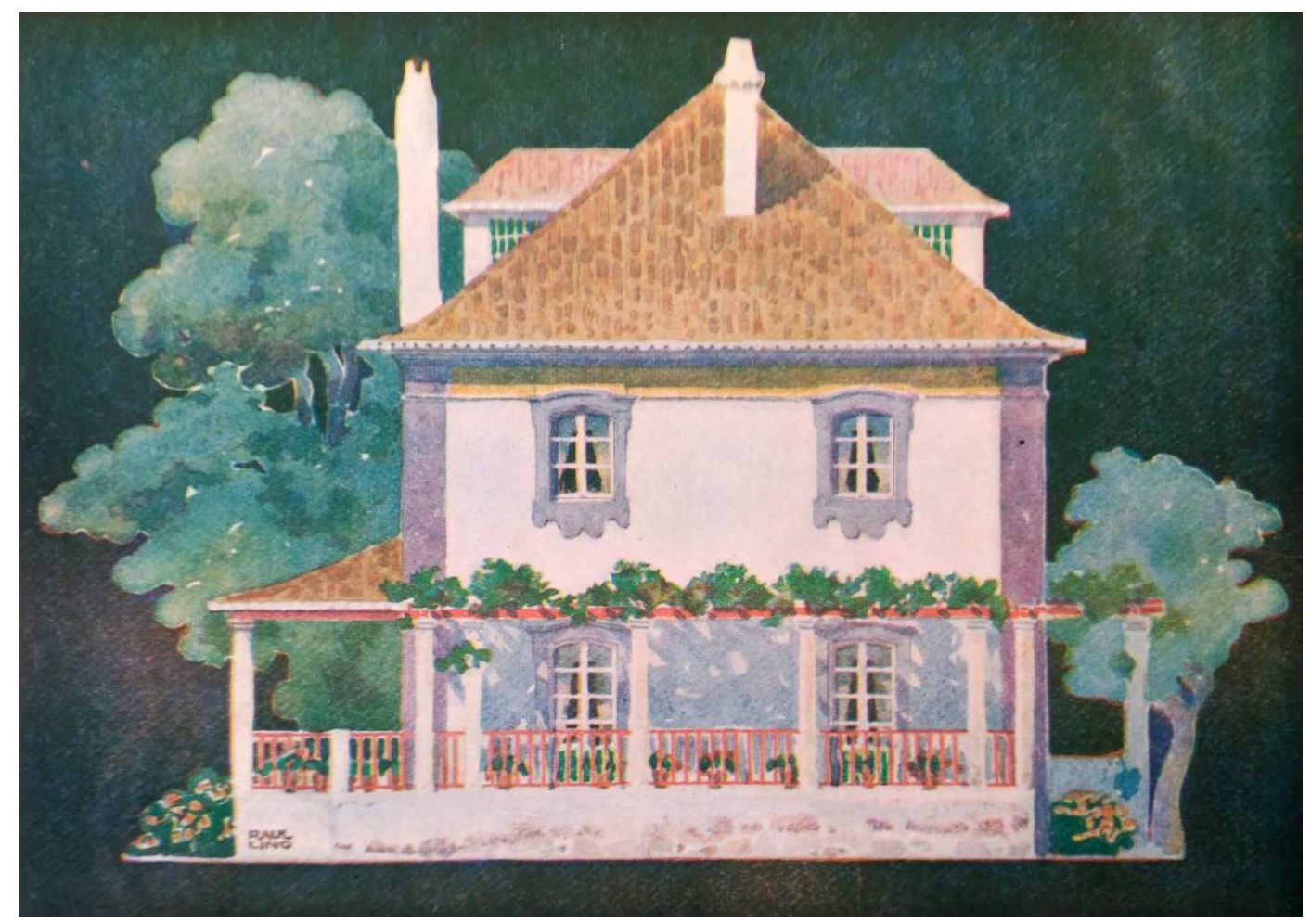

Diseño de Raúl Lino para una casa en los alrededores de Lisboa, lámina incluida en su obra Casas Portuguesas. Alguns Apontamentos sôbre o Arquitectar das Casas Simples, publicada en 1933

(Lino 1933) 


\subsection{EL PAPEL DE LAS EXPOSICIONES INTERNACIONALES Y DE LOS MUSEOS AL AIRE LIBRE EN EL DESARROLLO DE LA CUESTIÓN}

Lo pintoresco y el carácter individual han perdido su lugar en las construcciones de hoy; para reencontrarlos, es necesario buscarlos en las viejas aldeas que han quedado fuera del movimiento moderno o en los viejos barrios de nuestras metrópolis contemporáneas.

Charles Garnier y Auguste Ammann, L'habitation humaine, 1892

Las grandes exposiciones de la segunda mitad del siglo XIX y la primera mitad del XX se convirtieron en el marco perfecto para suscitar controversias y proponer soluciones en torno a la relación entre la arquitectura y las identidades nacionales y locales. Paralelamente, la misma fascinación suscitada por esta cuestión dio lugar a la aparición de museos de arte popular, y, con ellos, de los museos de arquitecturas populares, que, por la peculiaridad de sus necesidades espaciales, han venido a conocerse como museos al aire libre.

El gigantesco Palacio Ómnibus de la Exposición Universal de París de 1867 se hallaba rodeado de un nutrido grupo de construcciones de carácter mayoritariamente popular, convertidas en símbolo identificable de sus países de origen. Entre los pabellones nacionales, tuvo especial éxito el japonés, tanto por su atractivo vernáculo como por la calidad de los productos artesanales mostrados. La fascinación causada por él contribuiría en gran medida a la difusión de la moda del japonismo en las artes occidentales. Y un efecto análogo volvería a producir el edificio de la representación japonesa en la Exposición Mundial Colombina de Chicago de 1893, causando una profunda impresión a un joven Frank Lloyd Wright que nunca dejaría de admirar esta cultura.

Semejante disposición de arquitecturas eminentemente vernáculas en torno a la gran rotonda central se eligió para la Exposición Mundial de Viena de 1873, convirtiéndose en uso común en las grandes exposiciones sucesivas el recurso a este tipo de edificios para las representaciones nacionales. Mientras que países como Japón, Noruega, Suecia, Gran Bretaña, Rusia o diversos países del mundo islámico recurrieron con frecuencia a 
arquitecturas de tradición popular para dotar de carácter a sus edificios, España formó parte del grupo de naciones que buscaron simbolizar su identidad haciendo uso de los estilos históricos que habían adquirido un carácter más singular al integrarse en la cultura propia del país. Jerónimo de la Gándara fue el autor del plateresco pabellón elegido para representar a nuestro país en la Exposición Universal de París de 1867. Lorenzo Álvarez Capra se encargó de formalizar el edificio español en la de Viena de 1873, eligiendo para hacerlo el evocador estilo neomudéjar. La misma elección se hizo para la Centennial Exposition de Filadelfia de 1876. Y este estilo, aunque con rasgos más arabizantes, representó nuevamente a España en la Exposición Universal de París de 1878, siendo Agustín Ortiz de Villajos el encargado de proyectarlo, y en la Exposición Universal de París de 1889, donde estuvo a cargo de Arturo Mélida y Alinari. En la Exposición Mundial Colombina de Chicago, sin embargo, Rafael Guastavino optó por basar su diseño en las trazas góticas de la Lonja de Valencia. En la Exposición Universal de París de 1900 la delegación española trató de distanciarse de la extendida visión romántica y pintoresca de nuestro país con un pabellón de inspiración plateresca obra del arquitecto José Urioste y Velada, ya mencionado en el capítulo anterior. Sin embargo, la organización francesa no dudó en recuperar tan popular y estereotipada mirada a través de la instalación “L’Andalousie au temps des maures", diseñada por el arquitecto francés Dernaz. En ella, a los pies de una réplica de la Giralda, se extendía un pintoresco barrio norteafricano, donde no faltaban los bandoleros, el flamenco y las sevillanas. En la Exposición de Bruselas de 1910 volvió a recurrirse a lo andalusí, siendo el arquitecto Modesto Cendoya el encargado de concebir el pabellón español, que incluía una reproducción del Patio de los Leones de la Alhambra. Sin embargo, en la Exposición Internacional de Bellas Artes de Roma de 1911 el estilo plateresco fue nuevamente la opción elegida en la obra de Eladio Laredo y, en el mismo 1910, en la Exposición del Centenario Argentino, celebrada en Buenos Aires, se optó por el modernismo catalán como imagen de nuestro país, siendo el autor de este pabellón el arquitecto Julián García Núñez, discípulo de Puig i Cadafalch.

Más allá de estas representaciones arquitectónicas de la cultura española, resulta interesante comprobar cómo en el caso del diseño de pabellones destinados a representar identidades regionales la elección de referencias de tradición popular ha sido siempre más común que a la hora de tratar de reflejar el carácter de una nación en su conjunto. 
Así, para los pabellones que representaron a los diversos estados norteamericanos en la Centennial Exposition de Filadelfia de 1876, en la Exposición Colombina de Chicago de 1893 o en la Exposición Panamá-California de San Diego de 1915 fueron elegidas con frecuencia arquitecturas de marcado carácter popular, realizadas en madera o incluso en tierra, como el pabellón del estado de Nuevo México en la última de ellas, frente al carácter más monumental de buena parte de los pabellones internacionales que se diseñaban para estos eventos. El propio Bertram Grosvenor Goodhue hacía referencia a esta cuestión en su introducción al libro The Architecture and the Gardens of the San Diego Exposition: a pictorial survey of the aesthetic features of the Panama-California International Exposition (1916), señalando que por la amplia temática abarcada y las dimensión y complejidad alcanzada por las exposiciones internacionales al uso, en ellas "se ha perdido cualquier carácter local, étnico y ajustado", mientras que en el caso de San Diego, al ser de menores dimensiones y de carácter regional, se podía buscar de forma unívoca "recuperar en parte, en la medida de lo posible, las huellas del antiguo período español de las Misiones" (Vela Cossío 2017, 32-38).

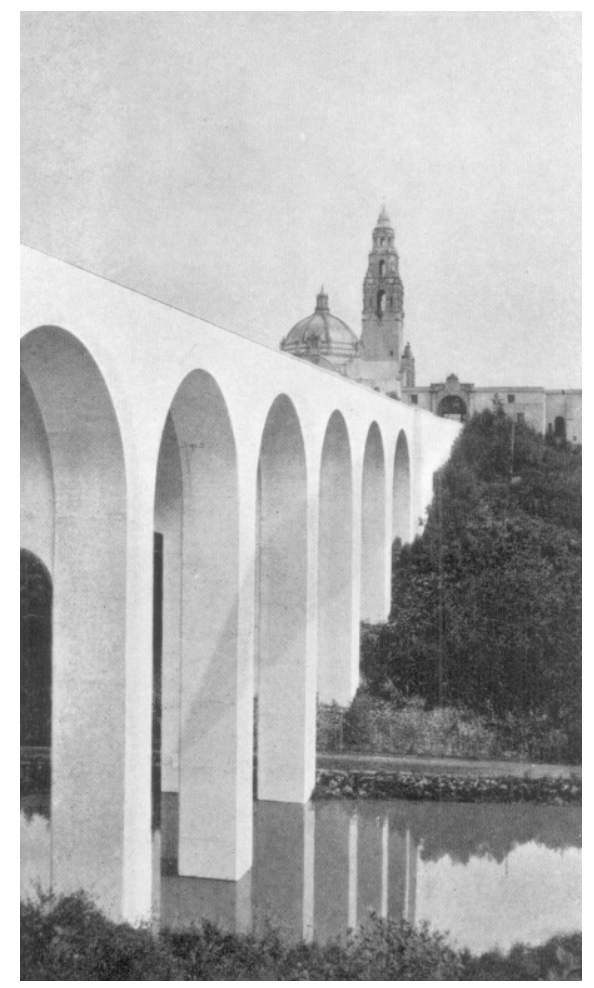

Vista de la Exposición Internacional Panamá-California de San Diego, con el Puente Cabrillo en primer plano, abierta al público en 1915. Sus principales edificios fueron diseñados por Bertram Grosvenor Goodhue (Vela Cossío 2017, 73) 
En la Exposición Iberoamericana de Sevilla de 1929 estuvo representada buena parte de las regiones españolas. Aunque en algunos pabellones regionales se tomaron como referencia simbólica edificios históricos representativos, en la mayoría de ellos se optó una vez más por un carácter de inspiración más vernácula. De ello son buenos ejemplos el pabellón de Granada, obra de Leopoldo Torres Balbás, un homenaje a las casas moriscas de la ciudad en el que puede comprenderse mejor la variante del regionalismo que este arquitecto propugnaba, lo que él mismo denominó, como se ha explicado anteriormente, "sano casticismo"; el pabellón de Barcelona, diseñado por Enric Sagnier, quien recurrió a las masías de la tradición catalana; el pabellón de Aragón, de formas más sencillas y, al mismo tiempo, más populares, con sutiles pinceladas de mudejarismo, de Pascual Bravo; el canario pabellón de Tenerife y Las Palmas, obra de Pelayo López, que incorporó en su composición las amplias galerías de madera de la tradición isleña; el pintoresco pabellón de Murcia, de Manuel Martínez Chumillas y Ramón Aníbal Álvarez, con un característico uso de la forja, la madera, el ladrillo y las superficies encaladas; el de Asturias, de Enrique Rodríguez Bustelo, inspirado, como el del País Vasco, que fue diseñado por Diego de Basterra, en una gran casona rural; el de Valencia, de Emilio Artal Fos y José Luis Testor Gómez, que fue quizá uno de los de carácter más popular, tomando como referencia la arquitectura de una alquería tradicional; y el de Huelva, de José María Pérez Carasa, que combina la reproducción de elementos arquitectónicos de algunos edificios de la historia Colombina con elementos de la tradición popular. El pabellón de Castilla la Nueva, obra de Baltasar Hernández Briz y Manuel Sánchez Arcas, aunque de diseño más ecléctico, incorporó como solución constructiva de buena parte de sus paramentos el tapial de brencas que, como se tratará más adelante, caracteriza también la arquitectura tradicional de un buen número de municipios sagreños.

Otro buen ejemplo, representativo del diverso carácter de las representaciones nacionales y regionales, es el de la Exposición Internacional "des arts et des techniques appliqués à la vie moderne", celebrada en París en 1937. En ella, predominaron en los pabellones nacionales el más moderno lenguaje clasicista, el Art Déco y el racionalismo de estilo igualmente moderno. Sin embargo, en el denominado Centro Regional, un grupo de pabellones que representaban a las diversas regiones de Francia y que conformaba un pequeño núcleo urbano con sus propias calles y plazas. Su diseño, debido a los arquitectos Charles Lestrosne, Jacques Gréber y Emile Maigrot, fue posible gracias a la visión de Edmond Labbé, quien fue nombrado comisario general de la Exposición. Esta propuesta 
hubo de imponerse a un más ambicioso proyecto de Auguste Perret en el que se planteaba una composición axial de edificios de gran monumentalidad y donde el Centro Regional era reemplazado por un núcleo denominado Vielle France, de mayor escala que el efectivamente construido con ese nombre, en él se replicaban edificios históricos de distintas regiones francesas. Frente a esta idea, que hubiera producido una instalación de carácter más folclórico, en línea con las aparecidas en gran número de eventos internacionales previos, tal como se explicará más adelante, Labbé veía una oportunidad para llevar a cabo un gran ensayo urbano que reflejara los ideales del movimiento regionalista. Para Labbé, al igual que para Letrosne y Gréber, la tradición no era algo estático, un capítulo de la historia ya cerrado y perteneciente a un pasado ya superado, sino una fuerza viva y dinámica que podía ser actualizada y con capacidad para mejorar los productos de su tiempo, haciéndolos más apropiados para los cambiantes requerimientos de cada lugar. Su defensa de una nueva arquitectura que fuese al mismo tiempo tradicional se planteaba así como oposición tanto a la visión romántica de la tradición como a las propuestas estandarizadas e indiferentes al clima, a la cultura o al lugar de los "ultra-modernistas. Y, al mismo tiempo, reivindicaban el papel del artesano como agente creativo e innovador, frente quienes veían en su labor un exotismo del pasado, siendo su oficio inadaptable a los nuevos tiempos, y frente a los promotores de la mecanización más radical. Paul Léon, comisario adjunto de la Exposición, llegaba a argumentar que Francia debía mostrar en ella la alta calidad y el carácter innovador de sus productos, pues nunca sería capaz de competir con la abundancia de mano de obra barata de Asia ni con la capacidad de producción industrial mecanizada de los Estados Unidos (Vigato 1994, 213-228; Storm 2010, 220-246). Los pabellones de las regiones marítimas se dispusieron a orillas del Sena. El Pont de Passy conectaba el núcleo principal con el pabellón de Córcega, situado en la Île des Cygnes, y con los de Argelia, Túnez y Marruecos, que ocupaban la orilla opuesta. Los diseños de los pabellones, seleccionados por concurso por las propias regiones, aunque con cierta supervisión desde la propia organización, fueron en su mayoría interesantes propuestas en las que se integraba tradición y modernidad. La referencia a formas de carácter popular fue la preferida entre las distintas delegaciones regionales, de lo que es buen ejemplo el conjunto de edificios de las regiones del País Vasco Francés, Bearne y Bigorra. Sin embargo, hubo incluso casos, como el del pabellón de Lyon, donde la comisión de arquitectura regional se negó a seleccionar un proyecto que incorporase rasgo vernáculo alguno en su diseño, no queriendo proyectar una imagen rural de una región que consideraban una de las más 
desarrolladas de Francia. El proyecto en su conjunto proponía que los pabellones se erigieran con materiales de calidad, de forma que pudieran perdurar y que el Centro Regional se convirtiera en la representación permanente de las distintas regiones francesas en la capital. Sin embargo, esto no fue posible. El gobierno del Frente Popular era favorable a una mayor representación de la Union des artistes modernes en la Exposición, concentrando su apoyo en las obras encargadas a los integrantes de este grupo de artistas de vanguardia. En consecuencia, centraron su atención en lo que se denominó el Centro Rural, diseñado, por el contrario, como un pueblo modelo en el que estandarizadas viviendas equipadas con la más moderna tecnología aparecían como elementos aislados.

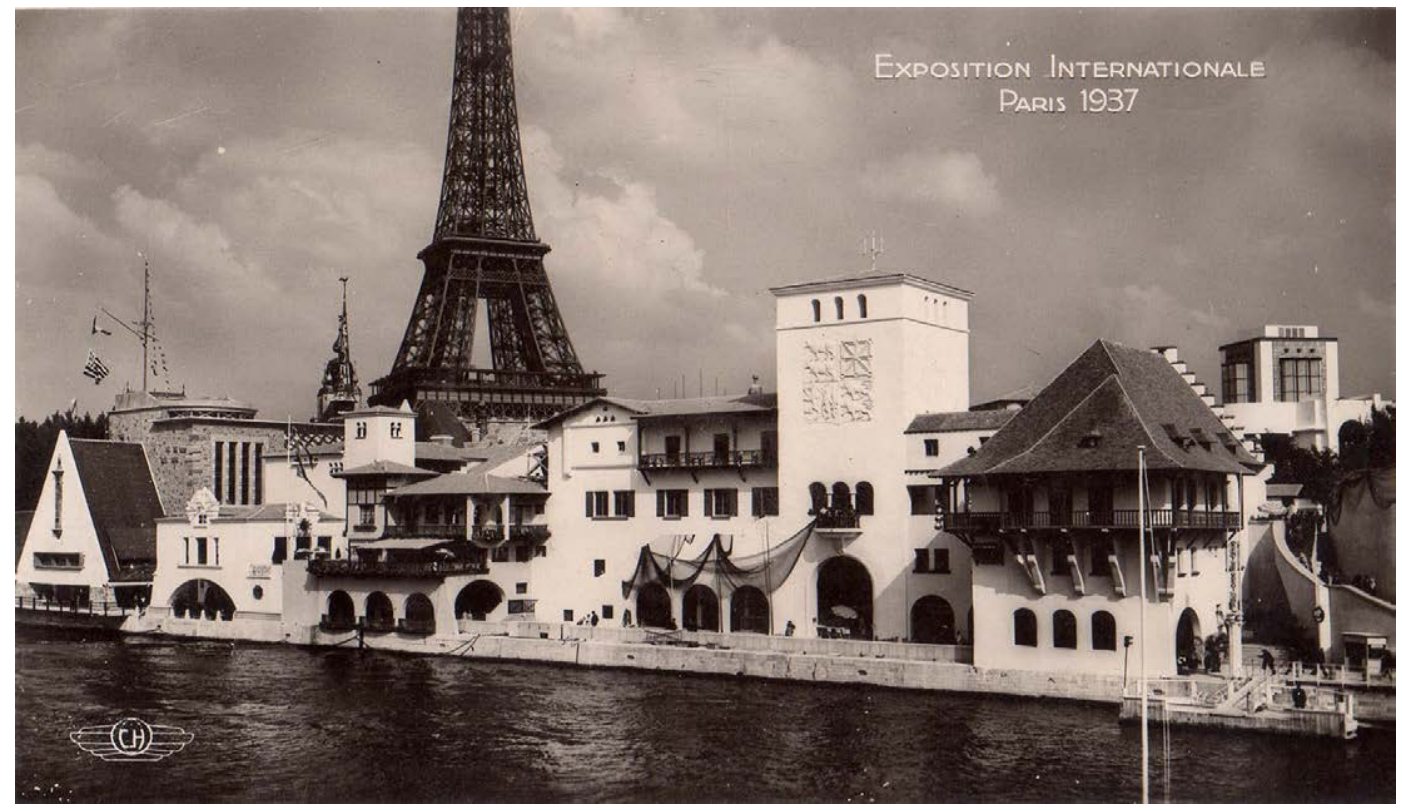

Vista del Centro Rural de la Exposición Internacional "des arts et des techniques appliqués à la vie moderne", celebrada en París en 1937. El diseño general del conjunto fue concebido por los arquitectos Charles Lestrosne, Jacques Gréber y Emile Maigrot (Ref. web: www.geneanet.org, consultada el 20 de agosto de 2018) 
$\mathrm{Al}$ interés despertado por los pabellones nacionales o regionales pronto vino a sumarse en este tipo de exposiciones el atractivo de atracciones conformadas por conjuntos de edificios cuya mayor complejidad permitía dotarlas de un mayor poder de evocación.

La "Histoire de l'habitation humaine" diseñada por el arquitecto Charles Garnier y el historiador Auguste Ammann para la Exposición de 1889 integraba más de 44 edificios que se apiñaban a los pies de la Torre Eiffel. No sólo presentaban un discurso histórico, sino también geográfico, reflejando así mismo tradiciones eslavas, laponas, escandinavas, sudanesas, etc. En la misma exposición, la Rue du Caire fue otro de los grandes atractivos, iniciativa personal del Barón Alphonse Delort de Gléon, que residía en El Cairo, fue diseñada y financiada por él. Un minarete inspirado en el del complejo funerario del sultán mameluco al-Ashraf Qaytbay preside una calle en las que Delort de Gléon replicó con todo detalle diversas casas del Cairo, incluyendo sus prominentes balcones de madera confinados por celosías (Delort de Gléon 1889, 5-11).

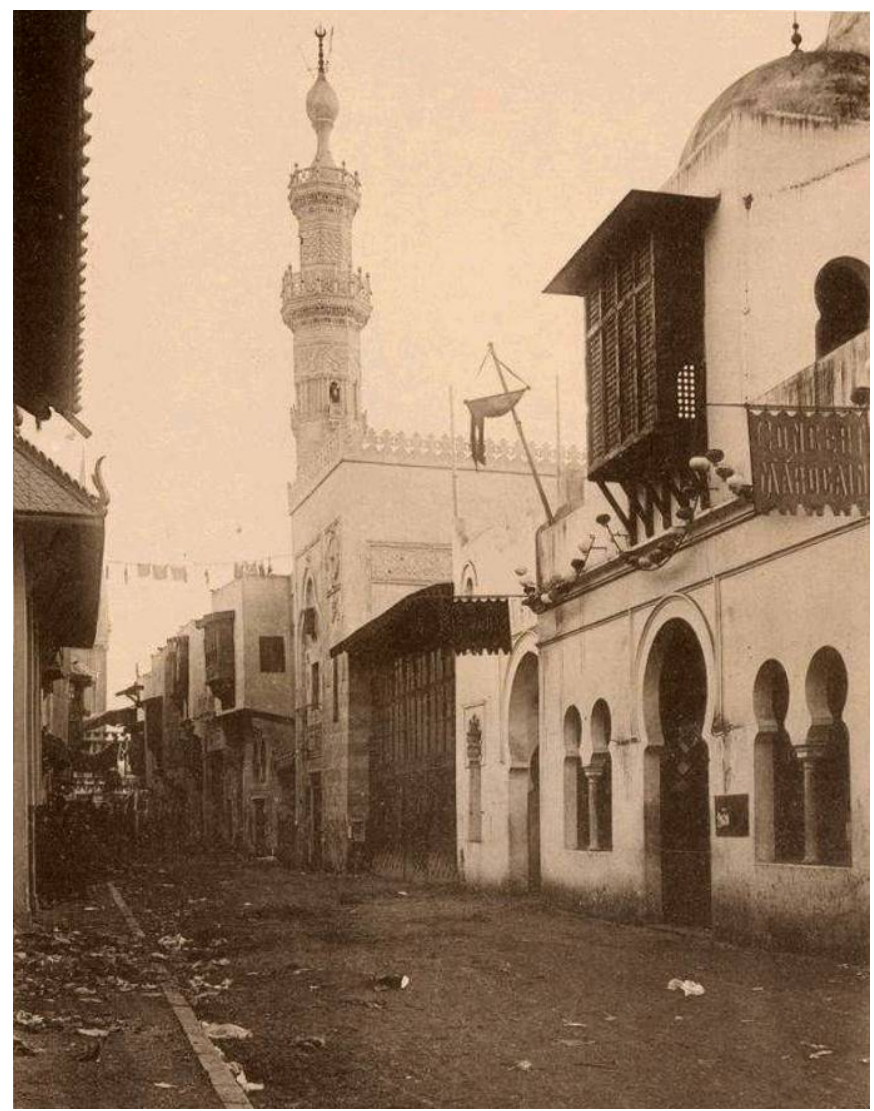

Vista de la Rue du Caire, creada por iniciativa del Barón Alphonse Delort de Gléon para la Exposición Universal de París de 1889 (Delort de Gléon 1889) 


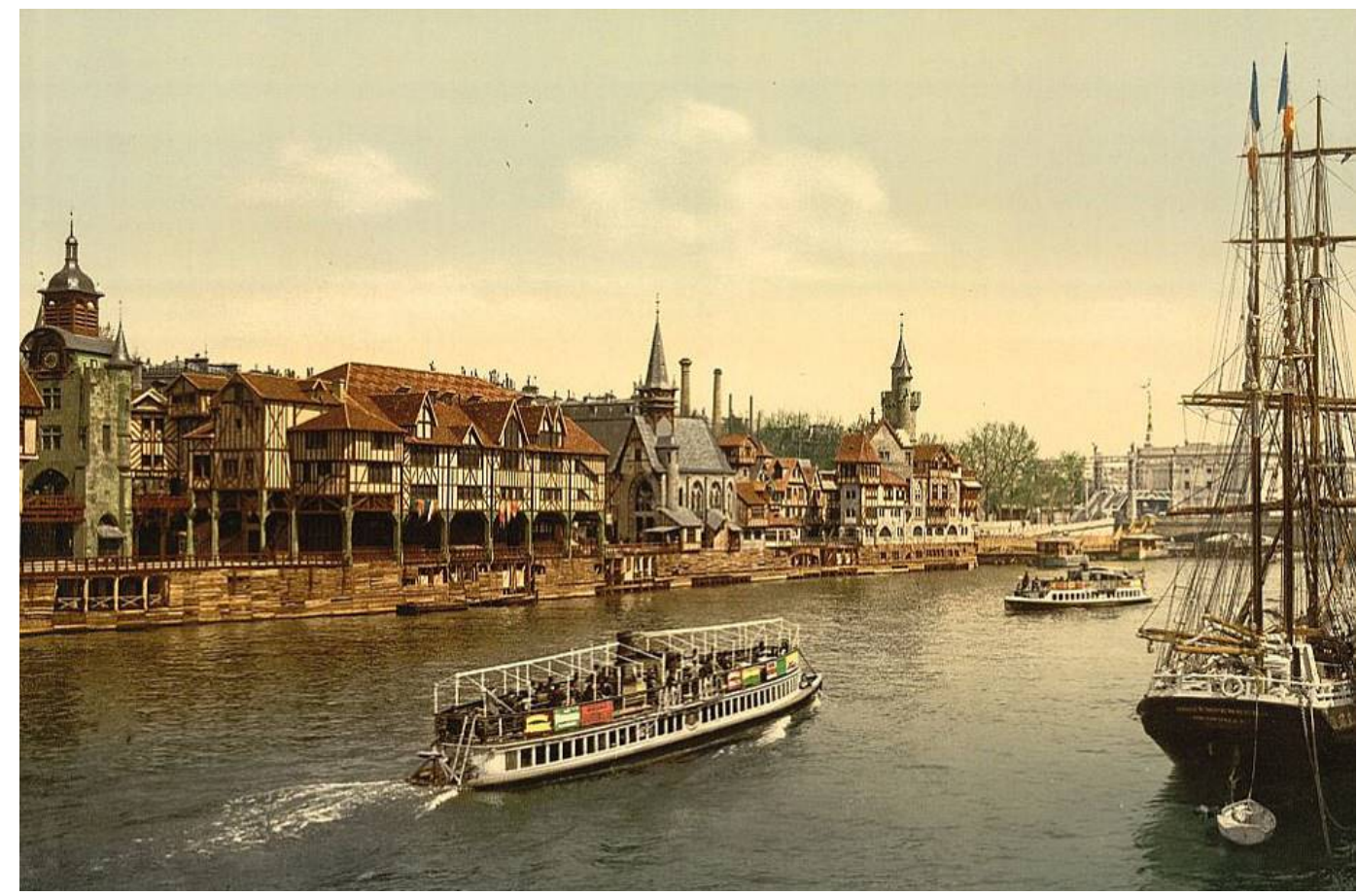

Vista del Vieux Paris, construido a orillas del Sena para la Exposición Universal de París de 1900 según los diseños de Albert Robida (Ref. web: www.dailymail.co.uk, consultada el 30 de agosto de 2017); y planta del Borgo Medievale de Turín, diseñado bajo la coordinación del arquitecto Alfredo D’Andrade para la Exposición Internacional de Turín de 1884 (Libro)

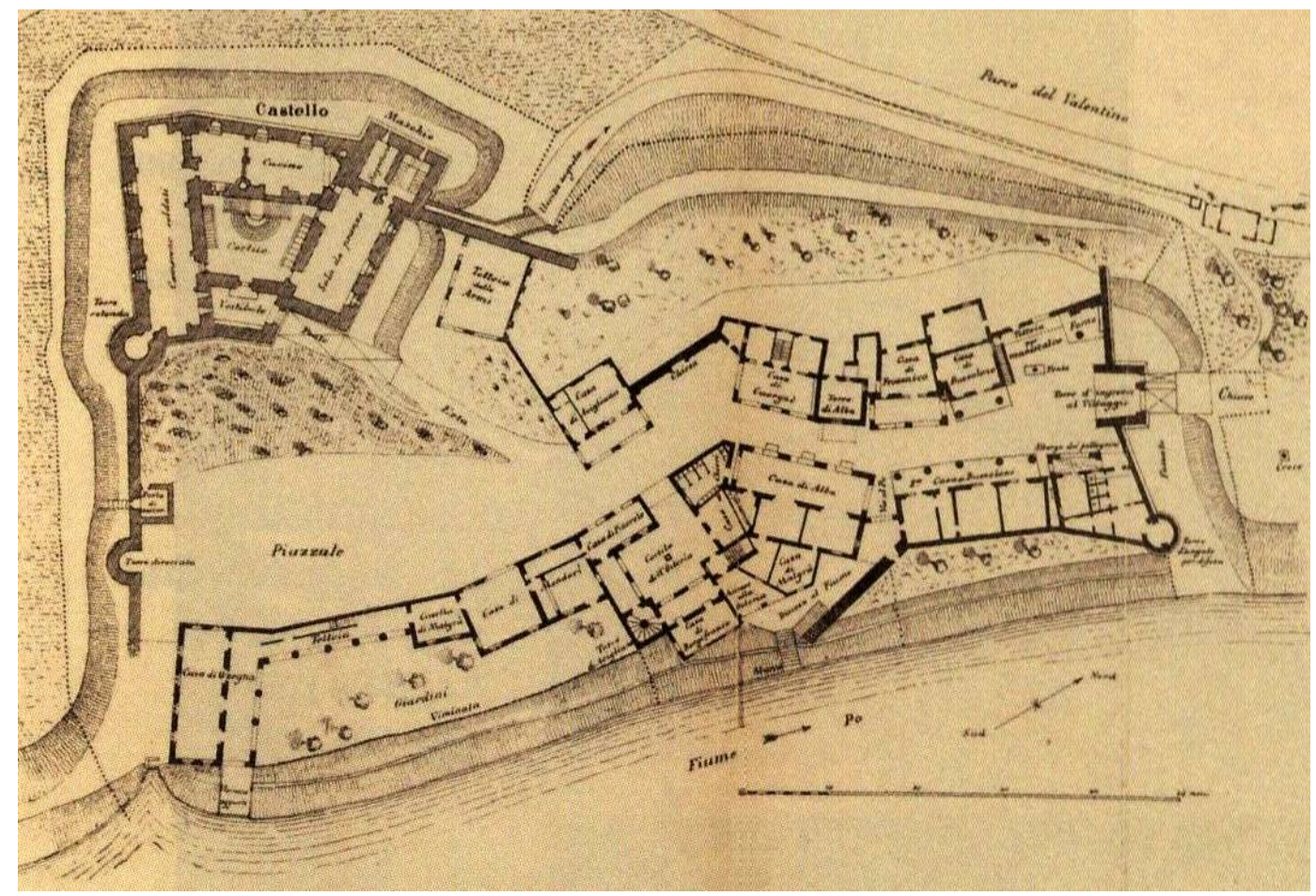


Los simulacros de ciudad tradicional construidos con motivo de las exposiciones internacionales comenzarían pronto a ser diseñados como conjuntos fácilmente comprensibles como unitarios, con sus límites bien definidos, e incluyendo ya no sólo arquitecturas tradicionales, sino una completa estructura de calles, plazas y plazuelas diseñada a imagen y semejanza de ciudades preindustriales. Pionero en este sentido sería el Borgo Medievale construido para la Exposición Internacional de Turín de 1884, inspirado en arquitecturas medievales del Valle de Aosta y el Piamonte y diseñado por un equipo coordinado por el arquitecto portugués Alfredo d'Andrade. De los modelos seleccionados, se reprodujeron diversos fragmentos combinándolos en un todo armónico, pese a integrar arquitecturas de diversas localidades.

La Exposición Universal de París de 1900 no sólo contó con la famosa Rue des Nations, en la que una sucesión de pabellones nacionales, cada uno con representando el carácter propio de su país, se extendía a la orilla del Sena, sino que incluyó también en la margen opuesta del río una porción completa de tejido histórico parisino simulado que se denominó Vieux Paris. Al haberse perdido el auténtico París histórico en el proceso de Haussmannización de la ciudad, su desaparecida arquitectura vernácula se había convertido en un elemento tan sugestivo y cautivador como las arquitecturas procedentes de los más remotos parajes. Este compacto conjunto de casas populares, coronado por torres y chapiteles y salpicado de placitas y callejuelas fue diseñado por el dibujante y escritor Albert Robida y ejecutado bajo la dirección de Léon Benouville. La elección de Robida se debió a su conocimiento de la arquitectura tradicional, mostrado en sus numerosos libros de viajes, que ilustró profusamente, a la par que a su estudio sobre la evolución histórica del tejido urbano de la ciudad: Paris de siècle en siècle; le coeur de Paris, splendeurs et souvenirs (1896). Contó esta exposición también con un amurallado Village Suisse, una elaborada aldea tradicional suiza construida al abrigo de una gran montaña de cartón piedra. Charles Henneberg y Jules Allemand fueron los arquitectos que se encargaron de su ejecución, incluyendo en el conjunto no sólo elementos originales transportados desde Suiza, sino también más de trescientos artesanos y campesinos suizos que daban vida a la recreación. Además de todo ello, completas calles norteafricanas y orientales fueron edificadas en el sector colonial que ocupaba el espacio comprendido entre la Torre Eiffel y el Palacio del Trocadéro. 


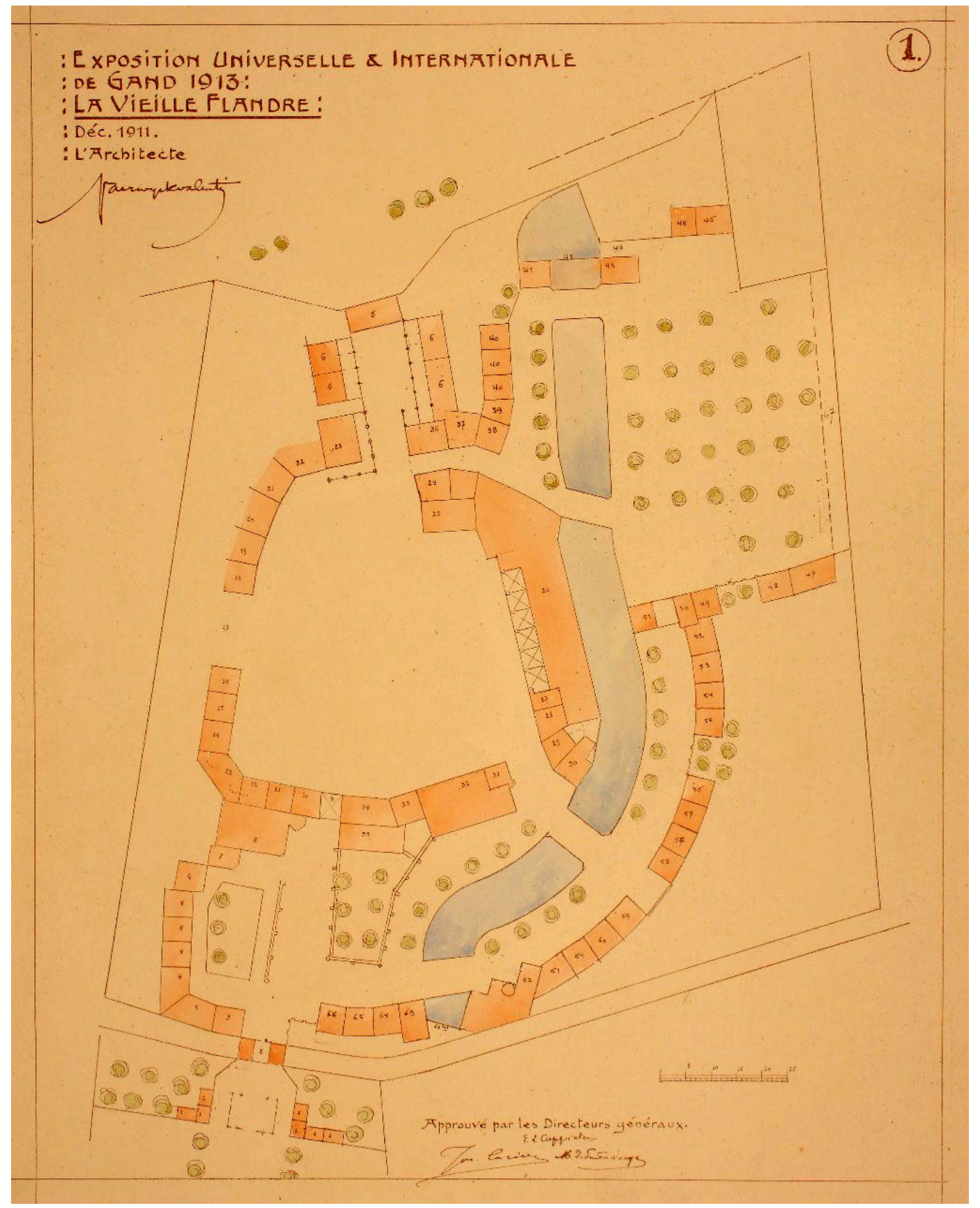

Planta de La Vieille Flandre, conjunto diseñado por el arquitecto Valentin Vaerwyck para la Exposición Universal de Gante de 1913 (Ref. web: www.sint-pietersdorp.be, consultada el 31 de agosto de 2018) 
El éxito del Vieux Paris llegó cuando este tipo de instalaciones se había convertido ya en una apuesta segura, convirtiéndose en un modelo para las grandes exposiciones de todo el mundo. La Exposición de Amberes de 1894 tuvo su Viel Anvers. La Exposición Internacional de Bruselas de 1897 incluyó un pequeño pueblo conformado por edificios tradicionales del Congo y su propia vieja Bruselas (Bruxelles Kermesse). La Exposición Universal de Lieja de 1905, además de un poblado senegalés y uno chino, tuvo su Vieux Liège, que incluyó edificios de, entre otros, Jean Ubaghs y Georges Koister. Singularmente bien logrado sería el Bruxelles Kermesse, diseñado para la Exposición Universal de Bruselas de 1910 por los arquitectos Jules Barbier y Franz van Ophem, un conjunto de edificios, calles, canales y plazas representativos de las tradiciones belgas que gozó de gran éxito hasta ser víctima del gran incendio que asoló buena parte del recinto de la exposición. En la Exposición Universal de Gante de 1913, el arquitecto restaurador Valentin Vaerwyck, además de recuperar el remate medieval del Campanario ("Belfort") de la ciudad para la ocasión, diseñó el Vieille Flandre, un núcleo urbano tradicional con varias calles y plazas e incluso un pequeño canal. En la Exposición Internacional de Amberes de 1930 Jos de Lange y Frank Blockx proyectaron la Vieille Belgique, en la que réplicas de edificios de las diversas regiones de Bélgica conformaban un pintoresco conjunto urbano. En la Exposición Universal e Internacional de Bruselas de 1935 volvió a aparecer una Bruxelles Kermesse del mismo tipo, aunque en este caso con un novedoso discurso histórico en el que cada barrio recreaba una época diferente de la ciudad. Tuvo igualmente esta exposición un poblado indio y unos zocos norteafricanos. Incluso la Exposición Internacional celebrada en París en 1937, en la que triunfó el clasicismo moderno de Boris Iofan y Albert Speer y España estuvo representada por el famoso pabellón de José Luis Sert y Luis Lacasa, además contar con el ya mencionado Centro Regional, siguió recurriendo al pintoresco carácter de los conjuntos tradicionales en su propia Vieille France, sus Souks Tunisiens y sus Souks Marocains. Tras la Segunda Guerra Mundial, sin embargo, este tipo de instalaciones iba a correr una suerte análoga a la de la arquitectura y el urbanismo de inspiración tradicional, desapareciendo prácticamente de las grandes exposiciones posteriores.

Un interés semejante al mostrado en Europa antes de dicho cambio puede constatarse en las exposiciones que se celebraban al otro lado del océano. La Exposición Colombina de Chicago de 1893 incluyó pequeños núcleos urbanos vernáculos representativos de distintas regiones del mundo. Exposición Panamericana de Buffalo de 1901 contó con un 
conjunto de cabañas filipinas y poblados de diversas tribus nativas. Para la Louisiana Purchase Exposition celebrada en San Luis de 1904 se construyó una réplica a escala reducida de la ciudad de Jerusalén. No sólo reproducía sus más famosos monumentos, como la Torre de David, el Santo Sepulcro o la Mezquita de Omar, sino también su característica estructura urbana, con un total de 22 calles, que ambientaban más de 1000 personas venidas desde la propia Palestina. La arquitectura regionalista estilo Spanish Colonial y Pueblo protagonizó la Exposición Panamá-California de San Diego de 1915, en la que se instaló además una réplica del Pueblo de Taos. Y la Exposición Internacional de Chicago de 1933, titulada “A Century of Progress”, que buscaba proyectar una imagen rotundamente moderna y tecnificada, seguía incluyendo pequeños "villages": el tunecino, el español, el alemán, etc.

Estos conjuntos presentaban compendiadas la arquitectura histórica nacional de diversos países o regiones, tipologías residenciales básicas de distintas épocas y climas o incluso fragmentos urbanos completos. La intención más obvia de sus diseñadores era ofrecer al público unos modelos muy generales, enciclopédicos y antropológicos, de gran contenido pedagógico, aunque en ocasiones teñidos de prejuicios coloniales y de una interpretación vulgar de las teorías evolucionistas. Pero además de ello, y por encima de todo, los montajes pseudo-urbanos de las exposiciones universales eran por derecho propio experiencias espaciales y arquitectónicas, realizaciones concretas y transitables cuyo encanto y poder de atracción reside precisamente en el pintoresquismo tradicionalista que presidía de la misma manera los tempranos experimentos de Mique y de Nash.

No menos importante sería este tipo de conjuntos en el caso español. Partiendo de las ideas iniciales de Puig i Cadafalch, la Exposición Internacional de Barcelona de 1929 tuvo su propio Pueblo Español, que fue diseñado por los arquitectos Ramón Reventós y Francesc Folguera, con la colaboración del pintor Xavier Nogués y el crítico de arte Miquel Utrillo. Fue construido en las faldas de Montjuic, donde aún hoy es visitado por más de un millón de personas cada año y se desarrollan numerosos eventos de ocio.

En el Pueblo Español de Barcelona, como en los casos ya mencionados del Vieux Paris o de la Bruxelles Kermesse, el objetivo no era simplemente mostrar un cúmulo de edificios representativos, sino proyectar una completa ciudad según el ideal tradicional (Canela 1998, 9-12). El arquitecto suizo Alfredo Baeschlin elogió su analogía con la "Kleinstadt" 
que propugnaba el regionalismo alemán. En el Pueblo Español de Montjuic habría incluso activos comercios, vida en las calles, una plaza mayor donde tuvieran lugar diversos festejos e iglesias donde se celebraran misas. No se trataba de reproducir los monumentos más espectaculares de nuestra geografía, sino de lograr que se ensamblaran en agradable continuidad ejemplares procedentes de muy diversas regiones españolas, de mostrar una unidad reconocible dentro de la variedad, conforme al ideal regionalista expuesto en el apartado anterior. Con estas premisas, sus autores recorrieron más de mil poblaciones documentando edificios, entre los que seleccionaron los más de cien que finalmente integrarían el conjunto, así como calles, plazas y plazuelas cuyas proporciones y dimensiones serían igualmente recreadas. El visitante puede verse transportado de una plaza segoviana a una callejuela andaluza en cuestión de minutos, generándose atractivos contrastes y transiciones, sin que esto vaya en detrimento de su percepción unitaria del conjunto.

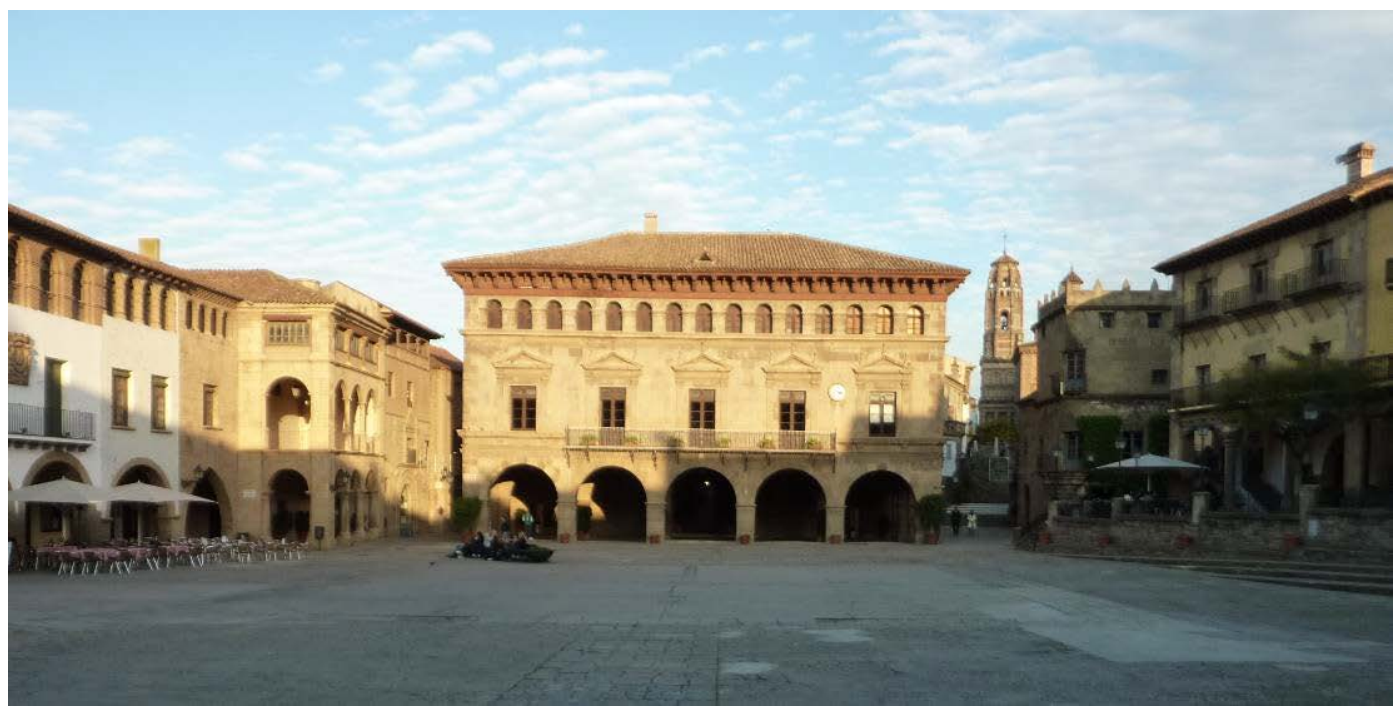

Vista de la Plaza Mayor del Pueblo Español de Barcelona, diseñado por los arquitectos Ramón Reventós y Francesc Folguera, con la colaboración del pintor Xavier Nogués y el crítico de arte Miquel Utrillo (fotografía del autor, enero de 2012) 


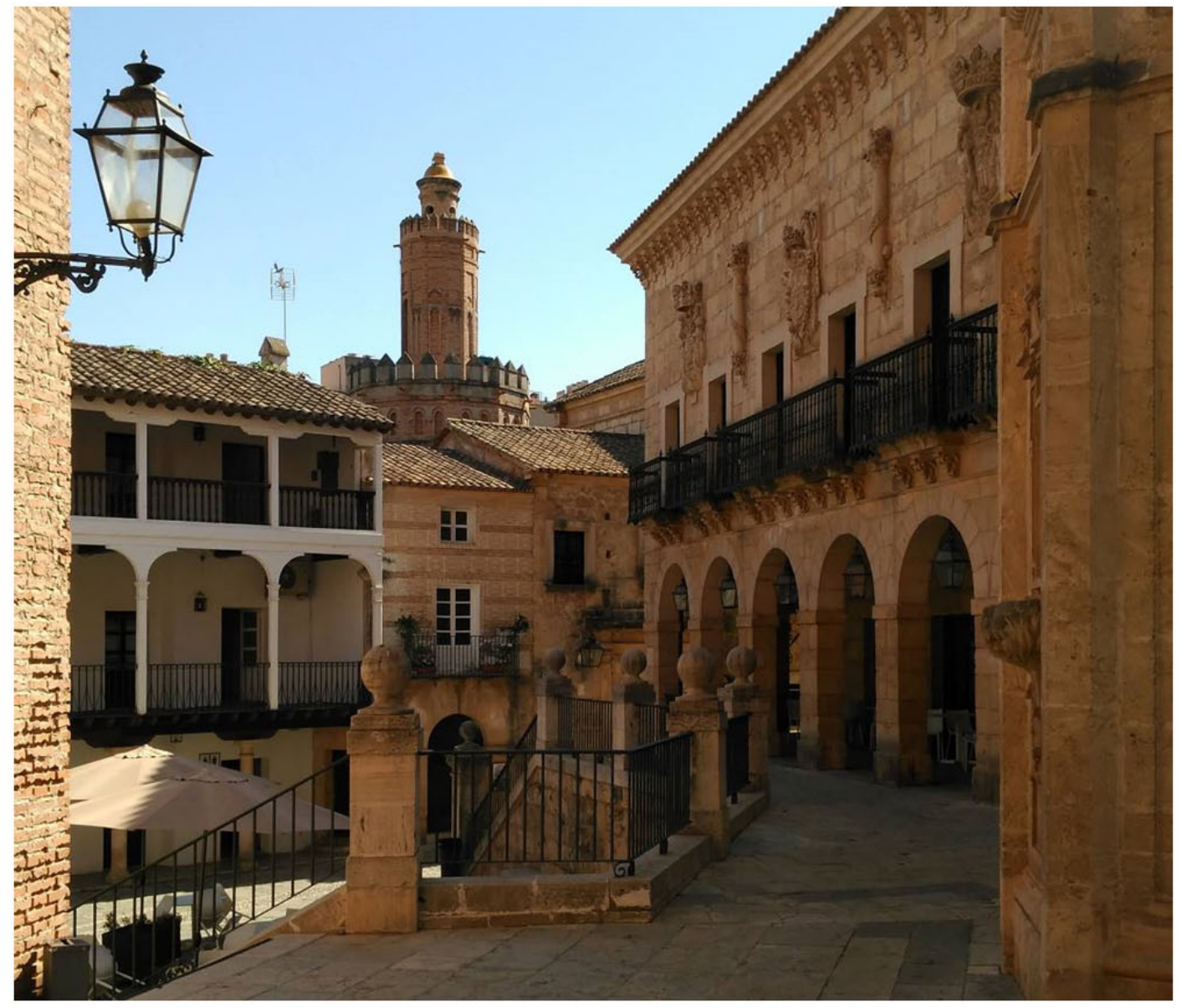

Vistas del Pueblo Español de Palma, Mallorca, obra de Fernando Chueca Goitia (fotografías del autor, julio de 2017)

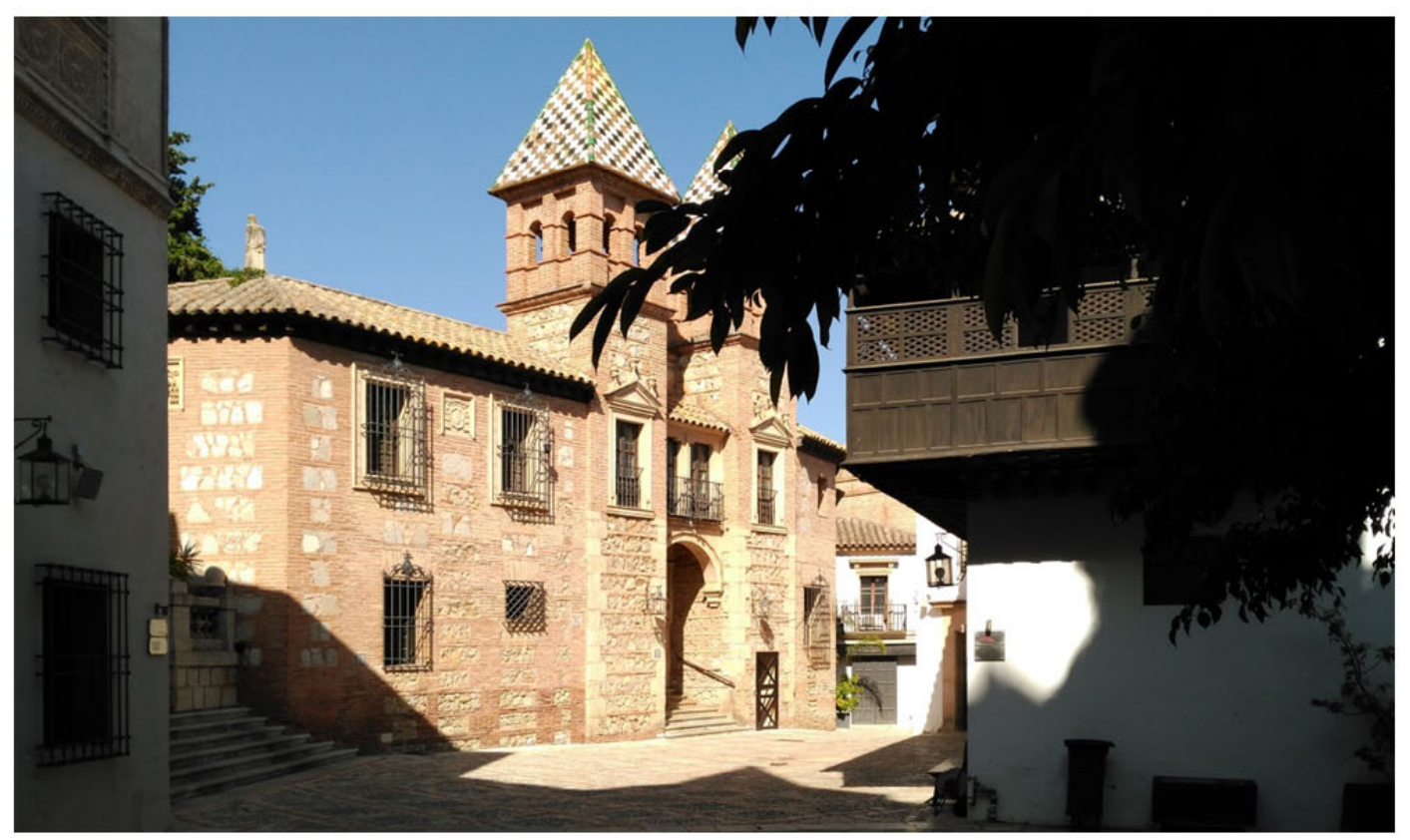


En la mayor parte de estos casos, al tratarse de atracciones inicialmente concebidas para desaparecer al clausurarse la exposición, las técnicas constructivas utilizadas distaban mucho de ser réplicas de las originales. Las calles se conforman así como un verdadero decorado, donde las imágenes reproducidas se limitan a la envolvente de los edificios. Pero esta forma de operar permite a estos conjuntos retener aún buena parte de sus virtudes. Así, el Pueblo Español de Palma de Mallorca, donde los edificios se concibieron en forma de reproducción más fiel, utilizando auténticas técnicas tradicionales de construcción, los atractivos que esto añade no trascienden el mero hecho de que en sus arquitecturas se perciba una mayor calidad arquitectónica y constructiva.

El atractivo de estos modelos no disminuye tampoco por hallarse amalgamadas diversas identidades tradicionales y tampoco en los casos de poblaciones completas diseñadas a imagen y semejanza de las propias de remotas geografías. La Rue du Cairo de Delort de Gléon fue, por ejemplo, un experimento cuyo poder de evocación no disminuía por el hecho de haber sido trasplantadas sus formas de otras latitudes.

Un efecto semejante puede percibirse en casos urbanos reales, tales como los pequeños conjuntos temáticos que George Merrick introdujo en su visionario proyecto de Coral Gables, edificado en las afueras de Miami a partir de 1922 y coordinado su diseño por un equipo conformado, entre otros, por el artista Denman Fink, los arquitectos H. George Fink y Phineas Paist, y el arquitecto paisajista Frank Button. El Chinese Village, el Dutch South African Village o el French Normandy Village, diseñados por arquitectos como Marion Sims Wyeth y Henry Killam Murphy, proporcionaron una mayor diversidad a una ciudad proyectada con un carácter de inspiración eminentemente mediterránea, contribuyendo así a generar barrios fácilmente identificables. $\mathrm{Y}$ algo similar sucede en el caso de la villa vacacional de Portmeirion, obra del arquitecto y polemista anti-moderno Clough Williams-Ellis, donde desde 1926 un pequeño conjunto urbano de inspiración italiana se ha ido erigiendo en un lugar tan aparentemente disonante con ello como es el norte de Gales.

Por tanto, independientemente de su mayor o menor fidelidad al modelo tradicional imitado, de su relación expresa con el lugar en el que se levantan o de su calidad constructiva, las ciudades así diseñadas se erigen en verdaderos manifiestos contra el tipo de tejido urbano más comúnmente edificado hoy, carente de cualquier identidad definida 
que sea legible para sus usuarios, lo que Rem Koolhaas acertadamente denomina "ciudad genérica”. La invención creativa de nuevas identidades locales basadas en la tradición no sólo es posible, sino también bien acogida.

Más allá del valor psicológico de los sistemas de referencia tanto históricos como geográficos que se despliegan estos conjuntos, existen también una serie de factores de carácter más pragmático de los que hacen casi invariablemente uso. Estos tienen que ver con aspectos de puro diseño espacial. Tomando como referencia espacios urbanos exitosos preexistentes en ciudades tradicionales, se logran en ellos ambientes urbanos de indiscutible calidad arquitectónica. El trazado de sus calles, las proporciones de sus plazas o la posición relativa de las arquitecturas que los conforman se determinan según este método de trabajo. El diseño espacial de la ciudad en base a logros precedentes tiene su origen en la ideas del arquitecto y urbanista austríaco Camillo Sitte, pudiendo considerarse las instalaciones que proliferaron con las grandes exposiciones internacionales como simulacros urbanos concebidos "según principios artísticos", tal como reza el título de su más conocida obra, Der Städtebau nach seinen künstlerischen Grundsätzen (1889).

Las dimensiones de las plazas de cualquiera de cualquiera de estos conjuntos, así como la disposición de sus edificios más representativos con respecto a ella, siguen fielmente los principios enunciados por Sitte. La Plaza Mayor del Pueblo Español barcelonés, por ejemplo, replica parcialmente la afamada plaza de Riaza (Segovia). El análisis de plazas como las de Chinchón (Madrid), Tembleque (Toledo) o Trujillo (Badajoz) inspiraría más tarde a Fernando Chueca el diseño de los principales espacios abiertos del Pueblo Español de Palma de Mallorca. Las bocas de las calles que se abren a todos ellos se disponen a menudo en molinete, como en el caso mallorquín, y nunca enfrentadas, evitando la circulación y las vistas cruzadas a través de ellos y favoreciendo la aparición en ellos de ámbitos estáticos y recogidos que la gente pueda apropiarse con facilidad. También aparecen en ellos las transiciones visuales y cambios de escala que conforme a estas ideas han de resolver las conexiones entre calles y plazas: arcos, soportales y escalinatas cumplen con frecuencia esta función.

Como postula Sitte, la ubicación tanto de los monumentos como del arbolado en los espacios públicos seguirá siempre el criterio de buscar su mayor pintoresquismo, no 
disponiéndolos fríamente en posición central o en simétricas composiciones, sino adecuando su disposición a la creación de imágenes que armonicen con los espacios y volúmenes circundantes.

La misma influencia puede percibirse en los juegos de perspectivas que enriquecen el trazado de sus calles. El campanario mudéjar de Utebo (Zaragoza), por ejemplo, se convierte así en un hito fundamental en la estructura urbana del conjunto barcelonés. Múltiples son las calles cuyo trazado se curva para enmarcar este elemento, jugando con el efecto sorpresa de su aparición entre los estrechos muros de las callejuelas al ir aproximándose a él. Cualquiera que sea el camino por el que se acceda a la plaza en la que se ubica, el monumento constituirá la principal referencia visual del espectador.

Como explicaba el propio Chueca, en el diseño de su Pueblo Español de Palma de Mallorca se trataba de "abrir calles, organizar plazas, combinar perspectivas, dar volumen a las cosas y abrir espacios que sean ambientes humanos y evocadores" (Calvo Serraller y Chueca Goitia 1967, 12).

Los límites de estos conjuntos aparecen siempre, además, bien delimitados, dejando bien patente donde termina el barrio y haciéndolo claramente identificable como tal. Tanto es así, que buena parte de ellos se encuentran incluso amurallados, tal como ocurre en el Borgo Medievale de Turín, en el Village Suisse de París o en ambos ejemplos de Pueblo Español. Lleguen o no a tal extremo, todos resultan claramente identificables como unidad bien definida y marcadamente autónoma.

Tanto el caso barcelonés como el mallorquín están por tanto entre las obras españolas que con mayor claridad siguen las recomendaciones del libro de Sitte, que precisamente había sido traducido al castellano por la editorial barcelonesa de Emilio Canosa Gutiérrez en 1926, sólo tres años de la muestra internacional barcelonesa.

Un fenómeno que ha de ponerse en relación con la aparición de estos simulacros urbanos en las grandes exposiciones es la aparición de lo que se conocería como museos al aire libre, en los que lo que se muestra son arquitecturas generalmente tradicionales. Estas arquitecturas, aunque en ocasiones son diseñadas y construidas ex profeso, son por lo general trasladadas desde diversas ubicaciones, habitualmente con el fin tanto de 
protegerlas, salvándolas de la ruina o la demolición, como de promover su valoración y conocimiento.

El primero de estos museos abrió en Oslo en 1881, compuesto apenas una decena de edificios tradicionales noruegos que formaban parte de la colección personal del rey Oscar II. Este conjunto, que incluía entre sus mayores atractivos la famosa iglesia de madera del siglo XIII traída de la localidad de Gol, se incorporó más adelante al Norsk Folkemuseum, creado en 1894 por el historiador Hans Aall, quien lo dirigió hasta su muerte en 1946. Hoy el museo está compuesto por más de 150 edificios en su mayoría rescatados de distintas regiones del país. Curiosamente, existe actualmente una réplica de la iglesia de Gol en el propio pueblo del que fue originalmente trasladada.

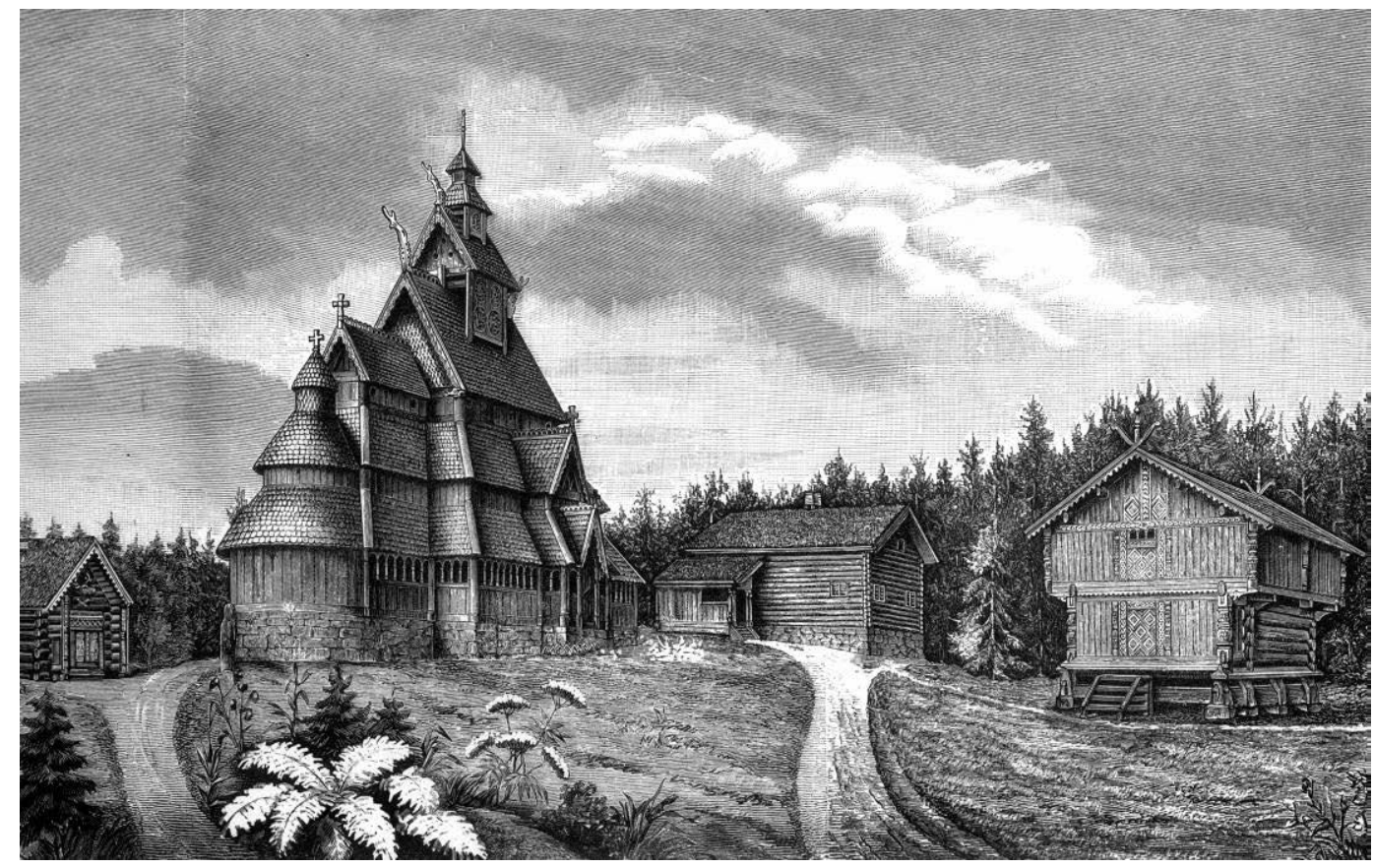

Ilustración de la guía de 1888 del Primer Museo al Aire Libre, inaugurado en Oslo en 1881e integrado pocos años más tarde en el Norsk Folkemuseum

(Ref. web: en.wikipedia.org/wiki/Norwegian_Museum_of_Cultural_History, consultada el 15 de agosto de 2018) 
Atraído por el éxito del innovador museo noruego, Artur Hazelius fundó en 1891 el conocido museo Skansen en Estocolmo. Tras numerosos viajes, Hazelius logró reunir en él más de 150 edificios tradicionales de todo el país, que fueron trasladados a un entorno en el que iba a desplegarse todo el poder escenográfico del diseño pintoresquista. Se trataba no sólo de dar a conocer las diversas tradiciones de las regiones suecas, sino de crear una ambientación completa que presentara una idealizada visión de la Suecia rural. Completando la imagen, numerosos artesanos desempeñan cada día sus oficios en sus instalaciones, mostrando los pormenores de los mismos a más de un millón de visitantes al año.

Skansen iba a convertirse en el modelo para un gran número de iniciativas del mismo género que se acometieron posteriormente por todo el mundo. El primero en América, por ejemplo, fue Greenfield Village, establecido en 1928 por Henry Ford en Dearborn (Michigan). Contaba con más de un centenar de edificios históricos dispuestos de forma que conformaran un pueblo completo en el que se podía entrar en contacto con las distintas formas de vida tradicionales que habían caracterizado los primeros siglos de existencia de la nación. El Museo de Etnografía de Transilvania de Cluj-Napoca abrió sus puertas en 1929. Le seguiría pronto el Muzeul Satului de Bucarest, creado en 1936 por Dimitrie Gusti, Victor Ion Popa y Henri H. Stahl e integrado por más de 250 casas tradicionales procedentes de distintas regiones rumanas. En 1932 el Museo Etnográfico al Aire Libre de Letonia comenzaba a funcionar a orillas del lago Juglas, en Riga. Plimoth Plantation, fundado en 1947 en Plymouth (Massachusetts), remite al visitante a los tiempos de la colonia inglesa En el Museo al Aire Libre de Estonia, abierto en 1957 en Rocca al Mare, cerca de Tallin, se reprodujo un pequeño pueblo de pescadores. En 1958 se inauguró el Museo al Aire Libre de Bokrijk, situado en el Limburgo belga. Coordinado por Jozef Weyns, fue presentado como la contribución de esta región a la Exposición Universal de Bruselas de 1958. En 1963 se edificaba el Museo Etara cerca de Gabrovo, en Bulgaria, bajo la dirección de Lazar Donkov.

En el caso español, sin embargo, los pocos museos al aire libre existentes no están entre los de este género, sino que se han dirigido exclusivamente a la restauración y valorización in situ de elementos tradicionales ya existentes en el espacio elegido, de lo que son buena muestras casos como los del ecomuseo de Somiedo o el conjunto etnográfico de Os Teixois, ambos en Asturias. 
Sea como sea, la lista no deja de crecer, enriqueciéndose progresivamente con nuevas variaciones sobre el mismo tema. Así, por ejemplo, no todos ellos han optado por la recreación de entornos rurales. En 1914, por iniciativa del profesor Peter Holm, fue inaugurado Den Gamle By (El Casco Viejo) en Aarhus, el primer museo al aire libre de carácter urbano. Se trata de un pequeño núcleo compuesto por más de 70 edificios tradicionales traídos de distintos pueblos daneses en cuyas calles, repletas de pequeños comercios y talleres, se recrea la vida de una ciudad tradicional. Este museo iba a servir más delante de modelo a otras iniciativas de este tipo, como las desarrolladas en Bergen o en Turku.

Sobre la situación del momento de este tipo de museos, publicó una interesante recapitulación José Manuel Gónzález-Valcárcel en un artículo titulado "La conservación del patrimonio rural en la actualidad: visión internacional" (1990).

A diferencia de lo ocurrido con los conjuntos urbanos de inspiración tradicional erigidos con motivo de las grandes exposiciones internacionales, este tipo de experiencias no sólo no perdería vigencia tras la Segunda Guerra Mundial, sino que al éxito de los ya existentes fueron sumándose más y más museos de distinto tamaño y contenidos por todo el mundo, aunque gozando de especial popularidad en Centroeuropa.

Desde que se definiera el ideal urbano tradicional que los distintos casos analizados en este capítulo toman como principal referencia, su realidad física se relacionó estrechamente con una realidad socioeconómica concreta e igualmente ideal: una sociedad donde predominan las clases medias de artesanos libres, donde los oficios tradicionales han suplantado la división de clases que la industria impone y donde una estructura gremial comunitaria protege a los más desfavorecidos. El utópico Londres del futuro mostrado en la "Ninguna Parte" de William Morris reflejaba ya este tipo de modelo social.

En el temprano caso del Borgo Medievale turinés los bajos de los edificios que lo componen se hallaban poblados por pequeños comercios y talleres artesanales que daban vitalidad a sus calles y convertían esta simulación urbana en un rentable negocio. Desde entonces, los conjuntos posteriores compartirían esta concepción. El Village Suisse de París reunió a numerosos artesanos suizos. Clausurada la exposición y desmantelada la 
instalación, aún predominaban en la zona los comercios dedicados a la venta de mobiliario y antigüedades, tradición que ha pervivido en el lugar hasta hoy en día. El Pueblo Español de Palma de Mallorca tiene desde inicio la función de museo arquitectónico al aire libre, pero también la de muestra de artesanía popular. Los oficios artesanales dominan también los locales existentes en el Pueblo Español barcelonés, generando a diario una importante actividad económica que favorece al pequeño comercio y al pequeño trabajador autónomo.

Lo mismo ocurre en buena parte de los Museos al Aire Libre, como en el mencionado de Bokrijk o en el de Aarhus, en los que los oficios tradicionales y la artesanía constituyen igualmente el principal motor económico del conjunto. Indudablemente, la actividad que esto genera y la vitalidad que confiere a la ciudad son parte inseparable del atractivo que estos conjuntos tienen para sus numerosos visitantes.

La defensa del pequeño comercio de barrio y de la producción artesanal, tanto con el fin de favorecer el desarrollo de la clase media local como con el de reducir el número de desplazamientos de largo recorrido dentro de la ciudad y, con ello, el uso del vehículo privado, ha sido una de las principales demandas de las principales teorías urbanas desde los años 60. Sin embargo, las políticas oficiales siguen promoviendo con frecuencia áreas zonificadas del tipo que postulara el urbanismo de la modernidad arquitectónica. Se favorece aún la implantación de núcleos de edificios de oficinas y de grandes superficies comerciales, incluso en el corazón de nuestras ciudades históricas, y es frecuente un tipo de diseño urbano donde las grandes avenidas y enormes manzanas y edificios, concebidos a escala del tráfico rodado, dificultan que en los nuevos barrios que se construyen se genere la atractiva vitalidad que presentan los conjuntos aquí analizados.

Se ha censurado a menudo la falta de autenticidad de estos modelos de inspiración tradicional. Sin embargo, el citado Borgo Medievale de Turín tiene semejante poder para transportar al visitante al Medievo al de la ampliamente restaurada ciudad de Carcasona o al de las menos alteradas ruinas que de aquel tiempo hayan llegado hasta nosotros. En cualquier taberna de Haarzuilens, la aldea de carácter medieval que el arquitecto holandés P. J. H. Cuypers concibió como parte integrante del paisaje que circundaba el castillo que recreó para la acaudalada familia Van Zuylen - Rothschild, el Castillo de Haar, puede tenerse una experiencia no muy diversa de la que se tendría en el más antiguo restaurante 
conservado en el país. $\mathrm{Y}$ es éste un caso singularmente interesante, pues Cuypers, pudiendo haber conservado un pequeño pueblo antiguo ya existente, prefirió demolerlo para abrir paso a los jardines que circundan el castillo, conservando únicamente su vieja iglesia, y construir en su lugar esta particular reinterpretación idealizada del Medievo.

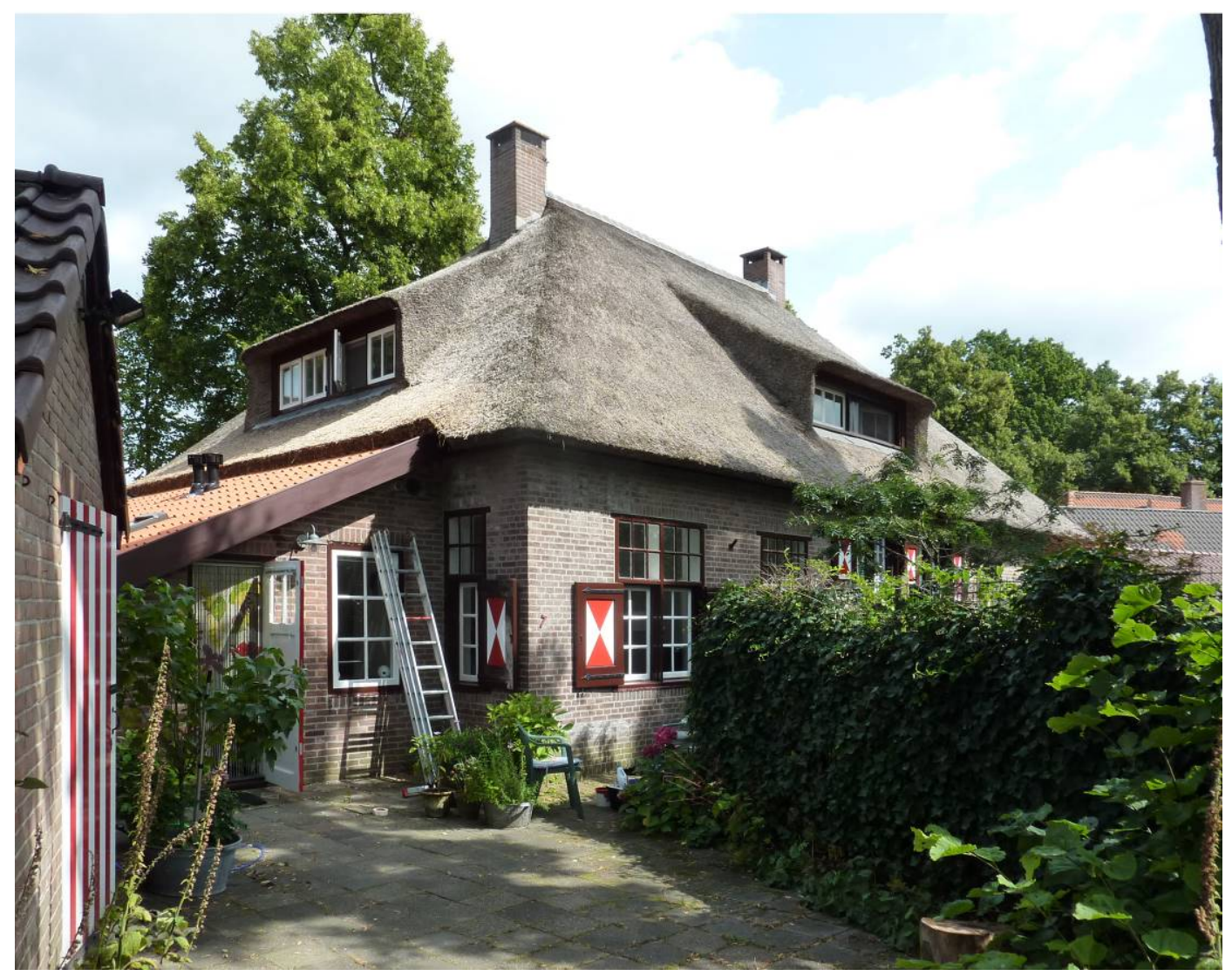

Vista del pueblo de inspiración medieval de Haarzuilens, Holanda, diseñado por P. J. H. Cuypers.

A él se trasladó a partir de 1898 a la población que residía en el pueblo del mismo nombre

(fotografía del autor, agosto de 2012)

Es posible viajar a una reinterpretación del siglo XVIII de un modo especialmente enriquecedor en el conjunto de Colonial Williamsburg, una ciudad colonial de Virginia que, tras décadas de abandono y deterioro progresivo, fue rescatada, restaurada y recreada gracias a la iniciativa del reverendo local W. A. R. Goodwin y al importante apoyo económico de John D. Rockefeller Jr. Los edificios que de su pasado colonial permanecían fueron restaurados para eliminar cualquier adición posterior, el resto, fueron 
reconstruidos o incluso proyectados y edificados desde cero al modo de la época. El proceso comenzó en 1926. Cientos de edificios fueron demolidos y otros tantos progresivamente añadidos al conjunto en un proceso que sigue aún hoy vivo. En la actualidad, dentro de sus edificios se recrean los ambientes y negocios propios de la época elegida, carpinteros, herreros y zapateros trabajan con tecnología de aquel tiempo ante los curiosos ojos de los visitantes, actores vestidos al uso colonial representan hechos históricos por sus calles y se ha convertido en uno de los destinos turísticos más populares del país. Su sugerente lema: "El futuro puede aprender del pasado". Su pasado, un pasado recreado desde el presente y, por tanto, plenamente actual.

En el Museo al Aire Libre de Arnhem, uno de los mayores y más importantes de su género, inaugurado en 1918 y en permanente crecimiento, el visitante puede pasear por las calles y plazas de aldeas conformadas por edificios trasladados no sólo de distintas regiones del país, y sentirse así transportado a Frisia o a Zelanda, sino también procedentes de distintas épocas. Además de poder ver el funcionamiento de antiguos molinos y batanes, disfrutar de las recreaciones de diversos oficios tradicionales, o conocer el proceso de fabricación de múltiples productos artesanales, es igualmente posible conocer cómo eran los apartamentos de las clases más desfavorecidas del barrio de Jordaan (Ámsterdam) en los años 70, en un fragmento de una calle de este barrio recientemente trasladado allí para salvarlo de la demolición.

Más allá del carácter más o menos vernáculo de estos ejemplos, la cuarta dimensión se convierte también en todos ellos en una herramienta más en manos del arquitecto. Los conjuntos analizados muestran, además, cómo es posible hacer un uso práctico y creativo del gran poder de representación, del importante valor simbólico de las referencias al pasado $^{14}$.

\footnotetext{
${ }^{14}$ Esta conclusión del análisis de estos casos es de gran relevancia para el objeto de esta investigación. El poder de representación y valor simbólico de los conjuntos históricos de los municipios sagreños analizados no sólo no tiene por qué verse mermado por la inserción de nuevas arquitecturas vernáculas de calidad, sino que éstos podrían potenciarse e incrementarse por esta vía. Es, sin embargo, el recurso a una arquitectura sólo pretendidamente vernácula, a un remedo vulgarizado de lo que fue la tradición arquitectónica local, lo que se ha convertido en una amenaza para su preservación.
} 


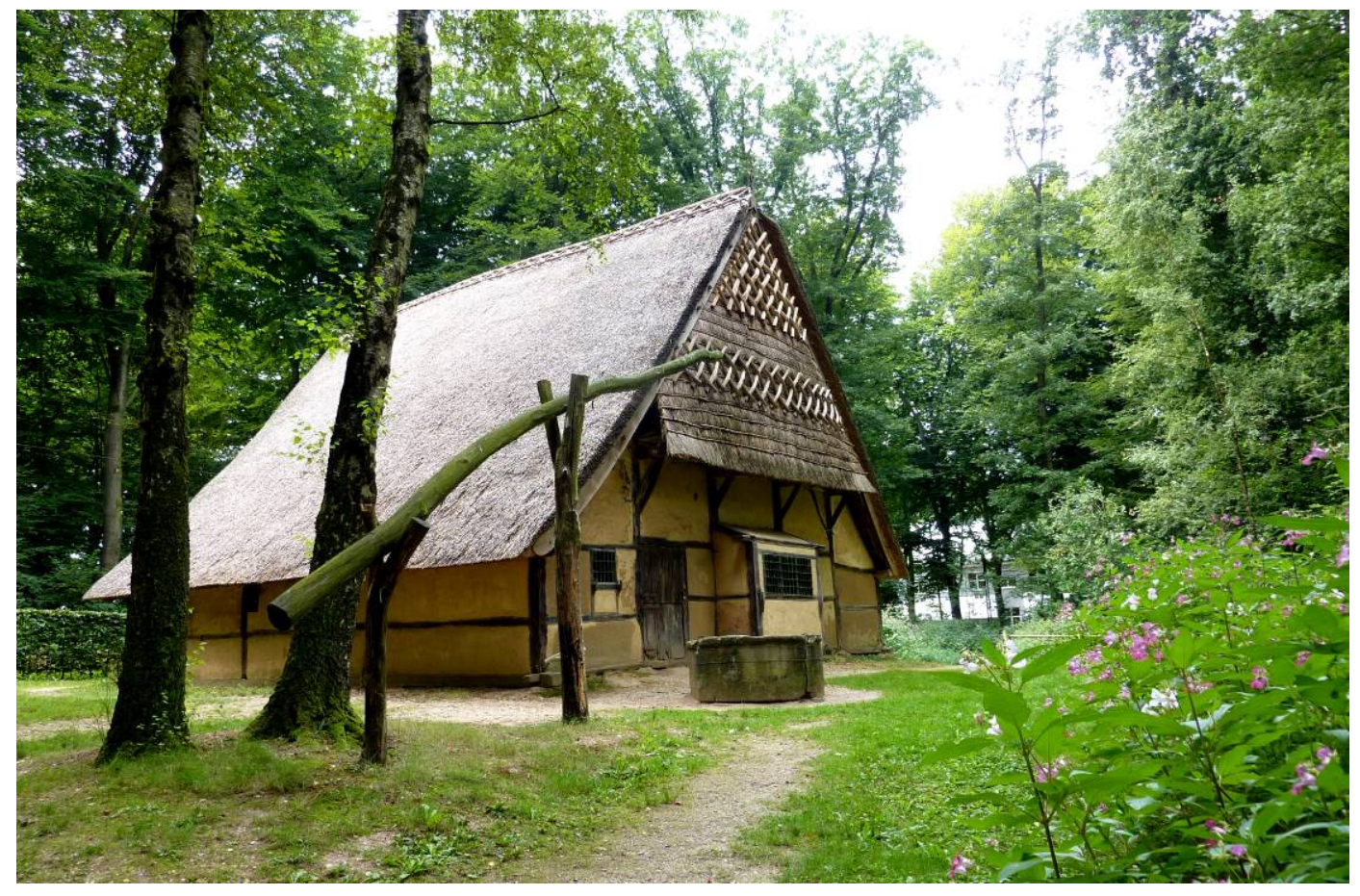

Vistas del Museo al Aire Libre de Arnhem, Holanda, inaugurado en 1918 (fotografías del autor, agosto de 2012)

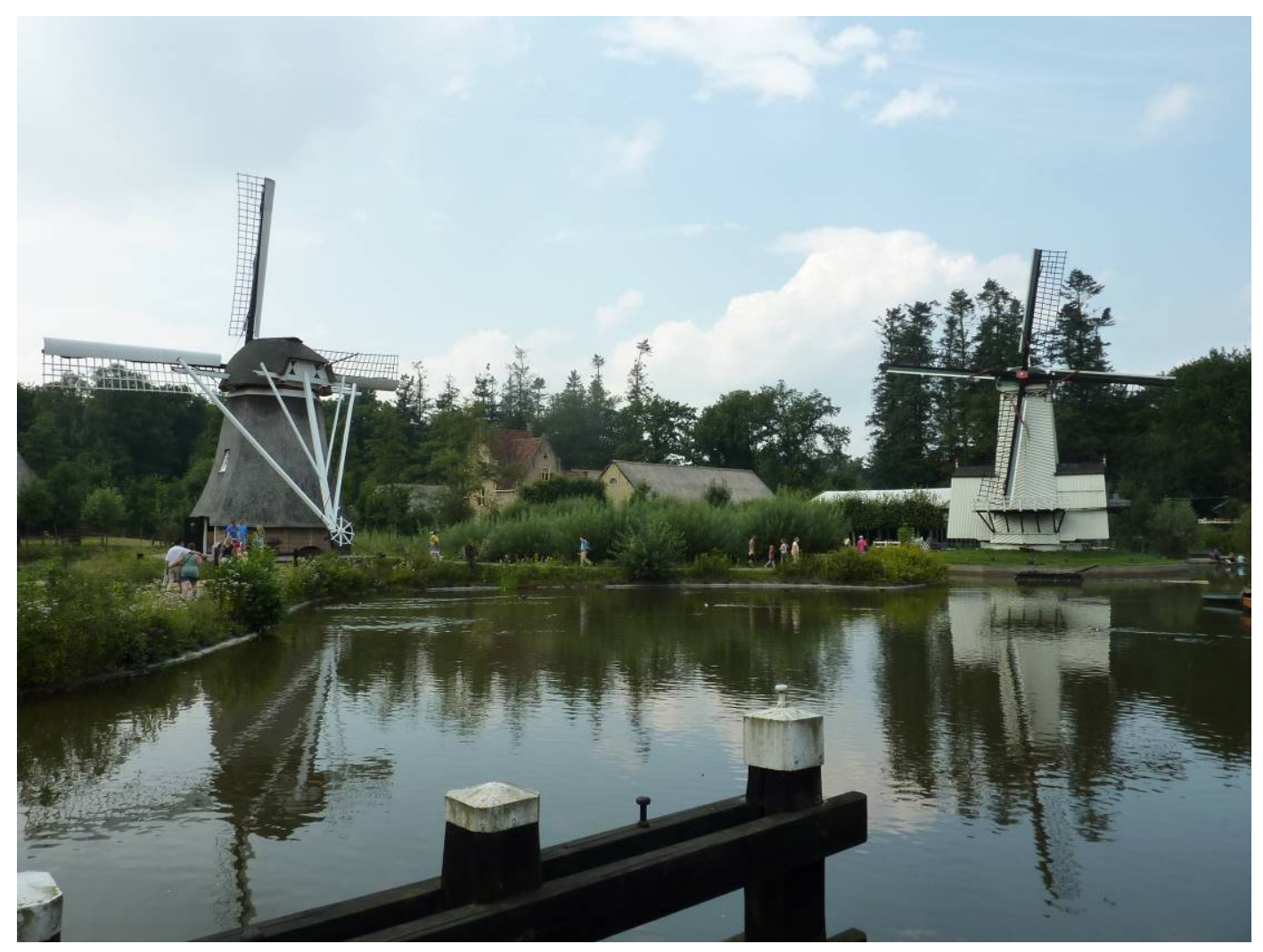




\subsection{LO VERNÁCULO COMO REIVINDICACIÓN FORMAL DE LA ARQUITECTURA MODERNA INTERNACIONAL}

Si nos colocamos contra el pasado, estamos obligados a concluir que el viejo código arquitectónico, con su masa de reglas y normativas que evolucionaron durante cuatro mil años, ya no tiene ningún interés.

Le Corbusier, Hacia una nueva arquitectura, 1923

Este radical llamamiento de Le Corbusier a romper con la milenaria tradición conquistaría a generaciones de arquitectos. Sus famosos cinco puntos de una nueva arquitectura, formulados en 1926, eran al mismo tiempo cinco manifiestos contra la tradición arquitectónica. Las nuevas construcciones debían demostrar con rotundidad no necesitar tejados, muros de carga o dinteles tradicionales. La continuidad de los tradicionales procesos de imitación e innovación encontraba un nuevo obstáculo para su pervivencia. El artesano, además de seguir teniendo que hacer frente a la dura competencia de los baratos productos industriales, iba a verse desplazado por esta nueva ideología. Las tradiciones de propias de los oficios de la albañilería, la forja o la carpintería carecían de interés para los defensores de lo que iba a conocerse como Estilo Internacional.

Fruto de una visión de la arquitectura cargada de determinismo histórico, para la mayoría de los arquitectos del momento, y tal como ocurre aún hoy con frecuencia, la historia de la arquitectura se reducía a una historia de los estilos arquitectónicos, estilos que se sucedían en el tiempo por una inescapable causalidad. Entendidos de este modo, aspectos como la industrialización o tecnificación de la construcción, al contrario de lo concluido por los ya citados estudios de Julio Caro Baroja, Amos Rapoport o Paul Oliver, imponían necesariamente una arquitectura nueva. "El modo clásico de formas establecidas para columnas, arquitrabes y cornisas es reemplazado por un vocabulario estereotipado de columnas de acero, parapetos horizontales y ventanas en esquina, para ser usado... tanto en junglas como en glaciares", explicaba Rudolph Schindler en "Space Architecture" $(1935,19)$. El arquitecto se veía ineludiblemente impelido por la historia y la técnica a rechazar la invención por vía de la imitación y a abrazar la inventio ex nihilo. Tal como expone Samir Younés en The Imperfect City: On Architectural Judgement (2012a: 35), 
esta mirada hacia el pasado del arquitecto moderno era rotundamente contraria a la visión de la historia como un flujo continuo, donde los condicionantes externos a la arquitectura influyen ininterrumpidamente sobre ella, moviéndola a muy diversas transformaciones, sin conducir necesariamente a su completa reinvención periódica.

Tampoco la ciudad tradicional iba a ser ya considerada una fuente de modelos para mejorar el urbanismo contemporáneo. El estilo moderno produciría interesantes resultados al ser aplicado sobre estructuras urbanas tradicionales preexistentes, como ejemplifican las obras de Erich Mendelsohn o las de muchos de los seguidores de su personal estilo, o al utilizarse subordinado a modelos urbanos tradicionales, con las dimensiones y configuración de parcelas, manzanas, calles y plazas propias de ellos, tal como puede apreciarse en algunos de los desarrollos urbanos diseñados para Rotterdam por arquitectos como Jacobus Johannes Pieter Oud, en la "Ciudad Blanca" de Tel Aviv o en la hoy revitalizada y exitosa Miami Beach. Sin embargo, no fue éste el tipo de ciudad promovido por la amplia mayoría de la vanguardia arquitectónica.

La calle era vista por Le Corbusier como "un residuo del paso de los siglos", como un "órgano inoperante, vencido" en el que se abigarraban miles de casas "negras" en “cacofónica relación de vecindad" $(1946,112)$. En su lugar, proponía la creación de altos bloques monofuncionales revestidos de vidrio y conectados entre sí por amplias autopistas concebidas para el desplazamiento en automóvil, todo ello rodeado de grandes extensiones de praderas verdes. Las propuestas urbanas de Ludwig Hilberseimer y Ludwig Mies van der Rohe no iban a prestar mucha más atención a aspectos tan indisociables del fenómeno urbano como la naturaleza y el funcionamiento de las relaciones humanas dentro de la ciudad. Los Congresos Internacionales de Arquitectura Moderna (CIAM), fundados en 1928 en el Château de la Sarraz, cerca de Lausana, y celebrados con periodicidad variable hasta 1959 , orientaron la visión urbana defendida por la ortodoxia moderna durante esas décadas. Sus principios fueron desde un comienzo los propuestos por Le Corbusier, quien ejerció de maestro de ceremonias de estos encuentros internacionales en sus inicios, siendo más adelante su principal discípulo español, José Luis Sert, el encargado de desempeñar este papel. No había cabida en ellos para versiones menos maquinistas de la ciudad, tales como las de Mendelsohn u Oud, que perdieron consecuentemente influencia sobre el común de la vanguardia arquitectónica. En el IV CIAM, celebrado en 1933, se discutió y acordó este modelo urbano, que sería 
plasmado en la Carta de Atenas, publicada por el propio Le Corbusier en 1943, aunque parte de las ideas en ella recogidas habían sido previamente incluidas por José Luis Sert en su libro Can Our Cities Survive? An ABC of Urban Problems, Their Analysis, Their Solutions, publicado un año antes.

En la propia Carta de Atenas se observaba, sin embargo, cómo "el espíritu de la ciudad se ha conformado con el paso de los años; los más sencillos edificios han adquirido un valor de eternidad, ya que simbolizan el alma colectiva; son el armazón de la tradición, que, sin que implique limitar el progreso futuro, condiciona la formación del individuo, tal como hacen el clima, la región geográfica, la raza y las costumbres". Y también se reconocían en ella las consecuencias negativas de la mecanización sobre el artesanado tradicional: "El uso de la máquina ha alterado completamente las condiciones de trabajo. Ha destruido un antiguo equilibrio, asestando un golpe letal a la clase de los artesanos". Sin embargo, la arquitectura tradicional y, sobre todo, sus ejemplos de carácter más popular, más allá del reconocimiento de las cuestiones mencionadas, era tratada como un obstáculo al progreso de la ciudad, y como un capricho el pretender conservarla. Incluso la conservación de las más "significativas y majestuosas muestras de los tiempos pasados" podía ser contraria a los intereses del progreso. Sólo algunos edificios, los más singulares, merecían sobrevivir a los cambios propuestos, siempre y cuando pudieran ser trasladados al lugar más conveniente y modificados para hacerlos más funcionales. Para sus autores, asumían una grave responsabilidad quienes militaran "por la preservación de ciertos pintorescos distritos antiguos, sin importarles la pobreza, la promiscuidad y las enfermedades que estos distritos albergan". No había salvación posible para los tejidos urbanos tradicionales: "La demolición de casas y tugurios insanos en torno a algunos monumentos de valor histórico destruirá un ambiente centenario. Esto es lamentable, pero es inevitable. La situación puede convertirse en una ventaja introduciendo áreas verdes". Y no sólo se condenaba la conservación de conjuntos tradicionales, sino la voluntad misma dar continuidad a esas tradiciones: "La práctica de usar estilos del pasado bajo pretextos estéticos para nuevas estructuras erigidas en áreas históricas tiene consecuencias dañinas. Ni la continuación de tales prácticas ni la introducción de iniciativas de este tipo serán toleradas en modo alguno".

Siguiendo estos postulados, se multiplicaron en todo el mundo los proyectos para destruir y reconstruir según este nuevo código los centros históricos de numerosas ciudades. Los 
más reconocidos arquitectos y urbanistas nos han dejado numerosos ejemplos de esta voluntad: las sucesivas propuestas de Le Corbusier para diversos sectores del antiguo París, para Argel o incluso para Nueva York, los proyectos de Hilberseimer para Chicago, el plan para La Habana diseñado en 1956 por José Luis Sert, que planteaba la destrucción de la Habana Vieja, etc. En los Estados Unidos, los centros históricos de numerosas ciudades fueron arrasados casi por completo, salvándose en muchas de ellas apenas algunos edificios religiosos y equipamientos públicos. El urbanismo de los CIAM se había erigido así en una amenaza más para la preservación de la arquitectura y el urbanismo tradicionales.

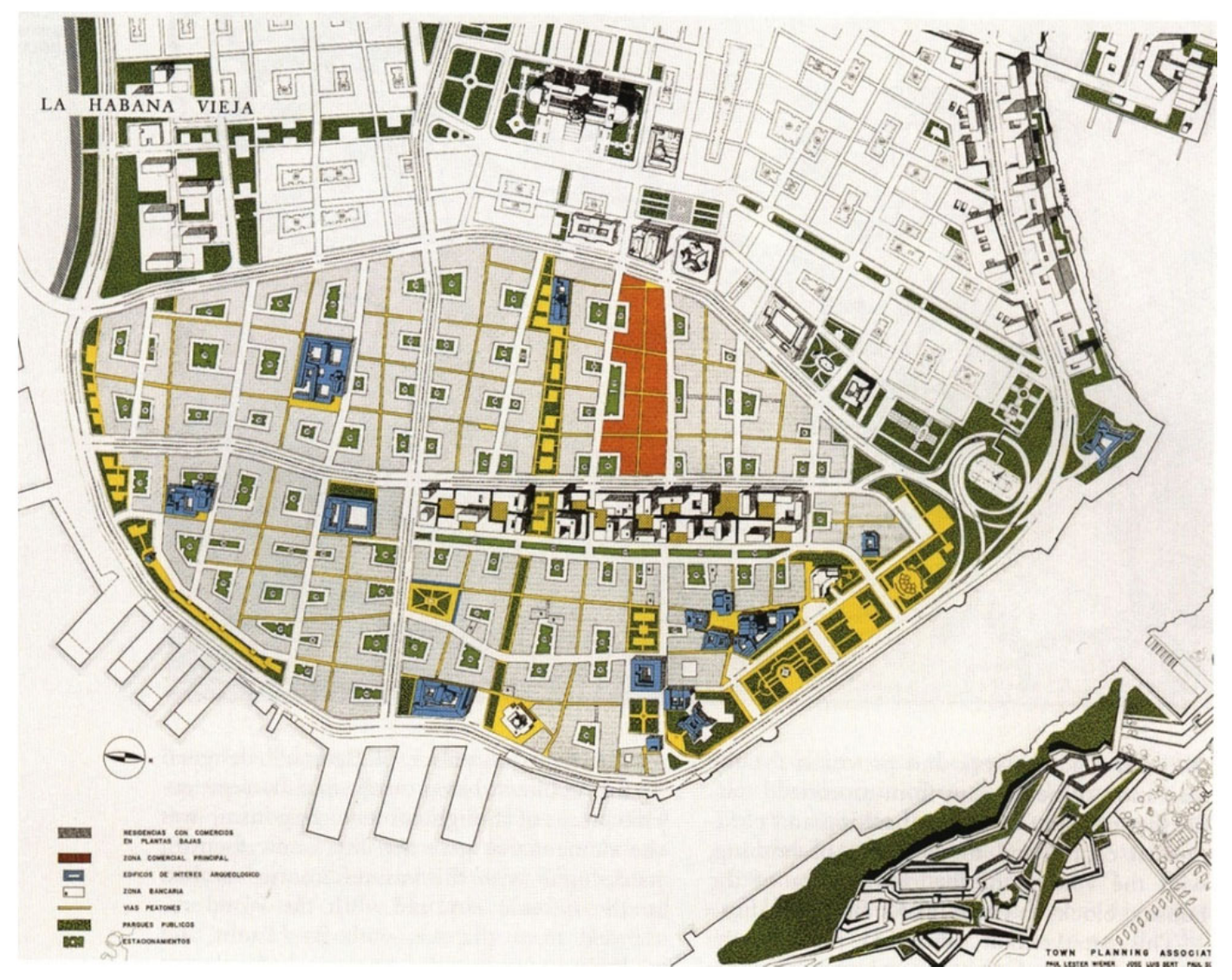

Propuesta de reforma urbana de José Luis Sert para La Habana Vieja, 1956 (Rovira 2003) 
Estas ideas han de ser puestas en contexto con los debates del momento. Poco antes de que se consensuara la doctrina de esta Carta de Atenas del IV CIAM, desde el ámbito de la conservación del patrimonio se había desarrollado una Carta de Atenas anterior a ésta, fruto de la reunión en Grecia en 1931 de la Comisión Internacional de Cooperación Intelectual de la Sociedad de Naciones, y en concreto de su Oficina Internacional de Museos. Esta Carta, contrariamente a lo planteado por la de 1933, "recomienda respetar, al construir edificios, el carácter y la fisonomía de la ciudad, especialmente en la cercanía de monumentos antiguos, donde el ambiente debe ser objeto de un cuidado especial". Recogía con ello, si bien de forma muy somera y desvirtuada, parte de las ideas presentadas en su libro Vecchie città ed edilizia nuova (1931) por el arquitecto italiano Gustavo Giovannoni, uno de los firmantes de esta primera Carta. En él la ciudad existente no es sólo apreciada por sus cualidades artísticas e históricas, sino por su funcionalidad, por su valor para la ciudad contemporánea. Plantea trabajar sobre el tejido urbano a dos escalas: una más cercana al diseño arquitectónico, interviniendo a pequeña escala barrio por barrio, incluyendo la ciudad preexistente; y otra comprendiendo la ciudad en su conjunto, integrando los barrios históricos como un componente más de cualquier urbe moderna. Su propuesta integración de la ciudad histórica en el planeamiento contemporáneo suponía una importante novedad sobre las ideas de autores precedentes como Camillo Sitte o Charles Buls, que inspiraban otros planteamientos incluidos por Giovannoni en la misma obra. Propone en ella un modelo urbano policéntrico, que alivie la presión que sufren los centros urbanos, en línea con lo que propugnaría Eliel Saarinen en 1943 en su The city: its growth, its decay, its future, o, varias décadas después, arquitectos como Leon Krier. Giovannoni defiende también con fuerza el contexto de los monumentos, subrayando la importancia de las arquitecturas populares que conforman junto a ellos el tejido histórico. Se refiere así mismo explícitamente al criterio urbano de Le Corbusier "de destruir lo que existe para crear un orden nuevo", que califica de “bárbaro, pero lógico" en el contexto de las ideas defendidas por éste $(1931,155)$.

En cuanto a la identidad local tradicional, no sólo era una cuestión secundaria para buena parte de los seguidores de las más vanguardistas corrientes arquitectónicas, sino que, para la mayoría de ellos, carecía ya de sentido seguir debatiendo al respecto. La nueva fórmula forma-función excluía, al menos en los debates teóricos, cualquier contenido simbólico o cultural, considerado ahora una rémora de un pasado ya superado. Algunas de las vanguardias artísticas de las que era heredero este movimiento imponían que la geometría 
abstracta y el lenguaje de la técnica desplazaran cualquier forma tradicional, desterrándose con ello la mayor parte de los posibles caracteres locales.

Nikolaus Pevsner, uno de los principales historiadores de estas nuevas corrientes arquitectónicas, afirmaba que "el arquitecto que quiera representar al nuevo siglo ha de ser más frío; frío para mantenerse al mando de la producción mecanizada, frío mientras diseña para satisfacer los deseos de sus anónimos clientes" (Watkin 1981, 134). La arquitectura debía ser para muchos de ellos, los defensores de la internacionalización, un servicio anónimo y mecánico, concebida por y para las masas y nunca para un individuo concreto ni para un lugar con una identidad particular. Arquitectos de la talla de Mies van der Rohe no dudaban en señalar que "el individuo está perdiendo importancia" y "su destino ya no nos interesa" (Óp. Cit., 137).

Le Corbusier publicaba en 1946 un pequeño libro de polémico afán titulado A propósito del Urbanismo. Incluyó en él sus irónicas respuestas a un real o figurado entrevistador inglés que en 1944 cuestionaba a Le Corbusier sobre sus ideas para la reconstrucción de las ciudades europeas tras la guerra, con la intención de publicar el resultado de esta entrevista en una nueva revista, Reconstruction, que nunca llegó a ver la luz. A la pregunta de si las viviendas prefabricadas podrían adaptarse a los muy diversos paisajes y condiciones físicas de las distintas regiones de Francia, Le Corbusier respondía que una obra de calidad siempre estaría adaptada al lugar en el que se emplazara. 

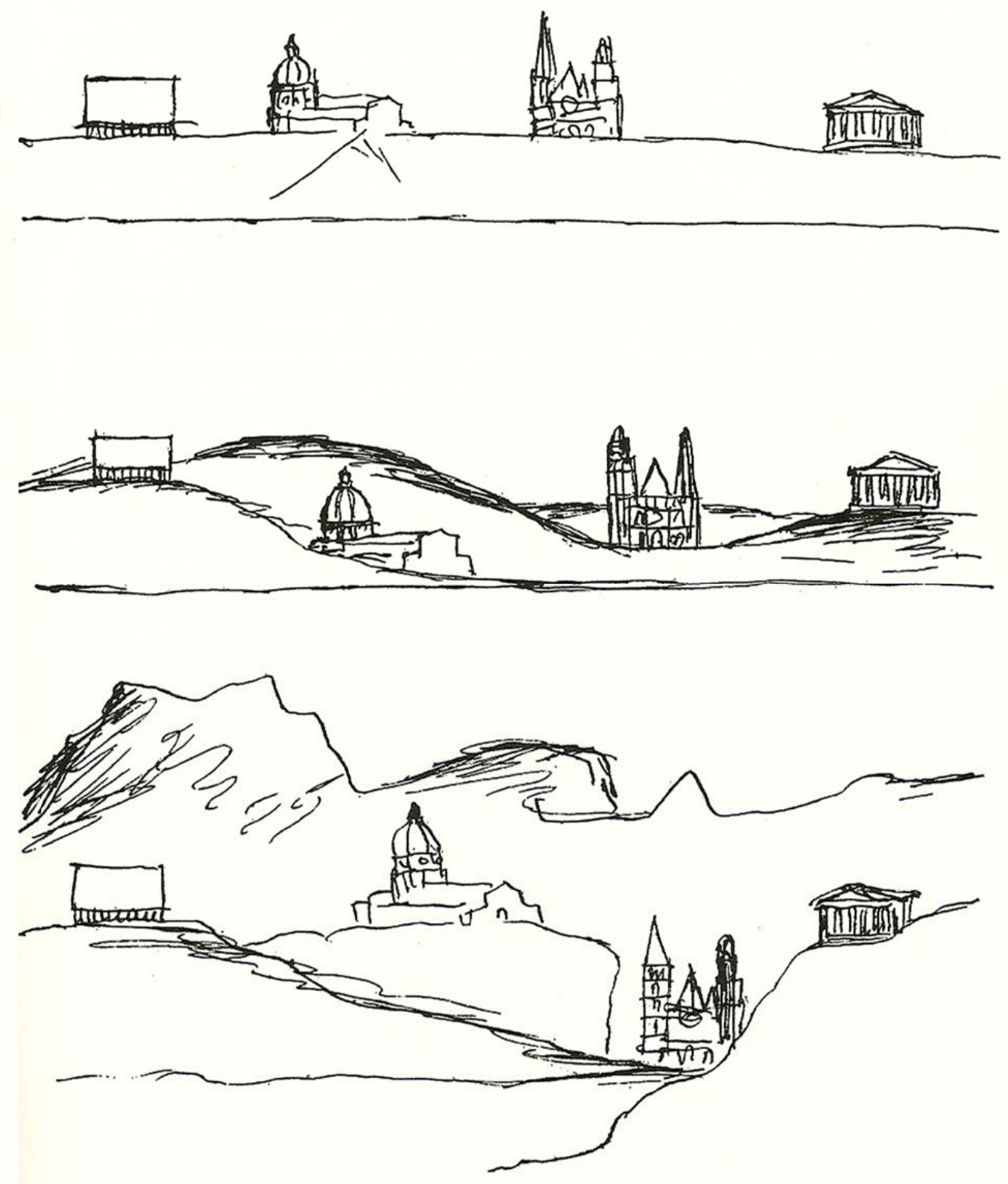

Le Corbusier, en A propósito del Urbanismo, responde con este dibujo a una pregunta sobre cómo cualquier arquitectura puede integrarse en los diversos paisajes, omitiendo en él las arquitecturas más populares, aquellas que socavarían en mayor medida su argumento (Le Corbusier 1946) 
El distanciamiento entre la ideología maquinista y el tradicionalismo era rotundo. Buena muestra de ello es hacer una comparación entre las conferencias impartidas en la madrileña Residencia de Estudiantes por los reconocidos arquitectos que visitaron esta influyente y prestigiosa institución. Los abstractos discursos de Theo van Doesburg, Walter Gropius o Sigfried Giedion contrastan fuertemente con la conferencia impartida por Sir Edwin Lutyens en 1934, en la que centra su exposición en los artesanos que habían colaborado en cada proyecto: carpinteros, albañiles, canteros..., el carácter del lugar, la procedencia y características de la piedra o de la madera, etc. Posicionaba además en ella su visión de la arquitectura como antagónica a las nuevas corrientes del momento: "En todos los países la arquitectura se ha desarrollado por influjo de las costumbres nacionales y las condiciones climáticas y geológicas. Hoy en día la máquina y el intranquilo automóvil han roto la tradición, y se prescinde de la geología para utilizar materiales universales" (Guerrero 2010, 389).

Pese a todo ello, lo vernáculo, y en concreto las arquitecturas más populares del Mediterráneo, iban a despertar un enorme interés en buena parte de los propios arquitectos que buscaban romper con la tradición. Sus formas impregnarían los diseños de arquitectos de todo el mundo, sin que se haya prestado aún suficiente atención al carácter y el origen de tan paradójico fenómeno.

Primeramente, es importante señalar que de las arquitecturas del pasado iban a interesar sólo o principalmente su composición o su forma abstracta, tal como se afirma en manifiestos y artículos del momento. Fueran obras monumentales o populares, su interés requería que su forma pudiera asimilarse a composiciones de figuras geométricas como prismas, pirámides, cilindros, etc. (Younés 2012a, 176-182), u obedeciera a determinadas proporciones numéricas. Así, un templo de la Grecia clásica u obras como el Panteón de Roma, podían servir de inspiración como juegos "bajo la luz" de volúmenes de cierta pureza, pero menos interesante iba a resultar la compleja composición de, por ejemplo, una catedral gótica, un artesonado mudéjar o un caserío tradicional vasco.

Un esclarecedor testimonio de esta forma de operar es ofrecido por el arquitecto italiano Giovanni Michelucci en su breve artículo "Fonti della moderna architettura italiana", publicado en 1932 (460-461). Buscando defender la arquitectura del Movimiento Moderno de los ataques de quienes la consideraban una moda de origen extranjero, y en 
concreto alemán, contrapone fotografías de casas tradicionales de la Toscana y diseños de estilo moderno inspirados en sus formas, buscando con ello mostrar la continuidad existente entre una y otra arquitectura. Reduce en estas muestras la tradición a una composición de volúmenes de perfecta geometría, en la que materiales, elementos constructivos y demás muestras de su adaptación al lugar y al clima toscanos son suprimidos en favor de los característicos elementos de este estilo, como las cubiertas planas, los vanos horizontales y las barandillas tubulares estilo barco. De este modo, prácticamente toda manifestación de la cultura material del lugar es sustituida por elementos abstractos y universales. Pero pervive de ella, en todo caso, un esbozo de sus principales formas.
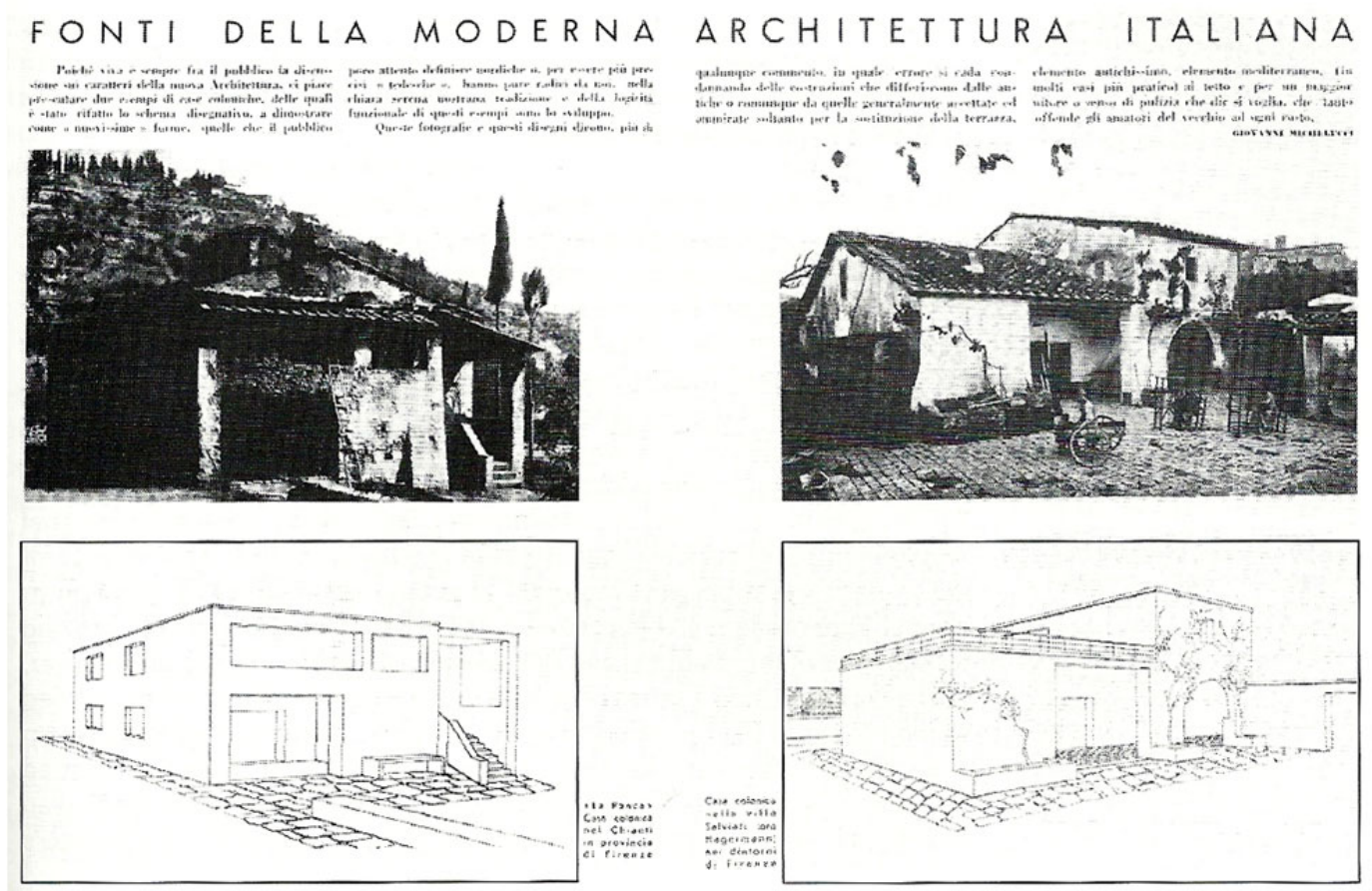

"Fonti della moderna architettura italiana", ilustraciones con las que Giovanni Michelucci explicaba la relación existente entre edificios vernáculos y nuevas arquitecturas, publicadas en 1932 (Lejeune y Sabatino 2010)

Sin embargo, no toda la arquitectura vernácula suponía un mismo problema. Extendiéndose por diversas regiones dispuestas a orillas del Mediterráneo, existía una tradición popular que satisfacía como ninguna otra arquitectura la buscada abstracción formal. Las arquitecturas populares tradicionales de lugares como Capri, Isquia, Procida, 
Ibiza o Miconos, ya apreciadas en el pasado, como se ha expuesto anteriormente, por reverenciados arquitectos como Schinkel o Hoffmann, respondían de forma bastante ajustada a los patrones fijados por la modernidad arquitectónica en Centroeuropa: volúmenes prismáticos, superficies encaladas, escasa decoración, cubiertas planas... Pronto el papel de estas arquitecturas tradicionales como inspiradoras de buena parte de los rasgos característicos de este nuevo estilo arquitectónico sería analizado y reivindicado por sus propios impulsores.

Fernando García Mercadal, quien destacó, como se ha explicado ya, por sus tempranos estudios de la arquitectura popular española, asistió junto a Juan de Zavala al primer CIAM como representante patrio y fue cofundador en 1930 del GATEPAC (Grupo de Artistas y Técnicos Españoles para el Progreso de la Arquitectura Contemporánea), creado para impulsar la difusión en España de esta nueva corriente arquitectónica. Haciendo uso de sus propias palabras, puede afirmarse que "algunas de las características de esta arquitectura mediterránea como la simplicidad de formas, la ausencia de decoración, su cubismo, la intervención del color, su cubierta en terraza... coinciden en absoluto con las de la arquitectura más avanzada, más en boga hoy en todas las naciones de Europa, en Francia, Alemania, Dinamarca, Checoslovaquia, Austria, etc... y sería curioso también investigar sobre la posible influencia de estas construcciones mediterráneas sobre los iniciadores de esta tendencia" $(1984,16)$. Esos rasgos formales, al igual que la supuesta determinación de su forma por aspectos puramente funcionales, son los valores de esta tradición popular que van destacar de forma recurrente en sus escritos los seguidores de este movimiento, refiriéndose a ella con frecuencia, además de como "arquitectura popular", como "arquitectura espontánea", "arquitectura natural", "arquitectura primitiva" o "arquitectura sin estilo".

La recurrente búsqueda de la pureza de lo primitivo se alzaba de nuevo como uno de los ideales artísticos del momento. Lo original, lo espontáneo se contraponía a una cultura, la "europea" de su tiempo, que con frecuencia denostaban. El propio Le Corbusier no iba a interesarse por lo vernáculo de las regiones que le rodeaban, ni siquiera por la arquitectura de la Bretaña rural que tanto admiraban los regionalistas franceses del momento, sino que su atención iba a concentrarse en aquellas arquitecturas de mayor "pureza" formal y compositiva (Passanti 2005, 145-147). 


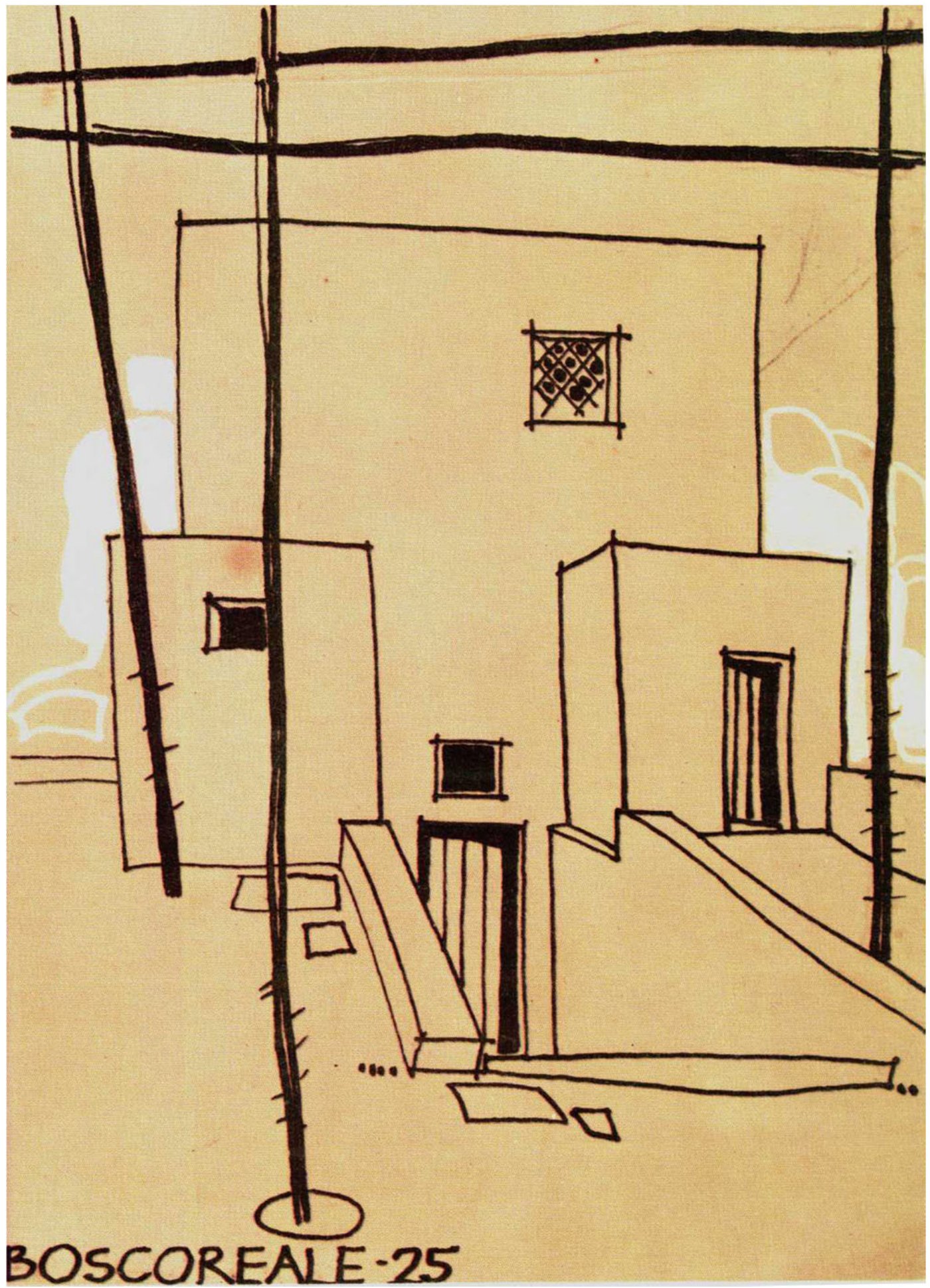

Casa de Boscoreale, Campania, dibujada por el arquitecto Fernando García Mercadal en 1925 y buen ejemplo del "cubismo" que destacaba su autor en la arquitectura mediterránea (García Mercadal 1984) 


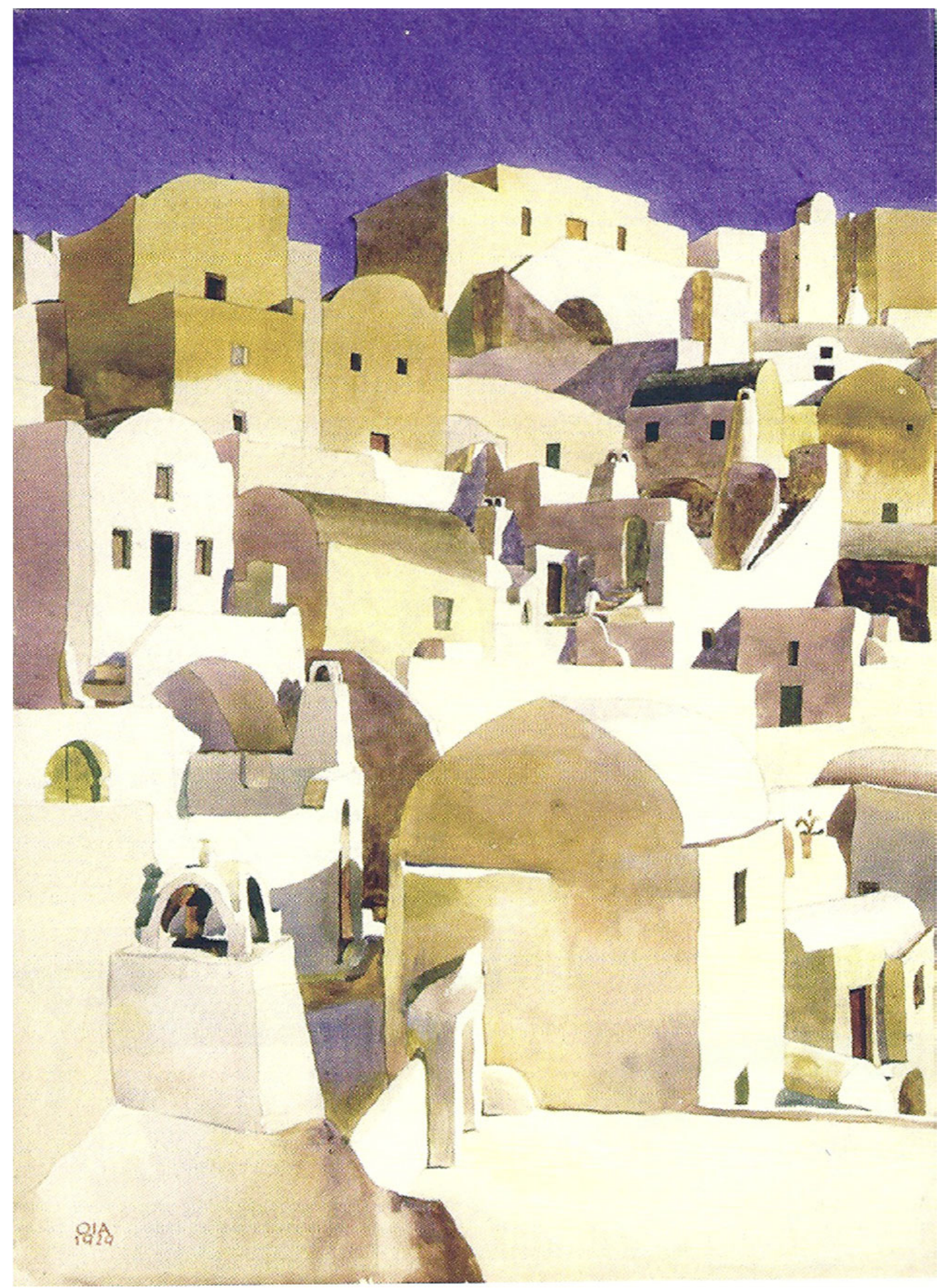

Vista de Oia, Santorini, obra de Bernard Rudofsky en 1929 (Ref. web: www. beaudouinarchitectes.fr, consultada el 5 de marzo de 2018) 


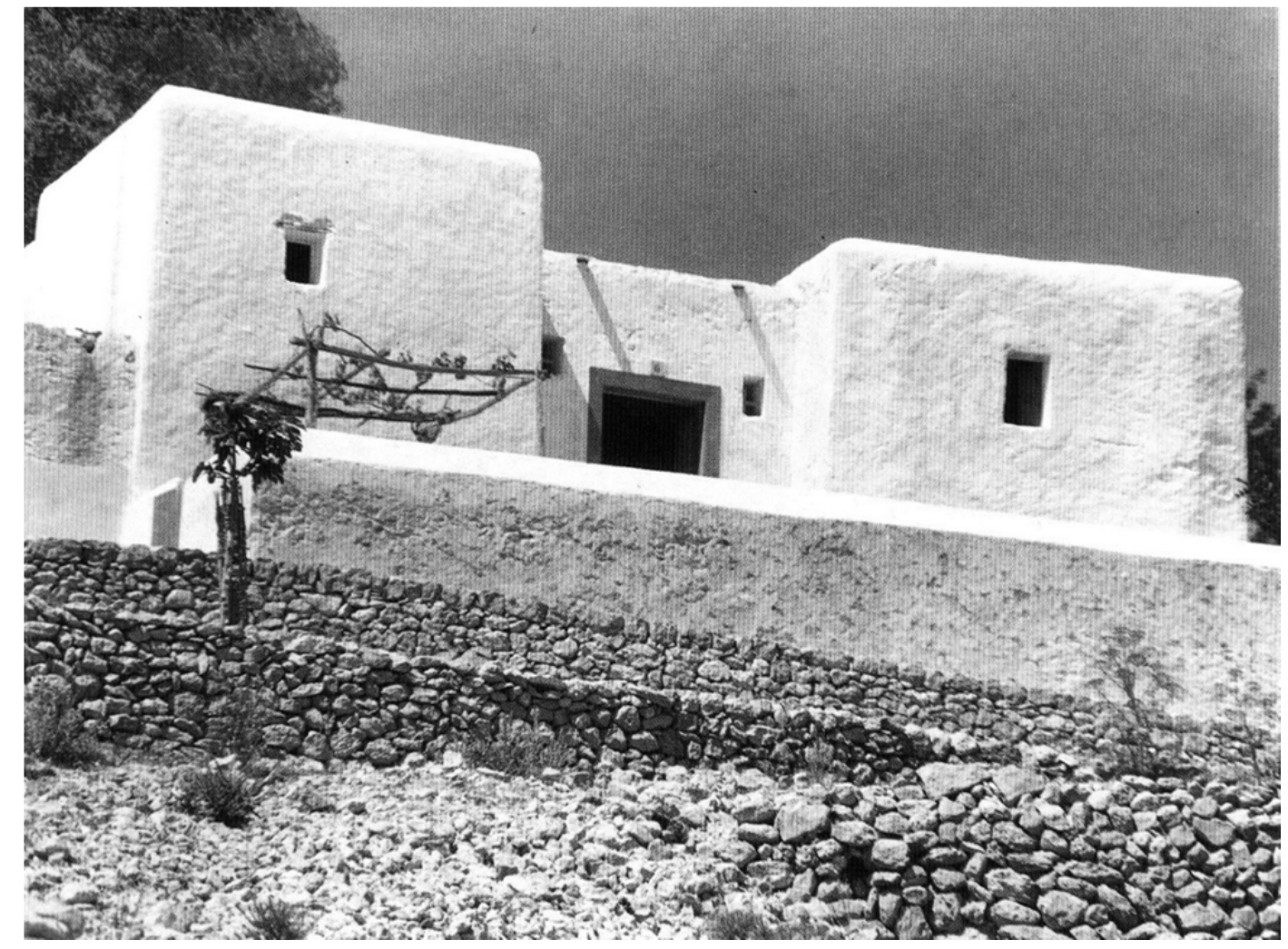

Casas tradicionales ibicencas fotografiadas por Raoul Hausmann: Can Mariano Rafel en Sant Agustí y casa cerca de Santa Eulàlia, ambas en Ibiza (Midant 1990)

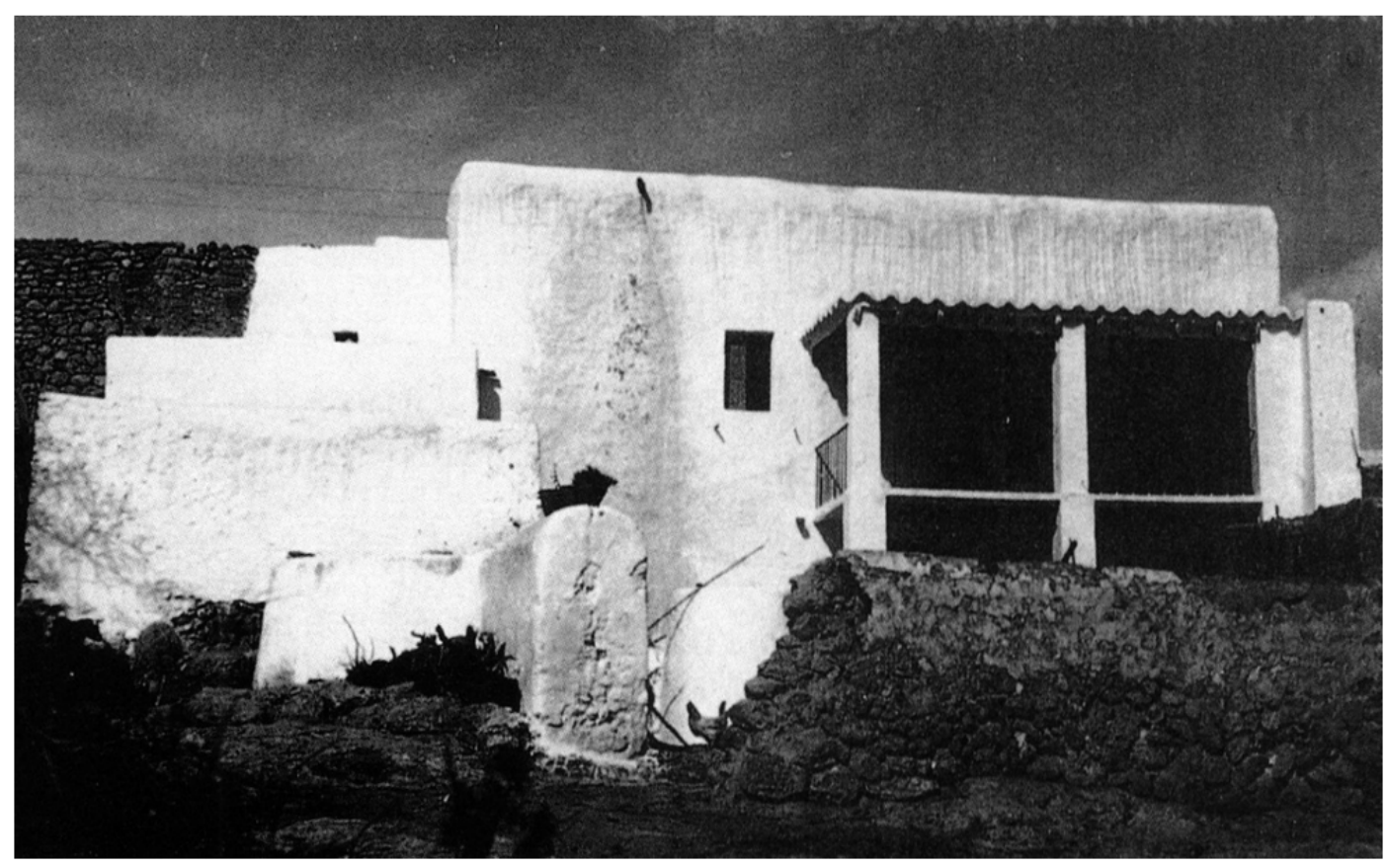




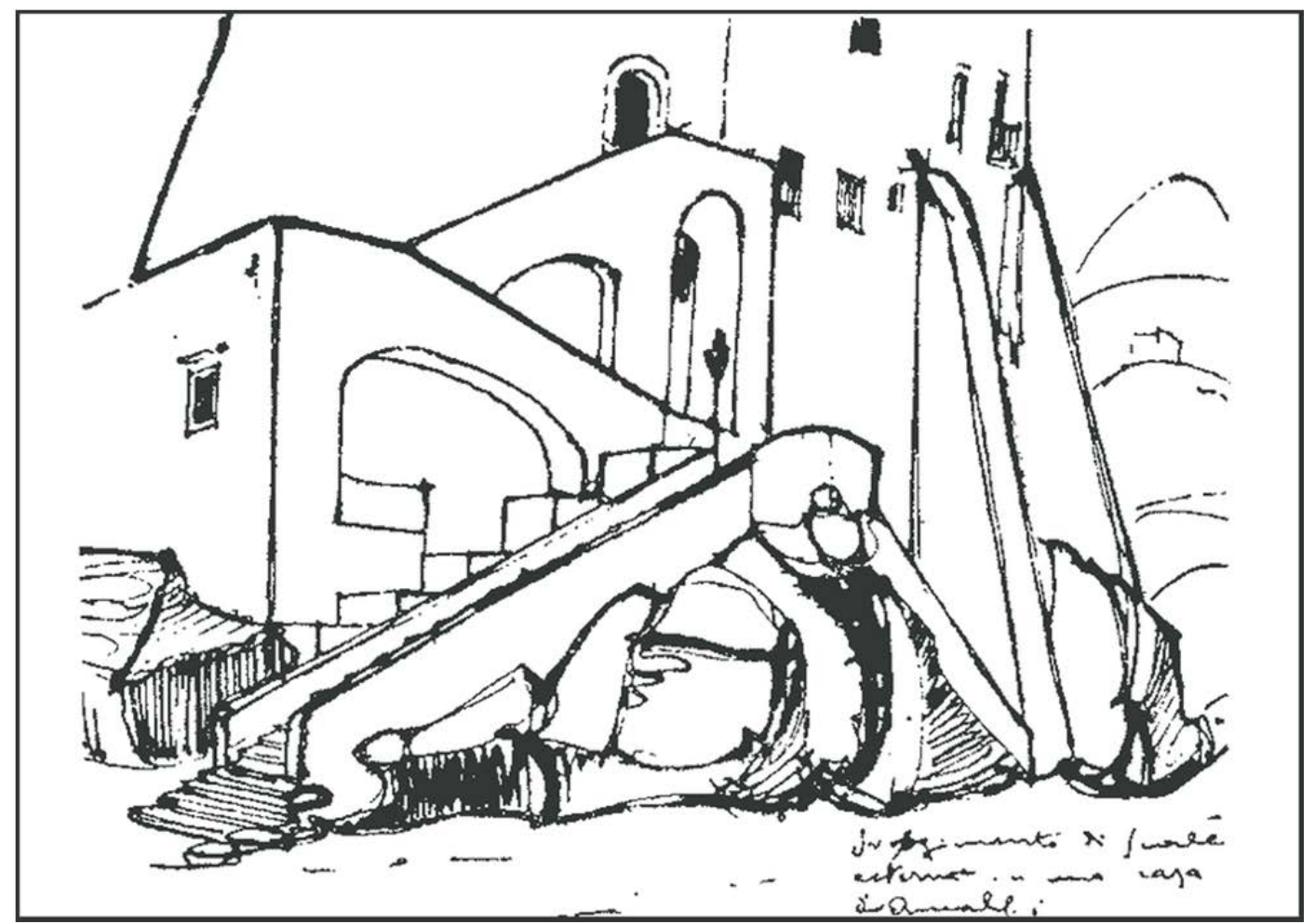

Hotel Luna en Amalfi, dibujado por Virgilio Marchi (Marchi 1922), y dibujos de la isla de Coo, en el Dodecaneso, y de nuevos edificios realizados allí por Mario Paolini entre 1934 y 1936

(Marconi 2005)
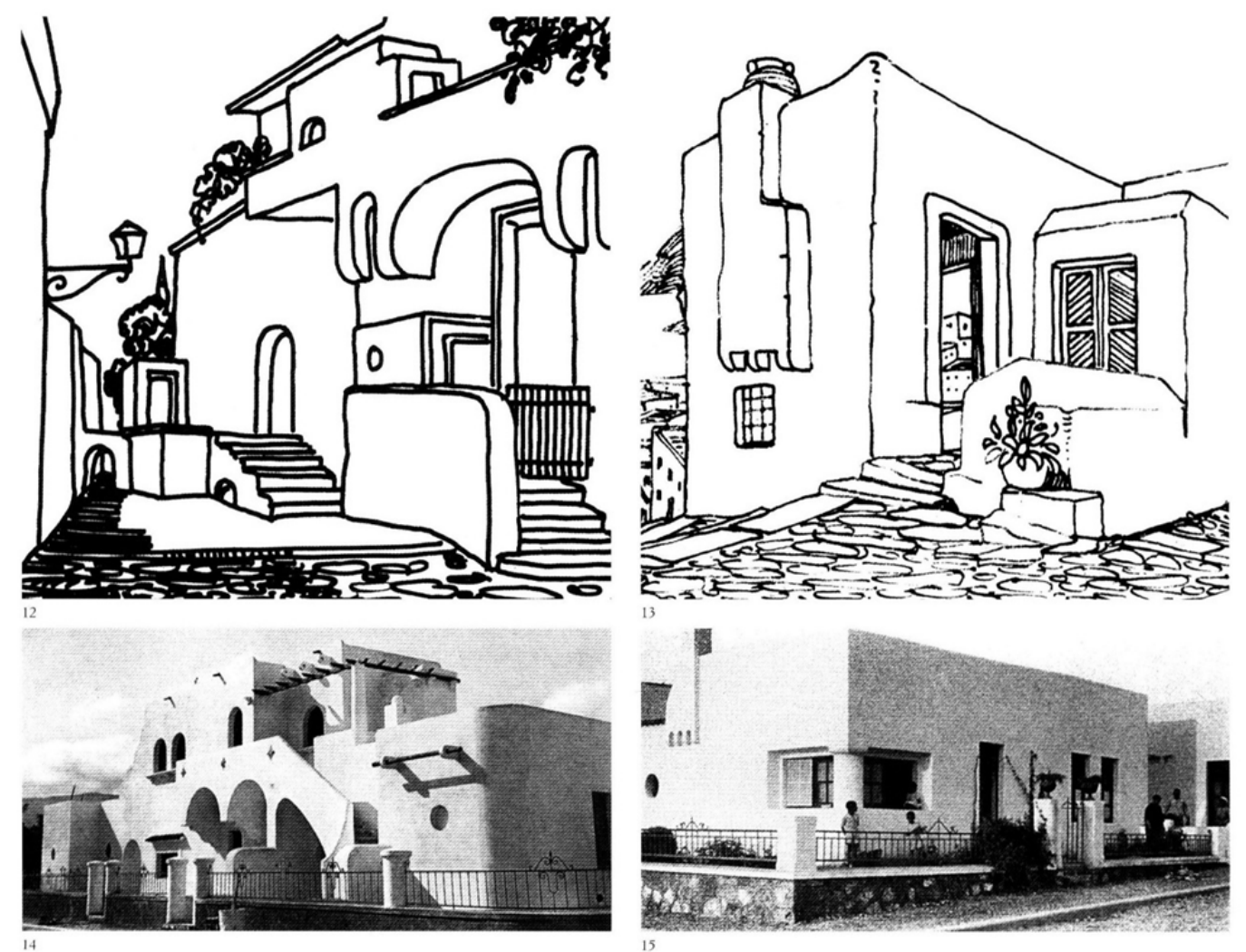
Artistas de vanguardia como Man Ray, Tristan Tzara o Raoul Hausmann iban a peregrinar a Ibiza en busca de ese primitivismo, de esa espontánea naturalidad. Así, un artista dadaísta como Hausmann, que en 1921 proclamaba que el "hombre nuevo necesita un lenguaje nuevo sin huella alguna del pasado" y que "este lenguaje se convertirá en el lenguaje de las masas, no del individuo, en el lazo fuerte de una comunidad", estaba doce años después en la apartada isla de Ibiza estudiando con entusiasmo su arquitectura tradicional y publicando artículos como "Ibiza et la maison méditerranéenne" (1935) o "Eivissa i l'arquitectura sense arquitecte" (1936). Su interés por la sociedad de masas había desaparecido y sus estudios sobre el hábitat y las tradiciones ibicencas adquirieron una profundidad inusual por entonces en los trabajos de los vanguardistas admiradores de estas formas populares (Michaud 1990, 11-23).

El mismo autor del Manifesto del Futurismo en 1909, Filippo Tommaso Marinetti, en el que cantaba "al vibrante fervor nocturno de los arsenales y de las obras, incendiados por violentas lunas eléctricas; a las estaciones ávidas, devoradoras de serpientes que humean; a las fábricas colgadas de las nubes por los contorsionados hilos de sus humaredas; a los puentes que como gimnastas gigantes salvan los ríos, brillando al sol como un centelleo de cuchillos; a los barcos de vapor aventureros que olfatean el horizonte; a las locomotoras de ancho pecho que piafan sobre los raíles como enormes caballos de acero embridados con tubos; y al planear de los aeroplanos, cuya hélice ondea al viento como una bandera, y parece aplaudir como una multitud entusiasta", dedicaba en 1928 a la arquitectura mediterránea, admirado por su vigoroso primitivismo, su "Elogio di Capri" (Op. cit., 41-48). Años antes, había seguido ya el mismo camino Virgilio Marchi, uno de los arquitectos más vinculados al Futurismo, publicando en 1922 el artículo "Primitivismi capresi" (Op. cit., 49-51).

Bernard Rudofsky, quien, como se ha mencionado ya, estudió la arquitectura de las islas Cícladas en su tesis doctoral, iba a habitar y trabajar durante años en lugares como Procida o Capri. El arquitecto griego Dimitris Pikionis organizaba excursiones tanto por la Grecia continental como por las islas del Egeo para documentar y analizar sus más "primitivas" arquitecturas, que difundió a través de publicaciones y exposiciones, siendo en 1930 uno de los fundadores de la Asociación para el Estudio del Arte Popular Griego (Syllogos Elliniki Laiki Techni). Luigi Figini, miembro tanto del Gruppo 7 como posteriormente del MIAR (Movimento Italiano per l'Architettura Razionale), visitó 
lugares como Isquia o Ibiza para estudiar sus arquitectura populares, publicando sus hallazgos como "Architettura naturale ad Ischia" (1949) y "Architettura naturale a Ibiza" (1950). García Mercadal iba a viajar por la costa italiana, visitando lugares como Boscoreale, Positano, Capri, Caprile..., y publicando artículos sobre la arquitectura del Mediterráneo. Sus dibujos de la arquitectura de estos lugares fueron más adelante dados a conocer por la Dirección General de Bellas Artes y Archivos del Ministerio de Cultura por medio de una exposición y de la publicación del catálogo de la misma: La casa mediterránea (1984). Los arquitectos catalanes agrupados en el GATCPAC (Grup d'Arquitectes i Tècnics Catalans per al Progrés de l'Arquitectura Contemporània), formado en Barcelona en 1929, mostraron su admiración por la arquitectura vernácula mediterránea a la par que un paradójico activismo maquinista y antitradicional, a través de la revista $A C$ (Documentos de Actividad Contemporánea - Documents d'Activitat Contemporània), que, dirigida por Josep Torres Clavé, se publicó entre 1931 y 1937.

El primitivismo mediterráneo se convertía así en un ingrediente fundamental del lenguaje del Movimiento Moderno. Otras tradiciones arquitectónicas, sin embargo, carentes de propiedades estéticas semejantes, gozaron por ello de escasa atención o fueron censuradas por ello.

Como muestra de esta preferencia, José Luis Sert, en su artículo "Raíces mediterráneas de la arquitectura moderna" (1935) afirmaba que, aunque técnicamente la arquitectura moderna tenía sus raíces en las naciones del norte, espiritualmente es "el estilo del Mediterráneo lo que influye en la nueva arquitectura" (Pizza 1997, 217).

Y ese carácter mediterráneo iba a presentarse con frecuencia, además, como una alternativa frente al "funcionalismo puro de la máquina de habitar", cuyo extremismo llegó a ser calificado de "absurdo" por parte de la vanguardia arquitectónica, incluyendo al propio Sert (1934). Se materializaba así un cisma en la arquitectura moderna que enfrentaría a los defensores del lenguaje de la técnica y a los amantes de la sencillez y pureza formal de la arquitectura vernácula mediterránea. Uno de los grandes impulsores de la modernidad arquitectónica antes de la Segunda Guerra Mundial, Bernard Rudofsky, en una conferencia impartida en Minneapolis en 1981, recogida por Andrea Bocco Guarnieri en su artículo "Bernard Rudofsky and the Sublimation of the Vernacular", relataba de forma particularmente cruda esta división, que fue plantada pronto oponiendo 
no sólo los términos maquinismo y primitivismo, sino también asociándolos respectivamente a culturas nórdicas y meridionales $(2010,47)$ :

Los profetas y pioneros de la arquitectura moderna, cuyas doctrinas no fueron cuestionadas durante años, eran casi invariablemente hombres de mentalidad provinciana, apenas viajados, y reacios a aventurarse más allá del tablero de dibujo. Su principal objetivo era homogeneizar el mundo de la arquitectura imponiendo sobre él un insípido "Estilo Internacional”. Enamorados de la mecanización, adictos al despilfarro, consideraban aquellas naciones que dependían principalmente de la energía del sol, el viento y el agua desesperadamente primitivas... Un verano, la curiosidad me llevó a Weimar donde acababa de inaugurarse la primera exposición de la Bauhaus. Ésta motivó mi primera premonición del viento enfermizo que iba a soplar sobre el campo de la arquitectura. Weimar, y más adelante Dessau, me pareció que tenían todo el encanto de un reformatorio para jóvenes.

Como un auténtico contraste, los tempranos escritos de Le Corbusier fueron una revelación para mí. La elegancia latina de sus razonamientos, su sofisticación nativa, hacía el ponderado pronunciamiento de sus colegas teutones parecer aburrido. Además, como pintor y escultor que era, admiraba enormemente las libremente modeladas casas de los pueblos de las islas griegas y del norte de África.

El propio Sigfried Giedion, quien fue uno de los promotores de los CIAM y defendió hasta el final de su carrera la inevitabilidad de la modernidad arquitectónica como consecuencia de la mecanización y de la aparición de nuevas técnicas y materiales de construcción, describía desilusionado pocos años después del final de la Segunda Guerra Mundial, en 1948, como conclusión para su libro Mechanization takes command, a contribution to anonymous history, cómo la búsqueda de la mecanización y la productividad habían dejado de ser medios para convertirse en fines en sí mismos, amenazando con la aniquilación al ser humano, pese a su "maravilloso comienzo". Para Giedion, "la esperanza se había convertido en amenaza". Terminaba por ello rompiendo una lanza en favor del Humanismo, defendiendo una "evolución alejada de concepciones 
meramente materialistas y mecanicistas que debe empezar desde una nueva mirada hacia la naturaleza de la materia y de los organismos" y la reorganización del "mundo considerado en su totalidad, permitiendo al mismo tiempo a cada región desarrollar sus particulares lenguaje, hábitos y costumbres" $(1955,714-723)$.

En todo caso, entre esos lenguajes de inspiración vernácula, el recurso a la mediterraneidad mantendría su predominio al menos hasta la crisis de los CIAM e impregnaría una significativa parte de la arquitectura diseñada hasta hoy en día. Esta tendencia iba a calar especialmente entre las agrupaciones de arquitectos vanguardistas de naciones situadas en el entorno de este mar, como Italia, Francia, Grecia o España.

En los citados países ese carácter mediterráneo sería intensamente reivindicado, además de por la obvia afinidad cultural, como defensa ante los ataques de los arquitectos que consideraban la arquitectura del Movimiento Moderno una moda extranjera, nórdica o germánica, atendiendo al lugar de origen de esta corriente arquitectónica (Gravagnoulo 2010, 28). En Italia se extendería de forma particular esta instrumentación de la mediterraneidad de las formas de la modernidad arquitectónica, adquiriendo en ocasiones tintes nacionalistas. Numerosos arquitectos de la vanguardia italiana pugnaban así con los defensores del clasicismo como paradigma de la latinidad, quienes iban ganando ascendencia sobre la arquitectura oficial del régimen fascista. Posiblemente con el mismo fin, el propio Le Corbusier enviaba al Duce una copia dedicada de su Oeuvre complète en 1934 (Óp. Cit., 35). En la segunda Exposición del grupo MIAR se buscó enfatizar precisamente la mayor latinidad de esta arquitectura por su carácter mediterráneo frente al clasicismo de otros arquitectos italianos contemporáneos, como el ya mencionado Gustavo Giovannoni, Armando Brasini, Cesare Bazzani, o Marcello Piacentini, cuyas obras fueron ridiculizadas ante Mussolini incluyéndolas en el famoso fotomontaje Tavolo degli orrori, presentado en esta exposición. De hecho, la tensión generada por este enfrentamiento provocaría finalmente la disolución del MIAR.

Una interesante referencia sobre la defensa de la italianidad de las formas de la modernidad en base a su carácter mediterráneo es el artículo de Michelangelo Sabatino "The Politics of Mediterraneità in Italian Modernist Architecture", recogido en 2010 en el libro Modern Architecture and the Mediterranean. Vernacular Dialogues and Contested Identities, editado por él mismo junto a Jean-François Lejeune y enteramente dedicado al 
análisis de este aspecto de la modernidad arquitectónica. Recopila en este artículo ilustradoras declaraciones sobre este tema realizadas por los arquitectos de la vanguardia italiana en los años 30 del siglo pasado. La fervorosa adopción de la "mediterraneità" por parte de arquitectos como Giuseppe Terragni, Luigi Figini, Gino Pollini o Adalberto Libera lleva a Sabatino a referirse a este grupo como "Mediterranean modernists" (2010, 46). Un nutrido grupo de arquitectos italianos del momento (Piero Bottoni, Mario Cereghini, Luigi Figini, Guido Frette, Enrico A. Griffini, Piero Lingeri, Gino Pollini, Gian Luigi Banfi, Lodovico B. Di Belgioioso, Enrico Peressutti y Ernesto N. Rogers) firmaron un manifiesto publicado en el primer número de la revista Quadrante en 1933 bajo el título "Un programa d'architettura" en el que afirmaban que veían el clasicismo y la "mediterraneità" como antagonistas al "nordismo, el barroquismo y la arbitrariedad romántica de una parte de la nueva arquitectura europea”. En el número 21 de la misma revista, publicado en 1935, Enrico Peressutti, miembro del estudio BBPR, en un artículo titulado "Architettura mediterranea" hablaba de ésta como "un patrimonio, que, redescubierto por Gropius, Le Corbusier, Mies van der Rohe, se ha camuflado como una novedad de origen nórdico, como una innovación del siglo XX. Y muchos lo han creído. Y muchísimos han tomado este camuflaje por una verdadera novedad, por una nueva ley universal. Sin darse cuenta de que a esta novedad le faltaba la vida, le faltaba la palabra, le faltaba el canto del Mediterráneo" (40-41).

Paradójicamente, en Alemania la situación era la opuesta. Los arquitectos de vanguardia trataban de distanciarse de la innegable afinidad formal entre su arquitectura y las de la tradición de esos singulares lugares del Mediterráneo. Esta semejanza daba a sus detractores un sencillo argumento para denunciar su falta de atención al contexto. Así, Schultze-Naumburg comparaba una vista de la Weissenhof Siedlung con una fotografía de un pueblo costero de Miconos en su libro Das Gesicht des deutschen Hauses (1929), mientras otros críticos se referían a su semejanza con una población "árabe", llegando a difundir un famoso fotomontaje donde la colonia aparece ambientada como un zoco, con camellos y vendedores de alfombras poblando sus calles.

La mediterraneidad de esta arquitectura pasaba de este modo a formar parte de los debates sobre la identidad, pasando a ser identificada con un abstracto concepto de la cuenca mediterránea, mucho más diversa y rica en tradiciones arquitectónicas de lo que estas versiones estereotipadas de la misma querían ver en ella. 


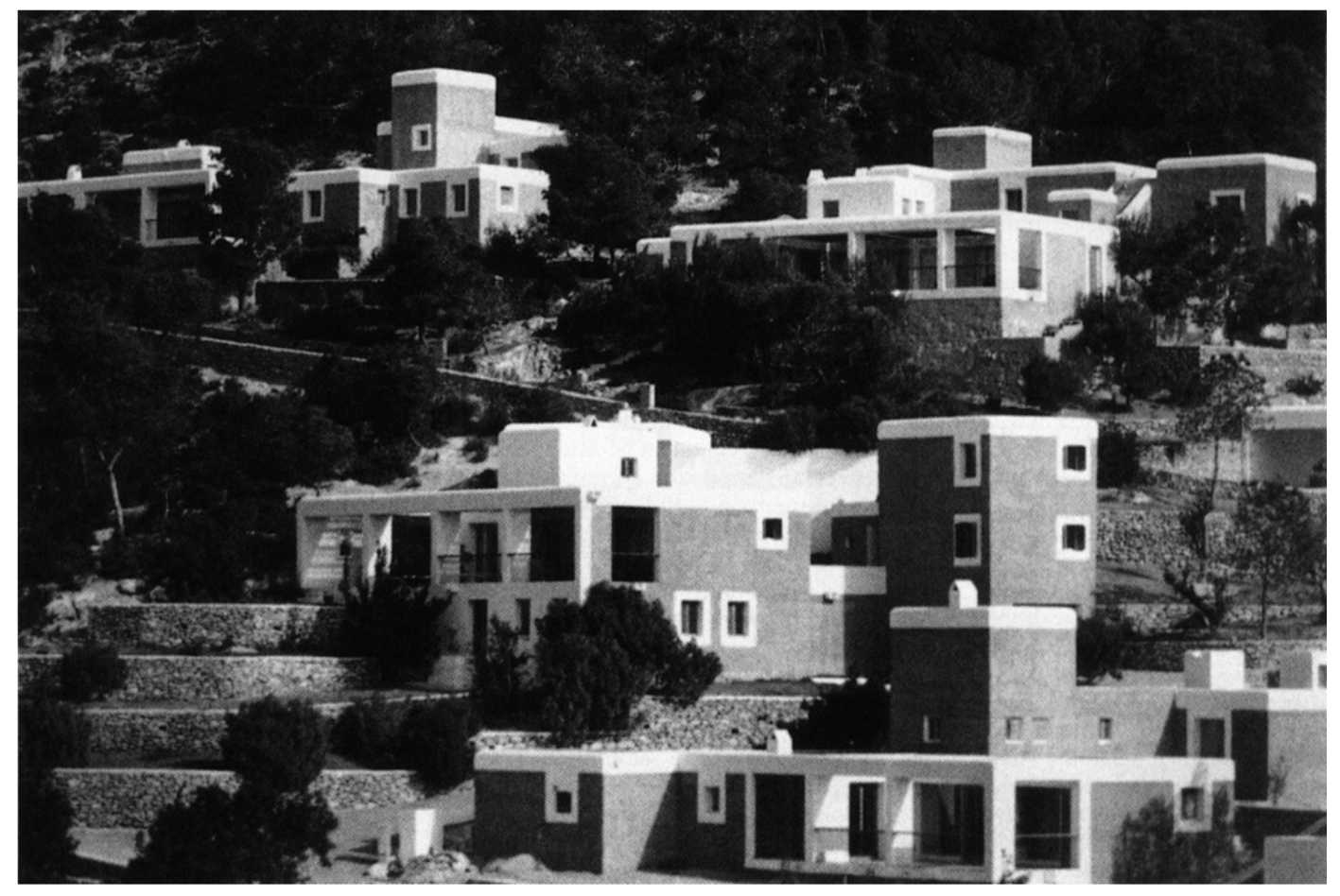

Conjunto de Can Pep Simó, Cap Martinet, Santa Eulàlia, Ibiza, obra de José Luis Sert realizada de 1963 a 1971 (Rovira 2003), y Habitación de la Pared Negra, Hotel San Michele, Anacapri, diseñada por Bernard Rudofsky y Gio Ponti en torno a 1938 y nunca construida (Guarneri 2010)

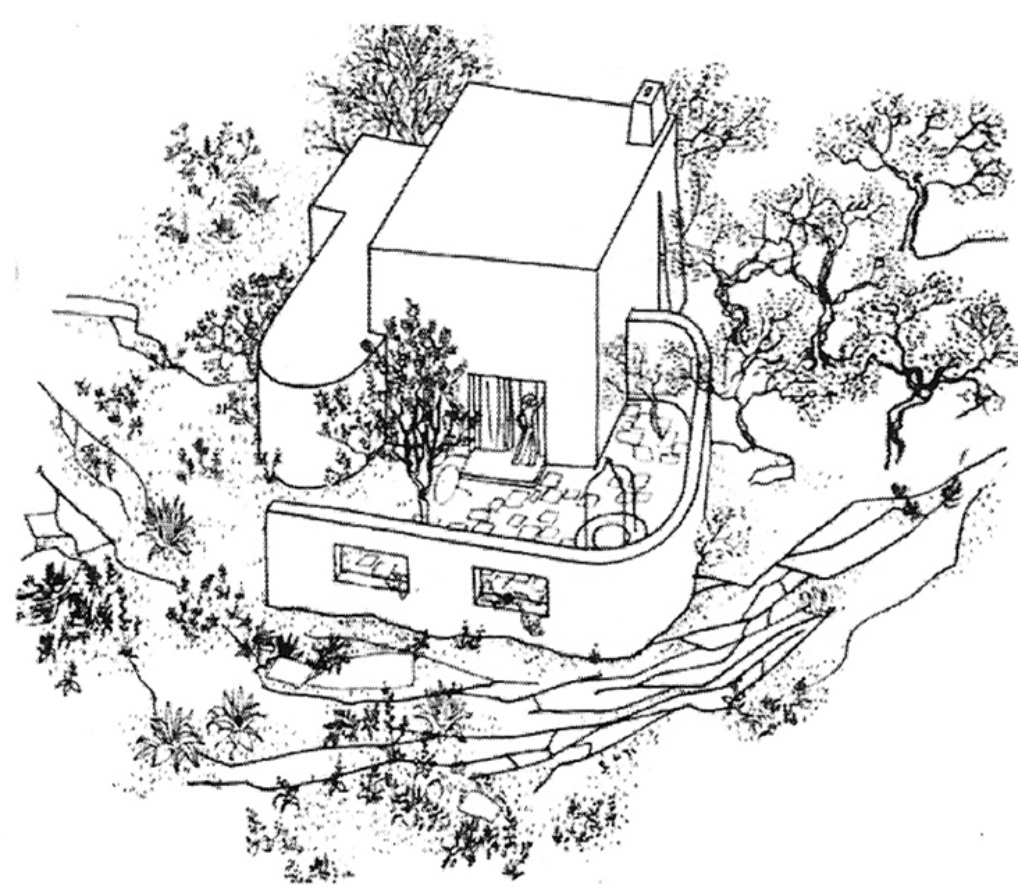




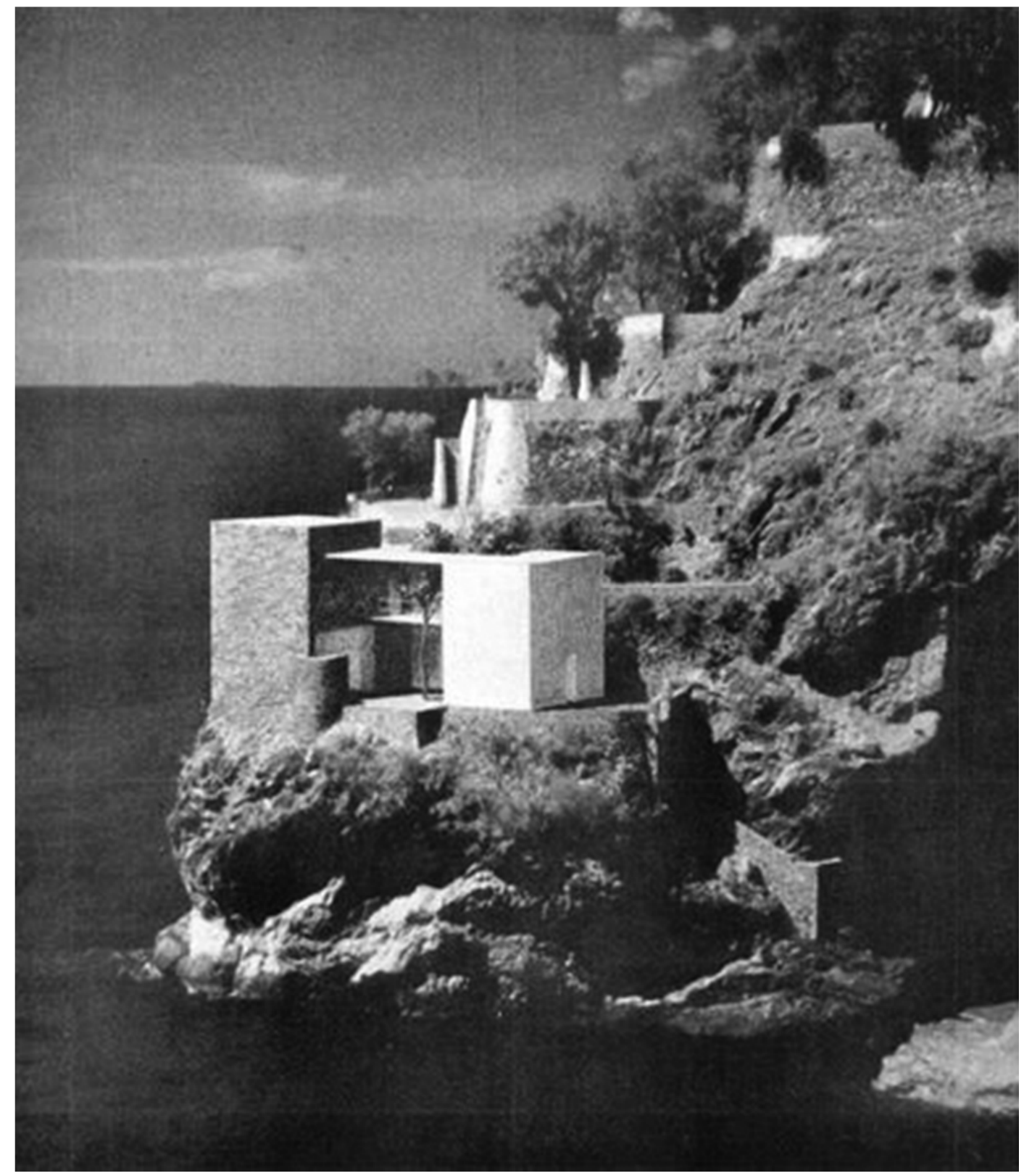

Villa Campanella, Positano, diseñada por Luigi Cosenza y Bernard Rudofsky en torno a 1936.

Fotomontaje de proyecto no construido (Ref. web: www. beaudouin-architectes.fr, consultada el 5 de marzo de 2018) 
Estos estereotipos e interpretaciones reduccionistas de lo mediterráneo inquietarían pronto a quienes habían llegado más lejos en su amor por la arquitectura popular mediterránea. Tras años de estudio de la arquitectura ibicenca, Raoul Hausmann, en su artículo "Recherches sur l'origine de la maison rurale a Eivissa", publicado en 1944 en la Revista de Tradiciones Populares (231-252), iba a mostrar su desdén por la interpretación simplista que del Mediterráneo hacían los jóvenes arquitectos españoles para validar la idea de una "modernidad mediterránea", recurriendo a analogías que se reducían a una abstracción de las casas tradicionales del Mediterráneo, de las que, despojadas de su sentido cultural, su relación con el medio y su funcionamiento, sólo quedaban los volúmenes cúbicos, las blancas superficies y las cubiertas planas de la arquitectura de vanguardia. Un mismo alejamiento progresivo de la ortodoxia del Movimiento Moderno puede apreciarse en arquitectos que habían compartido algunos de sus intereses, como Dimitris Pikionis (Theocharopoulou 2010, 117-119) o Bernard Rudofsky (Guarneri 2010, 246-249).

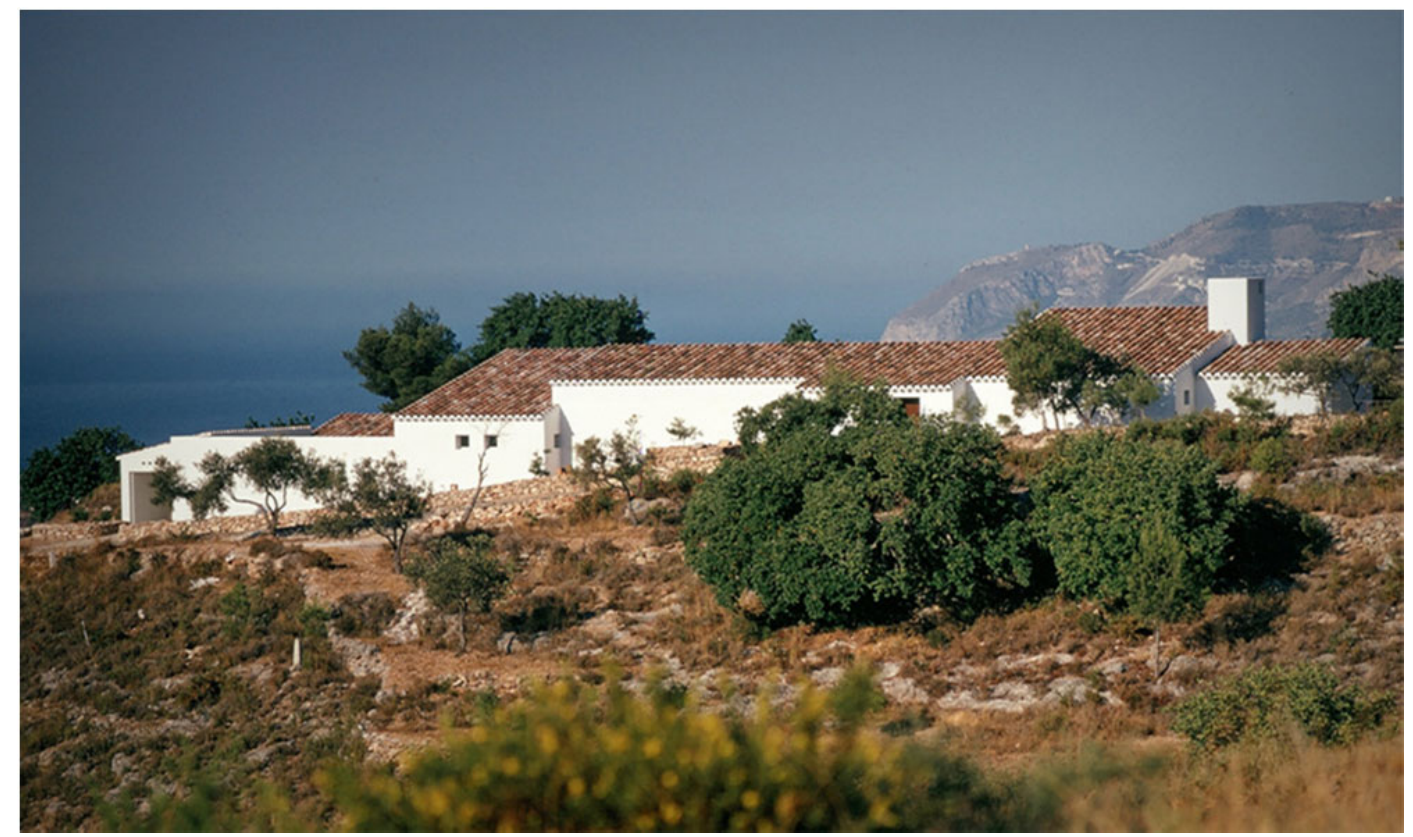

Casa de Bernard Rudofsky ("La Casa") en Frigiliana, Málaga, realizada por José Antonio Coderch y Bernard Rudofsky de 1968 a 1972 (Ref. web: ofhouses.tumblr.com, consultada el 5 de marzo de 2018). 
La ortodoxia moderna fue matizándose con visiones de lo vernáculo menos sesgadas. El progresivo reconocimiento de la relevancia de los aspectos culturales en la arquitectura iba a conllevar, de hecho, el cuestionamiento de muchos de los dogmas que había ido fijando la vanguardia arquitectónica. Al mismo tiempo, el fracaso de parte de estos planteamientos iba siendo asumido de forma progresiva, convirtiéndose una preocupación bastante extendida durante la década de los 50 del siglo XX. La homogeneización del paisaje, ahora ya operada a nivel global, comenzaba a inquietar tanto a sus principales impulsores, como a las nuevas generaciones de arquitectos (Morrison 2007, 281-287; Mumford 2007, 289-291; Giedion 2007, 311-319). Y esa preocupante realidad conllevaba que la propia asunción de la existencia de algo identificable como un estilo de carácter internacional resultara ya inconveniente e incluso molesta para sus practicantes.

La transformación operada tanto en la obra como en el discurso de uno de los pioneros del Movimiento Moderno, Erich Mendelsohn, al comenzar a trabajar en Palestina tras su forzoso exilio de Alemania en 1933, es buen reflejo de este proceso. Al enfrentarse a una realidad cultural tan desconocida y exótica como reverenciada, se convirtió en un activo opositor al trabajo de muchos de sus colegas, que iban poblando la Tierra Prometida de edificios de "estilo Mendelsohn". Frente a sus seguidores, Mendelsohn reconocía que las particulares condiciones climáticas y geográficas de la región, así como la cultura desarrollada conforme a ellas, exigían respuestas completamente diversas. Recomendaba a todos estudiar en profundidad las tradiciones arquitectónicas locales antes de erigir edificio alguno. No dudó en utilizar profusamente la caliza local para sus edificios, en renunciar a los grandes ventanales en busca de protección contra el sol y refrescantes espacios en sombra, ni en incorporar incluso formas arquitectónicas tradicionales como la cúpula, muy común en la arquitectura de la zona, rompiendo así muchos de los tabúes que atenazaban a otros arquitectos del momento.

Siguiendo un curso semejante al de Mendelsohn, Bruno Taut, otro de los protagonistas de la vanguardia arquitectónica alemana de aquel tiempo, proporciona otro buen ejemplo de ello. Forzado como él a salir de Alemania en 1933, eligió Japón como primer destino, pasando allí tres años dedicados principalmente al estudio de su arquitectura y sus costumbres, y se trasladó finalmente, en 1936, a Turquía, donde desarrolló una notable actividad como arquitecto y como docente hasta su fallecimiento en 1938. Buscando difundir sus hallazgos de esos años, publicó diversos libros sobre la arquitectura y la 
cultura japonesas y reunió sus reflexiones en 1937 en sus Mimari Bilgisi (Conferencias sobre Arquitectura). En estos escritos lamentaba las consecuencias que la difusión de la idea de la casa como "máquina de habitar" había tenido a nivel global y los daños ocasionados al paisaje y la sociedad de otras regiones por la réplica en ellas de los modelos desarrollados por las vanguardias arquitectónicas europeas, la expansión de un "modernismo degenerado" e incluso la importación de sus formas "cúbicas" (Akcan 2010, 193-211).

La generalización e internacionalización del Movimiento Moderno puso de relieve las deficiencias de los planteamientos que le habían servido como base. El descubrimiento y valoración de otras culturas y otras tradiciones arquitectónicas, así como de los perjuicios que la importación de modelos foráneos provocaba sobre ellas, minaba el inquebrantable dogmatismo de sus años iniciales. Pese a ello, estas voces críticas eran aún censuradas y ninguneadas por la mayor parte de sus compañeros y el Estilo Internacional proseguiría su expansión global de forma hegemónica.

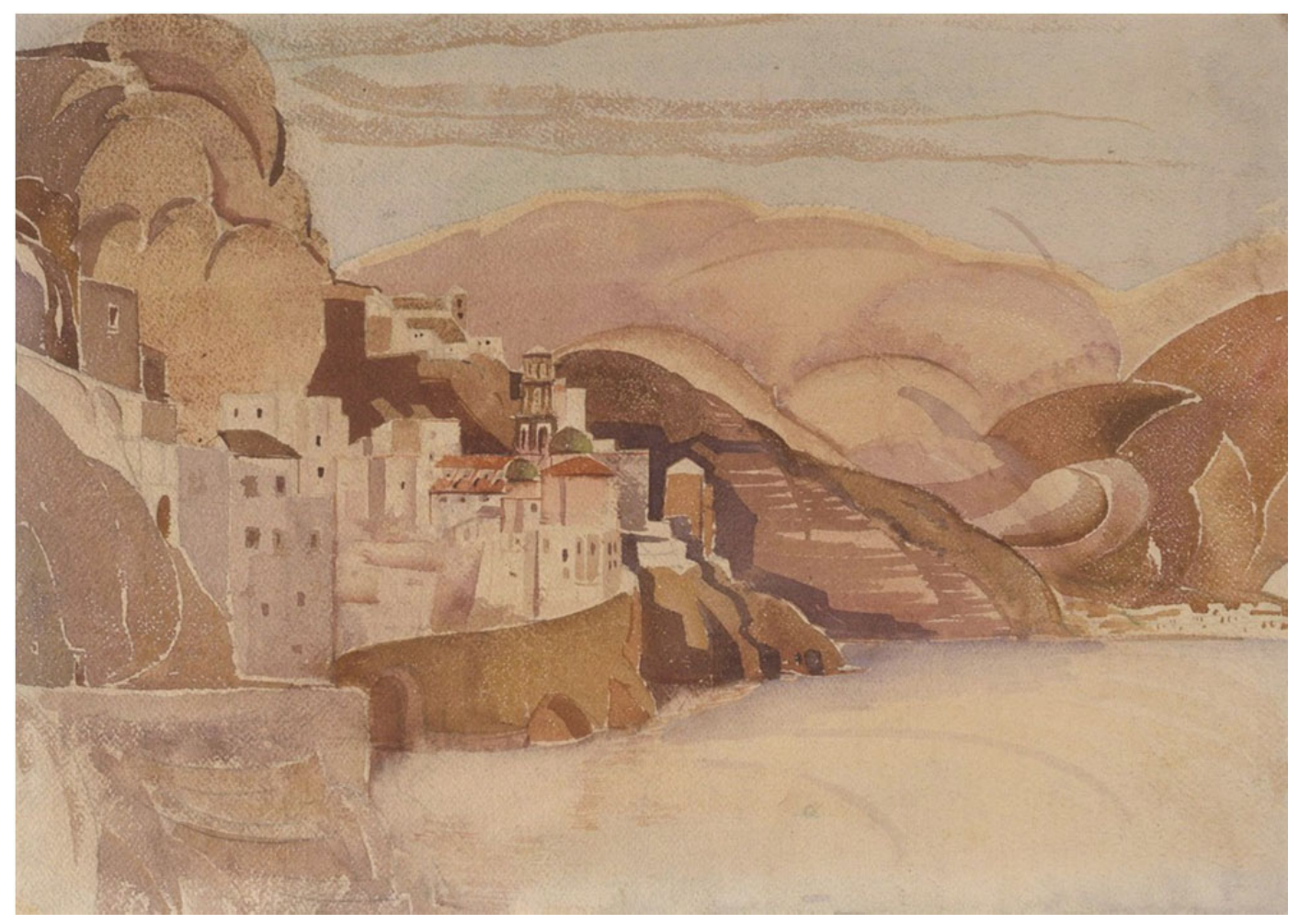

Atrani desde Torre Saracena, en la Costa Amalfitana, paisaje dibujado por Louis I. Kahn en 1929 (Ref. web: www.artsy.net, consultada el 5 de marzo de 2018) 
Así, cuando Lewis Mumford defendió en 1947 la existencia de una arquitectura moderna característica del Norte de California, el conocido como Bay Region Style, practicado por arquitectos como Bernard Maybeck, provocó una gran polémica por alejarse precisamente de ese dogmatismo. Para Mumford, esta arquitectura mostraba, entre otros méritos, haber tenido la capacidad de dar una respuesta arquitectónica moderna y al mismo tiempo acorde con el carácter local, aventajando así con ello al denominado Estilo Internacional (Mumford 2007). La reacción fue tal que el Museum of Modern Art de Nueva York, como patrocinador institucional del Movimiento Moderno, convocó a destacadas figuras de esta corriente arquitectónica para debatir sobre el estado de la cuestión en 1948 en un encuentro titulado "What is happening to Modern Architecture?", en el que su director, Alfred H. Bahr, junto a figuras como Walter Gropius, Marcel Breuer, Henry Russel Hitchcock o Sigfried Giedion, trataron de presentar este movimiento como el verdadero y legítimo depositario de las virtudes que Mumford había descubierto en la arquitectura de aquella región (Alofsin 2007).

En todo caso, la crisis del Movimiento Moderno no iba sino a agravarse en la década siguiente. El interés del influyente arquitecto norteamericano Louis I. Kahn por la arquitectura clásica y vernácula del Mediterráneo quedó reflejado en los múltiples dibujos que realizó durante su estancia en la American Academy de Roma, así como en la utilización en su trabajo posterior de referencias hasta entonces prácticamente vedadas para la ortodoxia moderna. En 1951 se exponía en la IX Trienal de Milán la Mostra di architettura spontanea, a cargo de Giancarlo de Carlo, Enzo Cerutti y Giuseppe Samonà, en la que se defendía el valor de actualidad del urbanismo denso de los núcleos tradicionales. Años más tarde, el primero de ellos no dudaría en tratar de integrar su vanguardista arquitectura en la tradición local de Urbino, y recurrirían también a la tradición, con menos complejos, Ludovico Quaroni y Mario Ridolfi en su Quartiere Tiburtino (1950-1954). Entre 1952 y 1954 se erigía cerca de Matera el nuevo barrio de La Martella, un conjunto de cierta inspiración vernácula diseñado por un equipo de arquitectos coordinado por el primero junto a Federico Gorio. En el noveno CIAM, celebrado en Aix-en-Provence en 1953, se invitó a participar a jóvenes arquitectos que se encontraban trabajando en Marruecos y Argelia, entre los que estaban Pierre Mas, Michel Écochard, Georges Candilis, Roland Simounet y Michel Emery. Su exposición se tornó en una reivindicación de la mayor humanidad y mejor conexión con las necesidades reales de la gente del urbanismo de las barriadas populares de chabolas que crecían sin control en 
torno a ciudades como Argel o Casablanca, causando el desconcierto de algunos de los viejos maestros allí presentes. Estos asentamientos, pese a su pobreza e insalubridad, eran vistos por los arquitectos más jóvenes como una muestra de urbanismo moderno en el que lo actual no suponía necesariamente la desaparición de lo tradicional. Ese mismo año, Aldo van Eyck publicaba en la revista holandesa Forum el artículo "Bouwen in de Zuidelijke Oasen" ("Construyendo en los Oasis del Sur"), en el que mostraba material recogido en sus viajes por los oasis del Sahara entre 1951 y 1952. El descubrimiento y la admiración por otras tradiciones provocaba de nuevo una renovación en la carrera de un arquitecto, que valoraba en ellas no sólo su adaptabilidad y permanente evolución, sino también la permanencia de todo aquello que siguiera gozando de validez. El propio Van Eyck iba a reconocer más adelante la importancia de lo simbólico en la arquitectura a través de su viaje a Mali en busca la arquitectura Dogón. Poco después, la iglesia de Notre Dame du Haut diseñada por Le Corbusier para Ronchamp (1953-1955) se convertía para parte de la modernidad arquitectónica de la época en un icono del triunfo del primitivismo de carácter vernáculo sobre el maquinismo y la estandarización internacionalista. En 1957, Sibyl Moholy-Nagy publicaba Native Genius in Anonymous Architecture, donde afirmaba que "necesidades artificiales, ensalzadas por la publicidad, han oscurecido el hecho de que no hay progreso en la arquitectura, sólo progreso en el equipamiento mecánico" (20) y que cualquier propuesta de "casa del mañana" que se basara en su prefabricación industrial fracasaría, al ser un hecho probado que cualquier ciudadano preferiría incluso una ilusión de mala calidad que asemejara ser fruto de un diseño personalizado a un edificio de aspecto prefabricado, lo que polémicamente ilustraba con una fotografía de un prototipo de la Dymaxion House de Buckminster Fuller (40-41). El arquitecto inglés James Stirling manifestaba en ese mismo año tener un mayor interés por "la arquitectura anónima de Italia" que por sus monumentos renacentistas o por sus obras modernas $(2007,327)$. Y, pese a sus formas de estilo vanguardista, la escala de pequeño pueblo tradicional del pabellón italiano de la Exposición de Bruselas de 1958, diseñado conjuntamente por Ignazio Gardella, Ludovico Quaroni y el estudio BBPR (Gian Luigi Banfi, Lodovico Barbiano di Belgiojoso, Enrico Peressutti y Ernesto Nathan Rogers), contrastaba fuertemente con la despreocupada celebración de la energía nuclear del edificio destinado a convertirse en icono de la misma exposición.

La rigidez de los principios arquitectónicos y urbanísticos que los CIAM parecían haber fijado hasta entonces impedía a éstos absorber estas divergencias. Le Corbusier dejaría 
oficialmente estas reuniones tras el desencuentro evidenciado en Aix-en-Provence. El esquematismo y la rigidez de la Carta de Atenas fueron objeto de creciente crítica, reivindicándose conceptos ausentes en ella como el de identidad. En el XI CIAM, celebrado en la ciudad holandesa de Otterlo en 1959, Van Eyck lamentaría que los arquitectos de vanguardia hubieran estado atendiendo "continuamente a lo que es diferente en nuestro tiempo hasta tal punto que se ha perdido contacto con lo que no es diferente, con lo que es siempre esencialmente lo mismo" (Avermaete 2010, 258). Éstas y otras disensiones precipitaron así la disolución definitiva de estos encuentros internacionales.

Por estas fechas llegaban también los primeros reconocimientos internacionales al ejemplar trabajo del arquitecto egipcio Hassan Fathy en la recuperación, revitalización y actualización de las tradiciones constructivas, arquitectónicas y urbanísticas. A finales de los años 30, Fathy, consternado por el proceso de desnaturalización que venía sufriendo el paisaje urbano de su país y por el desinterés de sus colegas por los saberes atesorados por un empobrecido pero aún existente artesanado, encontró en las tradiciones locales una alternativa para tratar de detener esta progresiva degradación. Su trabajo fue publicado con gran éxito en el Reino Unido en 1947, traduciéndose después a diversas lenguas. Aunque por corto tiempo, en 1954 se convirtió en director de los estudios de Arquitectura de El Cairo y desde 1957 comenzaría a colaborar en diversos proyectos internacionales. En cualquier caso, sería tras el final de la etapa de expansión de la modernidad arquitectónica, como veremos, cuando su trabajo se convertiría en un referente internacional de primer orden, multiplicándose sus seguidores. 


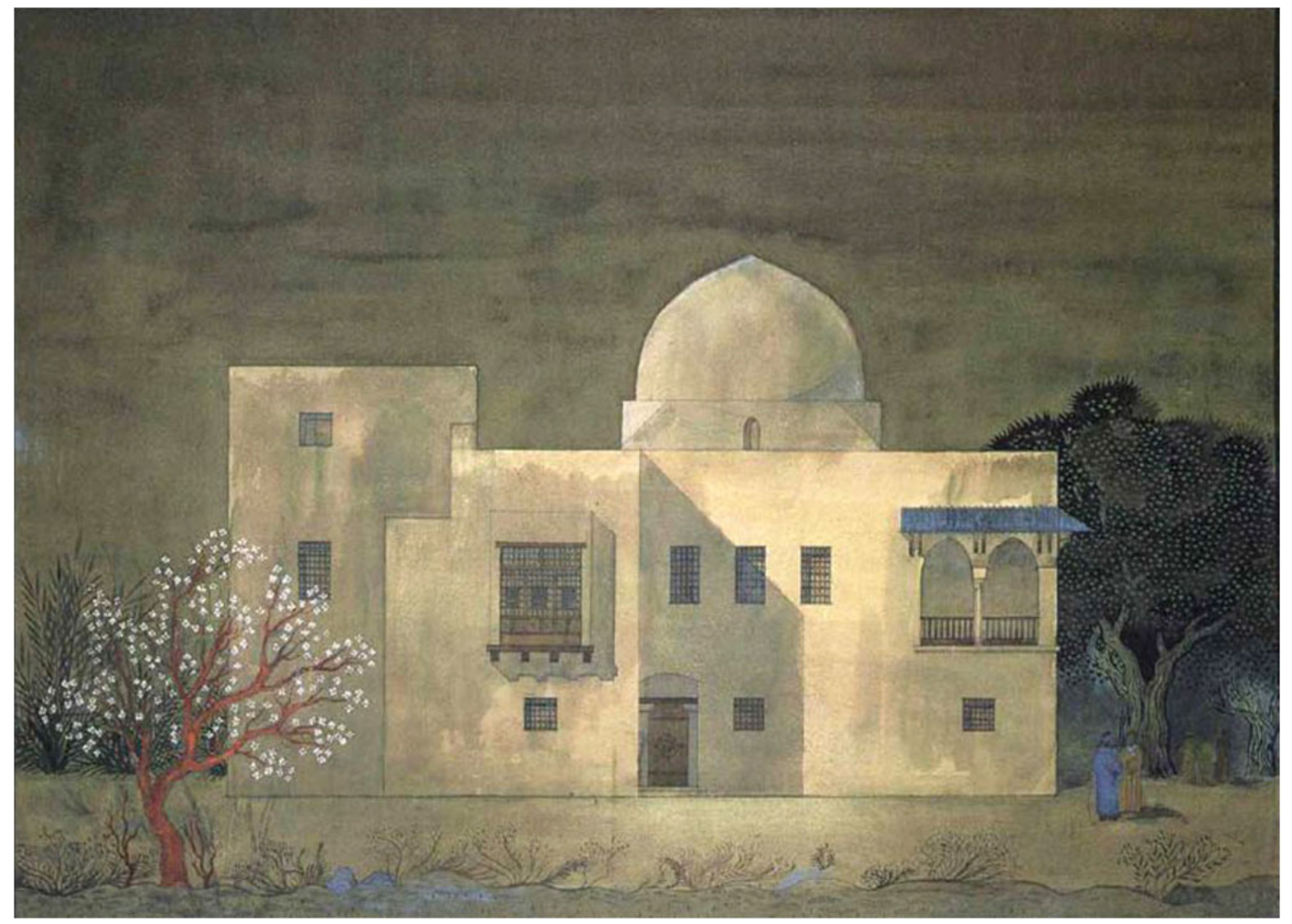

Alzado de la Casa Hamdi Seif al-Nasr, Egipto, diseñada por Hassan Fathy en 1942, y paisaje con casas de campo imaginadas por Hassan Fathy en torno al Lago Qarun, Fayoum, Egipto, pintado por Fathy entre 1940 y 1945 (Hamid 2010 y Steele 1997)

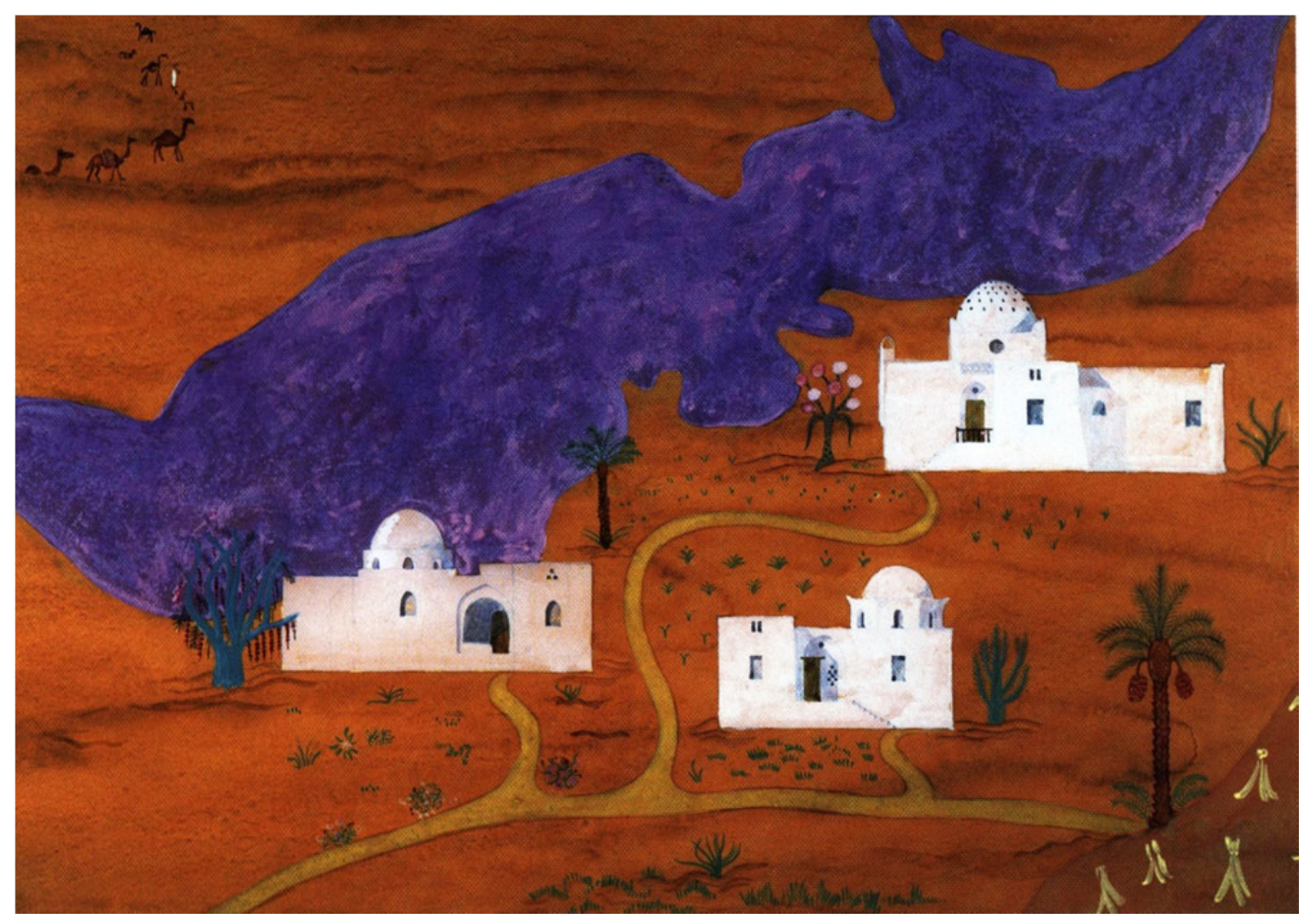




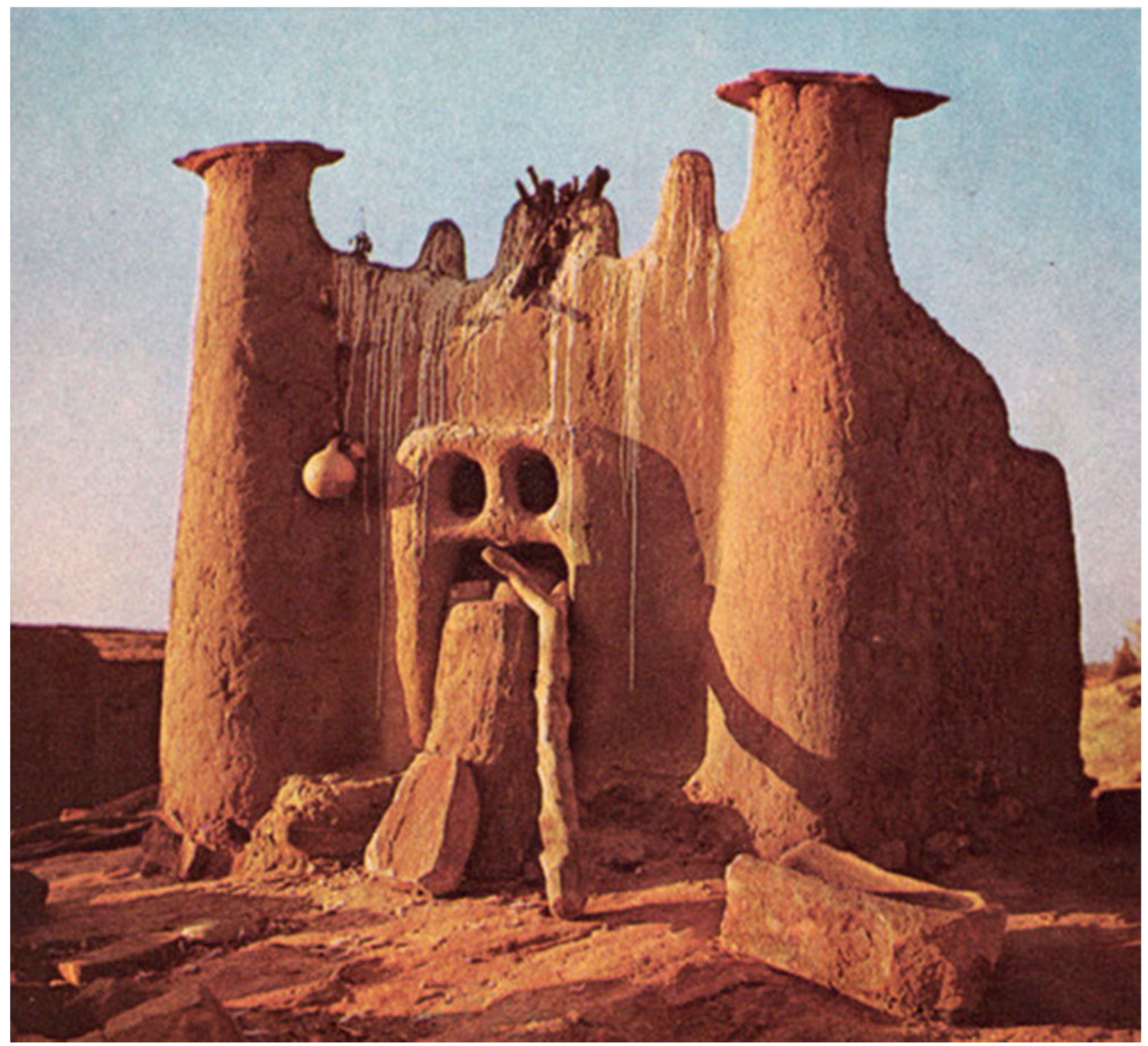

Almacén tradicional dogón. Fotografía de Aldo Van Eyck, 1968

La ya citada exposición Architecture without Architects, debida a Bernard Rudofsky e inaugurada en 1964 en el MOMA de Nueva York, iba a subrayar el definitivo cambio de rumbo en los intereses de los arquitectos de vanguardia de la época. La arquitectura tradicional ya no era vista como una fuente de formas, espacios y composiciones sugerentes, sino como el fruto de siglos de acumulación de conocimiento sobre el cómo habitar en distintos lugares y como depositaria de un importante patrimonio cultural. La exposición viajaría por todo el mundo, como se había explicado ya, y se traduciría a numerosas lenguas, incitando a numerosos arquitectos a recuperar el temporalmente perdido interés por lo tradicional. Tras el ocaso al que lo había abocado la ideología reinante en el período anterior, la progresiva asunción del carácter finito de los recursos naturales y de la fragilidad del equilibrio ecológico del planeta parecía colocarlo de nuevo en primer plano. 
En todo caso, desde la Segunda Guerra Mundial seguía operándose a nivel mundial la verdadera internacionalización de la arquitectura del Estilo Internacional. Los triunfantes Estados Unidos eran vistos como la principal fuente de modernidad y progreso, y este estilo se había convertido en la imagen deseada por la mayor parte de las crecientes multinacionales que comenzaban entonces a expandirse mundialmente. Alan Colquhoun, en su obra La arquitectura moderna. Una historia desapasionada, publicada en 2002, habla de cómo estudios de arquitectura como SOM se adaptaron a la perfección a las necesidades de las grandes corporaciones que buscaban proyectar una imagen global (237-239).

Además, la Guerra Fría no consistió sólo en un pulso militar y económico, sino también cultural, e iba a realizarse una fuerte inversión propagandística a nivel internacional, promoviéndose también grandes operaciones arquitectónicas donde lo local se convertía en símbolo de atraso y subdesarrollo. La nueva arquitectura global, impulsada tanto desde las instituciones norteamericanas como desde sus principales marcas comerciales, se presentaba por el contrario como la superación de pasadas miserias y como un salto adelante en un idealizado progreso, consumándose así la ruptura con el pasado. Se gestó en unas décadas el que sería el más fuerte impulso globalizador de la historia, así como el mayor ataque ideológico a los saberes tradicionales. Las frágiles identidades nacionales inventadas en las décadas anteriores, que habían debilitado ya los cimientos de las verdaderas tradiciones arquitectónicas locales, se vieron completamente sobrepasadas por este proceso. La estrategia fue tan exitosa que pronto traspasó el Telón de Acero, pudiendo considerarse esta conquista cultural el primer paso hacia la derrota del bloque soviético. Tras el acuerdo de 1958 entre Estados Unidos y la Unión Soviética sobre "Intercambio Cultural", la cultura del consumo y la nueva arquitectura global iban a calar profundamente también en los países comunistas (Adam 2012, 41-42).

En el caso español, concluida la dura etapa de la reconstrucción posbélica, el proceso iba a ser similar. Durante la etapa de posguerra, sin embargo, la escasez de materiales industriales y la imperiosa necesidad de acelerar la construcción de viviendas conllevaron una búsqueda generalizada de la optimización y estandarización de las tipologías y los procesos constructivos tradicionales, en la línea de lo experimentado anteriormente en el mundo germánico (Monclús y Oyón 1987, 103-122; Anaya 1987, 123-136; Sambricio 2000, 21-44). Este período produciría innumerables muestras del éxito de esta voluntad de 
actualización de la tradición, tanto a nivel urbanístico como arquitectónico. De ello son buen ejemplo la titánica labor de reconstrucción de los conjuntos urbanos afectados por el conflicto que desarrolló la Dirección General de Regiones Devastadas y el trabajo realizado por el Instituto Nacional de Colonización para la revitalización de áreas rurales infrautilizadas, y ya se hablado de la importancia que tuvieron para estas iniciativas publicaciones como la revista Reconstrucción. Estas experiencias adolecieron a menudo de un excesivo tipismo, en muchos casos más por necesidad que por voluntad, y tendieron con frecuencia al reduccionismo formal de la riqueza arquitectónica tradicional y a propasarse en la repetición de determinados motivos (D’Ors 1949, 23; Blanco 1987, 37 39), pero, al mismo tiempo, el análisis comparativo de la mayor parte de los núcleos urbanos reconstruidos en este marco no arroja dudas del interés de los arquitectos que contribuyeron a este esfuerzo por dar continuidad con sus diseños a las identidades tradicionales de las regiones en las que trabajaron. Para ahondar en esta cuestión, es de gran interés la tesis doctoral de Manuel Blanco Lage: Influencias formales en la configuración de la arquitectura española de la posguerra: la Dirección General de Regiones Devastadas (1987a).

Contrastando la nueva arquitectura diseñada para, por ejemplo, Gajanejos (Guadalajara) y la concebida para Pitres (Granada), es notable la determinación de sus autores por integrar en sus proyectos al menos una selección de los materiales, formas y soluciones constructivas característicos de cada zona. El propio Pedro Muguruza, Director General de Regiones Devastadas, explicó en una conferencia titulada Estudios para un plan de mejoramiento de las viviendas humildes, publicada en 1943, la importancia que concedía este organismo a la normalización de determinadas soluciones constructivas y tipos de edificios, así como la conveniencia de distanciarse al mismo tiempo al hacerlo de la serialización de la vivienda, de los modelos "standard", tanto por la necesidad de adaptación de la misma a la particularidades de cada lugar, como por los problemas sociales que ello conlleva, defendiendo, en sus propias palabras, al "trabajador-hombre" frente al "trabajador-máquina" (28-30). En el planteamiento de esta última cuestión, pervivían ecos de las teorías de John Ruskin o William Morris al respecto, llegando a posicionarse a favor de una "organización gremial" del trabajo frente a su convencional “organización liberal” (27). 


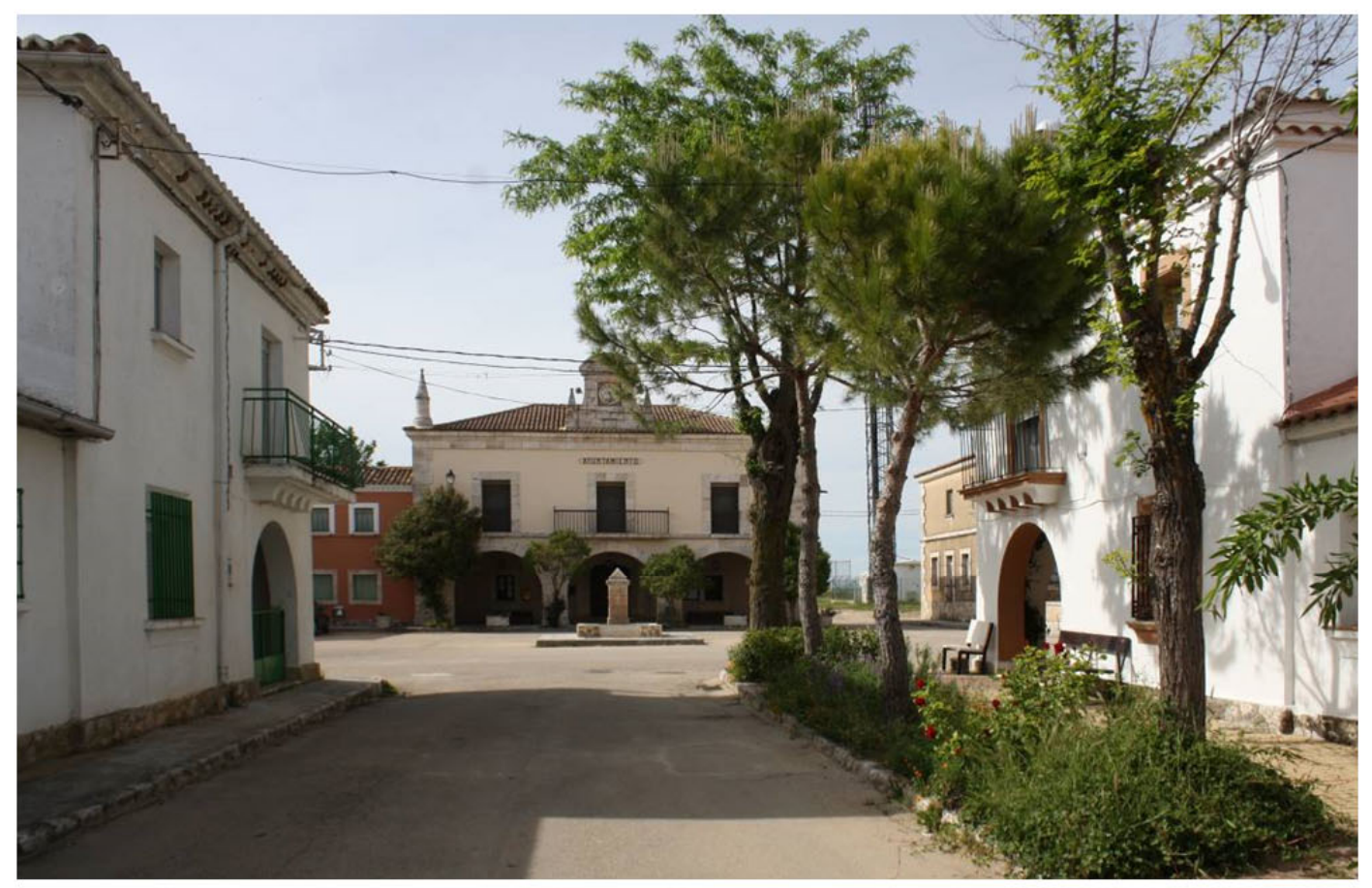

Vistas del pueblo reconstruido de Gajanejos, Guadalajara, y de Pitres, La Taha, Granada, ampliamente reconstruido también tras la Guerra. Son apreciables notables diferencias en el carácter de sus respectivas arquitecturas

(fotografias del autor, mayo de 2014 y agosto de 2015)

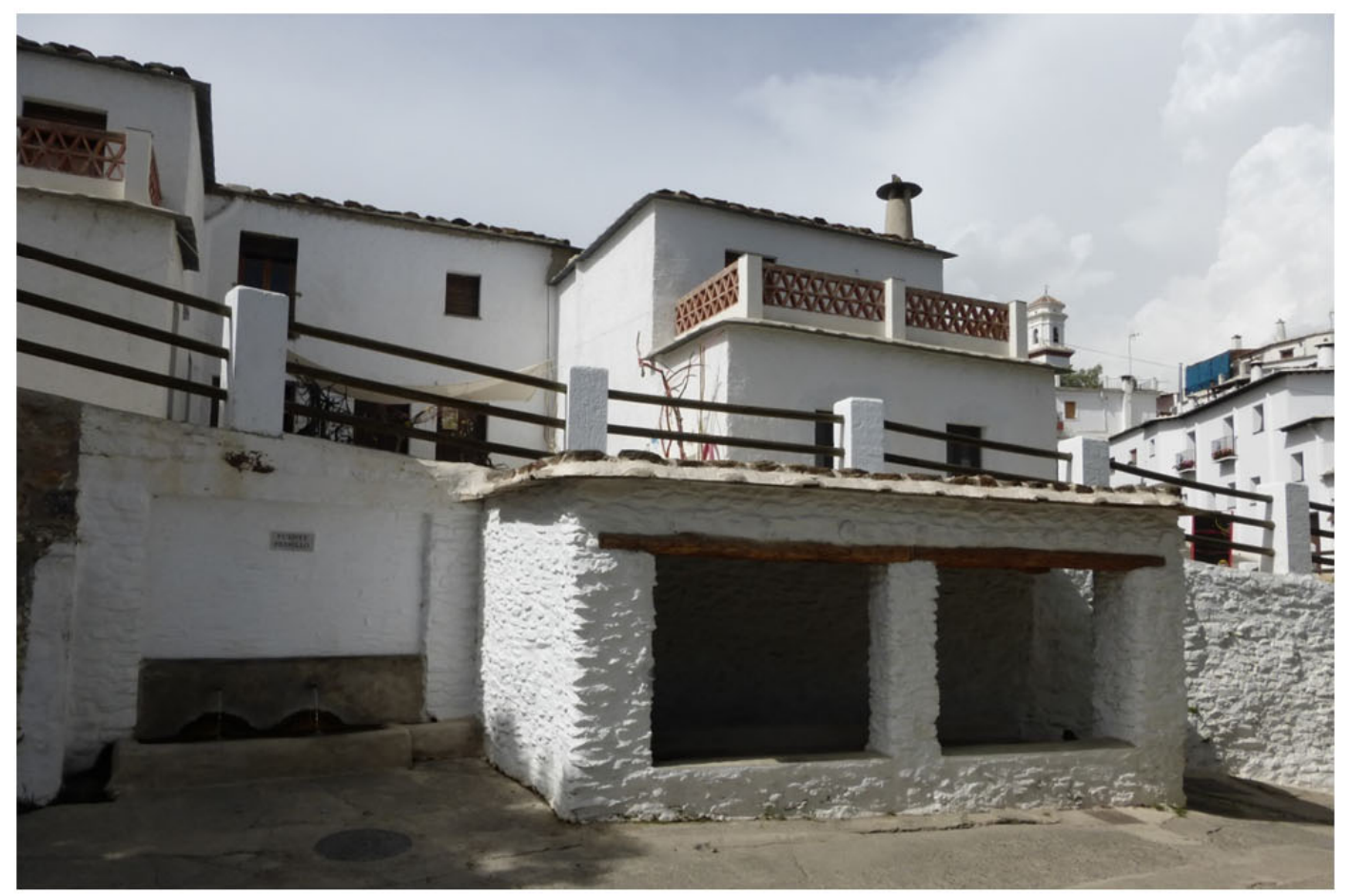




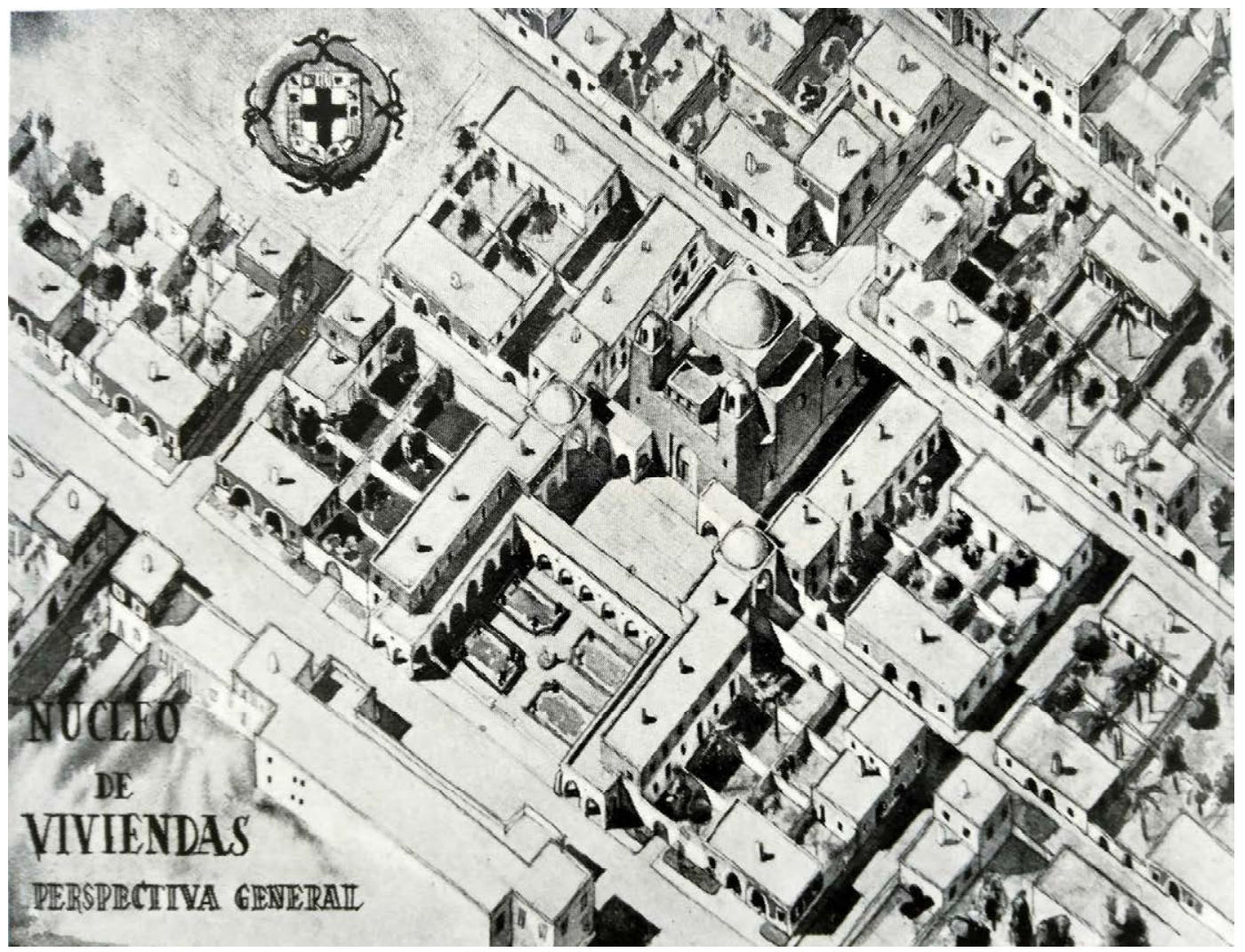

Proyecto de nuevo barrio para Almería realizado por el arquitecto Antonio Cámara y publicado en 1943 en el número 34 de la revista Reconstrucción (Cámara 1943)

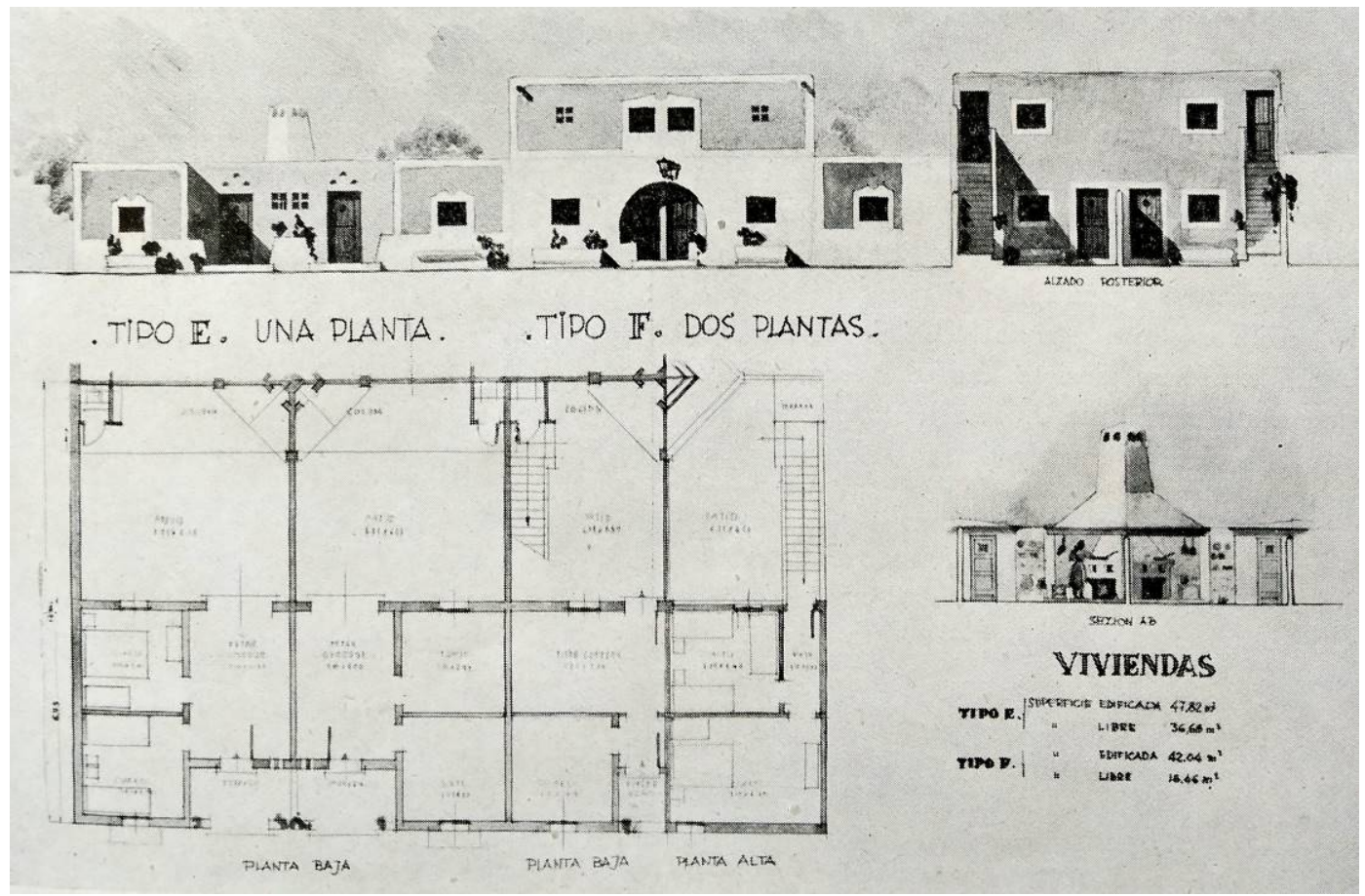




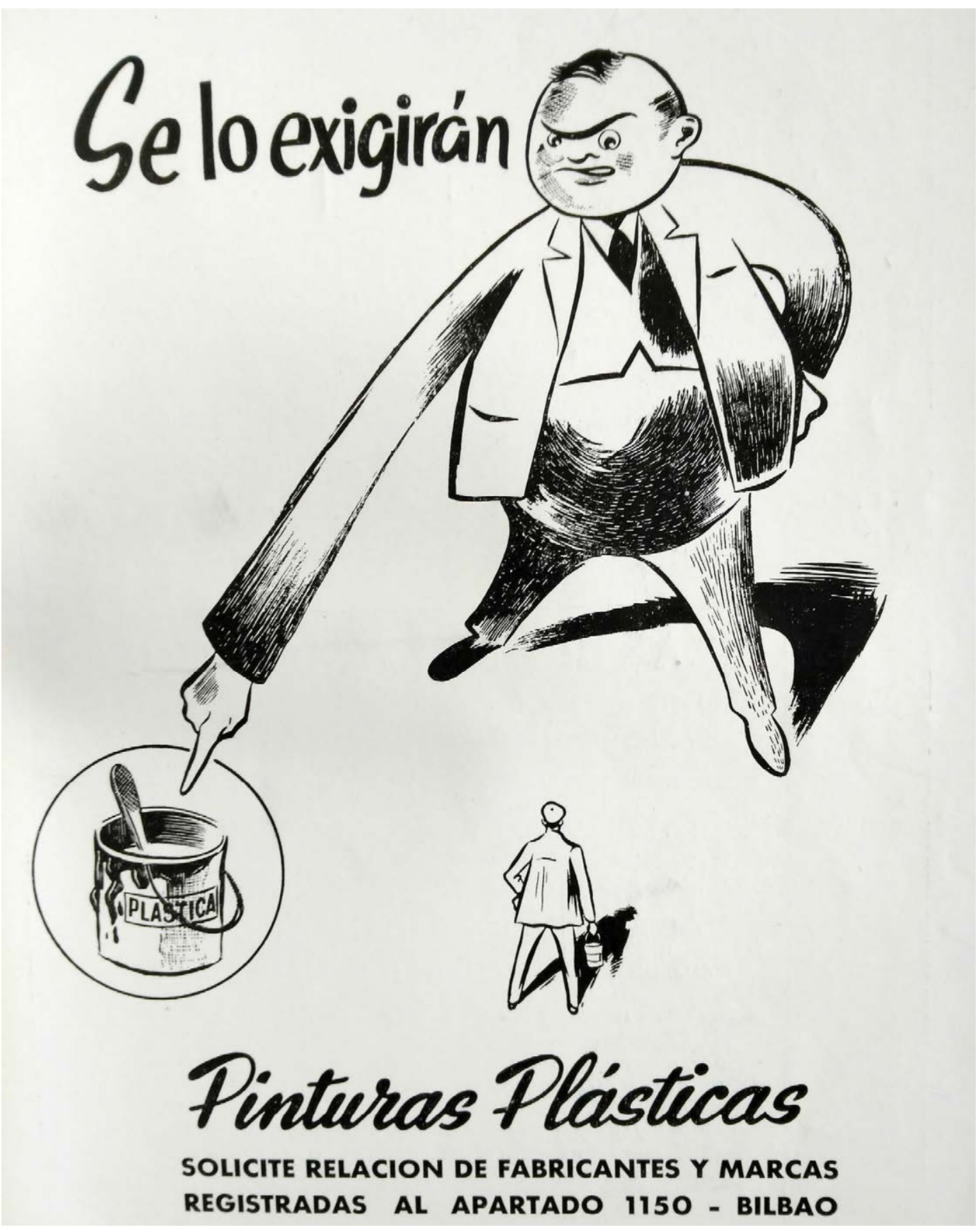

Anuncio publicitario extraído del número 132 de la revista Reconstrucción, publicado en 1956. La publicidad del momento refleja la completa transformación que sufrió en ese período el campo de la construcción, dando así comienzo la crisis de los oficios tradicionales de la construcción 
El Manifiesto de la Alhambra, suscrito por muchos de los más reconocidos arquitectos del momento, reunidos en Granada con el fin de debatir sobre el futuro de la arquitectura española, y publicado en enero de 1953 por la Dirección General de Arquitectura, que entonces presidía Francisco Prieto-Moreno, refleja el progresivo cambio de rumbo de la arquitectura "oficial" que tendría lugar en aquellos años. "Si los románticos veían la Alhambra de un modo trovadoresco (...), nosotros la vemos de un modo cubista", se afirma en él, reflejando el paso definitivo de la corriente arquitectónica dominante hacia la abstracción pura global. La arquitectura española a partir de mediados de los años 50 del siglo XX iba a mirar por lo general hacia la tradición arquitectónica, a lo sumo, como un cúmulo de experiencias meramente volumétricas, espaciales o formales, desvinculándola generalmente del medio, la tradición y la comunidad en la que se desarrolla y, por tanto, de su verdadera esencia cultural.

Las políticas estatales iban a favorecer este proceso. La progresiva liberalización económica, que dejaría atrás en unos años la etapa de la Autarquía, acababa de dar comienzo, y precisamente en 1953 se firmaban también los Acuerdos de Defensa Mutua y Ayuda Económica con los Estados Unidos, culminando en el Plan de Estabilización de 1959 y en el Desarrollismo que dominaría la siguiente década. El énfasis en la industrialización y la exaltación del progreso per se se afianzaron también en España, conllevando la sustitución de la noción previamente dominante de tradición como mecanismo evolutivo, dinámico y generador de riqueza por las nuevas etiquetas de estatismo, involución y pobreza, con las que iba a tener que cargar durante décadas. Un incisivo y agudo testimonio del pensamiento del momento es la letra del afamado tema principal de la película Bienvenido Mr. Marshall, estrenada también en 1953 y dirigida por Luis García Berlanga, aunque escrita en colaboración con Juan Antonio Bardem y Miguel Mihura, a quien se considera autor de la letra de la mencionada canción: "Los yanquis han venido, olé salero, con mil regalos, y a las niñas bonitas van a obsequiar con aeroplanos, con aeroplanos de chorro libre que corta el aire, y también rascacielos, bien conservaos en frigidaire".

La idealización del progreso y de la técnica, con las nuevas formas arquitectónicas a ellos asociadas, había impregnado también a toda una generación de arquitectos. Poco después, a comienzos de 1954 vería la luz el último número de la revista Cortijos y Rascacielos. Los "rascacielos" parecían estar desplazando definitivamente a los 
"cortijos". Este cambio de perspectiva tuvo en definitiva su reflejo directo en el pensamiento y la práctica arquitectónicos españoles, provocando una notable reducción no sólo de los proyectos que iban a tomar la arquitectura tradicional como referencia, sino también en la disminución de la atención que suscitaba entre profesionales e investigadores Los trabajos, estudios y publicaciones sobre la materia y, con ellos, la preocupación por la preservación de las identidades tradicionales pasaron progresivamente a un segundo plano, no recuperándose de esa situación hasta los años setenta.

Excepciones fueron los trabajos sobre arquitectura del etnógrafo español más importante del siglo XX, Julio Caro Baroja; la importante labor de arquitectos como Fernando Chueca Goitia o Francisco Pons-Sorolla, que mantuvieron vivo el tradicionalismo arquitectónico durante estos años, rescatando numerosos conjuntos urbanos tradicionales de la decadencia en que se hallaban sumidos; o el interés por la arquitectura vernácula que iban a manifestar arquitectos de vanguardia como Miguel Fisac, José Antonio Coderch o Curro Inza. En 1962 aparece también el primer número monográfico en la revista Arquitectura sobre la "arquitectura anónima de España", que incluyó ensayos de Antonio Fernández Alba, Luis Moya y Curro Inza. “¿Qué diría don Miguel [de Unamuno] de toda esta nueva oleada de materiales que están revistiendo nuestros hermosos pueblos?", se preguntaba en ella Inza $(1962,39)$, preocupado por una arquitectura moderna que "acaba con determinados materiales, sin explicar bien el porqué, para tratar de imponer otros sin explicar tampoco el motivo de este cambio", y proponiendo una arquitectura que no desechara el saber tradicional, sino que lo adaptara a las necesidades del momento.

Como réplica de los debates surgidos en los últimos CIAM, Oriol Bohigas publicaba en 1963 su Elogi de la barraca, donde como en ellos declaraba su admiración por los asentamientos populares, por los patrones urbanos no planificados, frente a la rigidez del urbanismo del Movimiento Moderno. El arquitecto manchego Miguel Fisac había impartido en 1951 en el Ateneo de Madrid una conferencia titulada "La arquitectura popular y su valor ante la del futuro". Publicada poco después, destaca en ella una apreciación de la arquitectura tradicional que debió ser común en los años posteriores, entendiéndola como una bella fuente de inspiración por sus formas y espacios y, al mismo tiempo, como muestra condenada a desaparecer de un mundo atrasado y unas técnicas primitivas que el progreso estaba permitiendo superar. 
En todo caso, también vieron la luz en España en esta etapa experiencias excepcionales en su entendimiento alternativo de la arquitectura o el urbanismo tradicionales, como la reconstrucción del centro histórico de Fuenterrabía por Manuel Manzano-Monís, haciendo un uso prácticamente simbólico del lenguaje de la tradición local en su arquitectura, pero mostrando al mismo tiempo un excepcional dominio del diseño urbano tradicional que le valió recibir en 1982 el Prix Européen d'Architecture Philippe Rotthier pour la Reconstruction de la Ville; el conjunto de vernacularidad genéricamente mediterránea de Binibeca, diseñado por Francisco Juan Barba Corsini y Antonio Sintes y construido en Menorca entre 1964 y 1968; el compacto pueblo vacacional de tradición andaluza de El Cuartón, proyectado por el arquitecto inglés Philip Jebb y edificado cerca de Tarifa entre 1966 y 1970; los múltiples trabajos en diversas regiones españolas de Rafael Manzano Martos, y especialmente en Sevilla, en cuyo centro urbano ha dado continuidad a la tradición local con incontables transformaciones y ampliaciones de edificios existentes, así como con un gran número de edificios de nueva planta; o las primeras obras realizadas cerca de Almuñécar por el arquitecto australiano Donald Gray, quien entre 1961 y 1962 iba a diseñar sus primeras casas, con las que buscaba promover el retorno de la arquitectura del momento a la tradición de la región, y que en 1965 construía sus primeros conjuntos de diseño urbano acorde con esa tradición, aunque aún de pequeña escala, San Juan, en la vega del río Verde, y San Nicolás, en La Herradura. Poco después vendrían sus más importantes trabajos, núcleos inicialmente concebidos como vacacionales pero diseñados como poblaciones completas que se convirtieron en los últimos continuadores del diseño arquitectónico y urbano de la tradición vernácula de la Costa del Sol: Pueblo López, comenzado a edificar cerca de Fuengirola en 1967 y rodeado entonces por campos de exuberante vegetación; La Virginia, cuya construcción en las afueras de Marbella arrancó en 1968; Las Lomas, la más grande, con 90 casas que se desarrollaron en varias fases ya más adelante, entre 1973 y 1984; y, por las mismas fechas, Pueblo Nuevo de Mijas. 


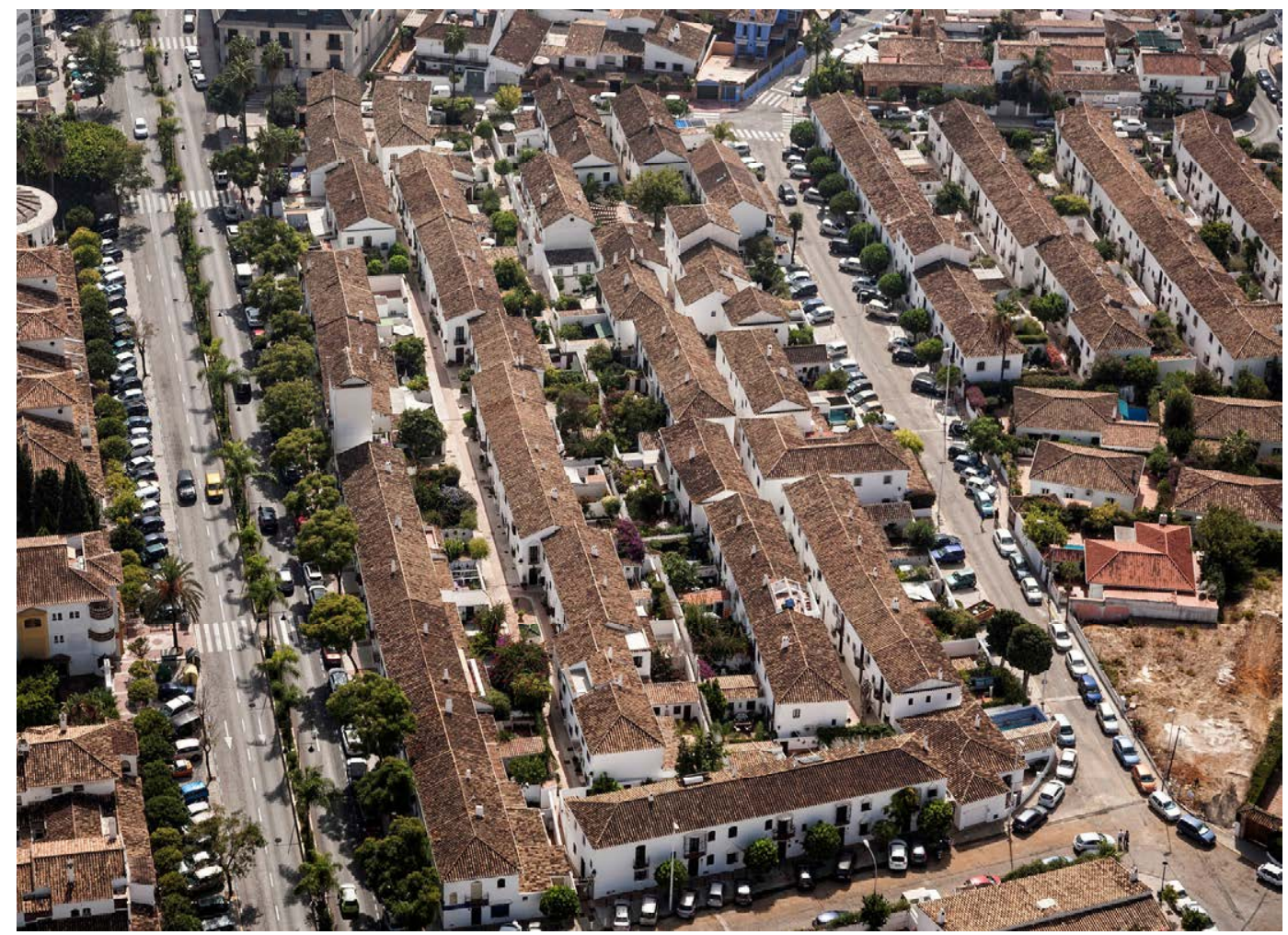

Vista aérea y detalle de uno de los edificios del nuevo conjunto urbano de Pueblo López,

Fuengirola, Málaga, diseñado por Donald Gray y comenzado a construir en 1967

(fotografías cedidas por José Miguel Llano, septiembre de 2016)

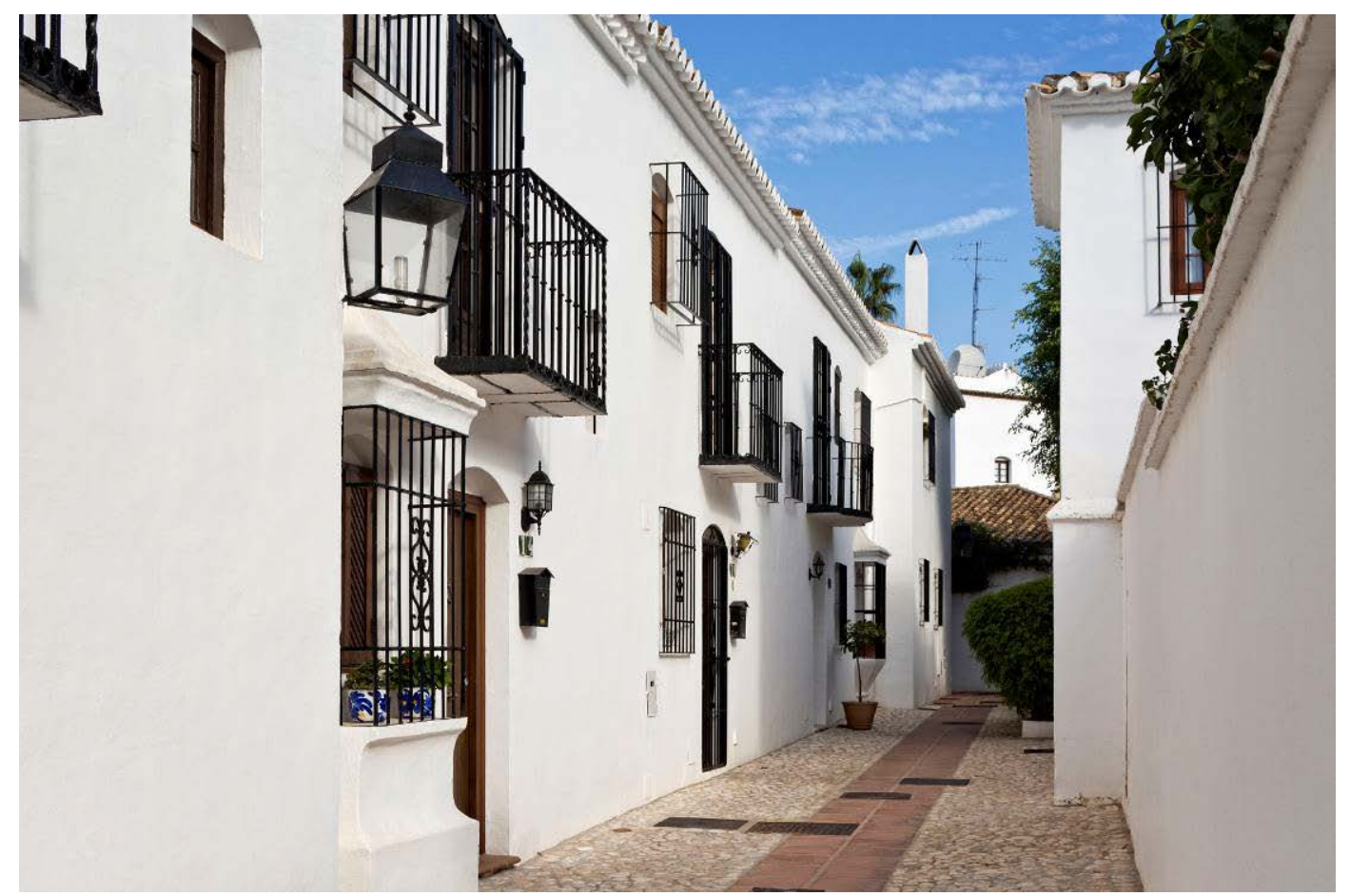




\subsection{LA NUEVA VALORACIÓN DE LAS TRADICIONES LOCALES TRAS LA CRISIS DE LA MODERNIDAD}

La forma, incluso, de nuestras ciudades es una cuestión de elección, no de suerte o destino; los que dicen lo contrario optan por pasar por alto que la farragosa apariencia de nuestras ciudades no es el resultado de un 'laissez-faire’ incontrolado, sino de una ideología urbanística errónea.

Leon Krier 2013, 33

Mientras la mayor parte de la arquitectura española se hallaba aún plenamente sumergida en el Desarrollismo, más allá de nuestras fronteras el final de los años sesenta estuvo marcado por un conjunto de trabajos que iban a poner especialmente de relieve la importancia de estudiar la arquitectura tradicional dentro de su contexto cultural, buscando liberarla "de sus asociaciones con el anonimato, la nostalgia y el pasado, y destacando explícitamente el papel que las tradiciones vernáculas pueden representar en la provisión de asentamientos y edificios más sostenibles para el futuro" (Asquith y Vellinga 2006, 4). Entre ellos, conviene destacar las publicaciones Shelter and Society, preparada por Paul Oliver, y la ya citada House Form and Culture, de Amos Rapoport, ambos publicados en 1969.

Poco antes, en 1966, el arquitecto milanés Aldo Rossi publicaba su influyente libro La arquitectura de la ciudad, un ataque a los preceptos funcionalistas a la par que una notable contribución a la mejor comprensión de la naturaleza de la estructura urbana. Más allá de las reduccionistas utopías maquinistas, entendía ésta como una construcción pluriestratificada integrada por múltiples componentes materiales e inmateriales, en la que la pervivencia de determinados tipos pone de manifiesto la continuidad y prevalencia de éstos frente a notables cambios de uso y significado. Tomó para ello como base el trabajo previamente desarrollado por Saverio Muratori, quien en 1959 había publicado sus Studi per una operante storia urbana di Venezia, que sirvieron para introducir de nuevo el concepto de tipo en el debate arquitectónico, a través de Giulio Carlo Argán, de la revista Casabella, y del propio Rossi (Younés 2016, 18-20). 


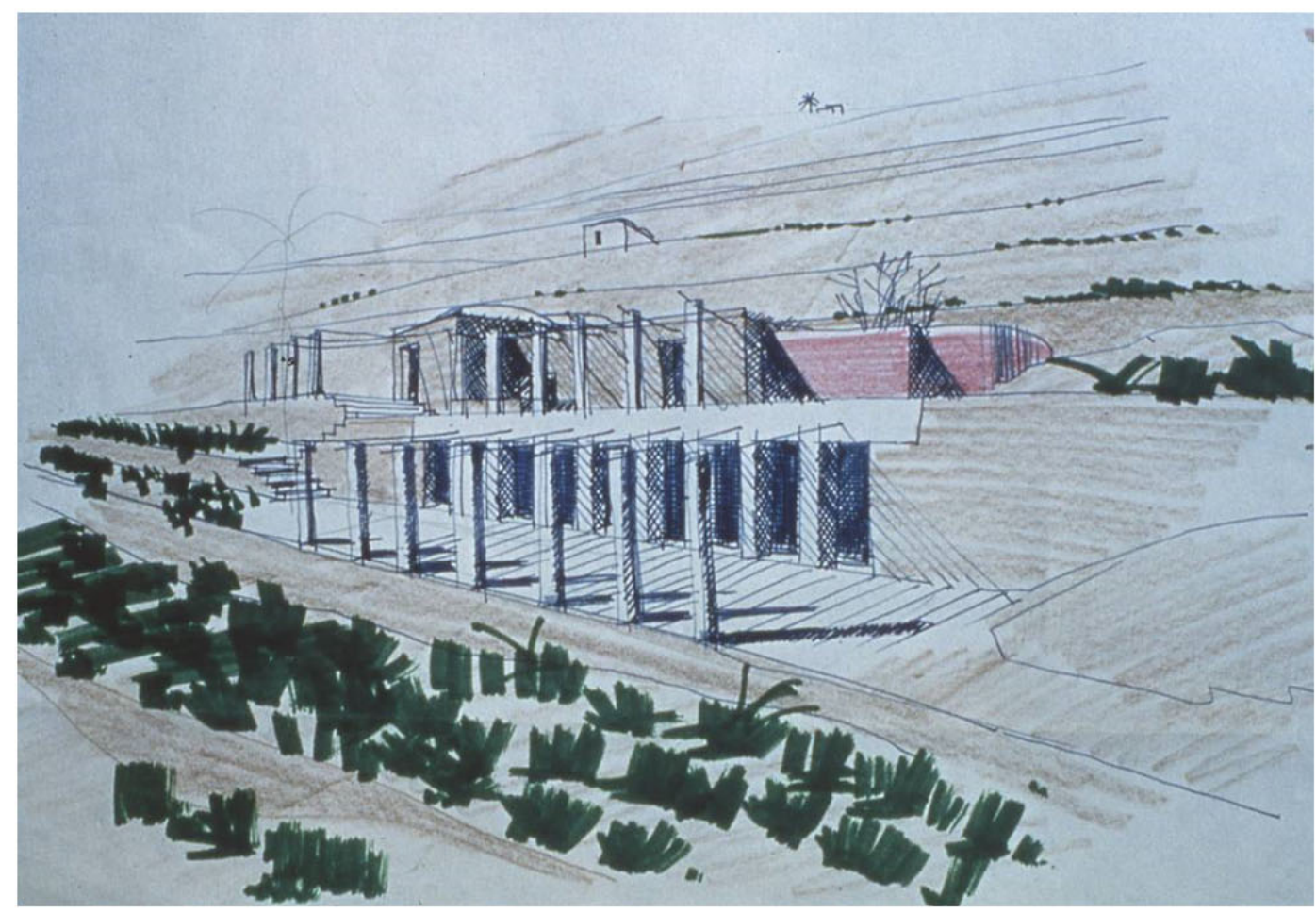

Casa en el litoral de la isla de Pantelleria, Italia, diseñada por Óscar Tusquets y Lluís Clotet y construida entre 1972 y 1975 (Ref. web: www.tusquets.com, consultada el 31 de agosto de 2018), e interior de la casa torre en Bagnano, Italia, diseñada por Leon Krier en 1974 (Krier 2013, 48)

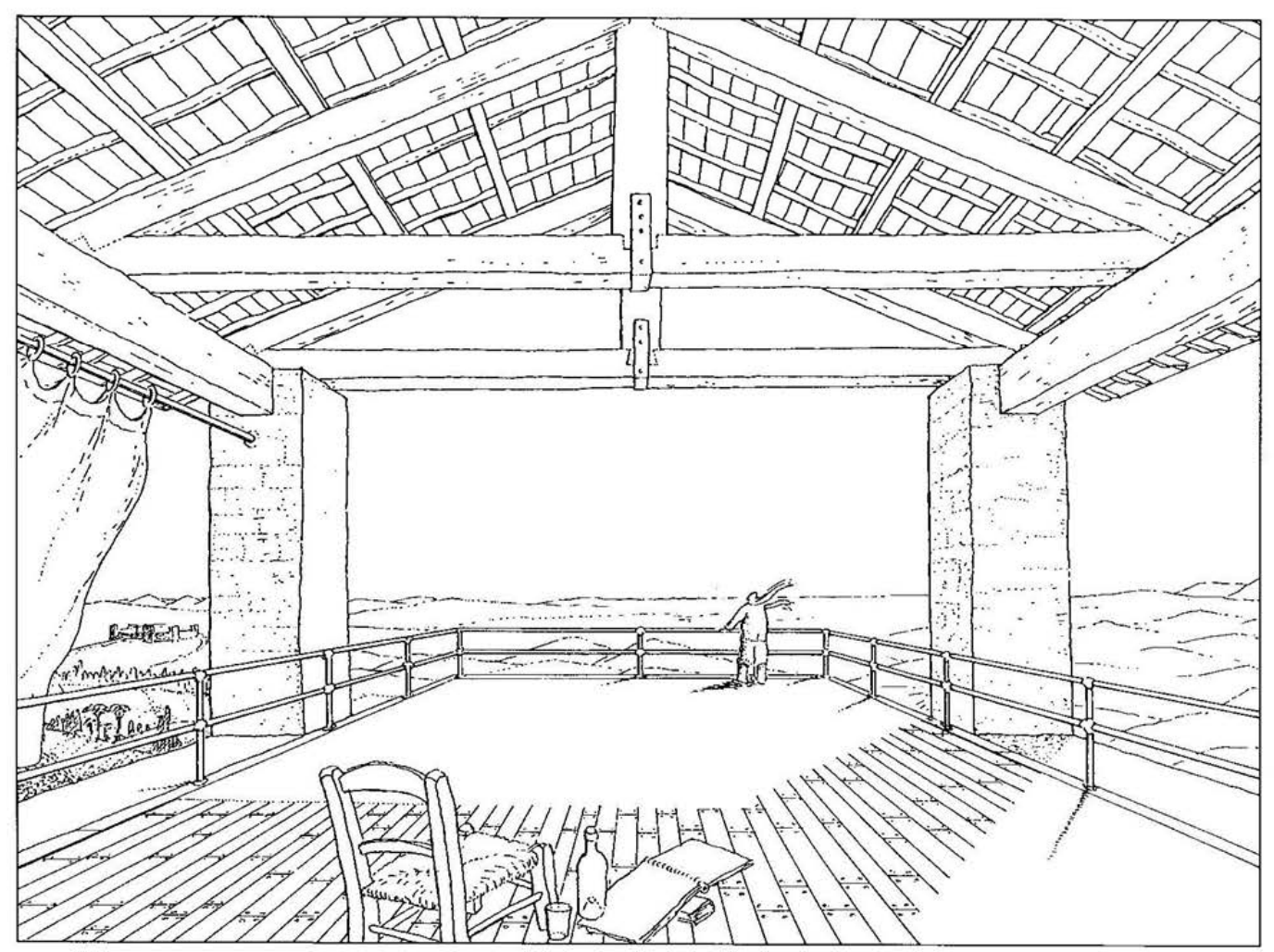


En 1973, bajo el lema "Architettura Razionale", Aldo Rossi y Massimo Scolari organizaron la sección de arquitectura internacional de la XV Trienal de Milán, en la que, presentando diversos proyectos internacionales de reestructuraciones e intervenciones en el tejido urbano de diversas ciudades, se condenaba expresamente el urbanismo funcionalista $\mathrm{y}$, frente al análisis historicista de la ciudad, se proponía una visión de la misma centrada en el estudio de la persistencia de los tipos y su relación con la estructura urbana general. Se convirtió en el emblema de aquella muestra la famosa pintura de Arduino Cantáfora Città análoga, en la que un grupo de proyectos arquitectónicos y edificios identificables y de diversos momentos históricos se hallaban reunidos conformando un conjunto urbano. Triunfaba así una nueva visión de la arquitectura liberada de los corsés que la ortodoxia moderna había fijado hasta entonces, de lo que constituye un buen ejemplo el proyecto que el mismo Rossi realizó en ese año en Borgo Ticino, inspirado en las casas vernáculas lacustres. En torno a estas ideas iba a surgir un movimiento para el que Scolari acuñó el término "Tendenza", bajo el que se agruparon también los trabajos cercanos a ellas de otros arquitectos italianos, como Carlo Aymonino, Giorgio Grassi, Bruno Minardi y muchos otros. Esta tendencia iba a extenderse pronto por numerosos países, reuniendo un nutrido grupo de seguidores que iban a enriquecerla con diversas aportaciones locales.

Dos años más tarde, Leon Krier organizaba en Londres y Barcelona un congreso que, acompañado de una exposición y, ya en 1978, de una publicación, recuperaba la denominación "Arquitectura Racional” para presentar una serie de proyectos propios, de su hermano Robert, y de Aldo Rossi, Massimo Scolari, Carlo Aymonino, Giorgio Grassi, Oswald M. Ungers y otros, entre los que hubo representantes españoles como José Ignacio Linazasoro, Manuel de Solà-Morales o Miguel Garay. El énfasis fue puesto una vez más en la morfología urbana y se reivindicó la recuperación de la ciudad tradicional. La selección reflejaba, además de la progresiva expansión internacional de estas ideas, la existencia de diversas sensibilidades al respecto.

También en 1978 Colin Rowe y Fred Koetter publicaban Collage City, que, con fines diversos, se sumaba a la defensa del contextualismo en la arquitectura, así como de la necesidad de que la arquitectura se plegara de nuevo a la preponderancia de la estructura urbana. 
En paralelo, el debate por la recuperación del simbolismo arquitectónico y, de su mano, de la cuestión identitaria, resurgió con fuerza tras la crisis del Movimiento Moderno. Resultó clave en ella la aparición de Aprendiendo de Las Vegas, de Robert Venturi y Denise Scott Brown (1972; versión revisada con el título definitivo, 1977), un libro que reivindicaba la relación simbólica que la arquitectura mantiene, fuera o no reconocido por las vanguardias arquitectónicas anteriores, con la cultura que hace uso de ella. Gracias en gran medida al ejemplo desprejuiciado y directo de los simulacros históricos y ambientales de Las Vegas (donde existían fantasías de inspiración romana, parisina u oriental, entre otras, y hoy las hay también venecianas, egipcias o neoyorquinas), las corrientes arquitectónicas del momento iban a redescubrir el valor de olvidadas nociones sobre la escala humana de la ciudad, con sus calles y plazas, las formas icónicas, la decoración o el carácter local.

Venturi y Scott Brown recibieron el apoyo de otras influyentes voces, tales como la de Vincent Scully, entonces profesor en la escuela de arquitectura de la Universidad de Yale. Las enseñanzas y escritos de Scully, así como su activa defensa del patrimonio arquitectónico, resultarían fundamentales para que varias generaciones de arquitectos se interesaran por la arquitectura y la ciudad tradicionales y abanderaran una arquitectura contextualista, tratando reparar los daños causados en el paisaje urbano tradicional por el urbanismo funcionalista y la proliferación de edificios ensimismados de muy diversa filiación. Y el propio Scully sería fundamental en el desarrollo posterior de la Escuela de $\mathrm{Miami}^{15}$.

Tras las reconstrucciones a gran escala de tejidos urbanos tradicionales destruidos en la Segunda Guerra Mundial que se habían multiplicado por toda Europa, la réplica de la identidad perdida había probado ser asumida sin dificultad por la población local, que se apropiaba pronto de la imagen tradicional recuperada, entendiendo su salvación como verdadera gesta comunitaria. Y ello a pesar de que estas reconstrucciones no pretendían ni pretenden aún hoy generalmente replicar el original con fidelidad, sino que utilizan sus componentes de manera completamente selectiva, tal como puede apreciarse, por

\footnotetext{
${ }^{15}$ Sobre este particular es de gran interés la consulta del libro Between Two Towers. The Drawings of the School of Miami, preparado por el mismo Scully y publicado en 1996 por The Monacelli Press. En él se recoge una selección de los trabajos de los alumnos y profesores que conformaron esta influyente Escuela.
} 
ejemplo, en la restauración aún en curso de los centros históricos de muchas ciudades alemanas, tales como Frankfurt o Dresde.

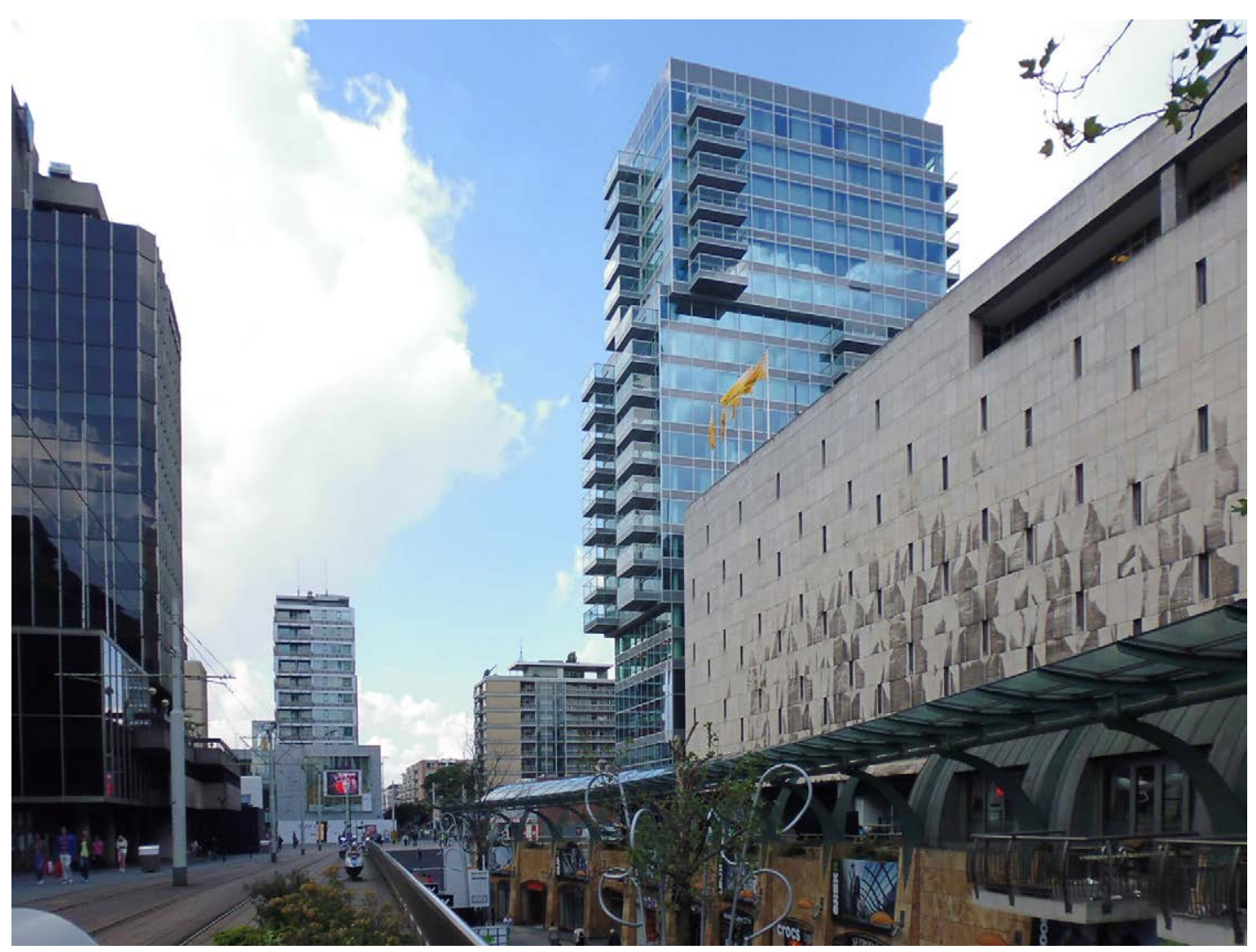

Centros de Róterdam y de Middelburg, representativos de dos criterios diversos de reconstrucción posbélica (fotografías del autor, agosto de 2013 y agosto de 2012)

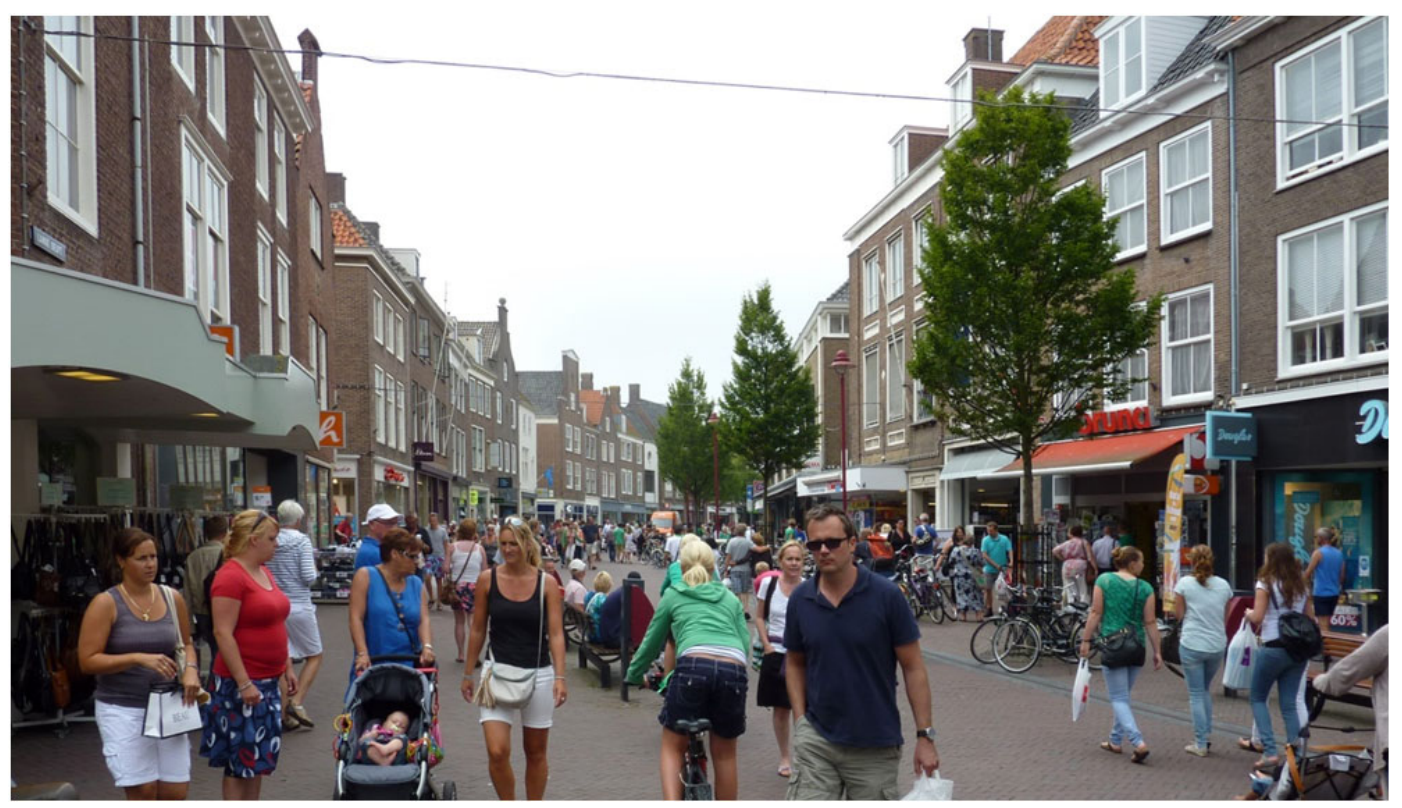


En todo caso, resulta esclarecedor, por ejemplo, pasear cualquier fin de semana por el centro de la ciudad de Róterdam, en cuya reconstrucción posbélica se aplicaron los más modernos criterios urbanos de la época sobre las ruinas que habían sobrevivido a los cruentos bombardeos alemanes, y hacerlo a continuación por la cercana Middelburg, donde, según los diseños del arquitecto Pieter Verhagen, se optaría por recuperar el tejido urbano tradicional, aunque no sin antes adaptarlo a los requerimientos de los nuevos tiempos. Podrá a simple vista comprobarse cómo, a diferencia de lo que sucede en la primera, buena parte de las calles y plazas de esta última ciudad rebosan de vida local, al tiempo que un gran número de turistas inunda sus reconstruidos espacios representativos cada fin de semana.

El arquitecto Charles Jencks, en The Language of Postmodern Architecture (1977), su libro más leído y citado, cuya próxima reedición Jencks prepara en estos mismos momentos, incluyó una de las afirmaciones más recordadas e impresionantes en la historia de la crítica de arquitectura, aquella según la cual "la arquitectura moderna murió en St. Louis, Missouri, el 15 de Julio de 1972, a las 3.32 de la tarde (más o menos)”. Se refería con ello a la demolición del fracasado conjunto de Pruitt-Igoe, diseñado por uno de los arquitectos más reputados de la vanguardia moderna, Minoru Yamasaki, y con este trabajo iniciaba una batalla internacional librada con el objetivo de facilitar el cambio de paradigma que colocaría la postmodernidad en el lugar del Movimiento Moderno. Se abría una etapa en la que el valor de actualidad de la arquitectura y el urbanismo tradicionales sería nuevamente reivindicado por unos y, al mismo tiempo, caricaturizado por otros.

Sin embargo, el uso de referencias históricas y tradicionales dentro del movimiento conocido como Posmodernismo fue con frecuencia, en el caso de muchos arquitectos, de grano grueso y superficial, limitándose a menudo a la mera banalización de las mismas, lo que acarrearía numerosas críticas que en los años 90 desembocarían finalmente en una nueva oleada modernista que volvería a sumir en un extendido olvido muchas de estas cuestiones.

En todo caso, frente a esta problemática, se desarrollaba una militante corriente alternativa que, encabezada por Leon Krier, centraría sus esfuerzos en la recuperación de la ciudad tradicional como modelo para el urbanismo de su tiempo. Con similares fines, el 
sociólogo René Schoonbrodt, desde el Atelier de Recherche et d'Action Urbaines (ARAU), abría el debate sobre el modo en que estaba transformándose la ciudad de Bruselas, mientras el arquitecto Maurice Culot y el historiador del arte Robert-Louis Delevoy reformaban el programa de estudios de la Ecole Nationale d'Architecture et des Arts Visuels, situada en la antigua abadía de La Cambre, en Bruselas, que pasó a dedicarse activamente a lo que iban a denominar la "reconstrucción de la ciudad europea", en referencia a los graves daños causados en urbes como la propia Bruselas por el urbanismo funcionalista y la arquitectura ajena a su contexto (Culot 2013, 57-59; Younés 2016, 25-26). Esta línea de acción iba a partir de fuertes reivindicaciones de naturaleza social y ecológica. En palabras de Maurice Culot $(2014,23)$ :

Crisis petroleras recurrentes, escasez de materias primas, costes energéticos prohibitivos, reagrupación de la mitad de la población mundial en desarrollos periurbanos, marasmo económico, calentamiento climático, bombardeo mediático, etc. terminan por imponer que haya que repensar un mínimo la cuestión del territorio, de la arquitectura y de las oportunidades para la industria. Lo duradero vuelve a estar a la orden del día en Europa, pero bajo una forma insidiosa: la de la norma sin relación con lo urbano. Se ignora la causa, y es que la alta calidad arquitectónica, el edificio de bajo consumo, la arquitectura pasiva y las múltiples etiquetas de comportamiento energético-ecológico no tienen sentido sino dentro de la ciudad densa y no en los desarrollos suburbanos, en lo que los americanos denominan sprawl. "No es sino nuestra economía lo que no es duradero", escribe con lucidez Marcel Gauchet, "es nuestra civilización -con sus actuales reglas de funcionamiento- lo que no es duradero. Nos mantenemos en la idea de la omnipotencia, pero estamos en una sociedad frágil y vulnerable”.

El mismo Culot cita un informe de las Naciones Unidas que, ya en 2004, afirma con rotundidad: "Para sobrevivir, debemos salir de la era de la conquista de la naturaleza y entrar en la era de la durabilidad y de la gestión prudente" (Culot 2013, 57), reivindicaciones éstas que se iban a entender ya como aspectos inextricables de la anhelada recuperación de la tradición arquitectónica. 


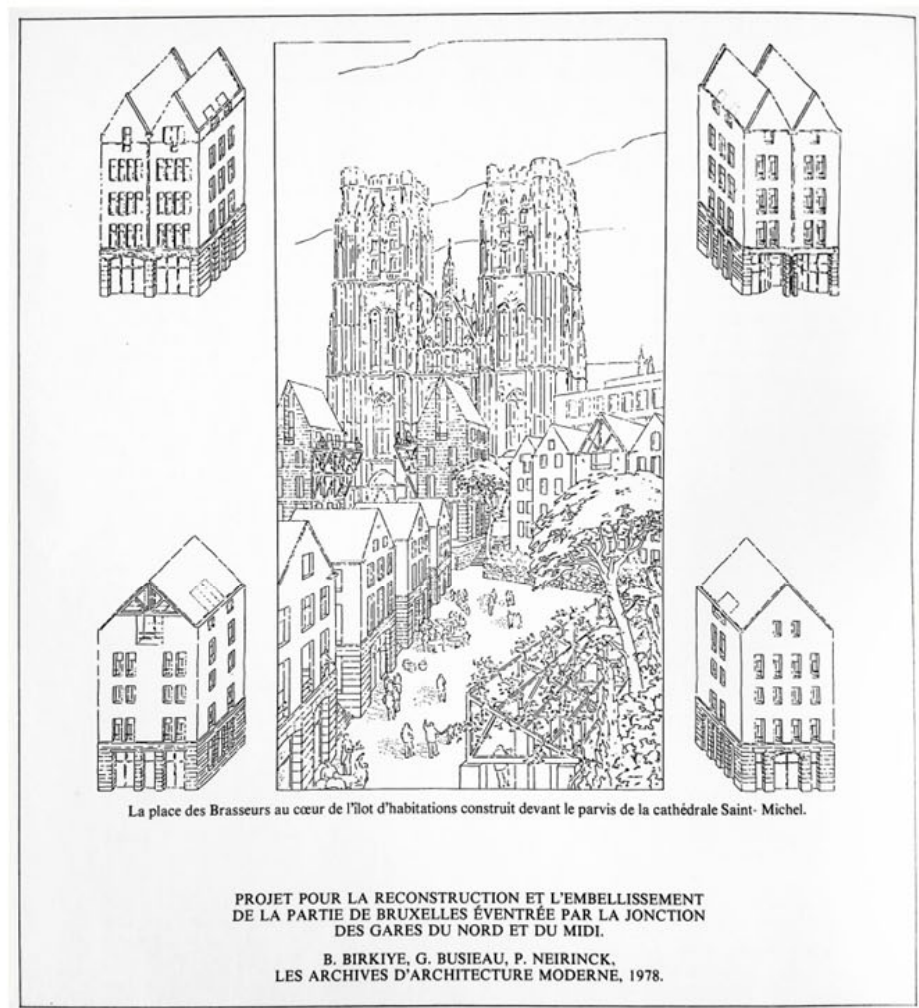

Proyectos para la reconstrucción de fragmentos de la ciudad de Bruselas previamente demolidos en nombre del progreso, el primero de S. Birkiye, G. Busieau y P. Neirinck y el segundo de S. Birkiye y G. Busieau, ambos realizados en 1978 e incluidos en la publicación Declaration de Bruxelles.

Propos sur la Reconstruction de la Ville Européenne (Barey 1980)

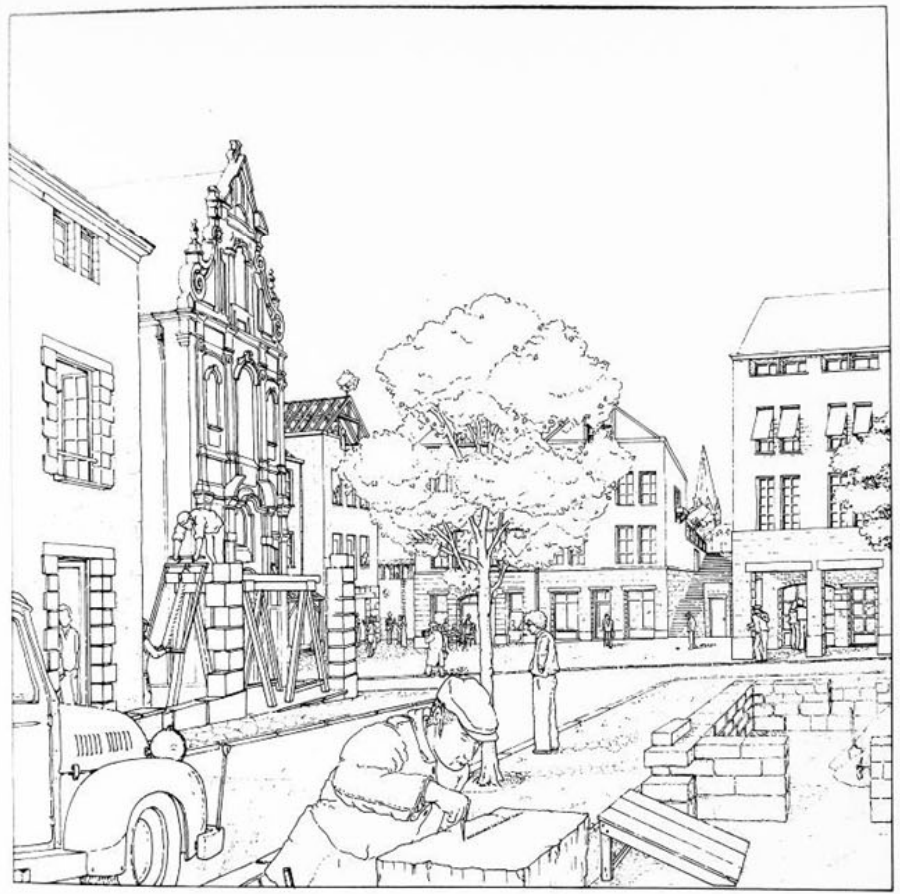


Pese a centrar su atención en el urbanismo, considerándolo el ámbito que con mayor urgencia requería un amplio replanteamiento, este grupo iba a hacer hincapié también en otros aspectos de la tradición arquitectónica que se han ido exponiendo en apartados anteriores, incluyendo la necesidad de recuperar el tejido artesanal que constituye el vehículo transmisor del saber tradicional. Así, Leon Krier se acerca en La arquitectura de la comunidad a algunas de las ya citadas ideas de los más tempranos defensores de la arquitectura tradicional, como William Morris y Charles Fourier, recuperando así la visión integral del problema que comenzaba a plantearse entonces (2013, 289-292):

La inmensa demanda de arquitectura tradicional -que se manifiesta en todos los mercados y democracias libres- debe, por el momento, satisfacerse con productos de inferior calidad, con sucedáneos y copias superficiales. La capacidad de desarrollo de este mercado, tanto en cuanto a cantidad como a calidad, está seriamente restringida, si no bloqueada, por una carencia general de facilidades adecuadas de formación práctica y teórica, y de representación institucional normal (...). La ideología industrial y el colectivismo han devastado los métodos artesanales y sus instrumentos de formación y enseñanza y, en efecto, la cultura artesanal en su conjunto: esa ideología obsoleta es la que ralentiza y a menudo impide su reconstrucción, aun siquiera parcial.

Al mismo tiempo, defendía la necesidad de proporcionar a la gente verdaderas alternativas arquitectónicas entre las que poder elegir, barrios o núcleos urbanos con identidades bien definidas que pudieran satisfacer las diversas preferencias de sus posibles habitantes: "las múltiples visiones urbanas y arquitectónicas pueden encauzarse hacia la creación de una variedad de asentamientos y poblaciones de estructura, arquitectura y densidades muy diferentes, cada una con su propia coherencia, armonía e idiosincrasia. La única forma de pluralismo no tiene por qué ser el crisol. Pluralismo no significa por fuerza aleación de estilos, sino respeto por las diferencias" (Óp. Cit., 32).

En 1978 este grupo se reunió en Bruselas, surgiendo de este encuentro una serie de reclamaciones dirigidas a la Comunidad Económica Europea, instándola a reorientar la enseñanza en las escuelas de arquitectura, a promover la recuperación de los oficios tradicionales de la construcción, a acabar con la zonificación urbanística, a acotar la 
expansión insostenible de tejidos suburbanos en el entorno de las ciudades, y a proteger el patrimonio histórico, no sólo preservando los centros urbanos, sino tomando como referente el legado de los mismos para el diseño de los nuevos desarrollos urbanos. Estas y otras demandas quedarían recogidas en la Declaration de Bruxelles. Propos sur la Reconstruction de la Ville Européenne (1980).

Erigiéndose en el principal sucesor de Camillo Sitte y sus seguidores en este empeño, Leon Krier ha batallado incansablemente en la defensa del modelo urbano tradicional, exponiendo sus ideas y propuestas en numerosos proyectos, artículos y libros que siguen resultando tan polémicos como de actualidad, y haciendo en ello causa común con el New Urbanism estadounidense, protagonizado por urbanistas revisionistas como Andrés Duany y Elizabeth Plater-Zyberk y Stefanos Polyzoides y Elizabeth Moule.

Tal como se ha mencionado, en 1988 el Príncipe de Gales encargó a Leon Krier proyectar el nuevo pueblo de Poundbury en las afueras de Dorchester (Dorset), lo que supuso la primera oportunidad para poner a prueba estos principios a gran escala. Fuertemente criticado durante años, sólo hoy en día sus resultados han podido ser evaluados y su éxito a la hora de proponer un modelo alternativo de desarrollo urbano contemporáneo ha comenzado a ser reconocido internacionalmente, e incluso replicado en países como Holanda o Suecia. En 1989 el propio Príncipe de Gales publicaba A Vision of Britain, en defensa del paisaje, la arquitectura tradicional y el tejido social artesanal británicos, ideas que retomó en 2010, situándolas dentro de un marco más amplio, publicando Harmony: A New Way of Looking at Our World. En 1993 creó su propio Instituto de Arquitectura, que formó a toda una generación de arquitectos interesados en la arquitectura y la construcción tradicionales antes de disolverse en 2001, siendo sustituido en la actualidad por la Prince's Foundation for Building Community, que promueve la arquitectura, el urbanismo y las técnicas de construcción tradicionales, ofreciendo también formación en los tres campos.

En 1992, se constituía en Bolonia el grupo internacional A Vision of Europe, cuya denominación se hacía eco del libro antes mencionado. A través de diversos encuentros, congresos y exposiciones internacionales contribuyó en gran medida al intercambio de experiencias y a la promoción del trabajo de un gran número de arquitectos de todo el mundo interesados de un modo u otro en la arquitectura y el tejido urbano tradicionales. 


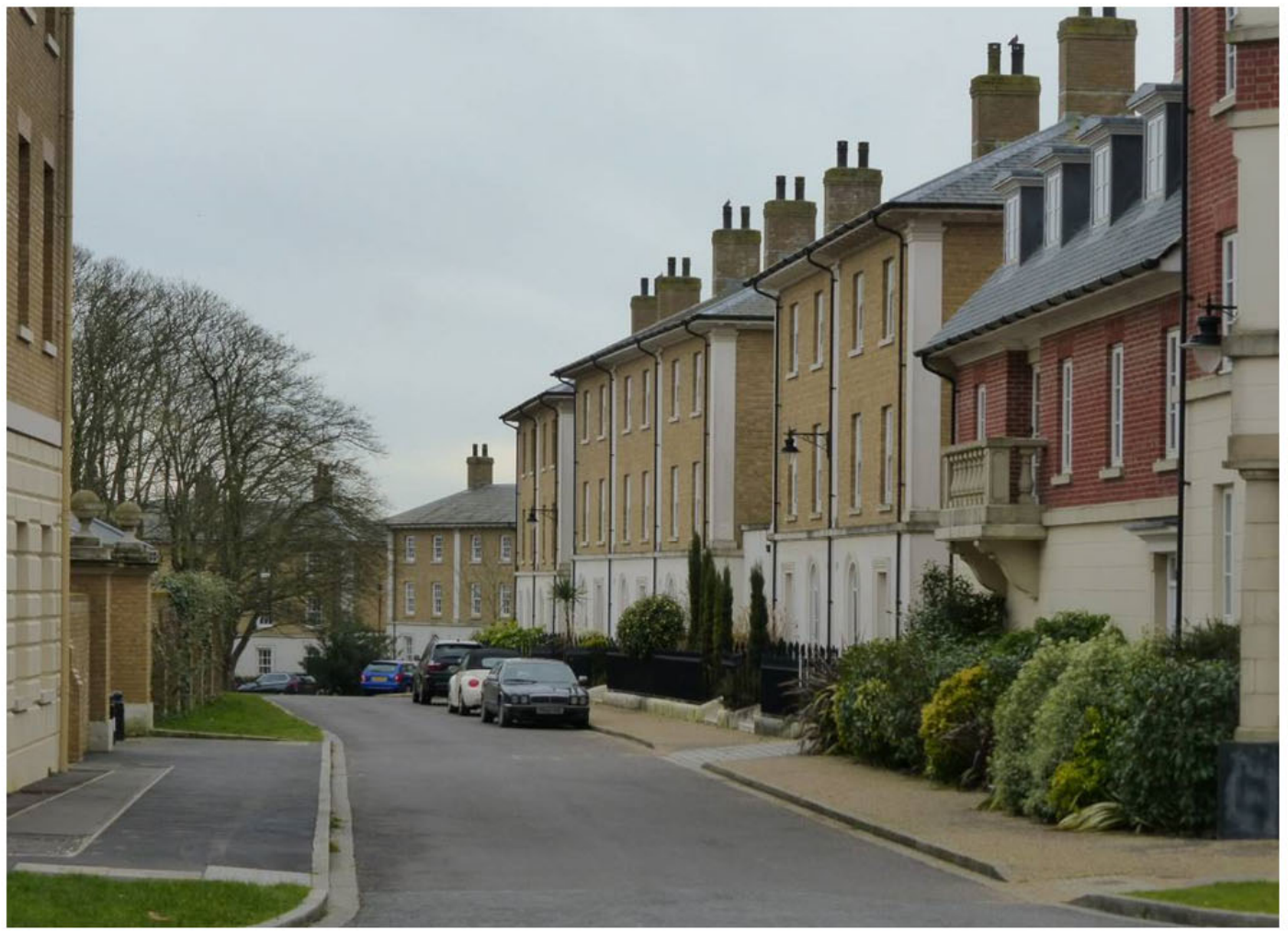

Vistas de Poundbury, Dorchester, Dorset, Reino Unido, edificado según proyecto de Leon Krier y aún en desarrollo (fotografías del autor, febrero de 2015)

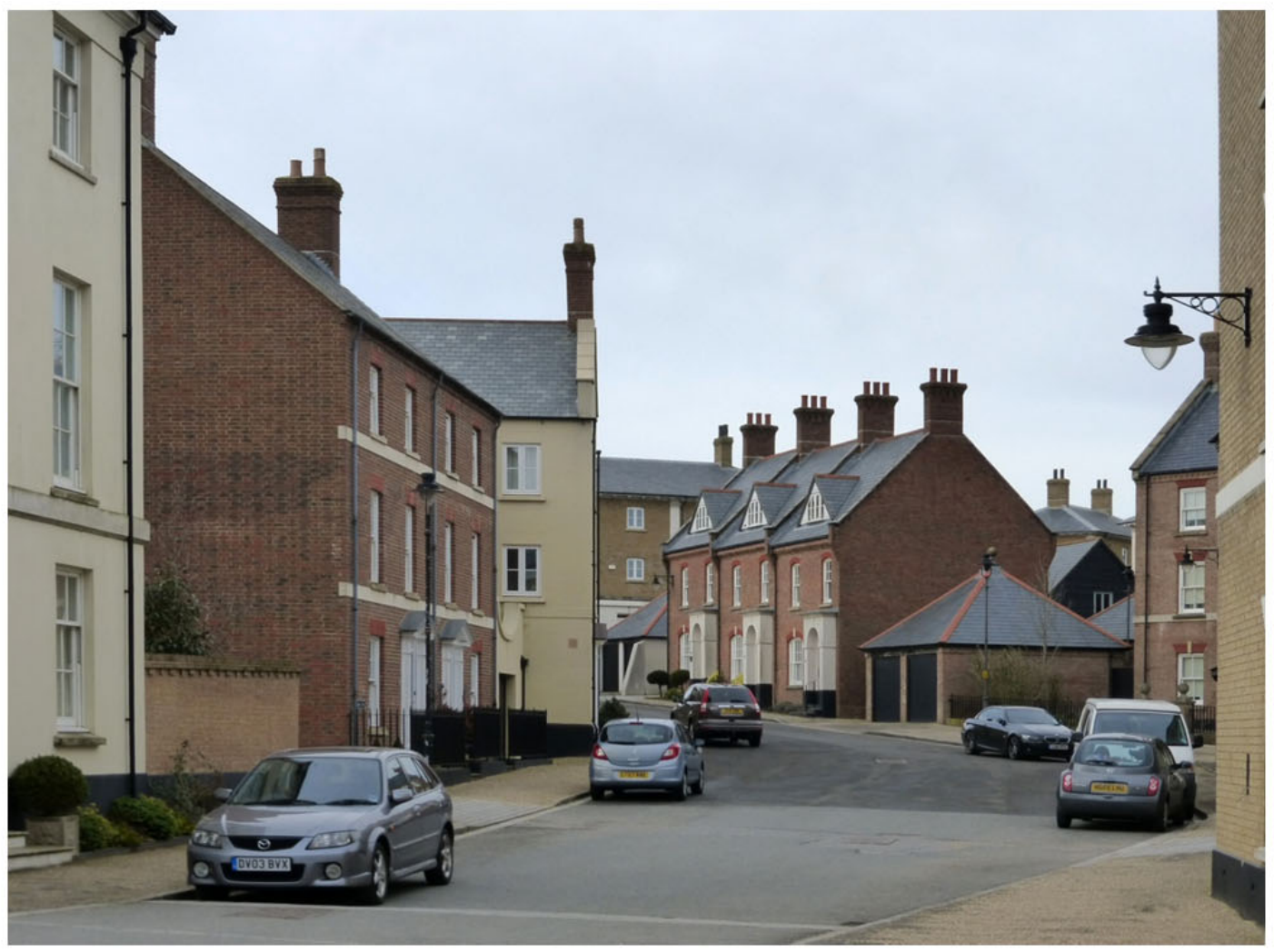


Regresando a Bruselas, en 1969 Delevoy y Culot fundaron la asociación Archives d'architecture moderne (AAM), que, bajo la dirección de Culot, publicaría la influyente revista del mismo nombre hasta 1990. Por medio de ella se difundieron internacionalmente investigaciones y trabajos de nueva arquitectura tradicional que habían pasado generalmente desapercibidos hasta entonces, tales como las obras del arquitecto Philippe Rotthier en la isla de Ibiza y sus estudios sobre sus tradiciones arquitectónicas y constructivas.

El propio Rotthier fundó en 1982 el Prix Européen de la Reconstruction de le Ville, otorgado trienalmente desde entonces a obras de arquitectura que destaquen en la continuación de las tradiciones locales del contexto en el que se edifiquen, siendo galardonados trabajos tan diversos como los de Ernest Schirmacher para la reconstrucción de varias casas del centro histórico de Frankfurt, Demetri Porphyrios, Tarak Ben Miled, Eusebio Leal, Pier Carlo Bontempi o Abdel Wahed El-Wakil, así como distintas obras realizadas en la Península Ibérica, entre las que se encuentran trabajos de Javier Cenicacelaya e Íñigo Saloña, Manuel Íñiguez y Alberto Ustarroz, Alberto Castro Nunes y Antonio Maria Braga, José Baganha, José Manuel Ábalos, César Portela o el recientemente premiado de Rafael Manzano.

Poco antes, en 1977, se había fundado el también trienal Aga Khan Award for Architecture, que, pese a haberse alejado en la actualidad de sus objetivos iniciales, buscaba inicialmente promover en el mundo islámico una arquitectura contemporánea concebida desde la tradición local. La presencia en su primigenio comité organizador de arquitectos como Hassan Fathy permitió que los galardones recayeran originalmente sobre obras tales como las del ya mencionado Abdel Wahed El-Wakil, el trabajo en Mali de André Ravereau o el de la Association pour le Développement naturel d'une Architecture et d'un Urbanisme Africains (ADAUA) en Mauritania, asociación en la que estaba integrado el arquitecto Jak Vauthrin.

El seminal libro de Hassan Fathy Construire avec le peuple vió la luz en 1969, y su edición inglesa, titulado de forma no muy afortunada Architecture for the Poor, en 1973. Poco después, en 1978, iba a tener un relevante papel en la reunión internacional conocida como Habitat I, auspiciada por el Programa de Naciones Unidas para los Asentamientos Humanos con el fin de buscar soluciones para mejorar las condiciones de vida en las 